US Army Corps of Engineers $S_{\circledast}$ Engineer Research and Development Center

\title{
Hydrodynamics of a Recently Restored Coastal Wetland: Hamilton Wetlands, California
}

Richard Styles, David W. Perkey, S. Jarrell Smith, Duncan B. Bryant,

July 2020 Joe Gailani, and Brandon M. Boyd
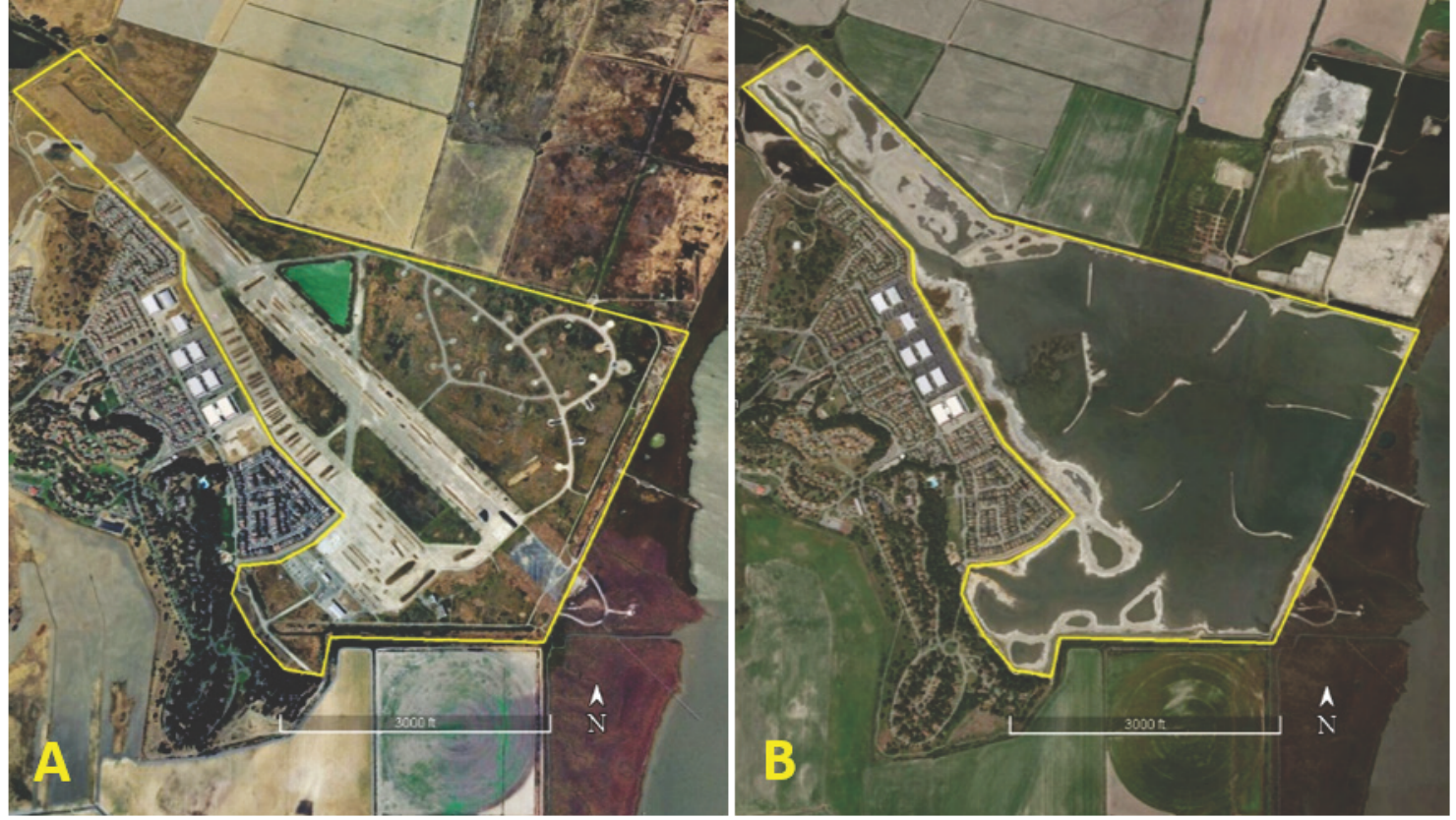
The US Army Engineer Research and Development Center (ERDC) solves the nation's toughest engineering and environmental challenges. ERDC develops innovative solutions in civil and military engineering, geospatial sciences, water resources, and environmental sciences for the Army, the Department of Defense, civilian agencies, and our nation's public good. Find out more at www.erdc.usace.army.mil.

To search for other technical reports published by ERDC, visit the ERDC online library at https://erdclibrary.on.worldcat.org/discovery. 


\section{Hydrodynamics of a Recently Restored Coastal Wetland: Hamilton Wetlands, California}

Richard Styles, David Perkey, Jarrell Smith, Duncan Bryant, Joe Gailani, and Brandon Boyd

Coastal and Hydraulics Laboratory

US Army Engineer Research and Development Center 3909 Halls Ferry Road

Vicksburg, MS 39180-6199

Final report

Approved for public release; distribution is unlimited.

Prepared for US Army Engineer Research and Development Center 3909 Halls Ferry Road Vicksburg, MS 39180-6199

Under Work Unit ERDC-219CDR-14-TT-Sediment Management, "Section 219 Center for Directed Research" 


\section{Abstract}

Hamilton Wetlands is a recently restored tidally influenced basin located along the northwest coast of San Pablo Bay, California. Instruments to measure waves, currents, and wind were deployed for a period of up to 2 years shortly after tidal flow was re-introduced to the wetland to examine the sediment and hydrodynamic response. The results indicate that local resuspension is relatively rare owing to the weak interior tidal currents and the limited fetch within the $3 \mathrm{~km}$ long basin. Asymmetries in the acoustic backscatter intensity combined with the much higher flow speeds measured at the entrance suggest a net import of fine sediment. The basin also experiences a distinct seasonal variation that likely contributes to sediment re-distribution. During the summer months, higher wind speeds correlate with turbidity suggesting local re-suspension of fines that are distributed by winds. Overall, the measurements suggest that the sediment dynamics in this shallow water system are controlled by two main factors: (1) net sediment import through the inlet entrance and (2) mixing of interior sediment through a combination of intermittent wind and wave stirring.

DISCLAIMER: The contents of this report are not to be used for advertising, publication, or promotional purposes. Citation of trade names does not constitute an official endorsement or approval of the use of such commercial products. All product names and trademarks cited are the property of their respective owners. The findings of this report are not to be construed as an official Department of the Army position unless so designated by other authorized documents. 


\section{Contents}

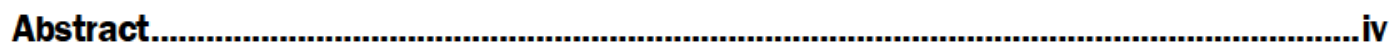

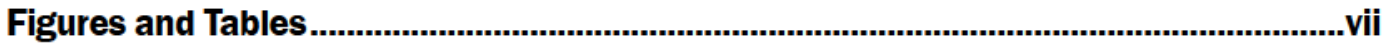

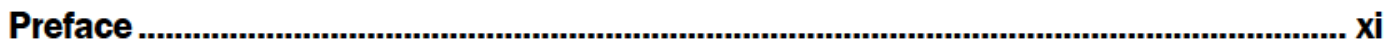

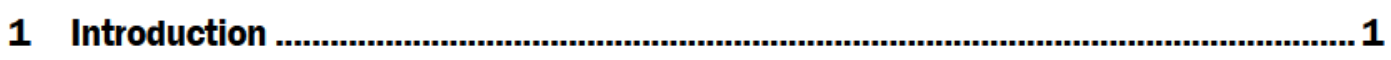

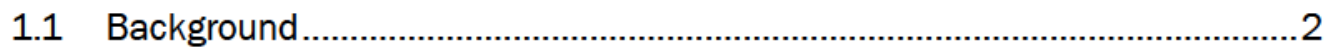

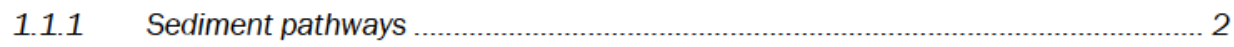

1.1.2 Historical development of Hamilton Wetlands ............................................. 3

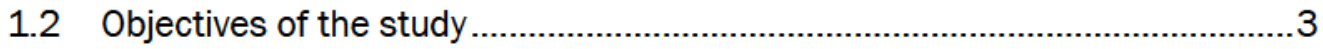

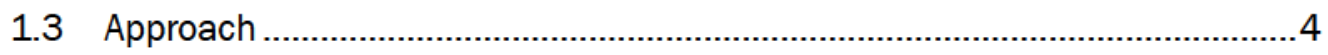

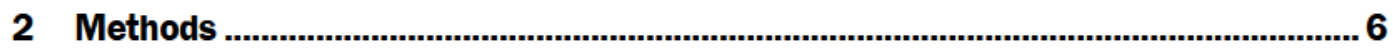

2.1 Study site

2.2 Instrumentation ............................................................................... 7

2.2.1 Water level and wave analysis ..................................................................... 9

2.2.2 Acoustic Doppler velocimeter (ADV) analysis ............................................ 10

2.2.3 Shear velocity estimates.............................................................................. 11

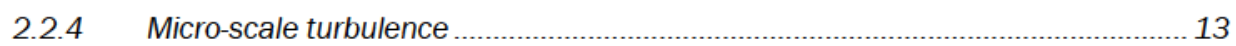

2.3 Core collection at Hamilton Wetlands ............................................................14

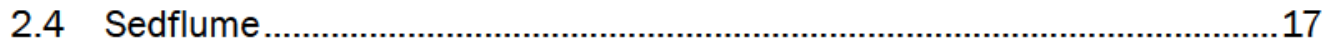

2.4.1 Erosion experiments ................................................................................ 18

2.4.2 Sediment bulk properties .............................................................................. 19

2.4.3 Multivariate erosion rate prediction .................................................................. 21

2.5 Sediment and stress modeling.............................................................. 22

2.6 Critical shear stress and the initiation of sediment motion........................ 22

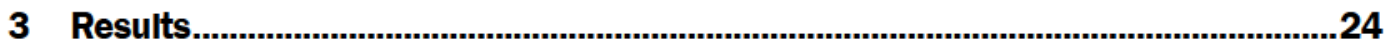

3.1 Regional winds and water level ........................................................24

3.2 Seasonal wind, water level, and water quality .......................................... 26

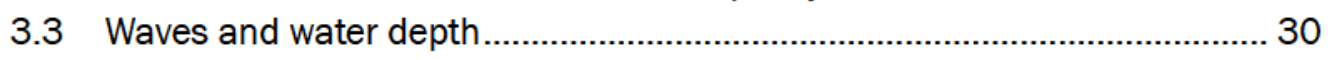

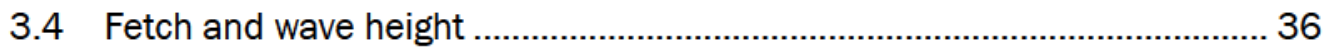

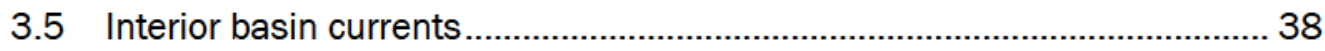

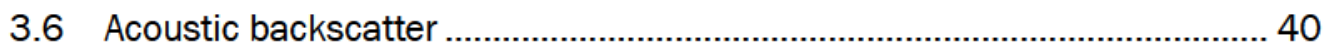

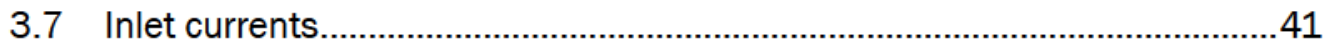

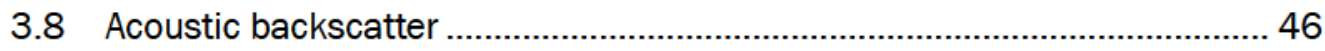

3.9 Cohesive sediment erosion ................................................................. 47

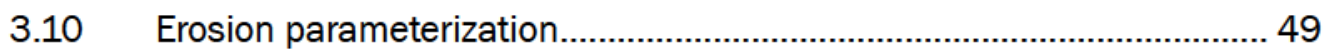

3.11 Bottom shear stress estimates ...................................................... 54

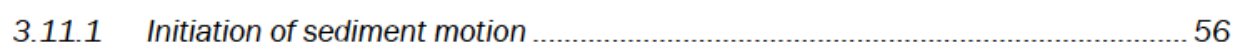

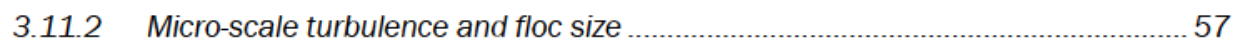




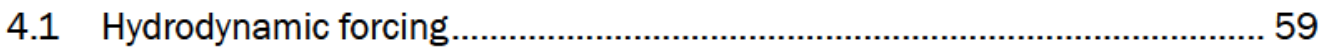

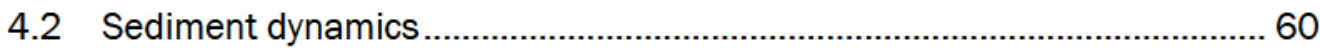

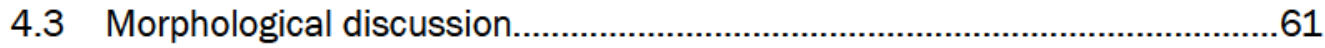

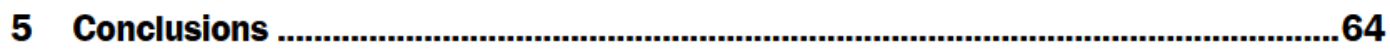

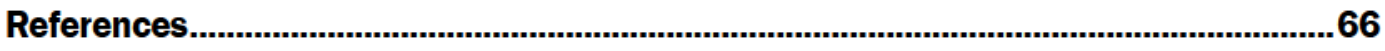

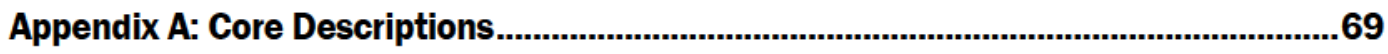

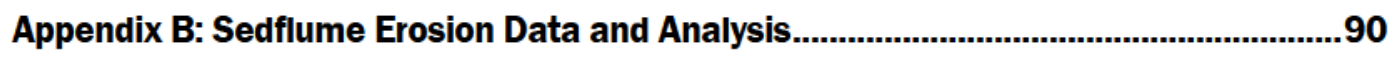

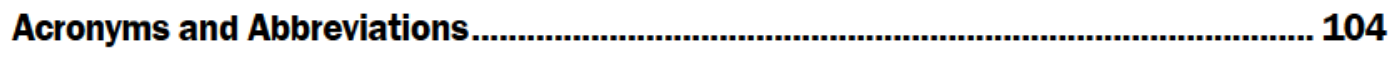

Report Documentation Page 


\section{Figures and Tables}

\section{Figures}

Figure 1. Location of Hamilton Wetlands project site in reference to the greater San Francisco Bay area. The project site is outlined in yellow, and four monitoring platform stations (Hamilton 1, 2, 3, and 4) are identified in blue on the aerial photo.

Figure 2. Aerial photo showing five core station locations...................................................14

Figure 3. Core sampling devices

Figure 4. Sedflume erosion flume (lower right). Core inserted into test section (upper left). Core surface flush with bottom of flow channel (upper right). Stress associated with channel flow rates (lower left table).

Figure 5. Diagram of sediment core erosion process. The brown arrow indicates direction of motion of the sediment into the flume. The blue arrow indicates flow direction of water. An example erosion sequence is provided in the table to the right of the sediment core.

Figure 6. Hourly averaged wind speed measured at Hamilton Wetlands..............................24

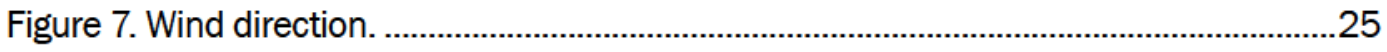

Figure 8. NOAA water level at San Pablo Bay station.........................................................25

Figure 9. Bar chart depicting monthly average wind speeds, including wind gusts...........26

Figure 10. Monthly averaged water level measured at NOAA buoy......................................22

Figure 11. Monthly averaged temperature at Hamilton Wetlands. …….................................28

Figure 12. Monthly averaged salinity at Hamilton Wetlands. ..............................................28

Figure 13. Monthly averaged turbidity at Hamilton Wetlands...............................................29

Figure 14. Turbidity as a function of monthly averaged wind speed at Hamilton Wetlands.............................................................................................................

Figure 15. Wave height at Hamilton 1. …………………………………………………….....31

Figure 16. Wave period at Hamilton 1. …..............................................................................31

Figure 17. Wave height Hamilton 2 …..............................................................................32

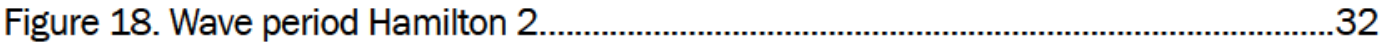

Figure 19. Wave Height Hamilton 4 . .....................................................................................33

Figure 20. Wave period Hamilton 4 …….............................................................................33

Figure 21. Water depth at Hamilton 1. ……....................................................................34

Figure 22. Water depth at Hamilton 2..........................................................................35

Figure 23. Water depth at Hamilton 4...........................................................................35

Figure 24. Relationship between fetch and wave height at Hamilton 1. Perimeter denotes the distance between the sensor location and the closest land point as a function of direction. Wave height denotes the average height of waves in 20

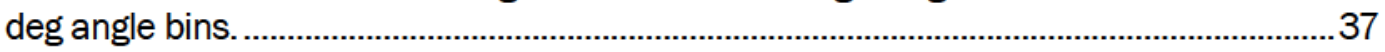

Figure 25. Fetch and wave height as a function of direction at Hamilton 2.........................37

Figure 26. Fetch and wave height as a function of direction at Hamilton 4........................38 


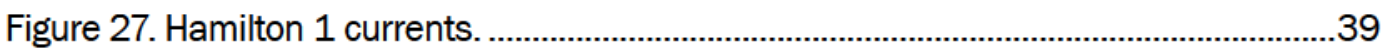

Figure 28. Hamilton 2 currents......................................................................................39

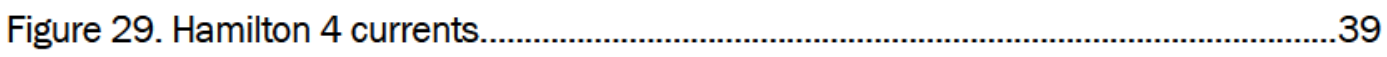

Figure 30. Acoustic backscatter as a function of current magnitude. ................................ 41

Figure 31. Water depth at the inlet throat measured by the ADCP. .....................................42

Figure 32. Spatially averaged currents in the inlet throat.................................................42

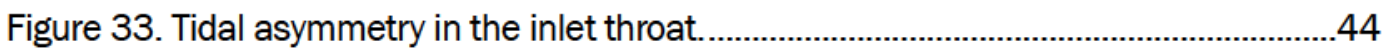

Figure 34. Vector plot depicting current distribution across the inlet over a tidal cycle. The panels are read from left to right and top to bottom. Upper left panel was at slack low, and the snapshots evolve in 1.4 hour increments. Maximum average speed across the inlet entrance was $1.17 \mathrm{~m} / \mathrm{s}$......................................................45

Figure 35. Flow versus stage curve. Positive currents denote flood. ..................................46

Figure 36. Acoustic backscatter as a function of flow. Positive current denotes flood.

Figure 37. Plot depicting the change in erosion rate with depth for core Station 1-

2. Colors indicate bed layers; symbols indicate applied shear stress.

Figure 38. Erosion rate data and best fit lines to Equation 14 for (A) layers within Station 1-2, and (B) layers after compiling data from Station 1 and Station 1-2.

Figure 39. Erosion rate data and best fit lines to Equation 14 for the surface layers of cores located within the Hamilton Wetlands basin (Stations 1, 1-2, 2, and 4).

Figure 40. Erosion parameterization uncertainty for layer L1 Station 1-2. Shear stress in Pascals and erosion rate $(\mathrm{E})$ in centimeters per second are plotted on the $x$ and $y$ axis, respectively. The solid line presents the best fit to Equation 14, with sample size $(\mathrm{N}), \mathrm{r}^{2}$, and $\mathrm{p}$-value displayed at the top of the figure. The $95 \%$ confidence intervals on the fit are indicated with the dashed lines.

Figure 41. Erosion rate data and best fit lines to Equation 14 for the surface layers of cores located within the Hamilton Wetlands basin (black symbols) (Stations 1, 1-2, 2, and 4). Surface layer data from Station $5 \mathrm{~N}$, located outside the basin, are indicated in red.

Figure 42. Time-averaged shear velocity derived from the velocity time series at Hamilton 1.

Figure 43. Shear velocity derived from the velocity time series at Hamilton 2...................55

Figure 44. Shear velocity derived from velocity time series at Hamilton 4.

Figure 45. Time-averaged shear velocity and the maximum combined shear velocity for the wave and current predicted from the BBLM for Hamilton 1 and 4.

Figure 46. Shields parameter and critical Shields parameter for the initiation of sediment motion at Hamilton 1 and 4.

Figure 47. Shear parameter estimates at Hamilton 1 and 4.

Figure 48. Kolmogorov micro-scale at Hamilton 1 and 4. Vertical axis is plotted on a log scale. 58

Figure A-1a. Cumulative grain size distributions for Station 1 physical samples. 71

Figure A-1b. Grain size distributions for Station 1 physical samples. . .72

Figure A-1c. Bulk density profile for core Station 1. 
Figure A-2a. Cumulative grain size distributions for Station 1-2 physical samples.............76

Figure A-2b.Grain size distributions for Station 1-2 physical sample. ....................................76

Figure A-2c. Bulk density profile for core Station 1-2. …................................................77

Figure A-3a. Cumulative grain size distributions for Station 2 physical samples. ...............80

Figure A-3b. Grain size distributions for Station 2 physical samples. ................................80

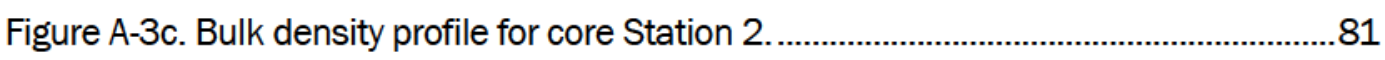

Figure A-4a. Cumulative grain size distributions for Station 4 physical samples. ...............84

Figure A-4b. Grain size distributions for Station 4 physical samples. ..................................84

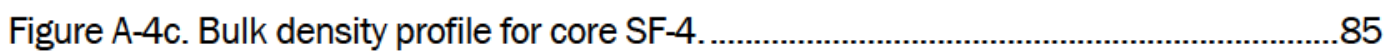

Figure A-5a. Cumulative grain size distributions for Station 5-N physical samples. ..........88

Figure A-5b. Grain size distributions for Station 5-N physical samples...............................8

Figure A-5c. Bulk density profile for core Station 5-N. ....................................................89

Figure B-1. Erosion versus depth for core Station 1. Colors indicate bed layers; symbols indicate applied shear stress.

Figure B-2. Erosion versus depth for core Station 1-2. Colors indicate bed layers;

symbols indicate applied shear stress.

Figure B-3. Erosion versus depth for combined cores from Station 1. Colors indicate bed layers; symbols indicate applied shear stress.

Figure B-4. Erosion versus depth for core Station 2. Colors indicate bed layers; symbols indicate applied shear stress.

Figure B-5. Erosion versus depth for core Station 4. Colors indicate bed layers; symbols indicate applied shear stress.

Figure B-6. Erosion versus depth for core Station 5-N. Colors indicate bed layers; symbols indicate applied shear stress.

Figure B-7. Erosion versus applied shear stress for core Station 1. Colors indicate bed layers. Solid lines represent the linearized best-fit of $E=A \tau^{n}$ to the data. Dashed lines indicate the $95 \%$ confidence interval of the fit line.

Figure B-8. Erosion versus applied shear stress for core Station 1-2. Colors indicate bed layers. Solid lines represent the linearized best-fit of $E=A \tau^{n}$ to the data. Dashed lines indicate the $95 \%$ confidence interval of the fit line. No dashed lines are present for the surface layer due to low number of observations $(\mathrm{N}<4)$.

Figure B-9. Erosion versus applied shear stress for combined Station 1 cores. Colors indicate bed layers. Solid lines represent the linearized best-fit of $E=A \tau^{n}$ to the data. Dashed lines indicate the $95 \%$ confidence interval of the fit line.

Figure B-10. Erosion versus applied shear stress for core Station 2. Colors indicate bed layers. Solid lines represent the linearized best-fit of $E=A \tau^{n}$ to the data. Dashed lines indicate the $95 \%$ confidence interval of the fit line.

Figure B-11. Erosion versus applied shear stress for core Station 4. Colors indicate bed layers. Solid lines represent the linearized best-fit of $E=A \tau^{n}$ to the data. Dashed lines indicate the $95 \%$ confidence interval of the fit line. 101

Figure B-12. Erosion versus applied shear stress for core Station $5 \mathrm{~N}$. Colors indicate bed layers. Solid lines represent the linearized best-fit of $E=A \tau^{n}$ to the data. Dashed lines indicate the $95 \%$ confidence interval of the fit line. 
Figure B-13. Erosion versus applied shear stress for surface layers within the Hamilton Wetlands Basin. Symbols indicate data from varying cores. The solid line represents the linearized best-fit of $E=A \tau^{n}$ to the data. Dashed lines indicate the $95 \%$ confidence interval of the fit line.

\section{Tables}

Table 1. Core sampling station locations and dates collected. 15

Table 2 Cohesive erosion parameterization. (L indicates layer) 51

Table 3. Cohesive erosion parameterization uncertainties ( $L$ indicates layer).....................52

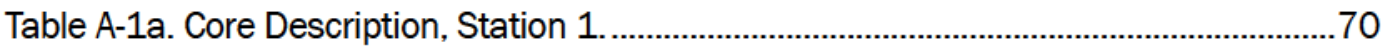

Table A-1b. Core Surface Photographs, SF-1 ….................................................................. 71

Table A-1c. Physical Sample Properties, Station 1............................................................ 71

Table A-2a. Core Description, Station 1-2. …................................................................... 74

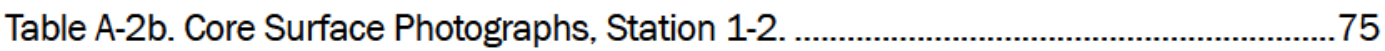

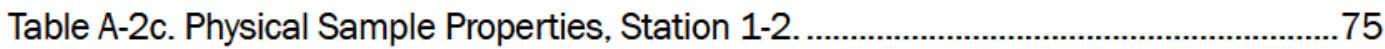

Table A-3a. Core Description, Station 2 .........................................................................

Table A-3b. Core Surface Photographs, Station 2 ...........................................................79

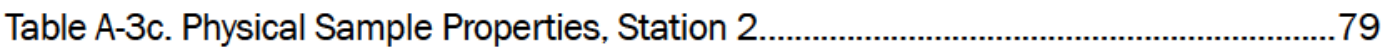

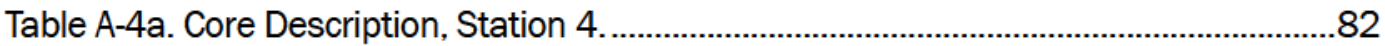

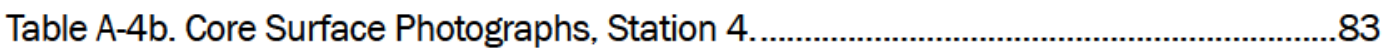

Table A-4c. Physical Sample Properties, Station 4.............................................................8

Table A-5a. Core Description, Station 5-N. …….............................................................86

Table A-5b. Core Surface Photographs, Station 5-N. ........................................................87

Table A-5c. Physical Sample Properties, Station 5-N...........................................................87

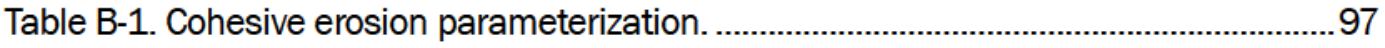

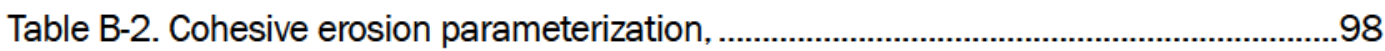

Table B-3. Cohesive erosion parameterization. ……….......................................................99

Table B-4. Cohesive erosion parameterization. .............................................................. 100

Table B-5. Cohesive erosion parameterization. ................................................................. 101

Table B-6. Cohesive erosion parameterization. .............................................................. 102

Table B-7. Cohesive erosion parameterization.................................................................. 103 


\section{Preface}

This study was conducted for the US Army Engineer Research and Development Center (ERDC), under Work Unit ERDC-219CDR-14-TTSediment Management, "Section 219 Center for Directed Research."

The work was performed by the ERDC Coastal and Hydraulics Laboratory (CHL), Coastal Engineering Branch, and the Field Data Collection Branch of the CHL Navigation Division, and by the Coastal Processes Branch of the CHL Flood and Storm Protection Division.

At the time of publication of this report, Ms. Lauren Dunkin was Chief, Coastal Engineering Branch; Mr. William Butler was Chief, Field Data Collection Branch; Dr. Jackie Pettway was Chief, Navigation Division; Ms. Ashley Frey was Chief, Coastal Processes Branch; and Dr. Cary A. Talbot was Chief, Flood and Storm Protection Division. The Deputy Director of ERDC-CHL was Mr. Jeffrey R. Eckstein, and Dr. Ty V. Wamsley was the Director of ERDC-CHL.

COL Teresa Schlosser was the Commander of ERDC, and the Director of ERDC was Dr. David W. Pittman. 


\section{Introduction}

Wetland restoration is one of the most widespread environmental engineering practices taking place in the world today (Mitsch and Jørgensen 2004; Verhoeven 2014; Zhang et al. 2010). Wetlands not only provide important habitats for diverse species of flora and fauna but serve as nursery grounds for aquatic organisms that spend the majority of their life cycle in the coastal or deep ocean (Sheaves et al. 2015). Wetlands likewise act as buffer zones protecting low-lying upland areas from storm surge (Gedan et al. 2011). A number of factors including agricultural expansion, industrial development, and a steady transition to urbanization have contributed to massive wetland loss in coastal areas worldwide (Lake et al. 2000; Zedler and Kercher 2005). Beginning in the latter half of the 1900s, a shift in prevailing attitudes towards unrestrained anthropogenic alternations to the natural landscape began to take hold as scientific evidence that conveyed the economic and ecological benefits of wetlands emerged (Prince 2008). Considering their ecological benefit and likely role in storm surge protection, increased efforts to reclaim and restore natural wetlands in heavily impacted areas have been a major focus around the globe (Kumar 2012). However, developing the science for successful restoration projects has been problematic due in part to a lack of information on the short-term hydrodynamic and morphological evolution and sustainability of newly constructed wetland projects. Monitoring newly restored wetlands remains an important activity to understand long-term functionality and resilience.

A primary challenge facing wetland restoration projects is the degree and rate of land-building potential in terms of cost-benefit indicators. The rate at which impacted areas can be restored to their previous natural state depends upon the degree to which the system can import and redistribute sediments to maintain wetland mass and produce a stable substrate for vegetation colonization and growth. The rate of land gain or loss is controlled not only by rising sea level but by the processes that govern sediment delivery, erosion, and deposition. Sediment supplied through suspended solids provides material to maintain wetland elevation so long as accumulation exceeds the rate of submergence and erosion. Complex morpho-dynamic processes redistribute material, thereby reshaping the surface in ways that can increase or decrease total wetland mass. 
Understanding wetland morpho-dynamics is important to planners and engineers as information gleaned from natural sediment processes may help to inform engineering practices that increase the efficiency of the delivery mechanism and maximize sediment retention in newly constructed wetlands. Identifying placement strategies that maximize stability and minimize cost is a primary design requirement for constructing resilient coastal wetland projects.

\subsection{Background}

One of the primary tasks to ensure a successful restoration project is to restore the hydrological balance that existed prior to the now altered landscape (Middleton 2002). In many restoration projects, the original area was drained and then reworked to support agricultural or industrial activities. The underlying flow conduits including creek networks and drainage systems were buried or excavated so that the established hydrological conductivity of the system was lost. Even the antecedent geological framework may have been altered if newer sediments composed of different physical or chemical properties were placed on top of, or mixed with, the original material.

One of the first steps is to reintroduce the flow into the impacted area. In coastal areas, flood pulsing through tidal exchange represents the most feasible way to restore the natural hydrological balance (Middleton 2002). Introducing pulsating flow delivers land-building material as well as nutrients and other constituents important for the development of newly seeded vegetation, which can also reinforce land growth and sustainability. Tidal exchange redistributes the flow to form channel networks that deliver particulate matter more efficiently throughout the wetland basin. The tendency for new material to deposit is a function of the hydrodynamic forces and the physical and chemical characteristics of the imported sediment.

\subsubsection{Sediment pathways}

In tide-dominated regimes, sediment delivery is composed of two main mechanisms: (1) creek networks hydraulically connected to adjacent channels that deliver sediment and fluid and (2) sheet flow during periods of high water when the wetland is submerged. The degree and delivery rate are controlled by the size (length) and density of the creek network distribution. A highly distributed network can be an effective sediment 
delivery method similar to coastal salt marshes (Novakowski et al. 2004). Under a higher tidal range, larger portions of the wetland become submerged during high tide, and both mechanisms contribute to sediment delivery. Sediment distribution is spread over a much wider area, and presumably sediments carried in suspension have the potential to reach a much larger fraction of the wetland interior.

\subsubsection{Historical development of Hamilton Wetlands}

Hydraulic mining activities during the California Gold Rush resulted in large quantities of fluvial sediment deposits in the Central Valley along the San Joaquin and Sacramento Rivers. Quantities of finer sediment were transported farther downstream to form thick deposits along the fringes of San Francisco Bay. Following the Gold Rush, areas containing newly deposited sediment were reworked and impounded to provide farmland during a period of agricultural expansion in the late 180os. In the 1930s, the US Army Air Corps constructed a military airbase on the location that is now Hamilton Wetlands located adjacent to San Pablo Bay. The airbase remained operational until the mid-1970s, which by then was managed by the US Air Force, and was then placed in caretaker status and transferred to the US Army. During the Base Realignment and Closure Act of 1990, ownership of the area containing the air strip and hangars was transferred to the state of California. In the early 200os, the state issued a plan to reclaim the area as part of a much larger and ambitious effort to restore wetlands throughout San Francisco Bay. It was estimated that Hamilton Wetlands would require nearly 7 million $\mathrm{m}^{3 *}$ of fill material to raise the surface to an elevation at which vegetation could begin to colonize the area (Best et al. 2005). Construction began in 1999, with much of the original runway and areas adjacent to San Pablo Bay infilled with dredge material. In 2014, the bay front levee separating the original airstrip from San Pablo Bay was breached to restore tidal flow to the basin.

\subsection{Objectives of the study}

As environmental stewards, the US Army Corps of Engineers (USACE) is charged with protecting coastal wetlands, which are critical habitats for a

${ }^{*}$ For a full list of the spelled-out forms of the units of measure used in this document, please refer to US Government Publishing Office Style Manual, 31st ed. (Washington, DC: US Government Publishing Office 2016), 248-52, https://www.govinfo-gov/content/pkg/GPO-STYLEMANUAL-2016/pdf/GPOSTYLEMANUAL-2016. pdf. 
wide variety of organisms. Likewise, understanding coastal wetland subsidence is a major issue affected by global sea level rise (Cahoon et al. 2006). The degree and rate of land loss in terms of sediment supply versus submergence remain active areas of research, and understanding wetland geomorphological processes provides the context for developing best practice methodologies that can be applied across USACE restoration projects. Nearly 90\% of the wetlands in the San Francisco Bay area have been lost since the industrial revolution and the State of California, along with local resource agencies, is spearheading an ambitious effort to restore 23,300 hectares of wetlands by 2050 (Best et al. 2005). Hamilton Wetlands accounts for a small fraction $(<1 \%)$ of the total area designated for restoration, yet the small basin provides critical information on how reestablishing hydraulic connectivity to San Francisco Bay affects wetland development. The successfulness of restoration projects like Hamilton Wetlands relies on accurate assessments of the critical initial building phase, where the wetland reestablishes its presence as a self-sustaining ecological system. Small restoration projects like Hamilton Wetlands represent a first step in reestablishing the natural environmental conditions along the fringes of San Francisco Bay that existed prior to industrialization.

The objective of this technical report is to describe the flow and sediment transport processes active within newly constructed Hamilton Wetlands to better understand the hydrodynamic regime and sediment delivery pathways. This report focuses on measurements and analyses from a field data collection effort conducted at Hamilton Wetlands between July 2014 and February 2017. The results present a summary of the meteorological, current, wave, and sediment transport characteristics at the study site. The site conceptual model section reveals insight into the sediment pathways that help inform coastal management strategies in the context of wetland restoration projects.

\subsection{Approach}

The approach was to analyze the hydrodynamic data in the context of the flow patterns in an impounded low-lying coastal wetland recently opened to a larger tidally influenced bay through a narrow inlet. To understand the local (internal) dynamics of the system, the data were reviewed in terms of regional wind forcing, which leads to localized sediment resuspension within the small basin. The larger-scale forcing was examined in the context of the newly breached levee, which has restored the tidal 
flow to the previously impounded basin. Chapter 2 provides a description of the study site, the field data collection effort including the instrument packages and processing, and numerical modeling. The results focus on the regional wind and water level data to place the measurements at Hamilton Wetlands in a broader context and include an analysis based on seasonal trends. The wave, current, and backscatter data collected within Hamilton Wetlands are presented, as well as current measurements acquired shortly after the levee was breached near the inlet throat. The discussion focuses on the role of waves and tidal currents on sediment re-suspension within the basin and on the evolution of the tidal flow in the inlet throat in the aftermath of the levee breach. The conclusions summarize the main findings of this field data collection effort. 


\section{Methods}

\subsection{Study site}

The study was conducted at Hamilton Wetlands located in San Pablo Bay, California (Figure 1). Hamilton Wetlands is a narrow, funnel-shaped basin located along the western edge of San Pablo Bay near Novato, California. The basin is $3 \mathrm{~km}$ long as measured from the bay front level to the most upland point. The width at the levee is $1.3 \mathrm{~km}$ and tapers almost linearly to a width of $350 \mathrm{~m}$ at $2 \mathrm{~km}$ from the entrance. The width is constant for the remaining $1 \mathrm{~km}$ to the landward-most point. Before the area was flooded, the State of California began placing dredge material in the eastern region of the basin where the airstrip was located. In 2005, the area still resembled the original airstrip. Over the next few years, material was placed directly on the unflooded surface in a series of mounds and ridges that resembled a disjointed berm network enclosing a number of isolated impoundments. The purpose of these placements was to maintain a series of interior sub-aerial features to represent the natural high stand of coastal wetlands and provide subtidal pools that would retain water at low tide. They also served as wind buffers to reduce the fetch within the newly constructed wetland to promote sediment retention. The berms were built on abandoned access roads, which served as opportunistic high stands that were easily accessible for material placement. The material used to construct Hamilton Wetlands was obtained primarily from the Port of Oakland dredging operation, which included the extraction of nearly 10 million $\mathrm{m}^{3}$ of dredge material over 12 years from the channel. This dredged material was then used to construct Hamilton Wetlands and other wetlands within the San Francisco Bay area. 
Figure 1. Location of Hamilton Wetlands project site in reference to the greater San Francisco Bay area. The project site is outlined in yellow, and four monitoring platform stations (Hamilton 1, 2, 3, and 4) are identified in blue on the aerial photo.

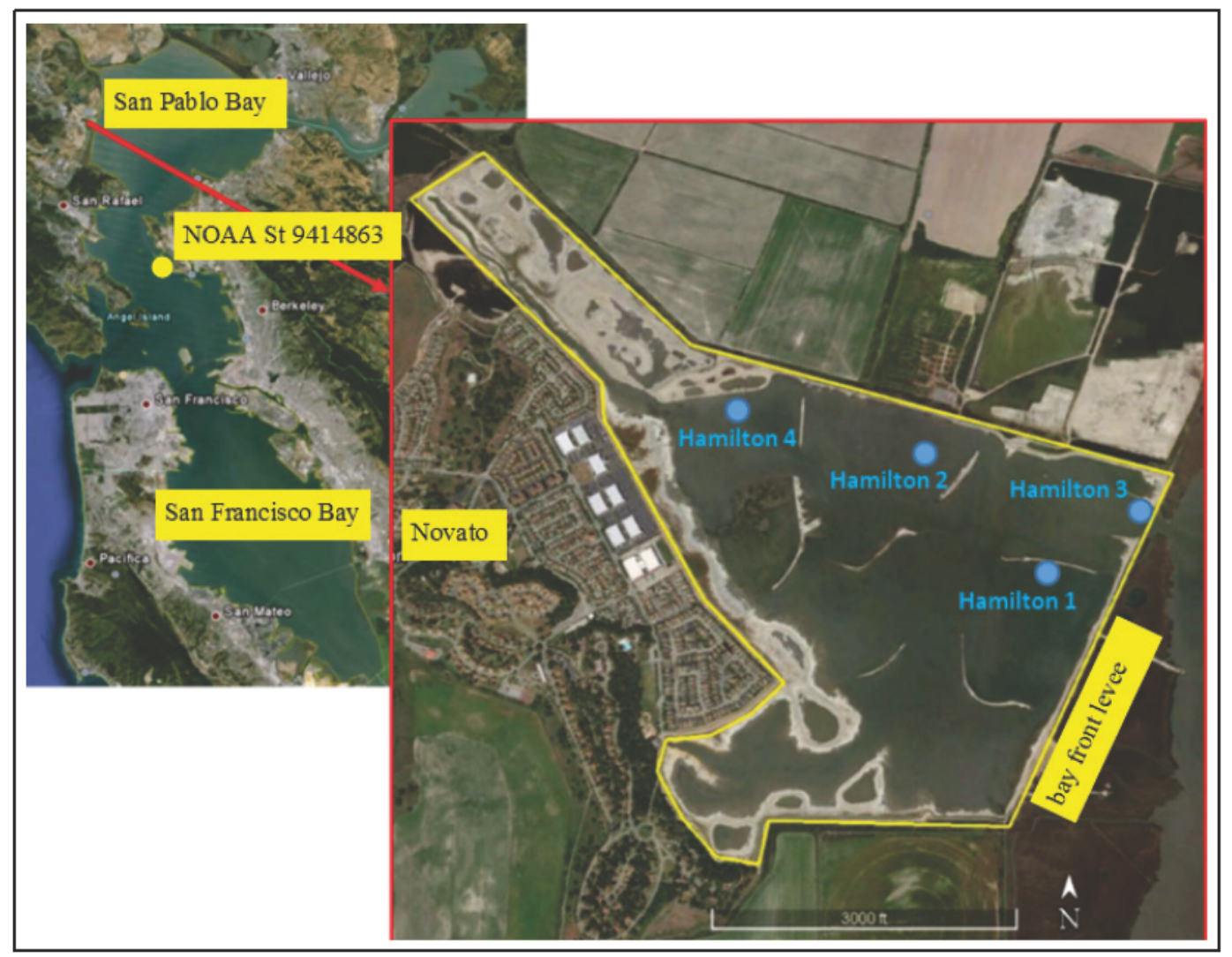

\subsection{Instrumentation}

Platforms: Four platform stations were installed in the Hamilton Wetlands to support instrumentation for the study (Figure 1). The platforms were distributed throughout the area to maximize the spatial monitoring of the system. Hamilton 1, 2, and 4 were located in the interior of the wetlands, and Hamilton 3 was located inside the inlet throat.

Hamilton 1, 2, and 4 were equipped with an acoustic Doppler velocimeter $(\mathrm{ADV})$ to measure currents and turbulence and a surface-piercing capacitance water level gauge. Solar panels were installed on each platform to provide long-term power to the instrumentation. The ADVs were programmed to sample at $25 \mathrm{~Hz}$ for a 2 min burst every $15 \mathrm{~min}$. The ADVs measured east $(u)$, north $(v)$, and vertical $(w)$ velocities, which were decomposed into mean $(U, V, W)$ and fluctuating $\left(u^{\prime}, v^{\prime}, w^{\prime}\right)$ components to calculate burst-averaged and turbulence quantities, respectively. 
A side-looking acoustic Doppler current profiler (ADCP) was deployed at Hamilton 3 to measure currents across the inlet throat. The ADCP was deployed on the wetlands side approximately $40 \mathrm{~m}$ away from the narrowest section ( $40 \mathrm{~m}$ wide). The distance to the opposite side of the inlet where the ADCP was deployed was $80 \mathrm{~m}$. The instrument recorded burst-averaged current every $15 \mathrm{~min}$ and was deployed from July 2014 until February 2015. Biofouling was an issue, so an analysis of the beam correlation diagnostics indicated that measurements obtained after 5 November 2014 were unreliable. The instrument was programmed with a total of 50 bins with a $2 \mathrm{~m}$ spacing and oriented to look across the inlet throat. However, only the first 30 bins provided consistent high-quality data, so the spatial range was restricted to $60 \mathrm{~m}$. This still provided quality measurements for the first 4 months of the study and included a significant fraction of the entrance width.

Wave and water level were measured at each platform with an Ocean Sensor Systems OSSI-010-002E wave staff outfitted with a $1 \mathrm{~m}$ long staff. The wave staff converted analog capacitance to digital counts and serially streamed the 12-bit digital data to the data logger. With 12-bit digital resolution distributed over a 1,000 mm length rod, the wave staff resolution was nominally $0.25 \mathrm{~mm}$. The manufacturer's stated accuracy of the staff measurements is $0.025 \%$ of full scale (in this case, $0.25 \mathrm{~mm}$ ). Data ensembles were collected with a $15 \mathrm{~min}$ sampling interval. Each ensemble consisted of 3,600 water surface positions collected at $30 \mathrm{~Hz}$ for $120 \mathrm{~s}$. Water level and wave measurements were not available when the island became subaerial, and the wave staff would be completely exposed. Wave and water level data were generated through data processing and analysis, which are described in Section 2.2.1.

The wave and current sensors were deployed at different times for the different stations. The current sensors for Hamilton 1, 2, and 4 came online in July 2014. The wave staff at Hamilton 1 came online in July 2014. The wave staffs at Hamilton 2 and 4 came online in February 2015. Hamilton 3 was located near the inlet throat and did not have an ADV or wave staff. Biofouling was a major issue, and data collection for the ADVs was very sparse. The wave data collection was more robust, but there were some noticeable gaps due to biofouling. Because of the remote location, the time between maintenance trips was sometimes extended, which also contributed to the scarcity of quality data. However, the wave data are the most robust with good coverage for a 2-year period beginning in February 
2015. The current coverage was sparser but, considering the dominant forcing associated with the tide, even the limited data set (2015 through 2017) still gave an overall sense of the magnitude of the tidal forcing within the basin.

Winds: Wind data were obtained from the National Oceanographic and Atmospheric Administration (NOAA) Station 9414863. The station was located approximately $16 \mathrm{~km}$ southeast of the study site in the northwestern portion of San Francisco Bay and provided 6 min wind speed and direction at $10 \mathrm{~m}$ height above the surface.

Tides: Water surface elevation was obtained from the same NOAA Station 9414863 as the winds for the same time period (2015 through 2017). The station provided 6 min water surface elevation measurements.

\subsubsection{Water level and wave analysis}

Water levels were determined at each platform from the ensemble-mean water level from the water-level staffs. This ensemble averaging removed the effects of surface wind waves. The mean water level for each $2 \mathrm{~min}$ data ensemble was recorded as the local water depth at that time. The water level staffs were not surveyed to a vertical datum for this study, so the tides are relative to local bed but can be approximately referenced to local tidal levels with additional analysis.

Initial processing of the water level data for wave analysis included detrending the signal (to remove low-frequency signals such as tides and vessel wakes) with a high-pass elliptic filter with stopband and passband frequencies of 0.10 and $0.20 \mathrm{~Hz}$, respectively. Surface variations with frequencies higher than $0.20 \mathrm{~Hz}$ were analyzed by time- and frequencydomain methods for estimating wave parameters.

In the time domain, a standard zero up-crossing method (CERC 1984) was applied to the high-pass filtered water surface signal to generate a dataset of wave heights $\left(H_{x}\right)$ and wave periods $\left(T_{x}\right)$. The significant wave height $\left(H_{s}\right)$ is defined as the mean of the largest third of $H_{x}$. The root-meansquare wave height is given by $H_{r m s}=\sqrt{\frac{1}{N} \sum_{i=1}^{N} H_{x, i}^{2}}$, where $N$ is the number 
of samples. For the zero-crossing methods, the characteristic wave period is the mean wave period, which is $T_{m}=\frac{1}{N} \sum_{i=1}^{N} T_{x, i}$.

In the frequency domain, the Welch (1967) method for power spectral density estimate was applied to the high-pass filtered water surface record to determine spectral estimates of wave characteristics (CERC 1984). The spectral wave height is given as $H_{m 0}=4 \sqrt{\int_{f 1}^{f 2} S_{\eta}(f) d f}$, where $f$ indicates frequency (Hz), $S_{\eta}$ is the spectral density estimate, and the limits of the integral are the frequency bounds over which surface gravity waves are expected at the site (in this case, $f_{1}=0.3 \mathrm{~Hz}$, and $f_{2}=3.0 \mathrm{~Hz}$ ). The peak frequency, $f_{p}$, is the frequency associated with the peak of the energy spectrum within the expected frequency interval $f_{1}$ to $f_{2}$. The peak wave period is the reciprocal of the peak frequency, $T_{p}=\frac{1}{f_{p}}$.

\subsubsection{Acoustic Doppler velocimeter (ADV) analysis}

The velocity data were put through several quality control (QC) measures prior to analysis. The $10 \mathrm{MHz}$ Sontek ADVs are accurate to within $1 \%$ of the measured data. However, data dropouts occur when the probes are not submerged, the acoustic signal is blocked, or an inadequate number of scatters exist in the flow. Waves at moderate water depths were also found to cause partial data dropouts, as a portion of the ADV probe might not be submerged during wave troughs. ADVs can likewise experience velocity spiking when the probe is not submerged, when large objects pass through or near the measurement volume (leaf litter, vegetation, etc.), or by aliasing of the Doppler signal. Therefore, each 2 min burst was evaluated in a two-step QC procedure prior to analysis: (1) data quality check and (2) de-spiking. First, data quality was assessed by examination of the signalto-noise ratio (SNR) and the correlation between successive pings for each sample in a 2 min burst (3,60o samples per burst). Samples with return amplitudes $<50$ and correlation $<70 \%$ were flagged. These criteria identified both the conditions of unsubmerged probes and inadequate scatters. While data dropouts occurred during most low tides when water levels fell below the sensor height, close inspection of the ADV data in conjunction with the water level showed that data dropouts due to low numbers of scatters were not a problem. In fact, SNRs were rarely below 95 when measured water levels were clearly above the probe. Bursts with 
$<85 \%$ qualifying correlation and $<50$ SNR were removed from further evaluation while those whose samples exceeded the $85 \%$ threshold were passed to the second QC routine with the errant data flagged.

Second, the data were passed through a de-spiking routine developed by Goring and Nikora (2002) with recommended improvements by Wahl (2003). Once errant spikes were identified, they were flagged. If the combined flagged samples from the data quality and de-spiking analysis exceeded $15 \%$, that burst was removed from further analysis. Filtered data were then used to calculate the mean flow properties.

\subsubsection{Shear velocity estimates}

In the absence of waves, the flow energetics and mixing can be described by the absolute intensity of the velocity fluctuations calculated as turbulent kinetic energy $(q)$ and the covariance of velocity fluctuations (Equation [2]).

$$
\begin{gathered}
q=\frac{1}{2}\left(\overline{u^{\prime} u^{\prime}}+\overline{v^{\prime} v^{\prime}}+\overline{w^{\prime} w^{\prime}}\right) \\
\operatorname{cov}=\left(\overline{u^{\prime} w^{\prime}}\right)+\left(\overline{v^{\prime} w^{\prime}}\right)
\end{gathered}
$$

The shear velocity, $u_{*}$, is also a measure of mixing and is typically used in conjunction with sediment properties to estimate sediment transport. The shear velocity can be calculated from the turbulent kinetic energy (TKE) as

$$
u_{*}=\sqrt{C_{D} q}
$$

where $C_{D}$ is a constant taken as 0.19 (Kim et al. 2000; Pope et al. 2006; Stapleton and Huntley 1995). Shear velocity can also be calculated from the covariance:

$$
u_{*}=\sqrt{-\operatorname{cov}}
$$

(Kim et al. 2000; Salehi and Strom 2012).

The correlation between horizontal and vertical wave orbital velocity components can create errors in bottom stress estimates computed using 
the covariance method (Shaw and Trowbridge 2001). As the covariance is a direct estimate of stress, several independent methods have been developed to reduce the potential errors that occur when waves are present.

Bursts sampled in the presence of waves require additional processing to accurately calculate the TKE and covariance. Each flow component contains the mean flow $(U, V, W)$, the turbulent component $\left(u^{\prime}, v^{\prime}, w^{\prime}\right)$, and the wave component $(\tilde{u}, \tilde{v}, \tilde{w})$. Removing the wave component from the fluctuating velocity requires the velocity to be analyzed in the frequency domain, which requires a continuous time series. However, the available wave and current data were sparse, and the information needed to apply methods to remove errors associated with the waves was not available. Therefore, the analysis considered only methods that assume the potential contamination by waves was not present.

An additional method for calculating the shear stress, called the inertial dissipation method, was proposed by Stapleton and Huntley (1995). This method assumes that turbulence generation and dissipation are in a local balance, and that the measurements are made within the constant stress part of the logarithmic boundary layer (i.e., the local stress is assumed equal to the bottom stress). The basis of this method given in Equation 5 calculates the shear velocity based on the assumption that an inertial subrange exists in which the spectral transfer of TKE is controlled primarily by dissipation. By Taylor's frozen turbulence hypothesis (Hinze 1975), the TKE equation can be transformed from wavenumber space to frequency space, allowing for the calculation of the shear velocity:

$$
u_{s}=\left(\phi_{i i}(k) k^{5 / 3} / \alpha_{i}\right)^{1 / 2}(\kappa z)^{1 / 3}
$$

where $\phi$ phi is the spectral density, $\kappa$ equals the von Karman's constant (o.4), $z$ is the vertical coordinate measured positive upwards from the bed, and $\alpha_{i}$ equals the Kolmogorov constant with $\alpha_{1}=0.51, \alpha_{2}=\alpha_{3}=4 \alpha_{1} / 3$ (Kim et al. 2000).

Bottom shear velocity is estimated using the methods described above: TKE method through Equation (3), covariance method through Equation (4), and inertial dissipation method through Equation (5). Shear velocity is also computed using a bottom boundary layer model (BBLM). 


\subsubsection{Micro-scale turbulence}

Suspended particles in fine-grained sediment environments tend to form cohesive flocs (Winterwerp and Van Kesteren 2004). Floc size is controlled by complex interactions between concentration and turbulence intensity. Neglecting particle collisions, floc size is limited by turbulence shear stresses that tend to break up flocs. Two measures used to investigate cohesive sediment dynamics are the dissipation parameter $(G)$,

$$
G=\sqrt{\frac{\varepsilon}{v}}
$$

and the Kolmogorov micro-scale $\left(\lambda_{0}\right)$,

$$
\lambda_{0}=\left(\frac{v^{3}}{\varepsilon}\right)^{1 / 4}
$$

where $\varepsilon$ is the turbulence kinetic energy dissipation and $v$ is the kinematic viscosity of water (Kolmogorov 1941). In shear-generated boundary layer flows, dissipation approximately balances production allowing $\varepsilon$ to be written as

$$
\varepsilon=\frac{u_{*}^{3}}{\kappa z}
$$

The Kolmogorov micro-scale is a measure of the size of the smallest turbulent eddies and therefore the maximum sustainable floc size. Flocs of greater diameter are subject to turbulence stresses that can overcome the cohesive bonding properties of fine-grained sediment, thereby limiting floc growth. At scales less than $\lambda_{0}$, viscous effects dominate, and the sediment cohesive properties can more easily maintain floc stability. Typical values obtained in estuaries range from 100 to $1,000 \mu \mathrm{m}$ (Winterwerp 1998). The dissipation parameter represents the velocity rate of strain and is proportional to the local shear. Higher rates of strain produce greater shearing force causing the breakup of larger flocs. Laboratory experiments conducted by Manning and Dyer (1999) show reductions in average floc size from 150 to $80 \mu \mathrm{m}$ for $G$ ranging from 45 to $12 \mathrm{~s}^{-1}$. 


\subsection{Core collection at Hamilton Wetlands}

From July $28-31,2015$, six $10 \mathrm{~cm}$ diameter cores were collected from five station locations (Figure 2) in the area of the Hamilton Wetlands site for the purpose of erosion experiments. Due to limited access to much of the wetland area during low tide, coring activities could not be completed within one working day. Cores from Hamilton Stations 1, 2, and 4 were collected on July 28, 2015. A replicate core was collected from Station 1 on July 30, 2015, and two cores were collected from San Pablo Bay just outside the Hamilton Wetlands basin (Stations $5 \mathrm{~N}$ and $5 \mathrm{~S}$ ) on July 31, 2015. Table 1 provides core logging information for each of the cores collected.

Figure 2. Aerial photo showing five core station locations.

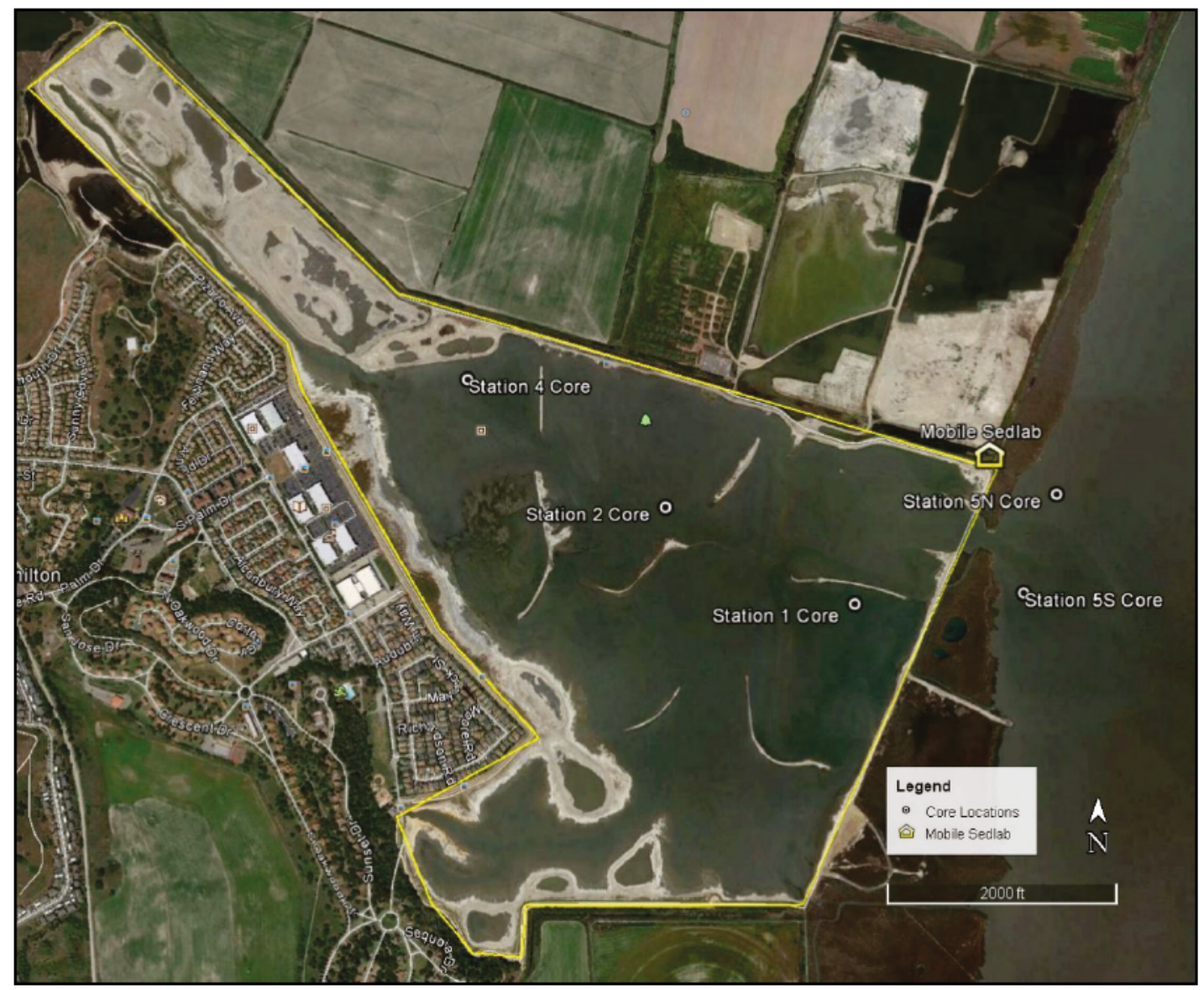


Table 1. Core sampling station locations and dates collected.

\begin{tabular}{|c|c|c|c|c|}
\hline Core ID & $\begin{array}{c}\text { Latitude } \\
\text { (north) }\end{array}$ & $\begin{array}{c}\text { Longitude } \\
\text { (west) }\end{array}$ & Collection Date & $\begin{array}{c}\text { Core Length } \\
\text { (cm) }\end{array}$ \\
\hline Station 1 & $38.0553^{\circ}$ & $122.4968^{\circ}$ & $07 / 28 / 2015$ & $35-37$ \\
\hline Station 1-2 & $38.0553^{\circ}$ & $122.4968^{\circ}$ & $07 / 30 / 2015$ & $36-37$ \\
\hline Station 2 & $38.0577^{\circ}$ & $122.5027^{\circ}$ & $07 / 28 / 2015$ & $39-40$ \\
\hline Station 4 & $38.0610^{\circ}$ & $122.5090^{\circ}$ & $07 / 28 / 2015$ & 54.5 \\
\hline Station 5N & $38.0580^{\circ}$ & $122.4903^{\circ}$ & $07 / 31 / 2015$ & $37-40$ \\
\hline Station 5S & $38.0556^{\circ}$ & $122.4915^{\circ}$ & $07 / 31 / 2015$ & \\
\hline
\end{tabular}

A push corer was used to collect all the above-mentioned cores. The ERDC push corer is composed of a polycarbonate core barrel, a $10 \mathrm{~cm}$ polyvinyl chloride (PVC) sleeve, a $5 \mathrm{~cm}$ PVC check valve, and aluminum push poles (Figure 3A). The push corer was lowered by hand to the bottom and vertically driven into the bed by the operator pressing downward on the attached push pole. Care was taken to keep the push pole and core in a vertical orientation during the coring process. The check valve serves to create a seal above the core to prevent the captured sediment core from slipping out of the core tube. Once the core was retrieved to the vessel, a plunger with bentonite paste (for sealing and lubrication) was inserted into the bottom of the core, and each end of the core was sealed with end caps (Figure $3 \mathrm{~B}$ and $\mathrm{C}$ ). Each core was labeled, logged, and stored submerged in water after collection. 
Figure 3. Core sampling devices.

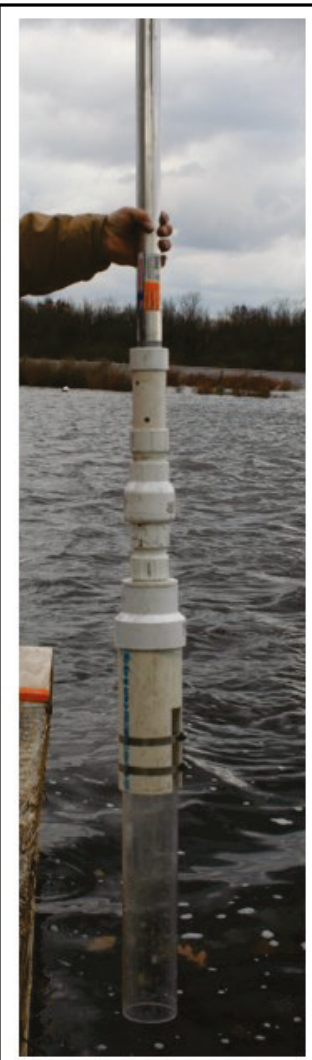

A) Push Corer.

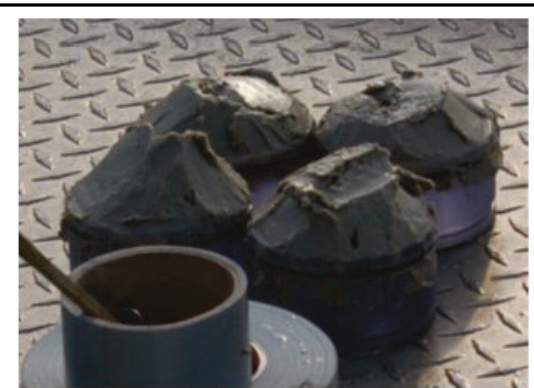

B) Plungers with Bentonite paste.

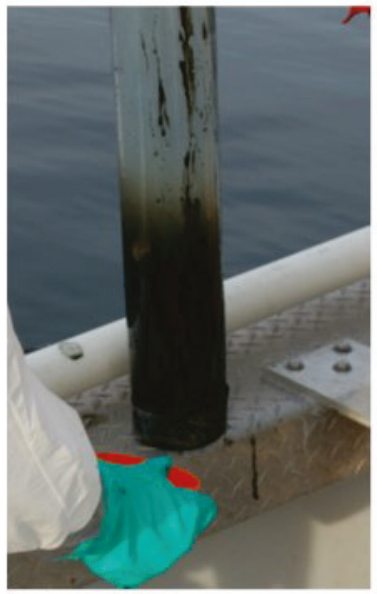

C) Core with plunger inserted.

Cores collected were transported by vessel to shore and carried by hand approximately $130 \mathrm{~m}$ to the ERDC Coastal and Hydraulics Field Sediment Laboratory located in the northeastern corner of Hamilton Wetlands (Figure 4, Mobile Sedlab). Erosion experiments were conducted from July 29, 2015, through August 1, 2015, in the field laboratory following the Sedflume methods (described in Section 2.4 Sedflume). During the time of erosion experiments, sediment cores were stored in a shaded barrel filled with site water.

During the period of July 27, 2015, through August 1, 2015, daily water levels within Hamilton Wetlands ranged by approximately $2 \mathrm{~m}$. The mobile sediment lab was strategically placed in the northeast corner of the wetlands, nearest the levee breach and greatest water depths, to limit the impacts tidal range might have on access to water for flume operations. Despite these efforts, reduced water clarity and access at periods of low tides limited the schedule of Sedflume operation. Due to these schedule restrictions, erosion experiments were not conducted over the entire 
length of the cores but were instead limited to the upper $15 \mathrm{~cm}$.

Additionally, the core collected from Station ${ }_{5} \mathrm{~S}$ was unable to be analyzed in the time permitted for field work.

\subsection{Sedflume}

Sedflume is a field- or laboratory-deployable flume for quantifying cohesive sediment erosion. The USACE-developed Sedflume is a derivative of the flume developed by researchers at the University of California at Santa Barbara (McNeil et al. 1996). The flume includes an $80 \mathrm{~cm}$ long inlet section (Figure 4) with cross-sectional area of $2 \mathrm{~cm} \times 10 \mathrm{~cm}$ for uniform, fully developed, smooth-turbulent flow. The inlet section is followed by a test section with a $10 \mathrm{~cm}$ diameter open bottom. Coring tubes and flume test section, inlet section, and exit sections are constructed of clear polycarbonate materials to permit observation of sediment-water interactions during the course of erosion experiments. The flume includes a port over the test section to provide access to the core surface for physical sampling. The flume accepts sediment cores up to $80 \mathrm{~cm}$ in length.

Figure 4. Sedflume erosion flume (lower right). Core inserted into test section (upper left). Core surface flush with bottom of flow channel (upper right). Stress associated with channel flow rates (lower left table).

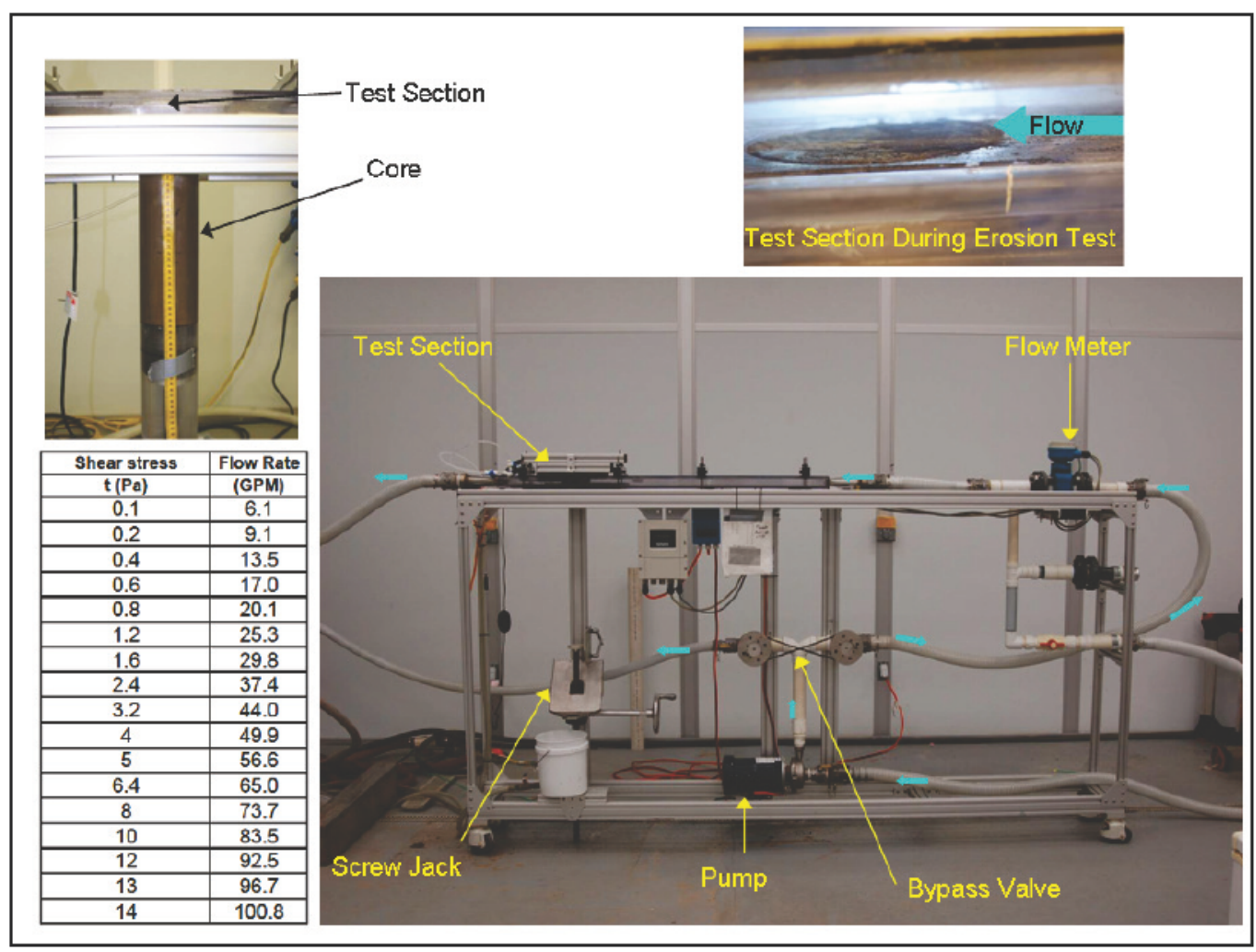




\subsubsection{Erosion experiments}

Prior to the erosion experiment, descriptions of the core are recorded, including length, condition of the core surface, biological activity, and any visual evidence of layering. Cores are inserted into the testing section of Sedflume and a screw jack is used to advance the plunger such that the core surface becomes flush with the bottom wall of the flume. Flow is directed over the sample by diverting flow from a $5.5 \mathrm{hp}$ trash pump, through a $5 \mathrm{~cm}$ inner diameter stiff hose, into the flume. The flow through the flume produces shear stress on the surface of the core. (Numerical, experimental, and analytical analyses have been performed to relate flow rate to bottom shear stress.) Erosion of the surface sediment is initiated as the shear stress is increased beyond the critical stress for erosion, $\tau_{c}$. As sediment is eroded from the core surface, the operator advances the screw jack to maintain the sediment surface flush with the bottom wall of the erosion flume. Figure 4 includes a photograph of the flume, a close-up photograph of the test section, and a table of flow rate/shear stress relationships.

Erosion velocity was determined from the displacement of the core surface over the elapsed time of the experiment. Generally, erosion experiments were performed by repeating a sequence of increasing shear stresses. Approximately 1 to $5 \mathrm{~mm}$ of sediment were eroded during each erosion experiment at a specified shear stress, and thus the duration of each test was dependent on the rate of erosion. Generally, these erosion tests were between 20 and $600 \mathrm{~s}$ in duration. Past experiments have shown that the operational upper and lower erosion velocity limits for Sedflume erosion experiments are $1.7 \times 10^{-2} \mathrm{~cm} / \mathrm{s}$ and $1.7 \times 10^{-4} \mathrm{~cm} / \mathrm{s}$, respectively. These velocities were used to set the bounds and determine the spacing of shear stress intervals for an erosion sequence. A diagram depicting this erosion test process along with an example erosion sequence is shown in Figure 5. 
Figure 5. Diagram of sediment core erosion process. The brown arrow indicates direction of motion of the sediment into the flume. The blue arrow indicates flow direction of water. An example erosion sequence is provided in the table to the right of the sediment core.

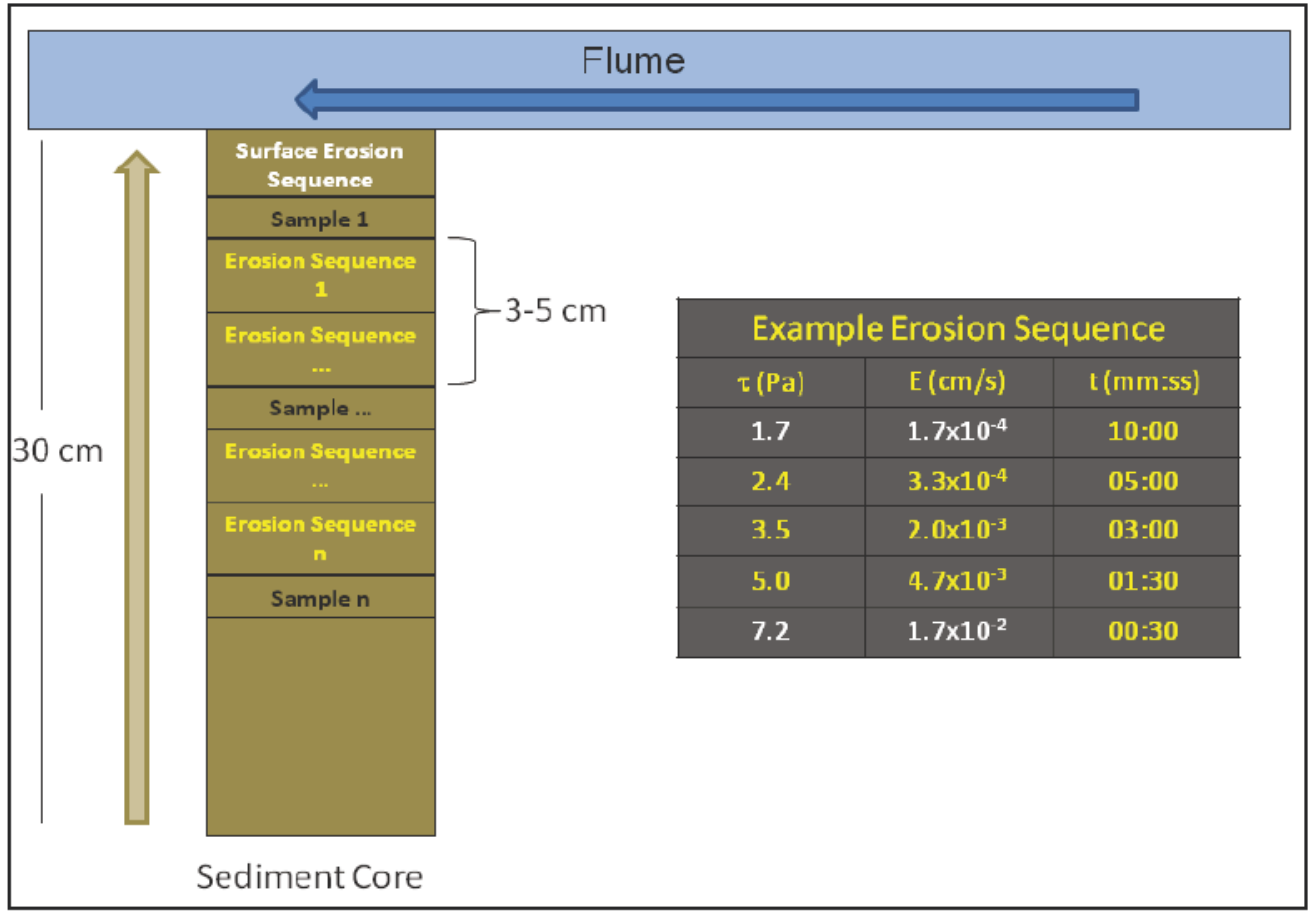

Physical samples for bulk sediment property measurements were taken at approximately 3 to $5 \mathrm{~cm}$ intervals during erosion experiments, generally at the end of a shear stress cycle. Physical samples were collected by draining the flume channel, opening the port over the test section, and extracting a sample from the sediment bed. These samples were then measured for bulk density and grain-size distribution. These properties strongly influence erosion; therefore, documenting any variation with depth was important in interpreting the erosion data.

\subsubsection{Sediment bulk properties}

Bulk Density Measurements. Bulk sediment density of physical samples was determined by a wet-dry weight analysis. Physical samples were extracted from the saturated core surface and placed in a pre-weighed aluminum tray. Sample weight was recorded immediately after collection and again after a minimum of 12 hours in a $50^{\circ} \mathrm{C}$ drying oven. Wet weight of the sample was calculated by subtracting tare weight from the weight of the sample. The dry weight of the sample was calculated as the tare weight subtracted from the weight after drying. The water content, $w$, was then given: 


$$
w=\left(\frac{m_{w}-m_{d}}{m_{d}}\right)
$$

where $m_{w}$ and $m_{d}$ are the wet and dry weights, respectively. A volume of saturated sediment, $V$, consists of both solid particles and water and can be written as

$$
V=V_{s}+V_{w}
$$

where $V_{s}$ is the volume of solid particles and $V_{w}$ is the volume of water. If the sediment particles and water have density $\rho_{s}$ and $\rho_{w}$, respectively, the water content of the sediment can be written as

$$
w=\frac{\rho_{w} V_{w}}{\rho_{s} V_{s}}
$$

A mass balance of the volume of sediment gives

$$
\rho V=\rho_{s} V_{s}+\rho_{w} V_{w}
$$

where $\rho$ is the bulk density of the sediment sample.

Equations 9 through 12 are used to derive an explicit expression for the bulk density of the sediment sample, $\rho$, as a function of the water content, $w$, and the densities of the sediment particles and water. This equation is

$$
\rho=\rho_{s}+\frac{w \rho_{s}\left(\rho_{w}-\rho_{s}\right)}{\rho_{w}+w \rho_{s}}
$$

For the purpose of these calculations, $\rho_{s}=2.65 \mathrm{~g} \cdot \mathrm{cm}^{-3}$ and $\rho_{w}$ was calculated for measured pore water at room temperature.

Particle-Size Distribution._Samples collected during erosion experiments were transported to the Sediment Transport Processes Lab at ERDC for grain-size analysis. A Malvern Mastersizer 2000 laser particlesizer was used to measure the particle-size distributions in sub-samples collected from the cores. The Malvern measures particle size over the range 0.02 to $2,000 \mu \mathrm{m}$. Sediments were homogenized, sub-sampled (1 to $2 \mathrm{~g}$ ), 
and deflocculated overnight in a solution of sodium metaphosphate (40 g/L). Samples were then passed through a \#18 mesh $(1,000 \mu \mathrm{m})$ sieve into the instrument's reservoir and sonicated for $60 \mathrm{~s}$ prior to analysis. The sample was then pumped and recirculated through the optical module. The optical module includes a spatial filter assembly containing a laser diode and laser beam collimator. The diffraction detector assembly contains a custom photodetector array that is used for the measurement of light scattering by the suspended particles. The distribution of grain sizes and median grain sizes was derived from this light scattering measurement. Organic material was not oxidized prior to grain size analysis.

\subsubsection{Multivariate erosion rate prediction}

The goal of erosion data analysis is to determine appropriate parameterization of erosion processes so that they may be incorporated into numerical modeling studies. Analysis of the erosion data from Hamilton Wetlands suggested that the erosion algorithm should be of the following form:

$$
\begin{array}{cc}
E=0 ; & \left(\tau<\tau_{c}\right) \\
E=A \tau^{n} ; & \left(\tau_{c} \leq \tau \leq \tau_{m}\right) \\
E=A \tau_{m}{ }^{n} ; & \left(\tau>\tau_{m}\right)
\end{array}
$$

where $E$ represents erosion rate (centimeter per second) from the bed, $\tau$ is bed shear stress, and $\tau_{c}$ is critical stress for erosion, $A$ is an empirical constant, $n$ is an empirical exponent, and $\tau_{m}$ is bed stress at which erosion rate becomes constant. Solution of Equation (14) to data requires solving for three parameters, $\tau_{c}, A$, and $n$. For the purposes of this study, critical shear stress was defined to be the shear stress at which a small, but measurable, rate of erosion occurred and was set to a rate of $1 \times 10^{-4} \mathrm{~cm} / \mathrm{s}$. Bed stress for the upper limit of erosion rate was determined by the previously reported upper operational erosional velocity of Sedflume, $1.7 \times$ $10^{-2} \mathrm{~cm} / \mathrm{s}$. The best fit of Equation (14) to measured data was accomplished through an iterative, multi-parameter, least-squares method on the linear transform of Equation (14). The resulting equation of this fit provided values for $A$ and $n$ and was used to determine $\tau_{c}$ and $\tau_{m}$ at their defined erosion rates. 


\subsection{Sediment and stress modeling}

The wave and current time-series measurements at each platform were used to drive a BBLM to predict the combined wave and current shear stress components. The theoretical model is an extension of the combined flow model developed by Glenn and Grant (1987) as modified by Styles and Glenn (2000) but without the correction for suspended sediment induced stratification. The details of the model formulation can be found in the above references.

The model input included near-bed wave excursion amplitude $(A b)$, wavebottom orbital velocity amplitude $\left(U_{b}\right)$, and near-bed mean current $\left(u_{r}\right)$ at a known height above the bed $\left(z_{r}\right)$. The wave parameters were estimated from the wave height, wave period, and water depth measurements using linear wave theory (e.g., Dean and Dalrymple [1991]). The mean current was determined from the burst-averaged ADV measurements, and $z_{r}$ was set equal to $10 \mathrm{~cm}$ corresponding to the height of the ADVs above the local bed elevation. The model computes the time-averaged shear stress associated with the current $\left(\tau_{c}\right)$, the maximum shear stress associated with the wave ( $\tau_{w m}$ ), and the combined maximum wave plus current shear stress $\left(\tau_{c w}\right)$. The corresponding shear velocities are $u^{*_{c}}\left(=\sqrt{\tau_{c} / \rho}\right), u^{*} w m(=$ $\left.\sqrt{\tau_{w m} / \rho}\right)$, and $u^{*} c w\left(=\sqrt{\tau_{c w} / \rho}\right)$, respectively, where $\rho$ is fluid density.

\subsection{Critical shear stress and the initiation of sediment motion}

Initiation of sediment motion is determined using the Shields criteria:

$$
\psi=\frac{\left|\tau_{b}^{\prime}\right|}{\rho(s-1) g d_{r}}
$$

where $\left|\tau_{b}^{\prime}\right|$ is the magnitude of the maximum skin friction shear stress over a wave period, $d_{r}$ is the grain diameter, $g$ is the acceleration due to gravity, and $s$ is the specific gravity $\left(=\rho_{s} / \rho, \rho_{s}\right.$ is sediment density). Sediment mobilization occurs when the Shields parameter $(\psi)$ exceeds the critical value for initiation of sediment motion $\left(\psi_{c r}\right)$. The Shields criteria help identify wave and current conditions that favor sediment 
resuspension and thus provided a quantitative measure of sediment transport activity at each of the four sites.

The critical shear stress for the initiation of sediment motion for finegrained sediments varies widely in natural environments (Winterwerp and Van Kesteren 2004). For loose, unconsolidated sediments, as typical of freshly deposited material, motion can occur at approximately $0.1 \mathrm{~Pa}$. As new material is deposited on top of old material, compaction leads to consolidation, increasing the internal bonding properties of the sediment. Critical stresses on the order of $5 \mathrm{~Pa}$ are not uncommon for compacted cohesive sediments (Winterwerp and Van Kesteren 2004). The critical stress was measured using Sedflume from cores acquired at the three internal monitoring stations (Stations 1, 2, and 4). The critical stress measured at the surface varied between 0.14 and $0.21 \mathrm{~Pa}$ at these three internal Hamilton monitoring stations. The critical stress used in the BBLM for this study was set to $0.14 \mathrm{~Pa}$, to simulate conditions that most favor maximum sediment mobilization. 


\section{Results}

The results focus on the hydrodynamics and sediment transport processes. Regional wind and tide measurements are presented to help place the Hamilton Wetlands measurements acquired in the interior of the bay in a broader context.

\subsection{Regional winds and water level}

Wind data from NOAA buoy 9414863 located southeast of San Pablo Bay, California, are depicted in Figure 6. The record shows somewhat higherthan-average wind speeds between June and October 2016 compared to lower-than-average wind speeds in the winter. Annual average wind speed was $3.0 \mathrm{~m} / \mathrm{s}$. However, the winter months show the highest absolute wind speeds but are shorter in duration. The pattern is indicative of the regional climatic variability in which winter storms, consisting of strong but shortlived wind events, contrast the more persistent higher-than-average winds sustained for longer periods during the summer. The wind direction was variable (Figure 7 ) with a noticeable trend of southerly winds $\left(180^{\circ}\right)$ between June and October.

Figure 6. Hourly averaged wind speed measured at Hamilton Wetlands.
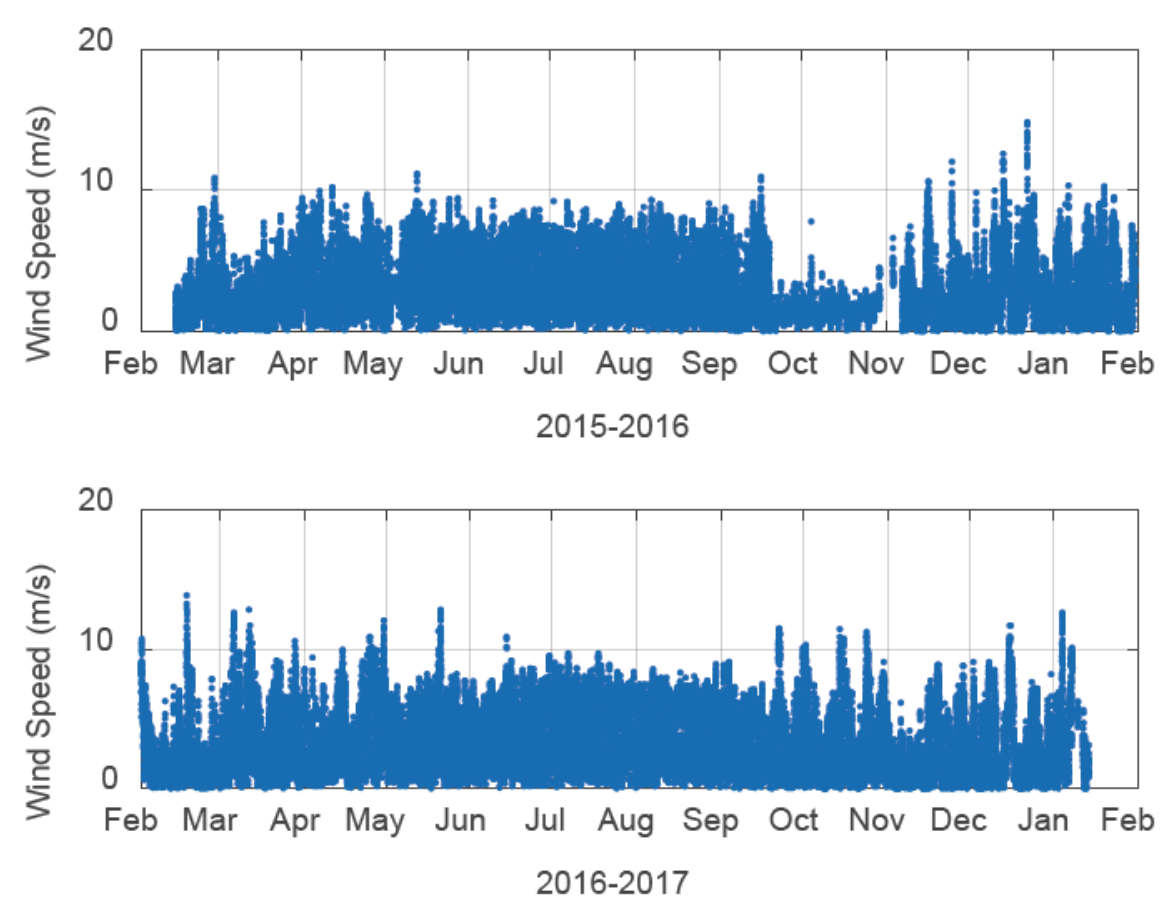
Figure 7. Wind direction.

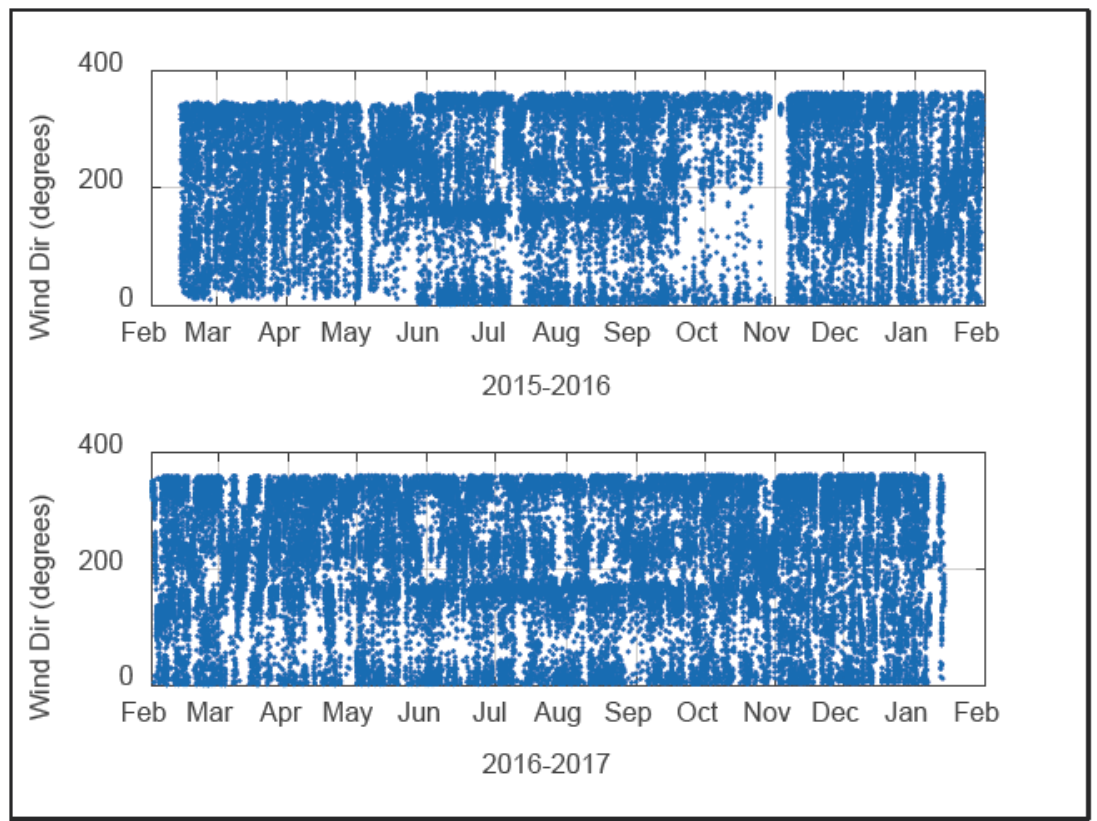

Water levels were measured at the same NOAA station as the wind (9414863). The data indicate a semi-diurnal tidal signal and low-frequency variations that includes a slight increase in water level starting in June and continuing until the end of October (Figure 8). Episodic fluctuations in the low-frequency signal, especially between November and May, are also of note and are likely indicative of atmospheric frontal systems in which strong winds caused brief periods of setup or setdown in the bay.

Figure 8. NOAA water level at San Pablo Bay station.

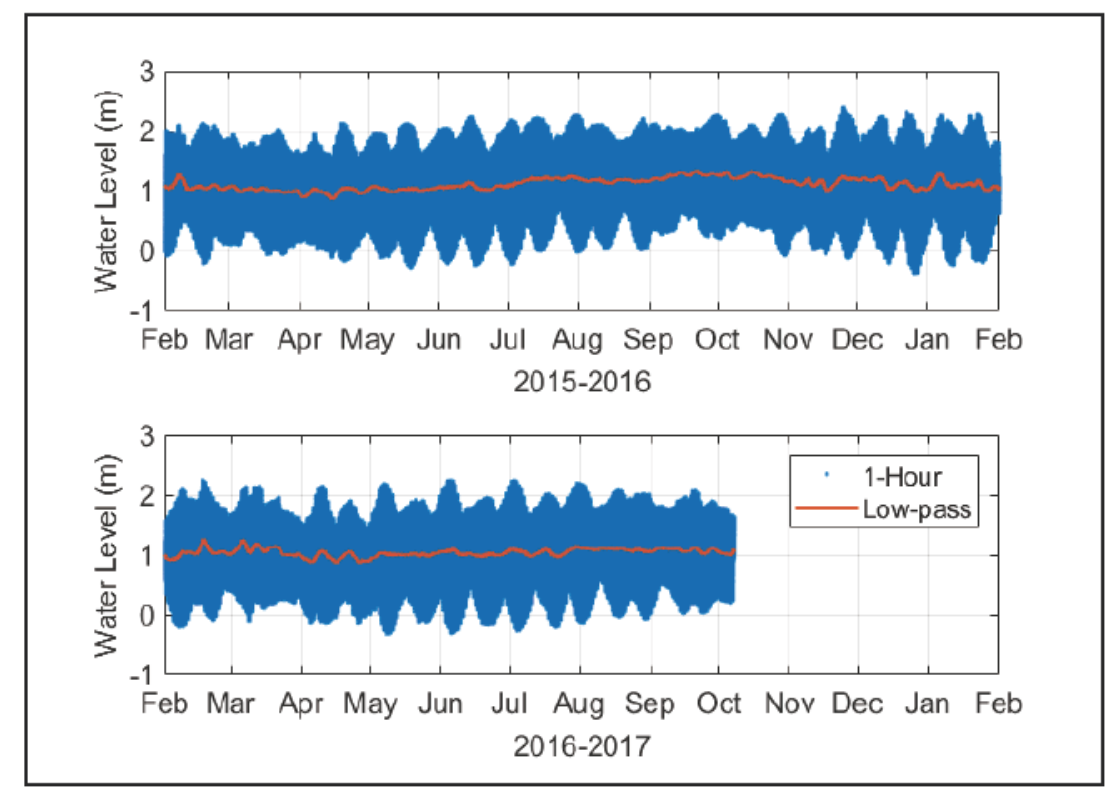




\subsection{Seasonal wind, water level, and water quality}

Because the time series spans multiple years, it was possible to explore seasonal variations caused by changes in the meteorological forcing and precipitation over the course of the year. Figures 9 through 13 depict monthly average conditions to elucidate the seasonal trends associated with Hamilton Wetlands. The time series were subdivided by month and then averaged to produce a record that highlights monthly trends. Average wind speeds were higher between April and August (Figure 9) and then show a general decrease until December. However, gusts tended to be more evenly distributed throughout the year. Note that the gusts also represent monthly averages so that the seasonal distribution is slightly smoothed, thereby reducing the effect of individual storms.

Figure 9. Bar chart depicting monthly average wind speeds, including wind gusts.

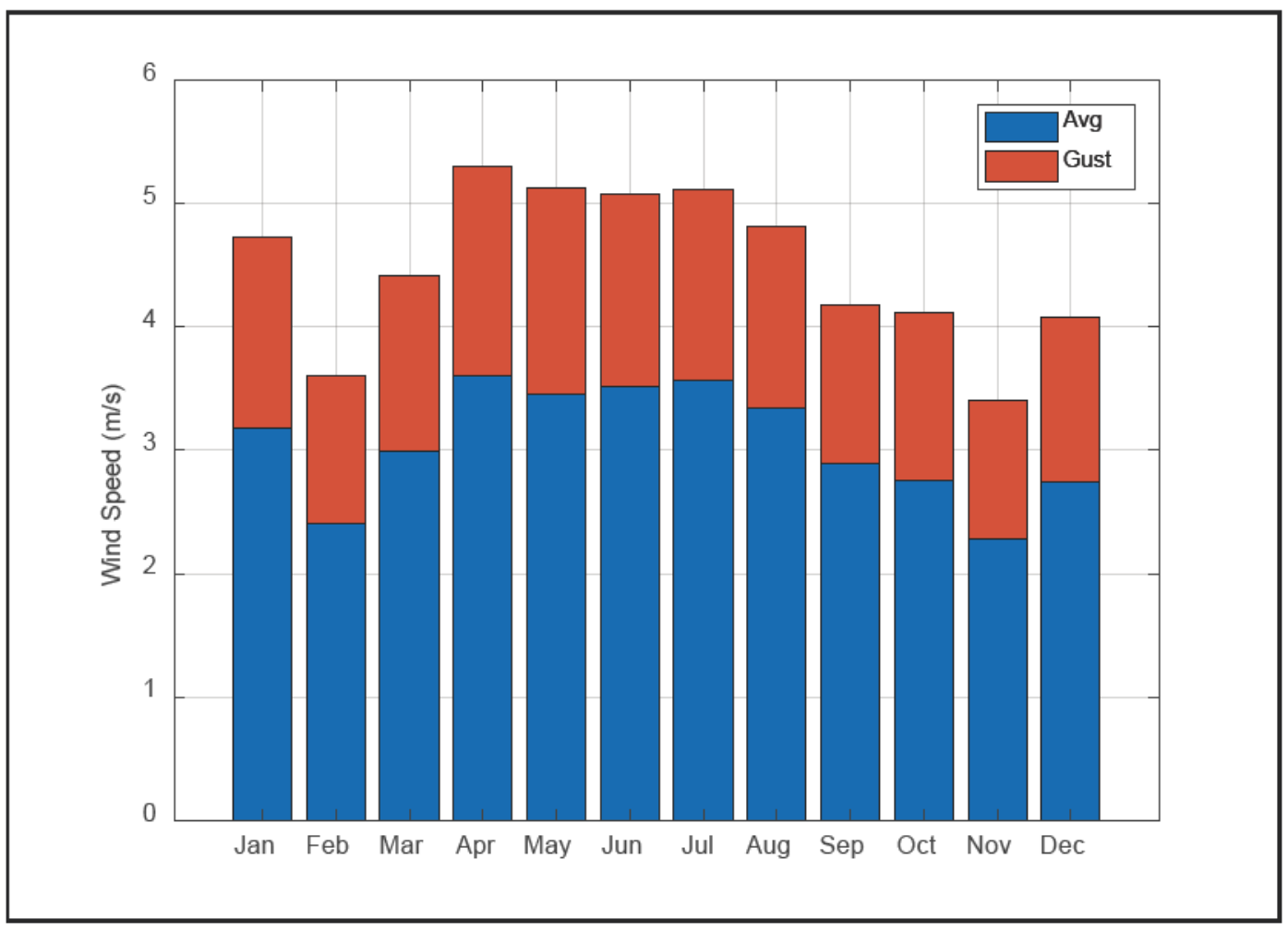

Higher monthly averaged winds starting in the spring and continuing through summer were caused by shifts in the regional atmospheric forcing along the central California coast. During the spring, the Pacific high shifts towards the north in response to increased warming with the change of season. The increase in average temperatures also produces a persistent low-pressure system within the California Central Valley. By summer, the inland low-pressure system and the Pacific high are well 
established, producing a pressure gradient that drives westward winds throughout the bay area.

Monthly averaged water levels increased steadily starting in April and peak in October (Figure 10). This trend was followed by a reduction in water level between December and April. While the data do not indicate a direct correlation with the wind, there is a general increase in wind velocity through the spring with the strongest winds and above-average water levels occurring in the summer and early fall.

Figure 10. Monthly averaged water level measured at NOAA buoy.

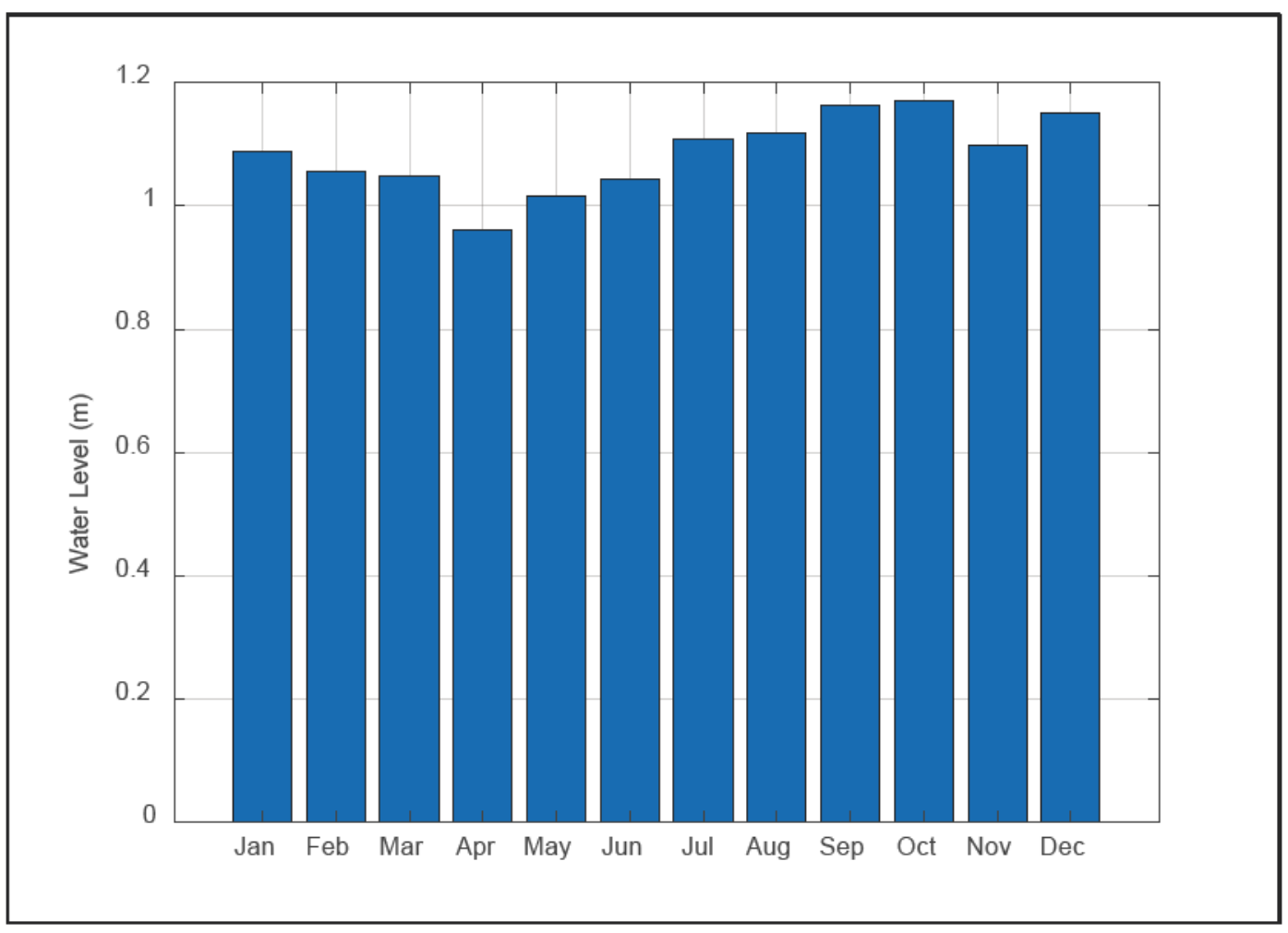

Monthly temperature changes at Hamilton 1 follow the seasonal trend for shallow systems at mid-latitudes, with highest temperatures during the summer and lowest temperatures during the winter (Figure 11). Monthly average salinity was highest in May and then steadily decreased until February (Figure 12). Salinities indicate a brackish environment with average values less than about $25 \mathrm{ppt}$. The salinity nearly doubled between February and June. The dry season for the San Francisco Bay area is during the summer, resulting in lower freshwater input and higher average salinities. 
Figure 11. Monthly averaged temperature at Hamilton Wetlands.

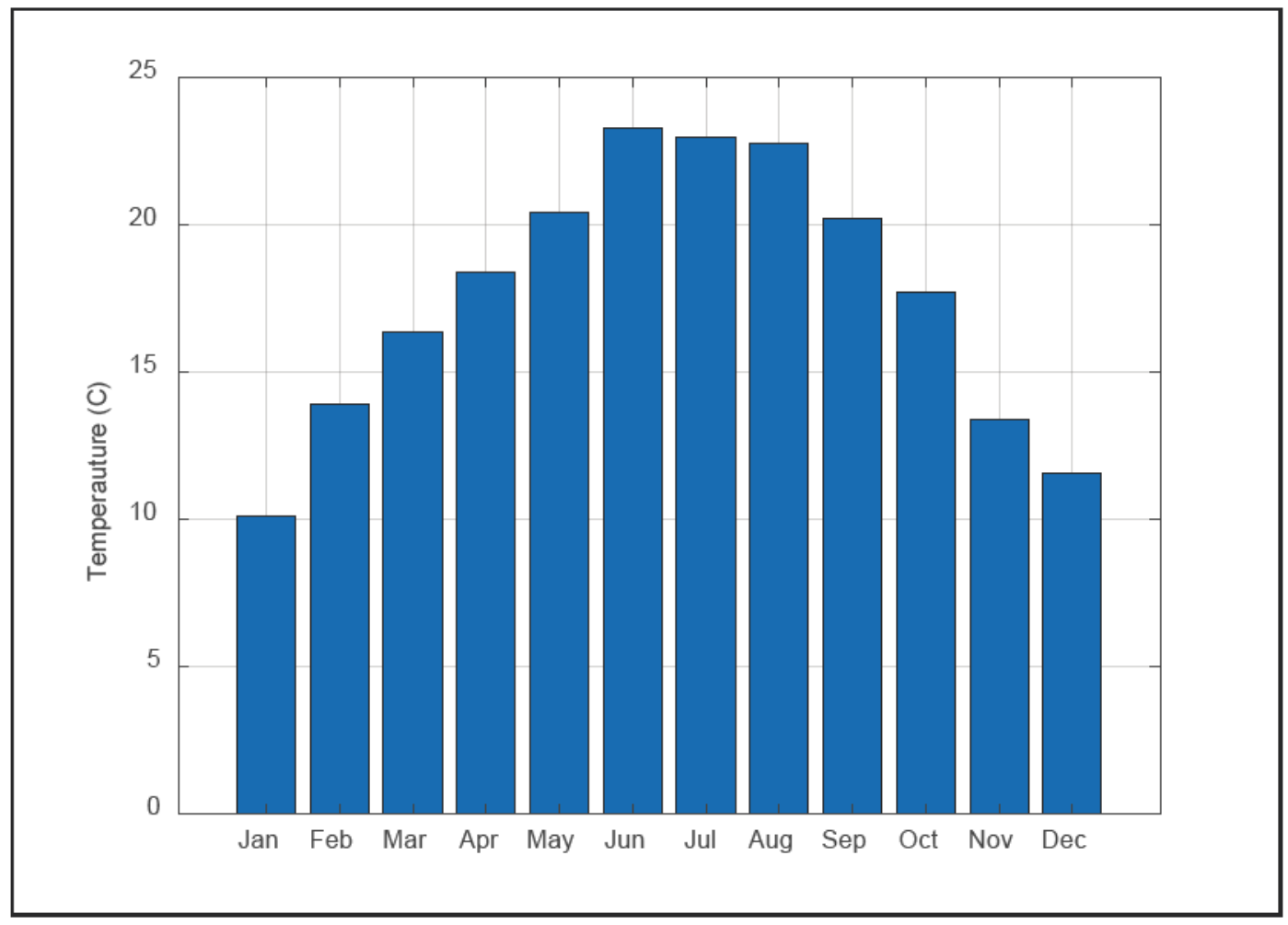

Figure 12. Monthly averaged salinity at Hamilton Wetlands.

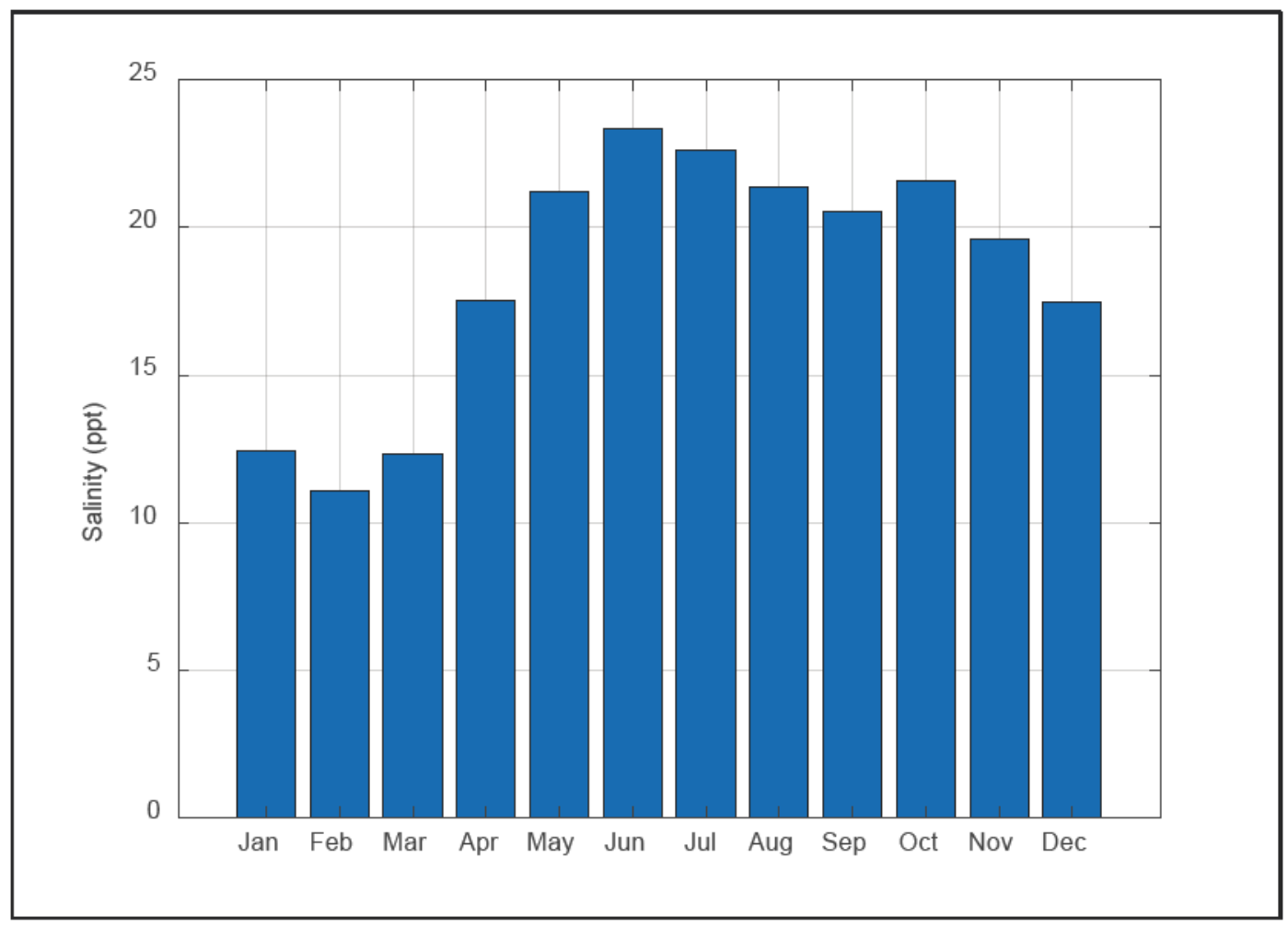


Unlike temperature and salinity, turbidity does not show a clear seasonal trend (Figure 13). However, if the month of May is removed from consideration, then a trend emerges with higher-than-average turbidity in the summer and lower-than-average turbidity in the winter. The potentially anomalously low turbidity in May was likely due to bio-fouling of the sensor, in which the probe was removed for servicing and replaced in June of both years. Therefore, both the turbidity values and the number of averaging points are skewed compared to data collected during the other months. Even so, the highest turbidities occurred in the summer, which coincides with the highest average wind conditions.

Figure 13. Monthly averaged turbidity at Hamilton Wetlands.

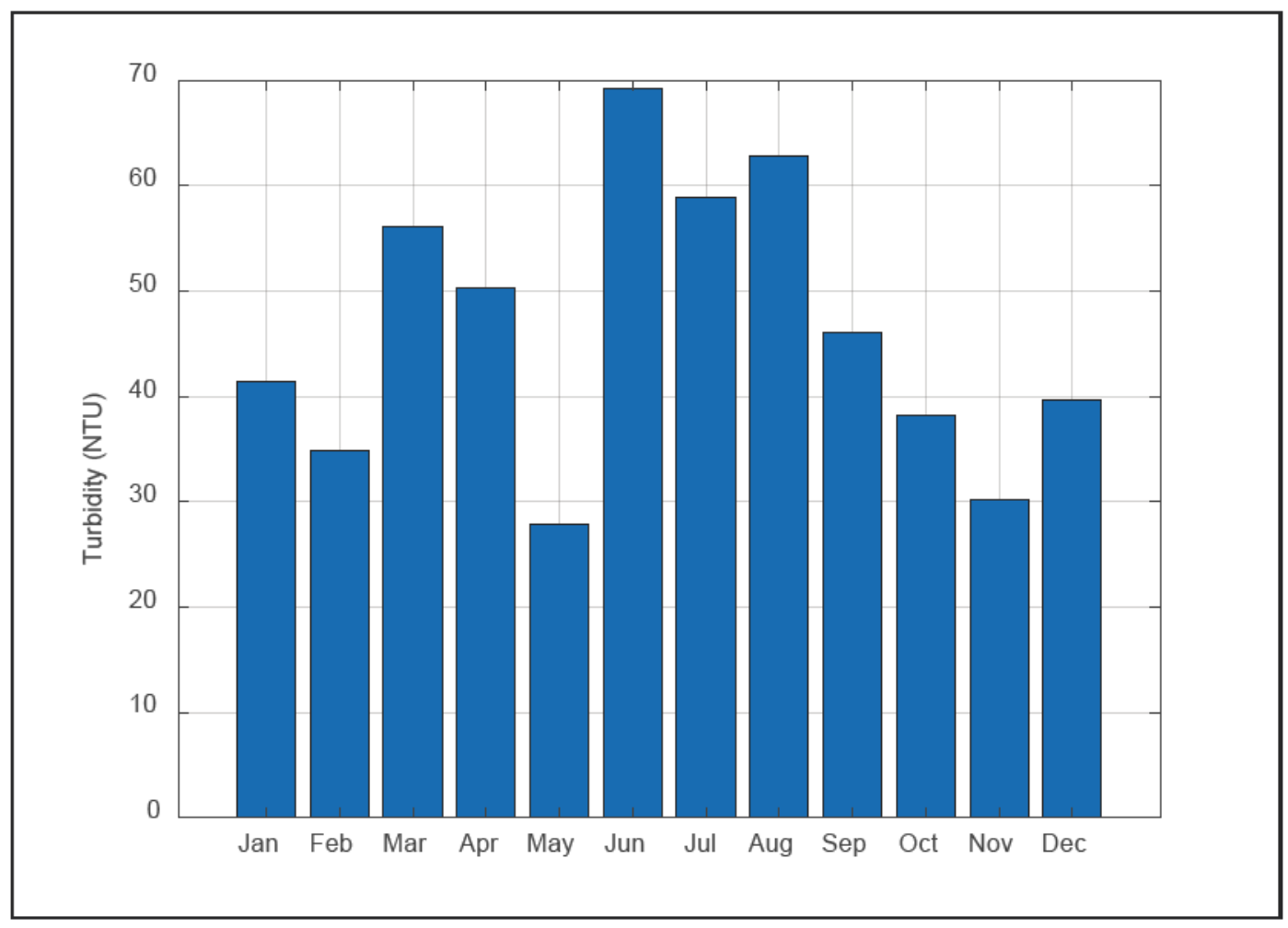

In shallow water systems, turbidity can be correlated with mixing generated by strong currents or winds. Considering that the data suggest that the wind played a role in resuspending sediment, Figure 14 depicts a scatter plot of the monthly averaged turbidity as a function of the monthly averaged wind. There is a clear trend with increasing turbidity associated with increasing wind speed. The greatest anomaly is for the month of May, in which the turbidity falls well below the other values for similar wind speeds. It was previously mentioned that the May data were potentially 
skewed due to instrument biofouling, and thus the lone data point is likely an underestimate of the actual turbidity for that month.

Figure 14. Turbidity as a function of monthly averaged wind speed at Hamilton Wetlands.

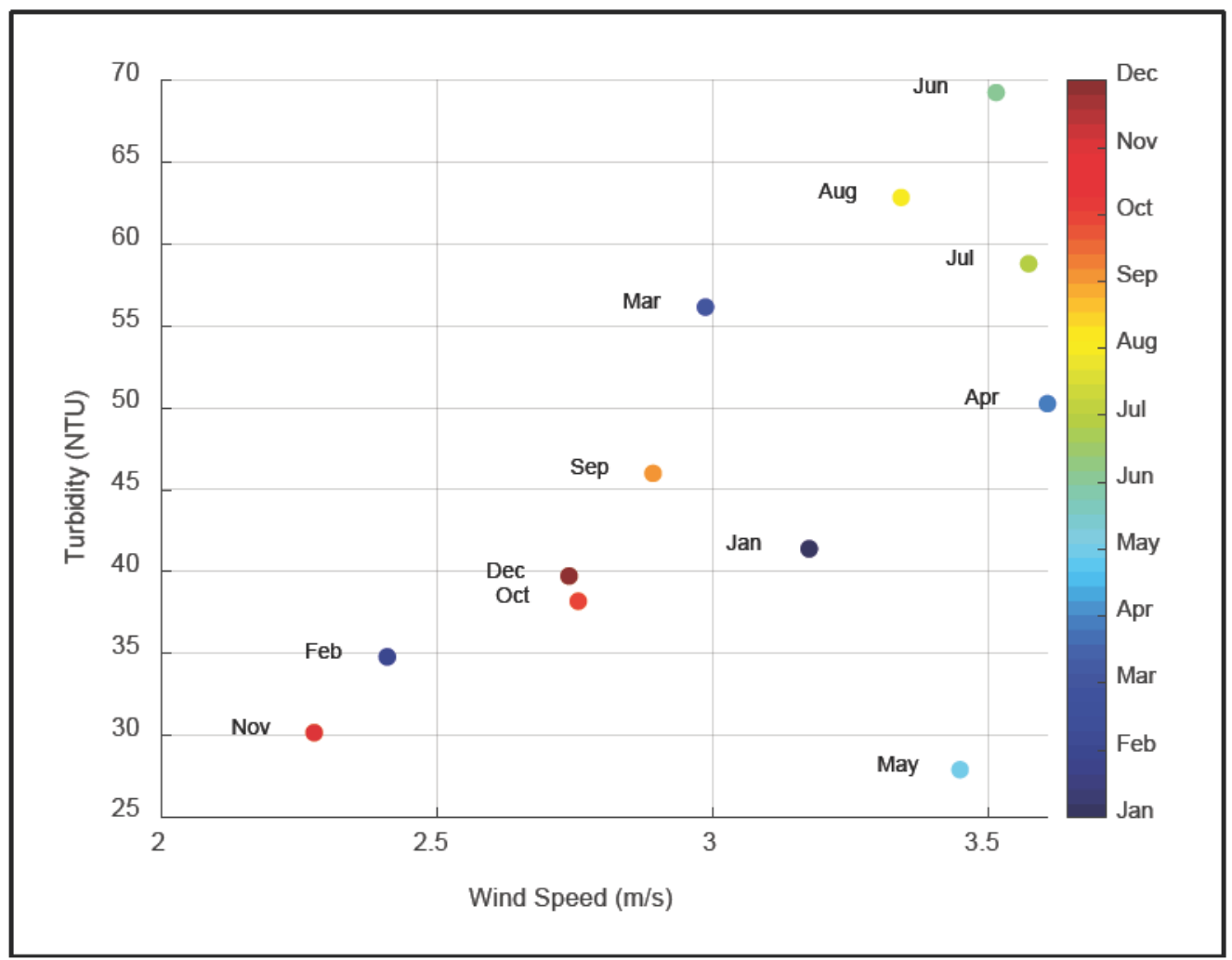

\subsection{Waves and water depth}

Wave height and period at stations Hamilton 1, 2, and 4 are depicted in Figures 15 through 20, respectively. The coverage varied between station and through time due to data gaps caused by biofouling or temporary instrument failure between servicing. Wave heights were typically < $0.01 \mathrm{~m}$, and peaks did not exceed $0.4 \mathrm{~m}$ at any site. The sheltered geometry of Hamilton Wetlands prevents significant fetch and associated wave growth. The highest waves and the station with the most wave events was Hamilton 2. There were more instances of wave heights $>0.2$ $\mathrm{m}$ here than at the other locations. Wave periods were typically $<2 \mathrm{~s}$, and maximum periods were $<4 \mathrm{~s}$ at all stations. The limited fetch precludes Hamilton Wetlands from experiencing higher and longer period waves. 
Figure 15. Wave height at Hamilton 1.

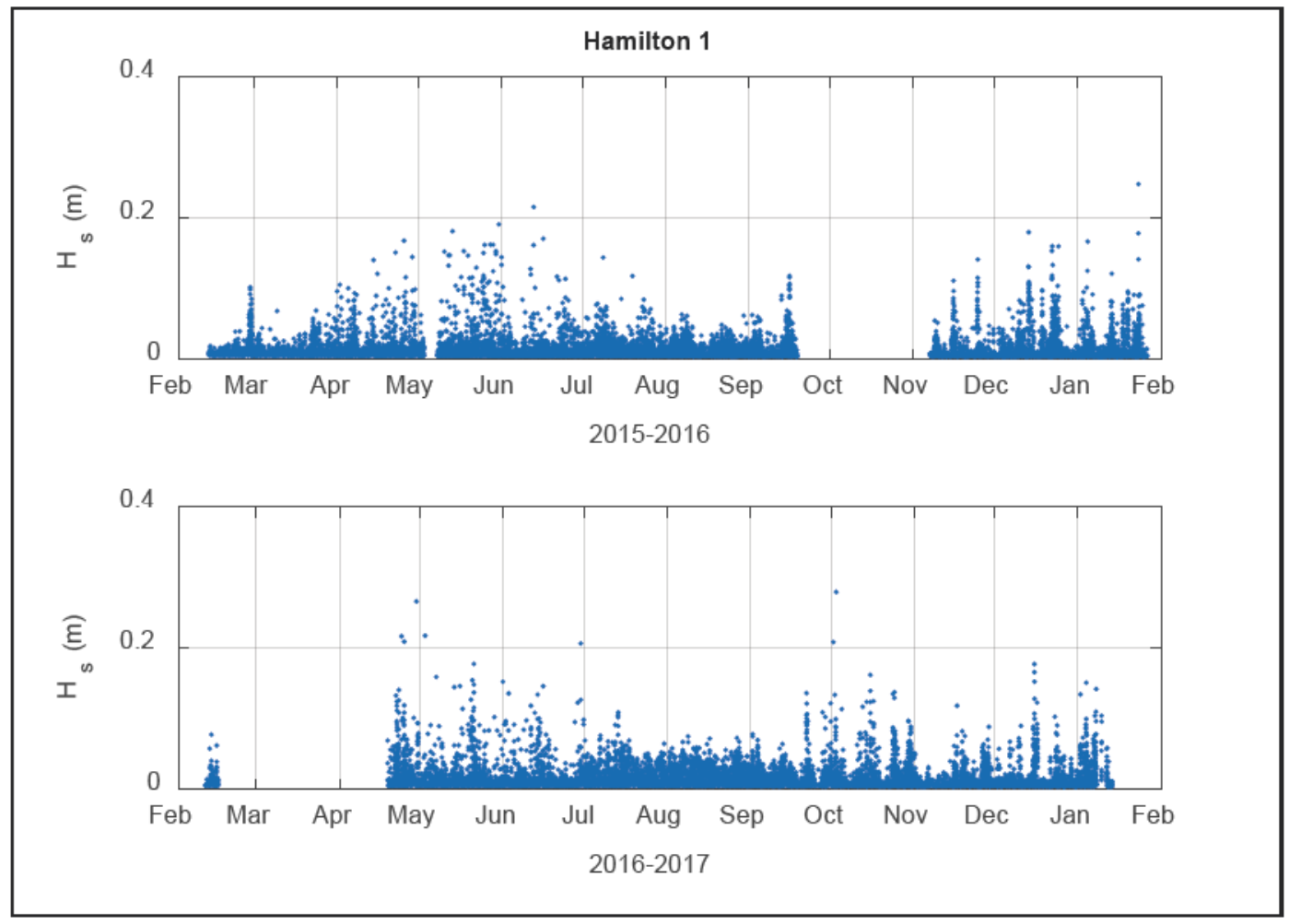

Figure 16. Wave period at Hamilton 1.

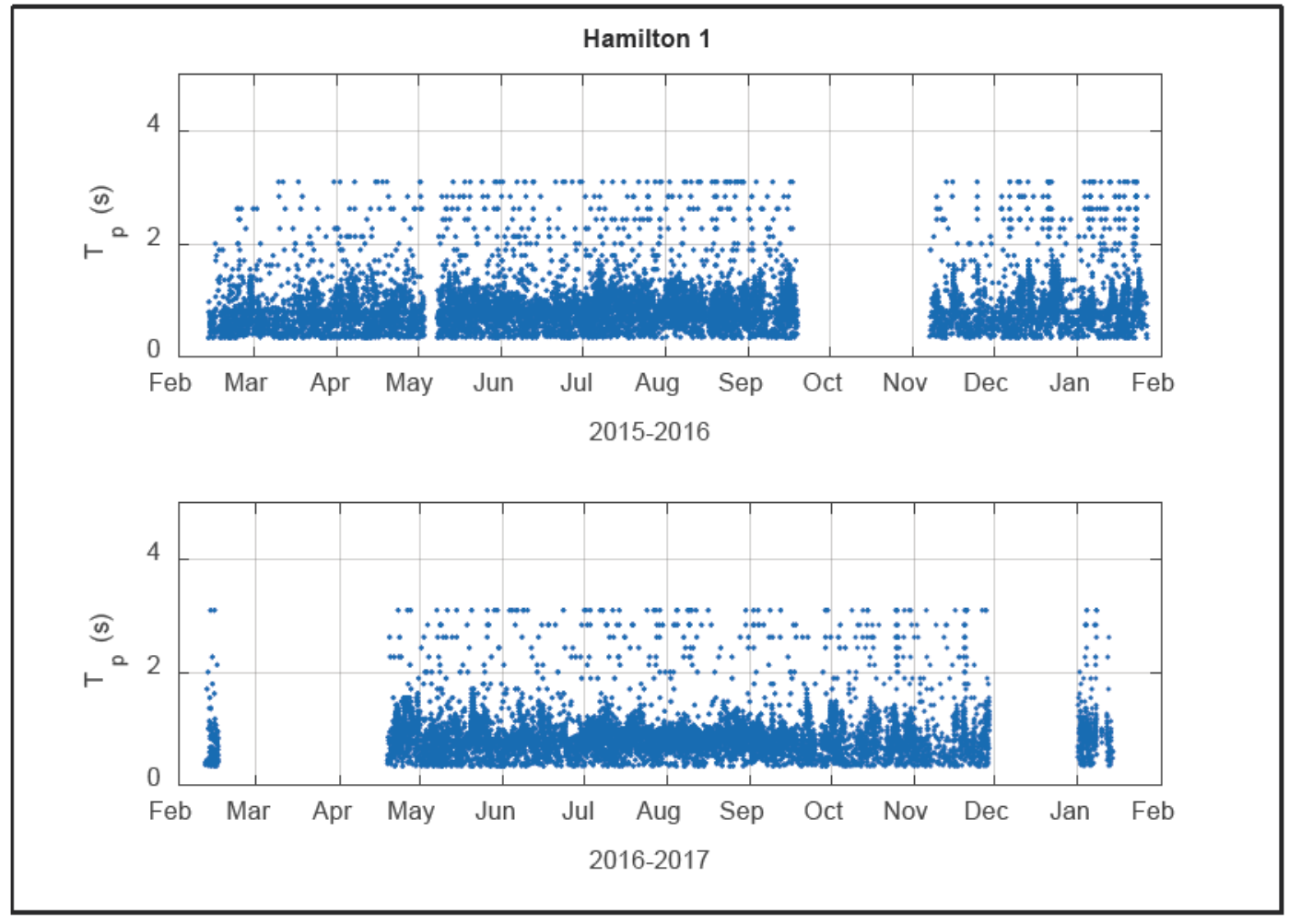


Figure 17. Wave height Hamilton 2.

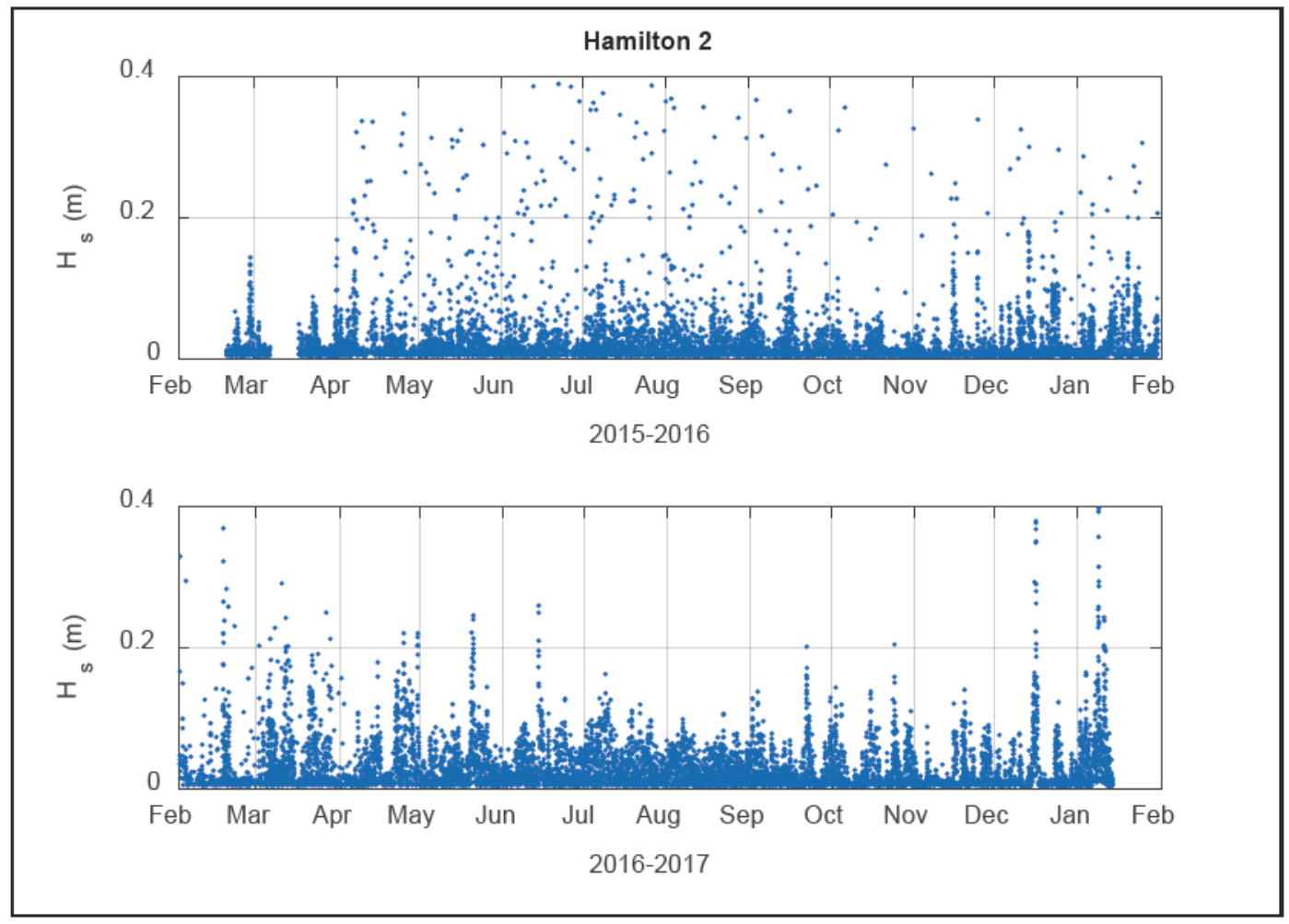

Figure 18. Wave period Hamilton 2.

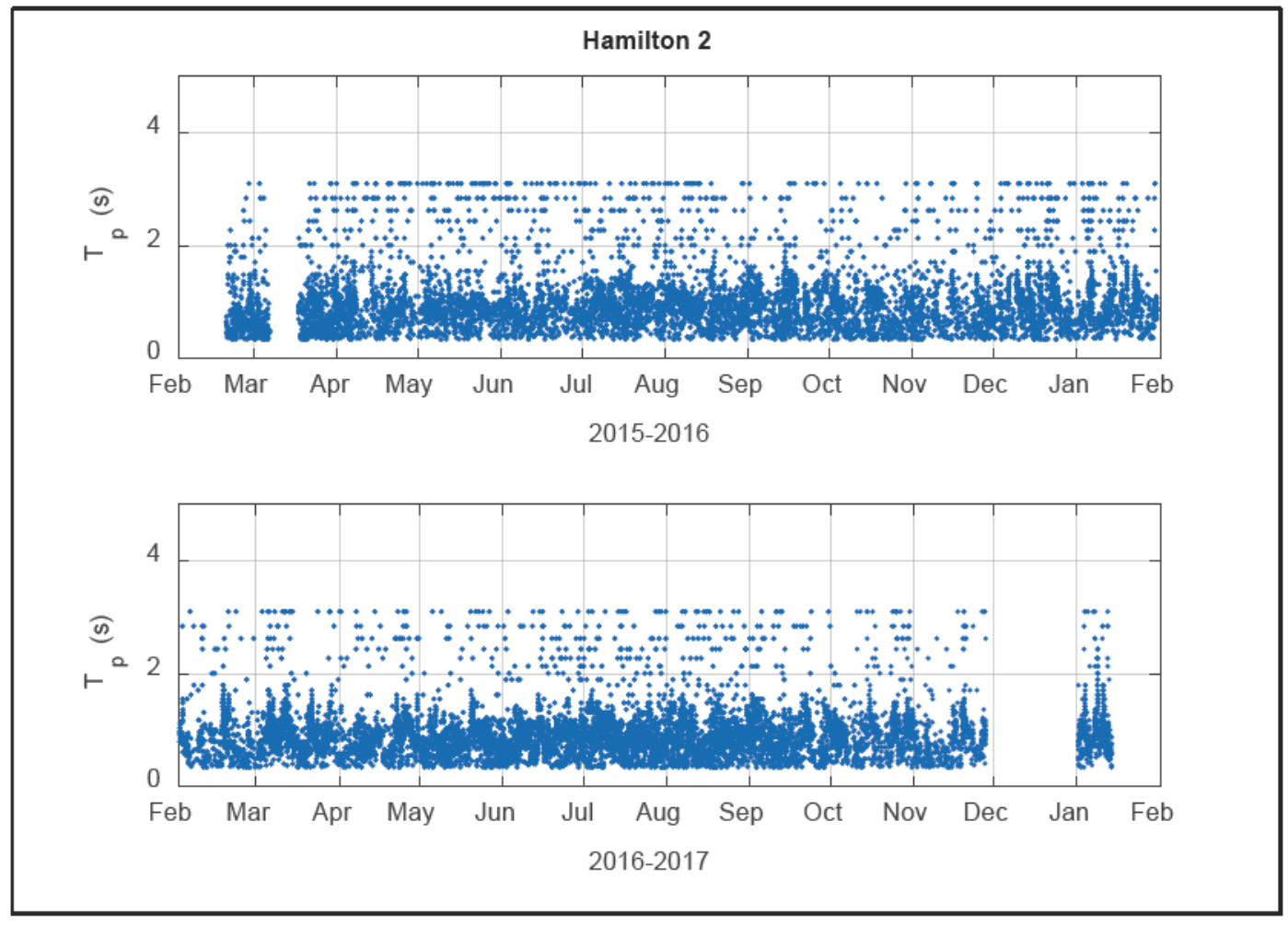


Figure 19. Wave Height Hamilton 4.

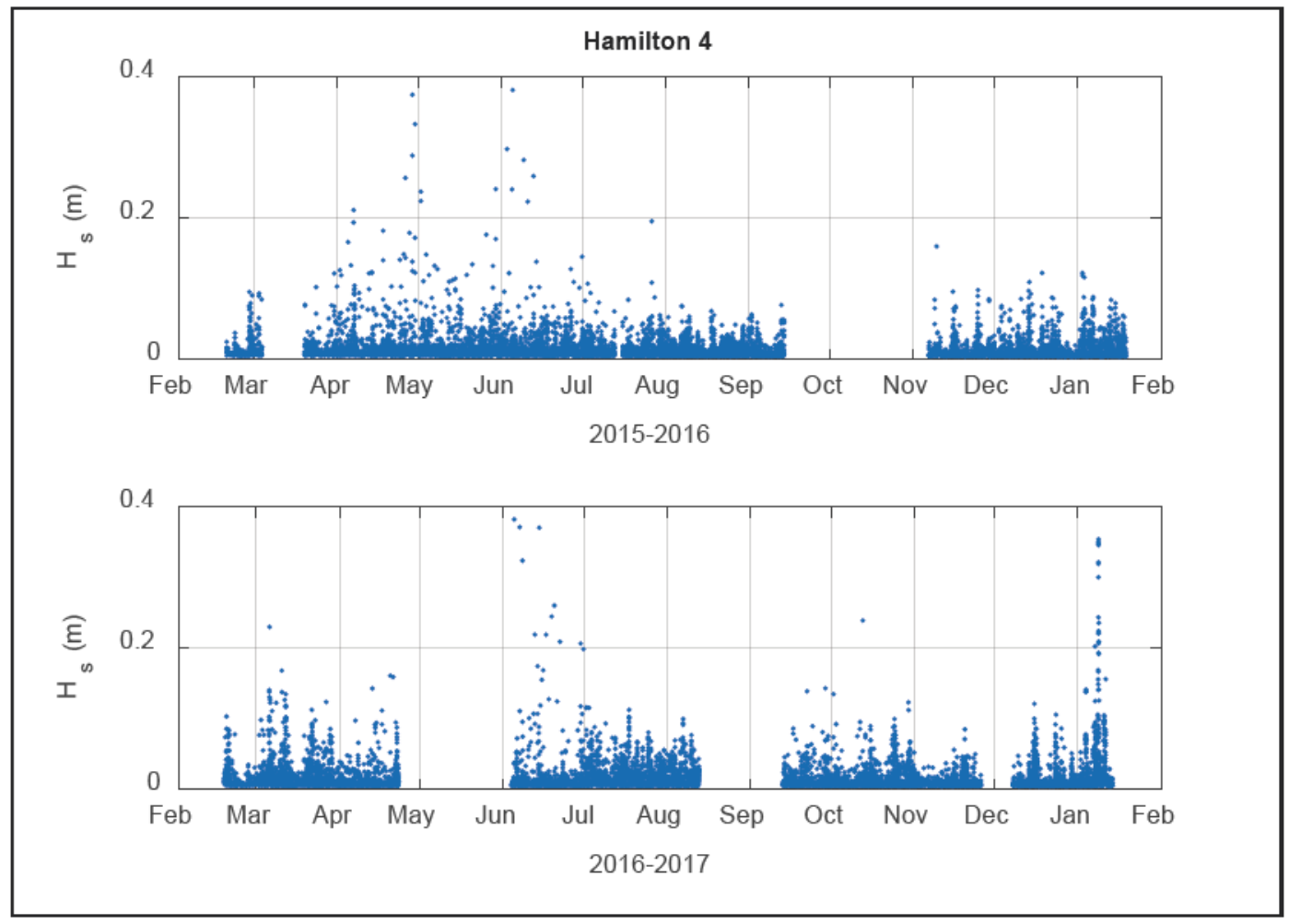

Figure 20. Wave period Hamilton 4.

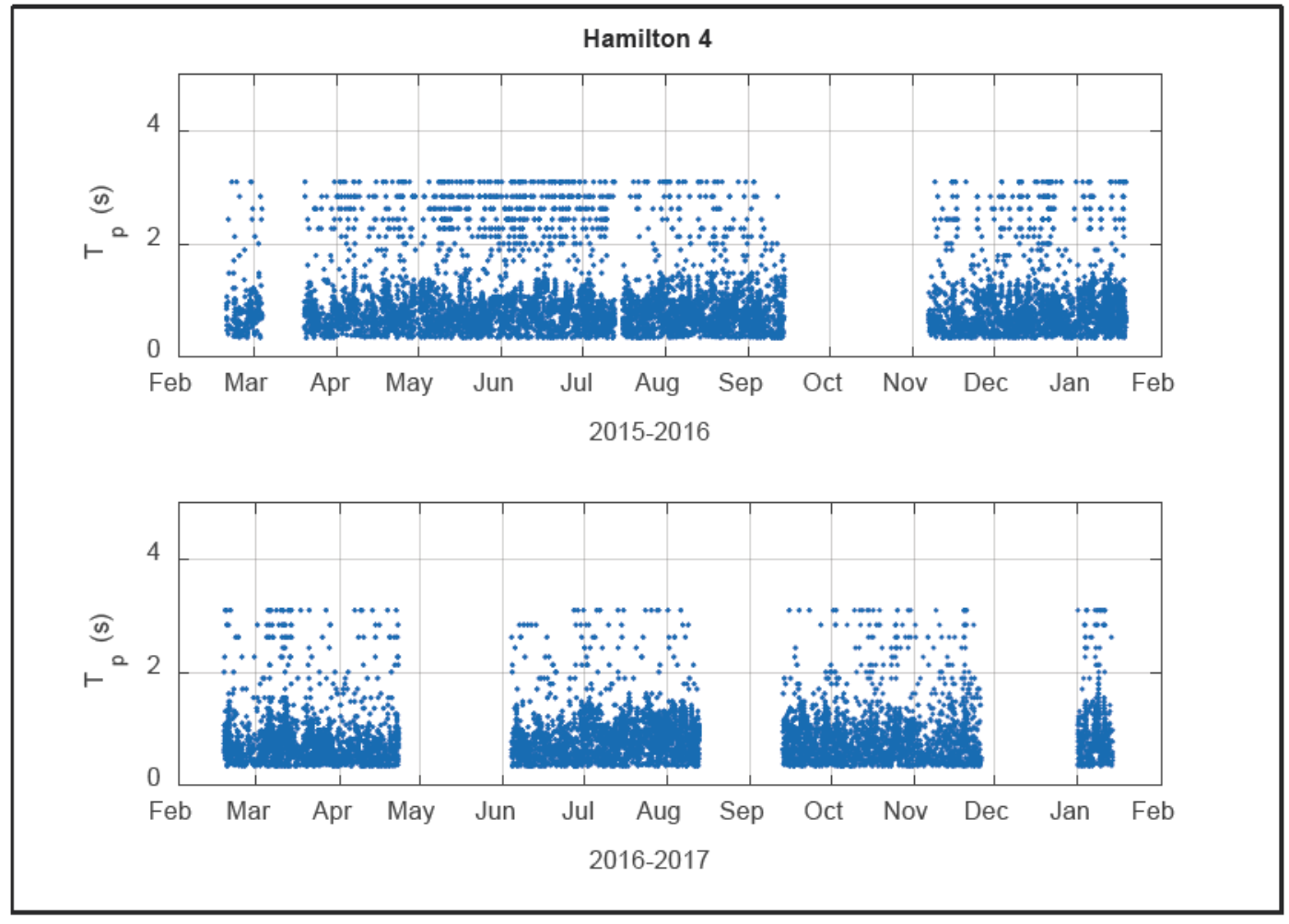


Water depths at Hamilton 1, 2, and 4 showed a strong tidal signal that was modulated by the spring/neap cycle (Figure 21, Figure 22, and Figure 23). Average depths are less than $2 \mathrm{~m}$ at all stations. Gaps in the record denote periods when the instruments were not recording due to biofouling or other malfunctions.

Figure 21. Water depth at Hamilton 1.
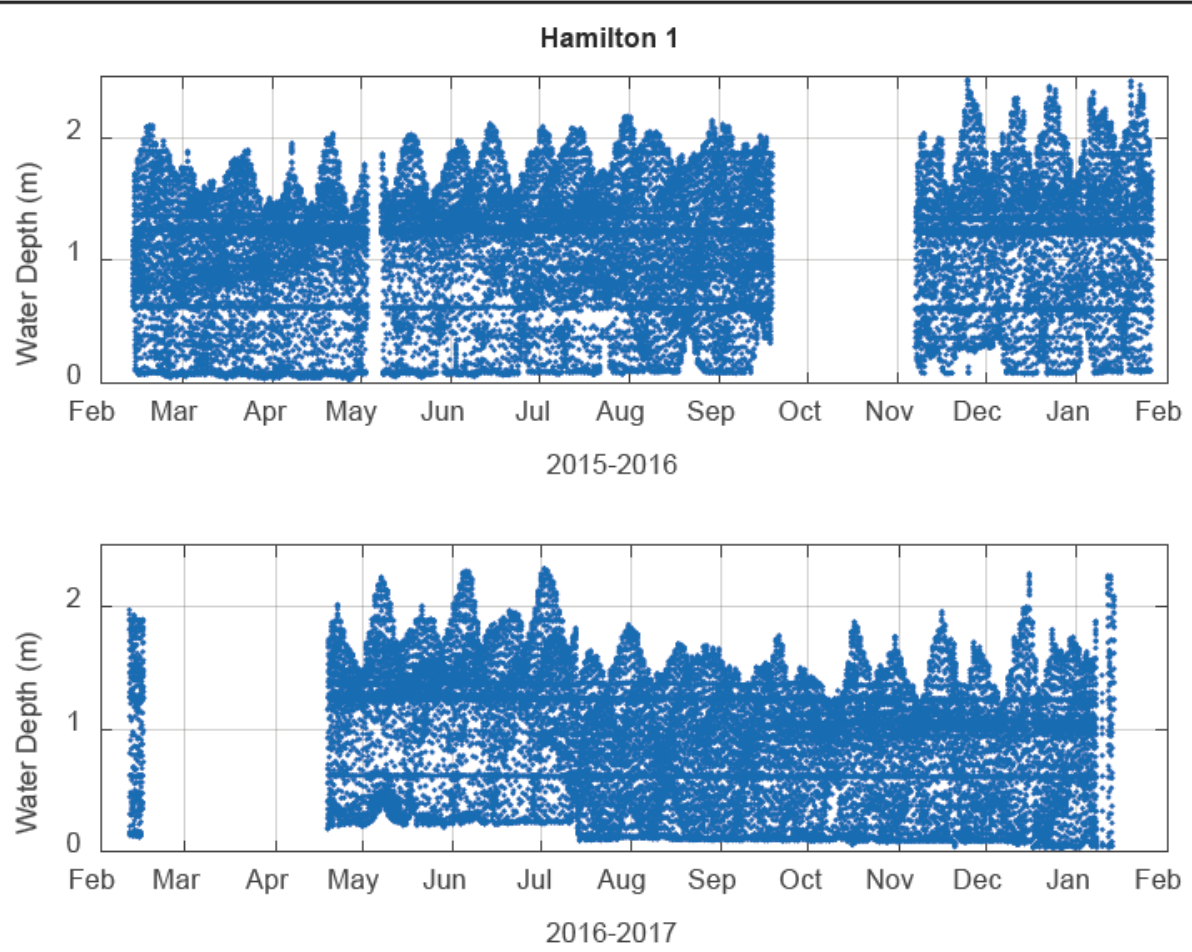
Figure 22. Water depth at Hamilton 2.

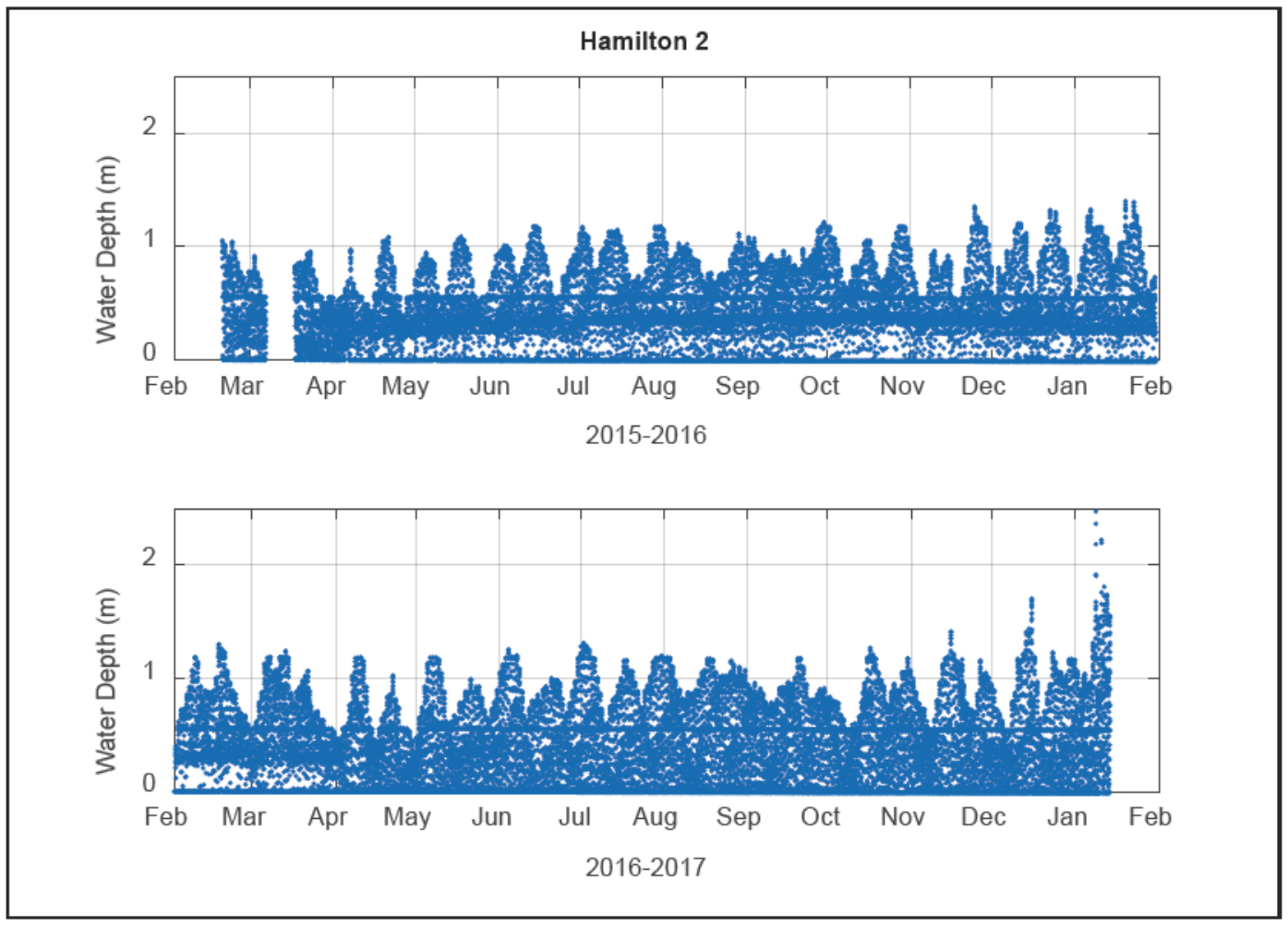

Figure 23. Water depth at Hamilton 4.

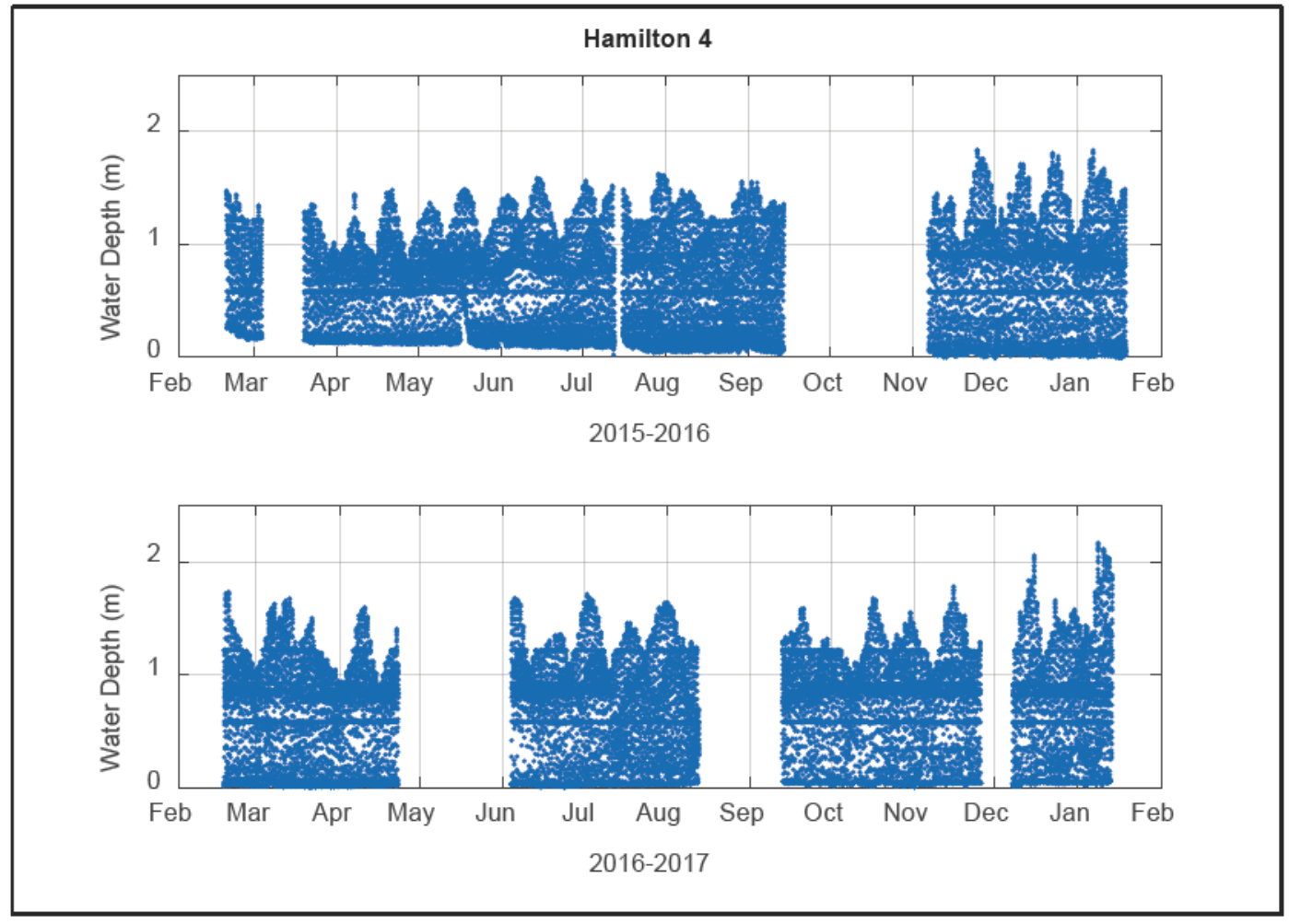




\subsection{Fetch and wave height}

Hamilton Wetlands is a relatively small basin that is closed off from the much larger San Pablo Bay by a linear dike. A small inlet permits exchange, but it is too narrow to allow for large waves to propagate into the system. Within the system, there are a number of constructed berms and intertidal flats that can further reduce the fetch, depending upon wind direction and instantaneous water level. Because these features are distributed throughout the system, the fetch is primarily controlled by wind direction. For example, station Hamilton 1 is located just south of a $380 \mathrm{~m}$ long berm that runs nearly east-west (Figure 1). Because of its proximity to the berm $(30 \mathrm{~m})$, any wind-generated waves originating from a semi-circular arc between west-northwest and east-southeast (between 300 and 100 deg meteorologically) will be blocked by the berm. However, waves originating from the southwest have a fetch of approximately $1 \mathrm{~km}$.

To explore the effect of fetch, a perimeter was established for each of the stations that measured the distance to the closest shoreline point as a function of direction. Depending upon the direction relative to the sensor, this distance could extend to the basin boundary or to the shoreline of one of the berms. To explore the effect of fetch on the waves, the wave height was averaged in $20 \mathrm{deg}$ bins and plotted in conjunction with the perimeter measurements. The results revealed a trend in which average wave height increased with distance (fetch) to the nearest land point (Figure 24, Figure 25, and Figure 26). The farther the sensor was from the shoreline, the higher the average waves. 
Figure 24. Relationship between fetch and wave height at Hamilton 1. Perimeter denotes the distance between the sensor location and the closest land point as a function of direction. Wave height denotes the average height of waves in 20 deg angle bins.

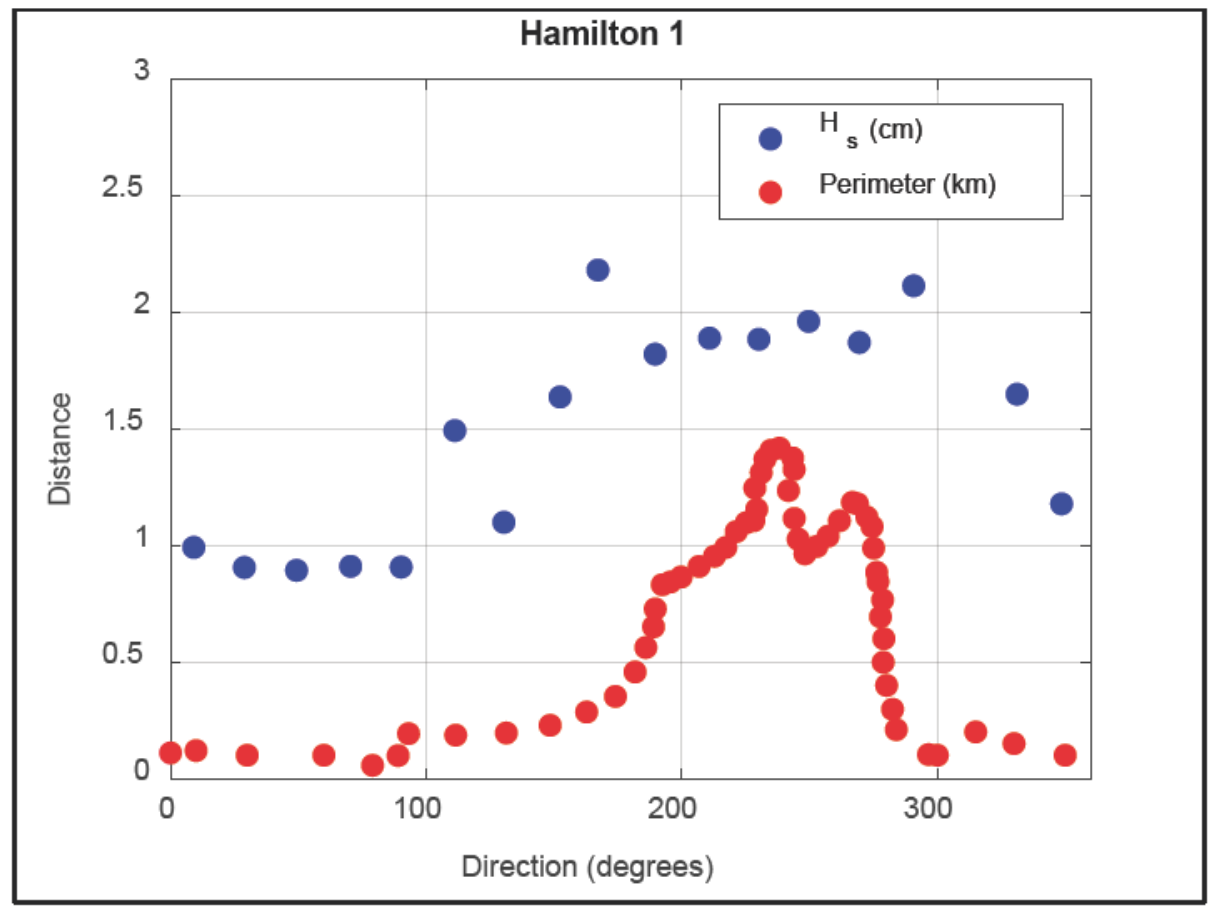

Figure 25. Fetch and wave height as a function of direction at Hamilton 2.

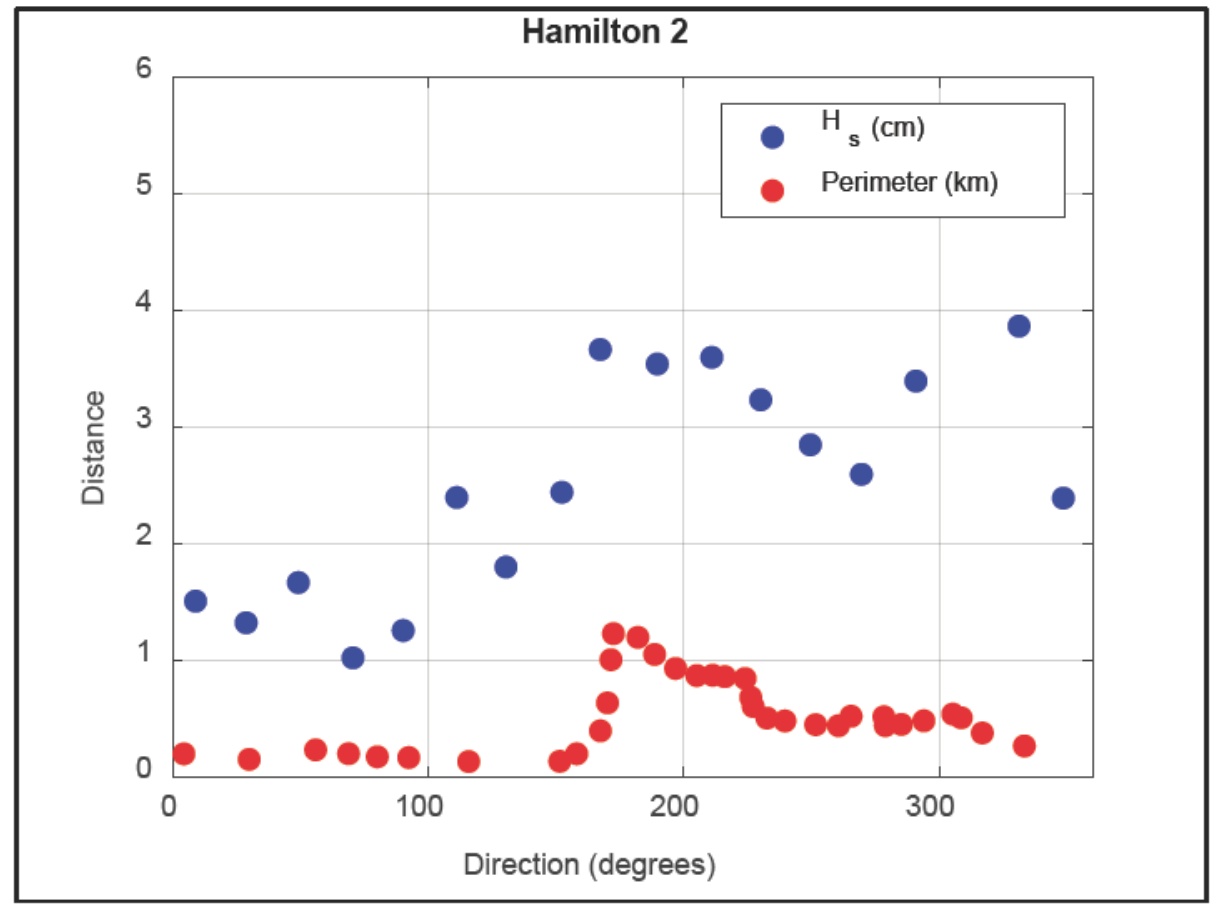


Figure 26. Fetch and wave height as a function of direction at Hamilton 4.

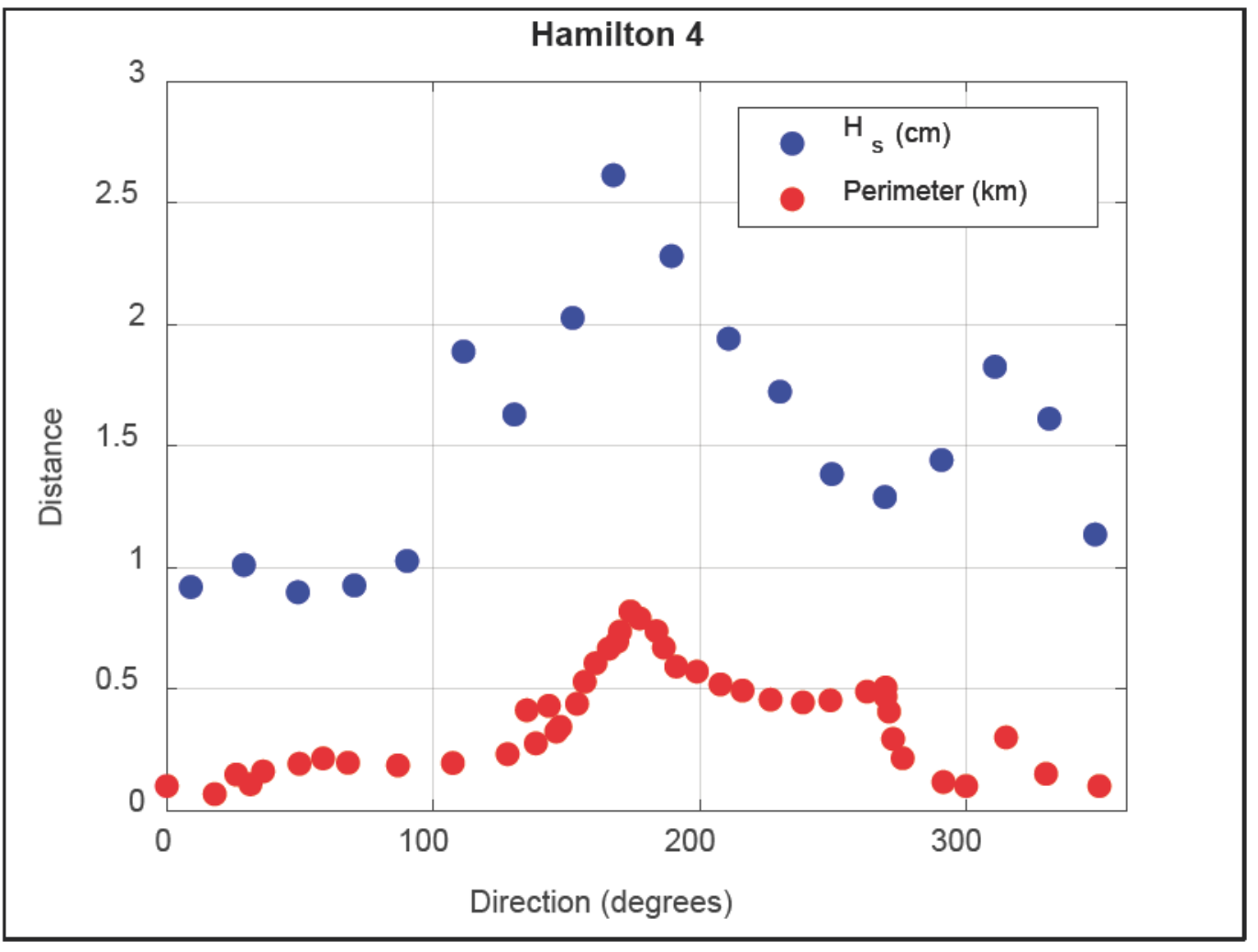

\subsection{Interior basin currents}

Current measurements at stations Hamilton 1, 2, and 4 are depicted in Figure 27, Figure 28, and Figure 29, respectively. The available current data at all three stations were sparse. Biofouling and extended periods between servicing reduced the number of data points, so it was not possible to investigate low-frequency motions such as seasonal trends, the effects of anomalous weather patterns, or storms. The time series did indicate a strong tidal signal, and there were significant differences in tidal current amplitude at the stations. Maximum tidal current amplitudes at Hamilton 2 and 4 were approximately $0.08 \mathrm{~m} / \mathrm{s}$, whereas Hamilton 1 showed much smaller amplitudes $(0.02 \mathrm{~m} / \mathrm{s})$. From a mechanical energy standpoint, the tidal currents at all three locations are relatively weak in terms of their potential to resuspend bed material. 
Figure 27. Hamilton 1 currents.

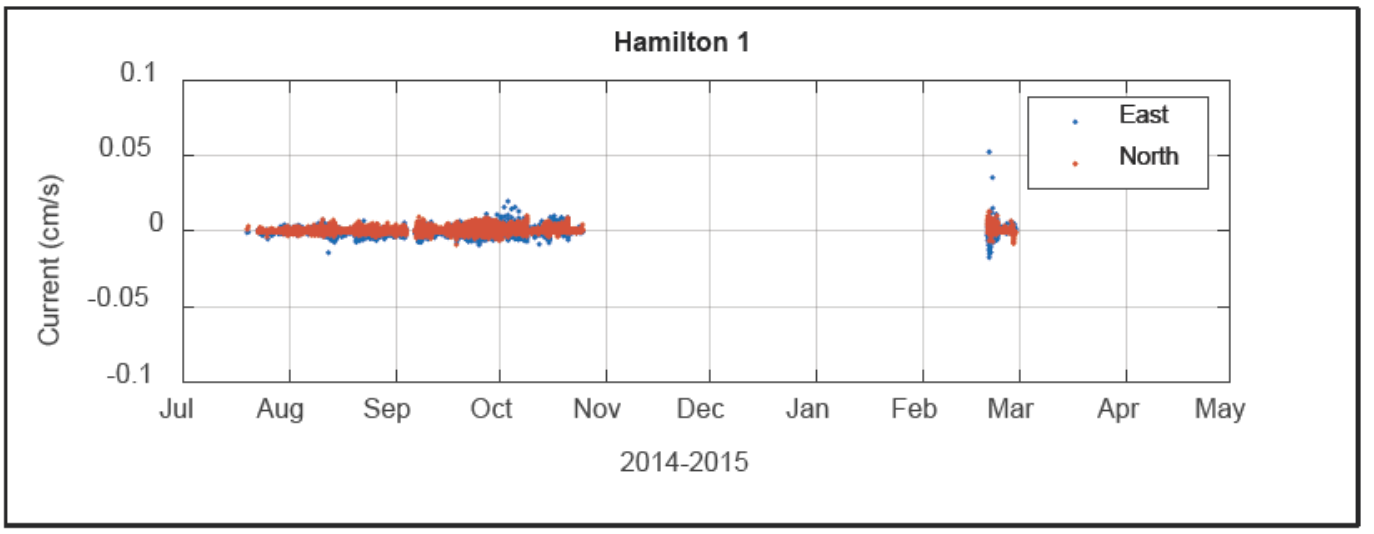

Figure 28. Hamilton 2 currents.

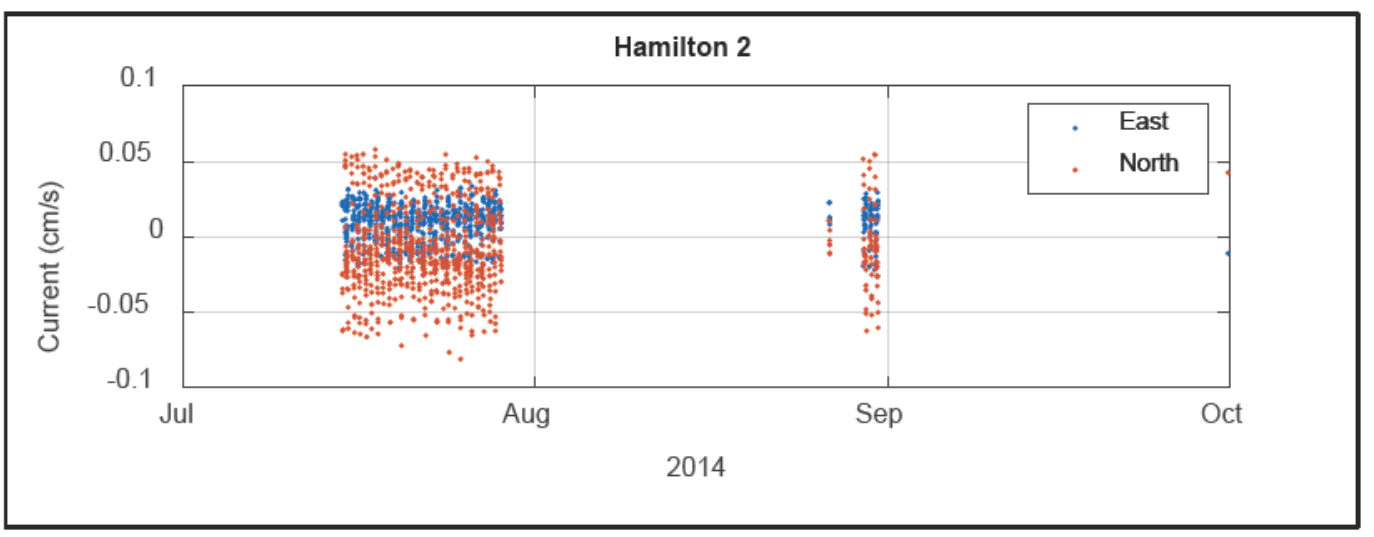

Figure 29. Hamilton 4 currents.

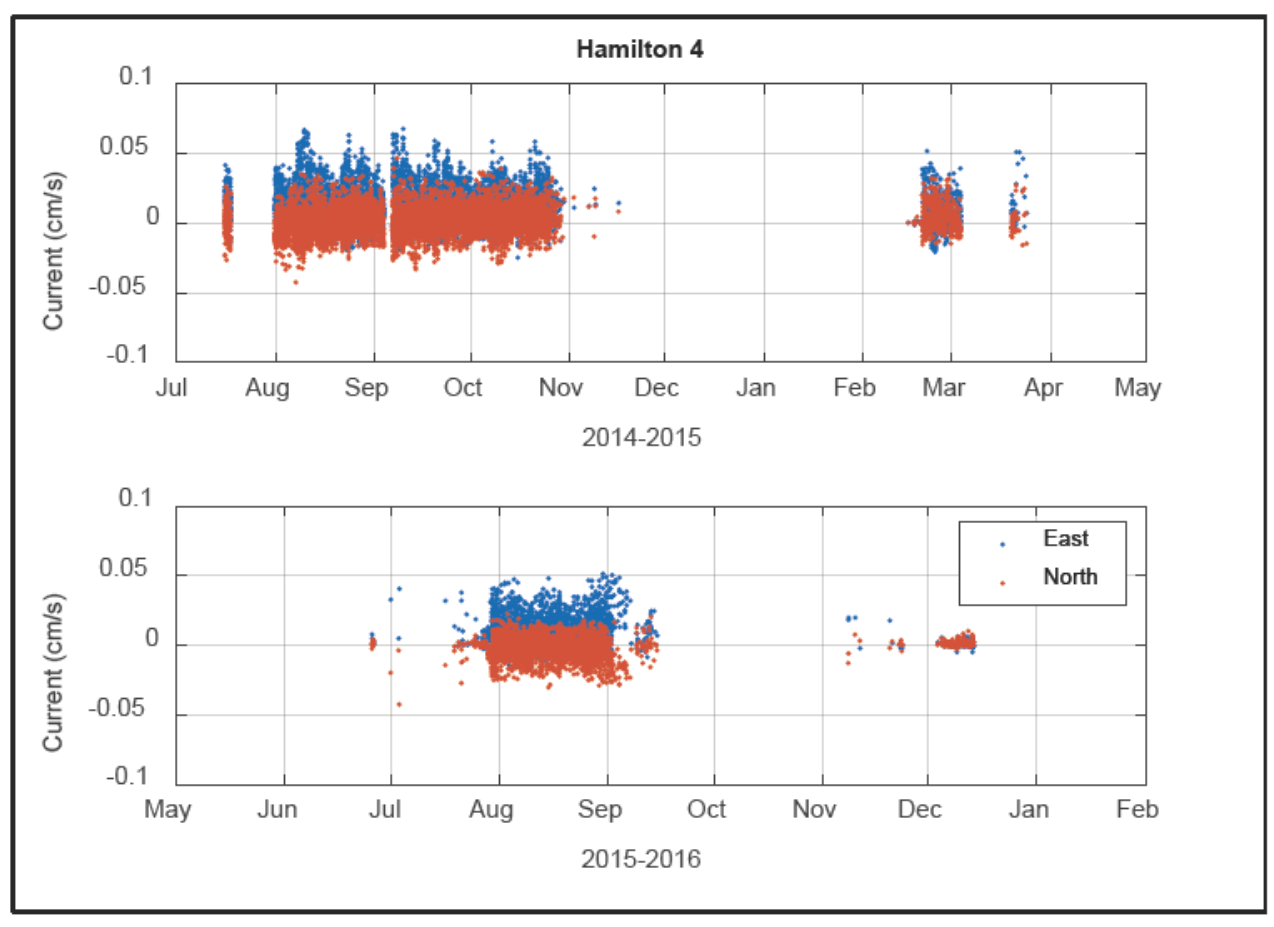




\subsection{Acoustic backscatter}

The acoustic intensity (backscatter) measured by the ADVs is proportional to the number of scatters in the water column. As such, when concentration measurements are not available, backscatter is routinely used as a relative measure of the suspended solids in the water column. A positive correlation between backscatter and the magnitude of the current or waves is considered to be indicative of local resuspension. When direct measurements of concentration are not available, examining the relationship between backscatter and the currents can be used to determine if the tidal flow is a likely mechanism controlling the dynamics.

Hamilton 2 showed a trend that suggested tidal flow may induce local resuspension (Figure 30). However, the correlation coefficient was small $\left(\mathrm{r}^{2}=0.21\right)$. Hamilton 1 and Hamilton 4 showed large variability and no apparent trend between backscatter and current magnitude. The correlation coefficients at Hamilton 1 and Hamilton 4 were 0.36 and 0.003 , respectively, but the slope at Hamilton 1 was negative indicating a decrease in backscatter as a function of current speed. An estimate of the shear stress for a mean current of $0.1 \mathrm{~cm} / \mathrm{s}$ (which is greater than maximum measured tidal currents) and a drag coefficient of 0.005 (which is typical of skin roughness over muddy beds) is 0.05 , which is less than the critical shear stress that was measured at all three stations. As such, the weak correlation between backscatter and flow speed indicated that interior basin tidal currents generally were insufficient to resuspend sediment, and the regression analysis supported that conclusion. 
Figure 30. Acoustic backscatter as a function of current magnitude.

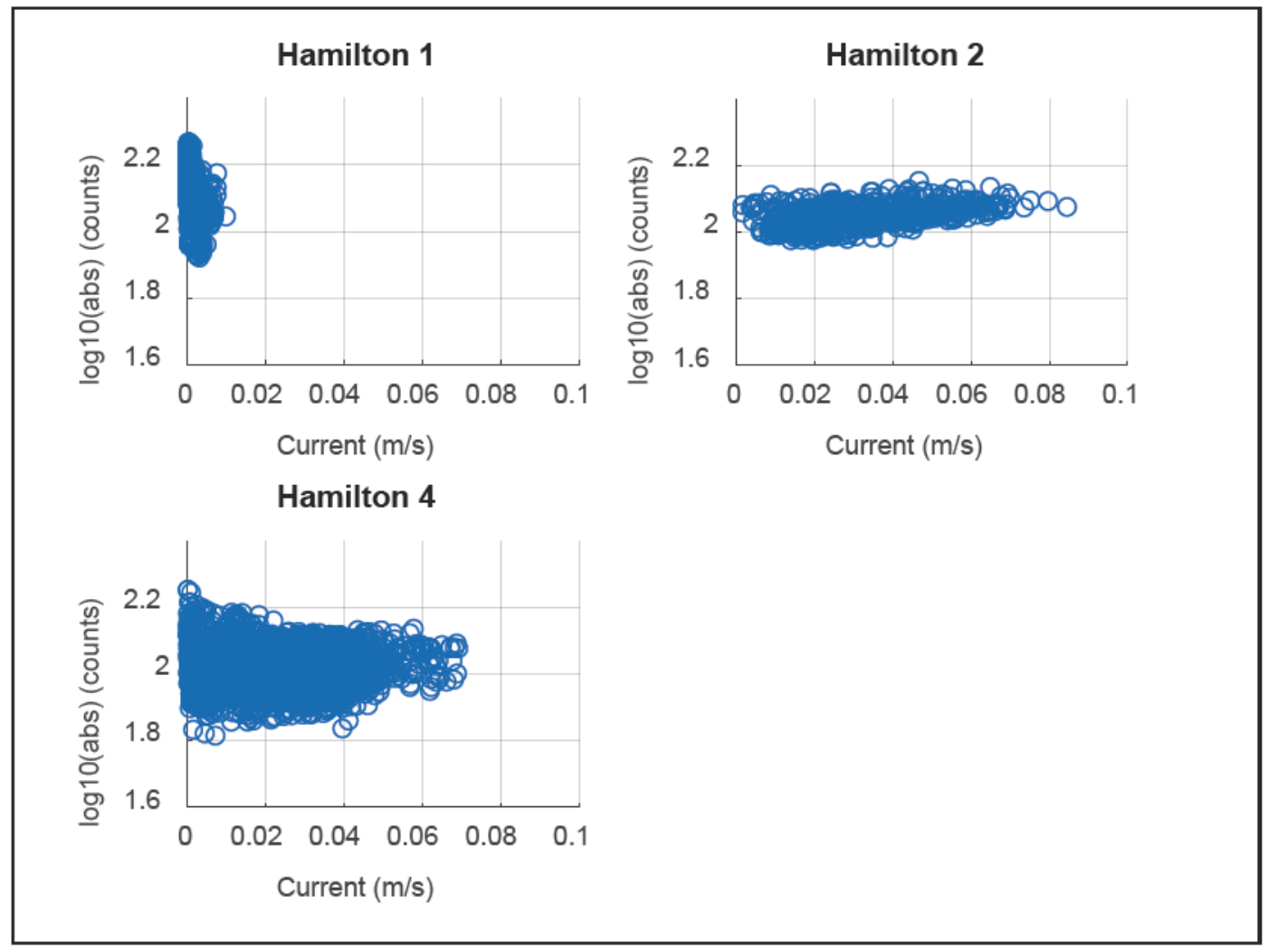

\subsection{Inlet currents}

The side-looking ADCP deployed at Hamilton 3 measured the water depth and the currents along a cross-channel axis at the inlet throat. Water depths at Hamilton 3 indicated a mixed semi-diurnal tide modulated by the spring/neap cycle (Figure 31). Tidal range at spring tide was approximately $2 \mathrm{~m}$. To examine inlet flows, the currents were rotated into along- and cross-channel directions. Additionally, the currents were averaged across all bins to make it easier to visualize net exchange between the basin and San Pablo Bay. Current patterns also reflected a spring/neap variability with maximum spring tide amplitudes of approximately $1.40 \mathrm{~m} / \mathrm{s}$ (Figure 32 ). This was much larger than within the basin, where maximum currents did not exceed $0.10 \mathrm{~m} / \mathrm{s}$. Along-channel current amplitude decreased over the course of the deployment such that by the end of October, maximum amplitudes did not exceed $1.00 \mathrm{~m} / \mathrm{s}$. There was no corresponding decrease in tidal height amplitude during this same time period. 
Figure 31. Water depth at the inlet throat measured by the ADCP.

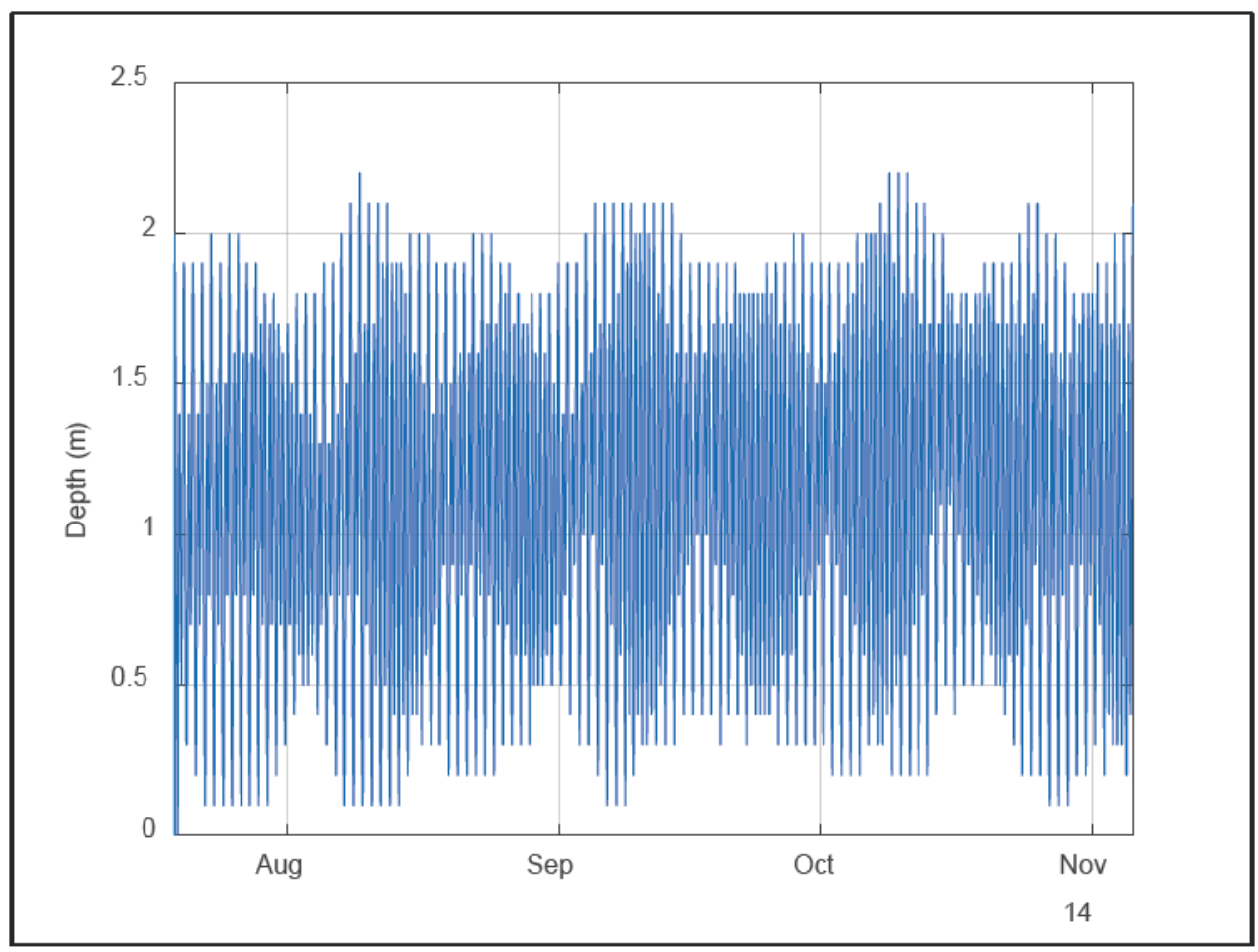

Figure 32. Spatially averaged currents in the inlet throat.

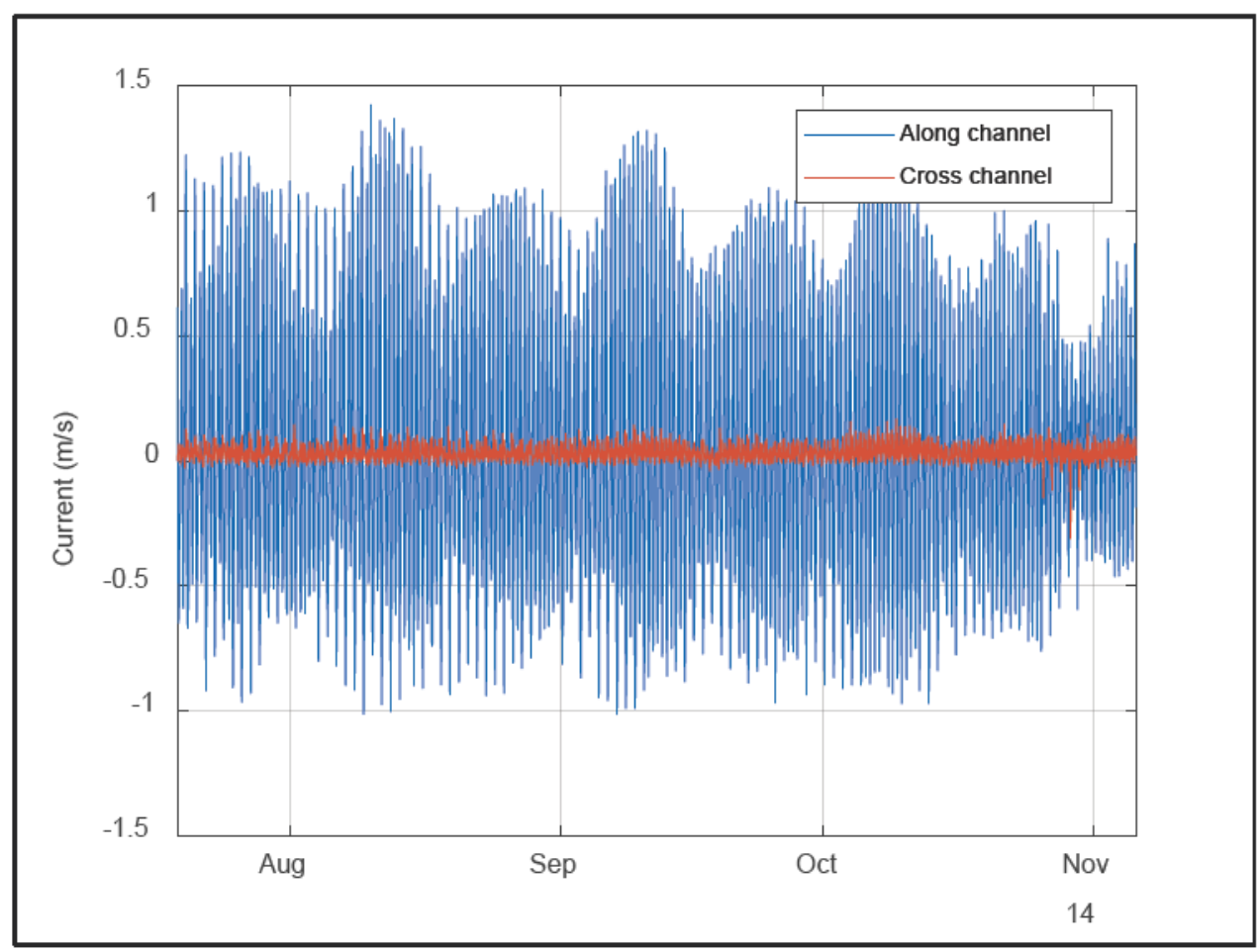


Tidal asymmetry is a measure of the difference between maximum flood and maximum ebb flow speeds over the tidal cycle. Flood-dominated systems tend to import sediment as the maximum flow speeds and associated shear stress responsible for sediment resuspension and water column carrying capacity are greater during the flood phase. For the same reasons, ebb-dominated systems tend to export sediment. In general, tidal asymmetry is a statistically steady measure in that a system is either flood dominated or ebb dominated as determined over many tidal cycles. Flood or ebb dominance is a function of inlet and bay morphology, as these factors along with friction modulate the relative amplitude of the tidal constituents responsible for producing flow asymmetries (Friedrichs and Aubrey 1988). At Hamilton Wetlands, the bay front levee was breached to produce a new inlet. Over time, the inlet widened, increasing the crosssectional area of the entrance, which reduced the magnitude of the current and altered the tidal prism. Because of these morphological changes, flood or ebb dominance is not a statistically steady phenomenon and can change as the inlet and basin adjust. To capture changes in flood or ebb dominance, tidal asymmetry is defined as the difference between maximum flood currents and the absolute value of maximum ebb currents, $T_{A}=u_{\max }-\left|u_{\min }\right|$ over a tidal cycle. The system is flood dominated if $T_{A}>0$, and ebb dominated if $T_{A}<0$. This analysis focused on the longer term ( $>$ tidal cycle) trends to see if the system exhibited any variation during the initial widening of the inlet throat.

The results indicate that Hamilton Wetlands was flood dominated shortly after the breach of the bay front levee (Figure 33). Over time, the system remained flood dominated, but there was a trend that suggested the system was becoming less flood dominated. However, the trend line indicated the system was still adjusting and had not reached equilibrium by the end of the measurement period. Not only was there a reduction in the amplitude of the current as the inlet breach widened but the system tended to become less flood dominated. 
Figure 33. Tidal asymmetry in the inlet throat.

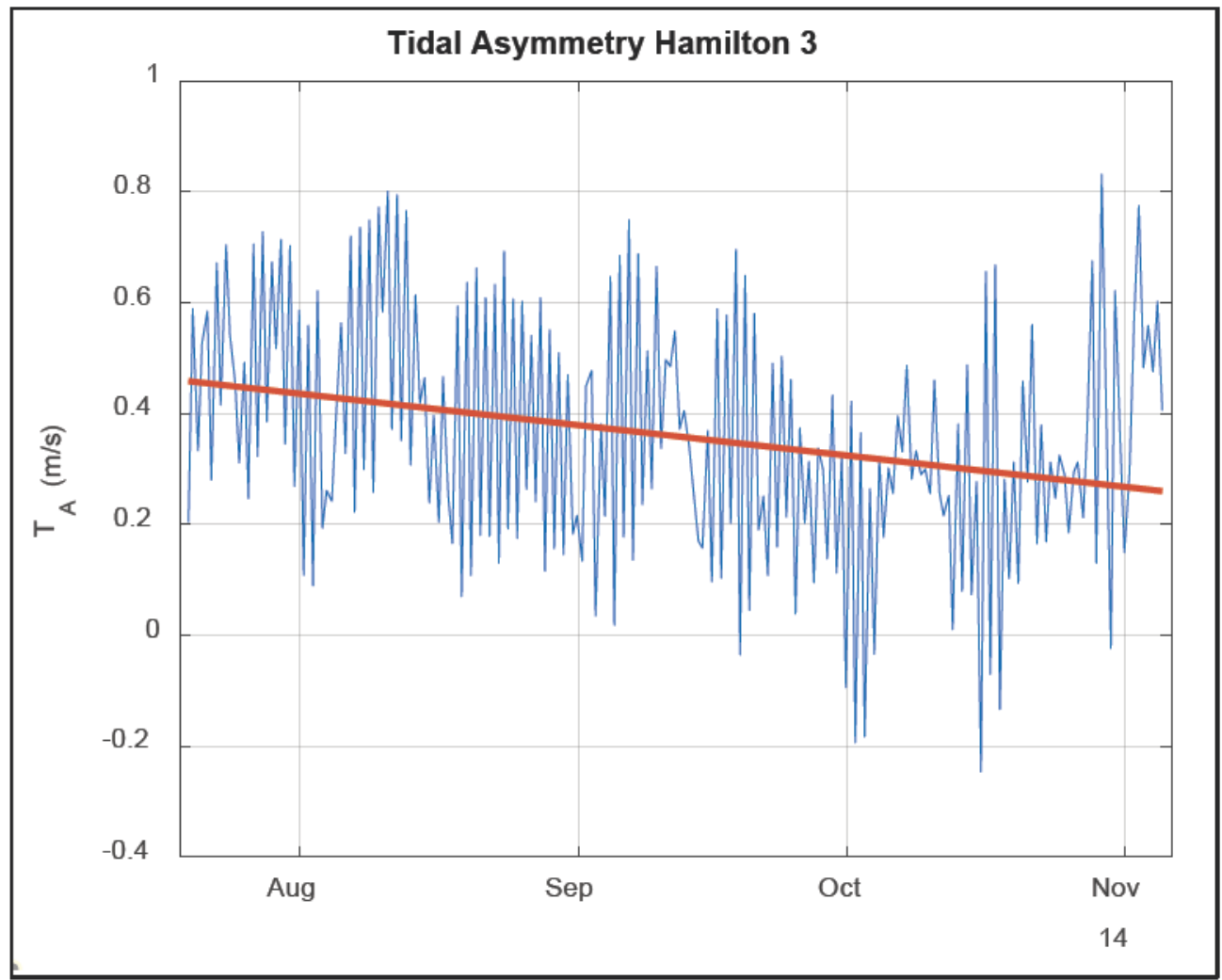

Cross-channel currents during a spring tidal cycle showed spatial variability in the flow patterns, with generally higher flows in the center of the channel (Figure 34). However, there were some noted exceptions especially near slack high and slack low, when the currents were generally weakest and exhibited greater spatial variability. Another interesting feature was the drop in current magnitude during ebb when the water depth was $1.3 \mathrm{~m}$. The pattern was suggestive of a counter flow possibly due to an opposing eddy, in which the outgoing flow encountered a reversal induced by an eddy such that the net flow was near zero. However, there was no clear obstruction or shoreline curvature that suggested eddy formation in the location that would produce the observed spatial current pattern. The sharp reduction in current magnitude between approximately 30 and $60 \mathrm{~m}$ from the instrument during the latter half of ebb was a persistent feature that requires additional information such as a bathymetric survey of the area or flow visualization to map current patterns in the vicinity of the ADCP to explain the observed pattern. 
Figure 34. Vector plot depicting current distribution across the inlet over a tidal cycle. The panels are read from left to right and top to bottom. Upper left panel was at slack low, and the snapshots evolve in 1.4 hour increments. Maximum average speed across the inlet entrance was $1.17 \mathrm{~m} / \mathrm{s}$.

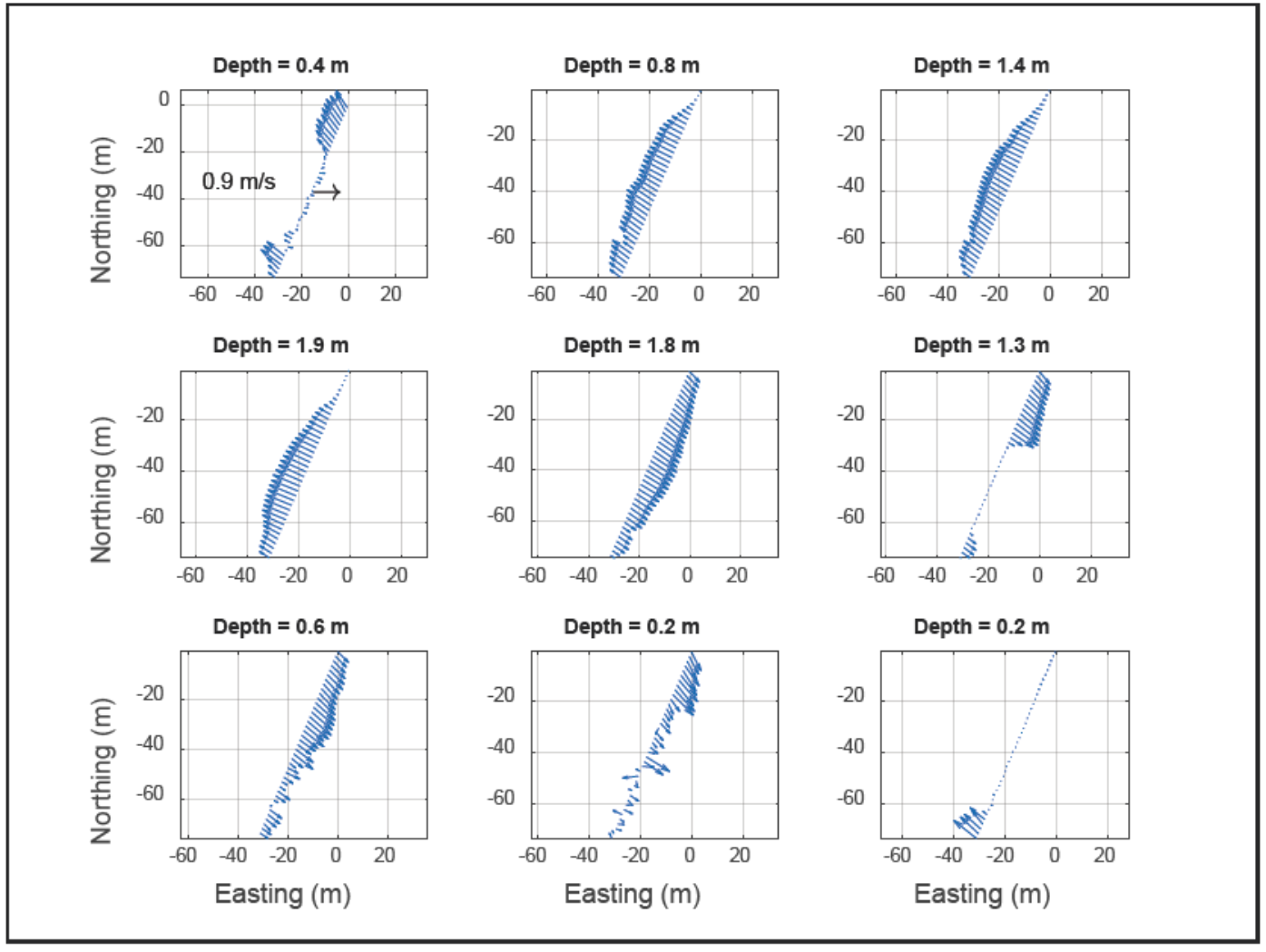

There was a slight asymmetry between stage height and maximum tidal flows such that maximum flood occurred near mid-tidal stage while maximum ebb occurred at a slightly higher stage (Figure 35). Near the end of flood, currents were decreasing while water level was increasing. Immediately following slack high, there was initially very little change in stage during early ebb, but currents were increasing. This asymmetric pattern is similar to other estuaries that exhibit variations in basin area and tidal wave propagation speed as a function of depth and flow direction (Blanton et al. 2002). 
Figure 35. Flow versus stage curve. Positive currents denote flood.

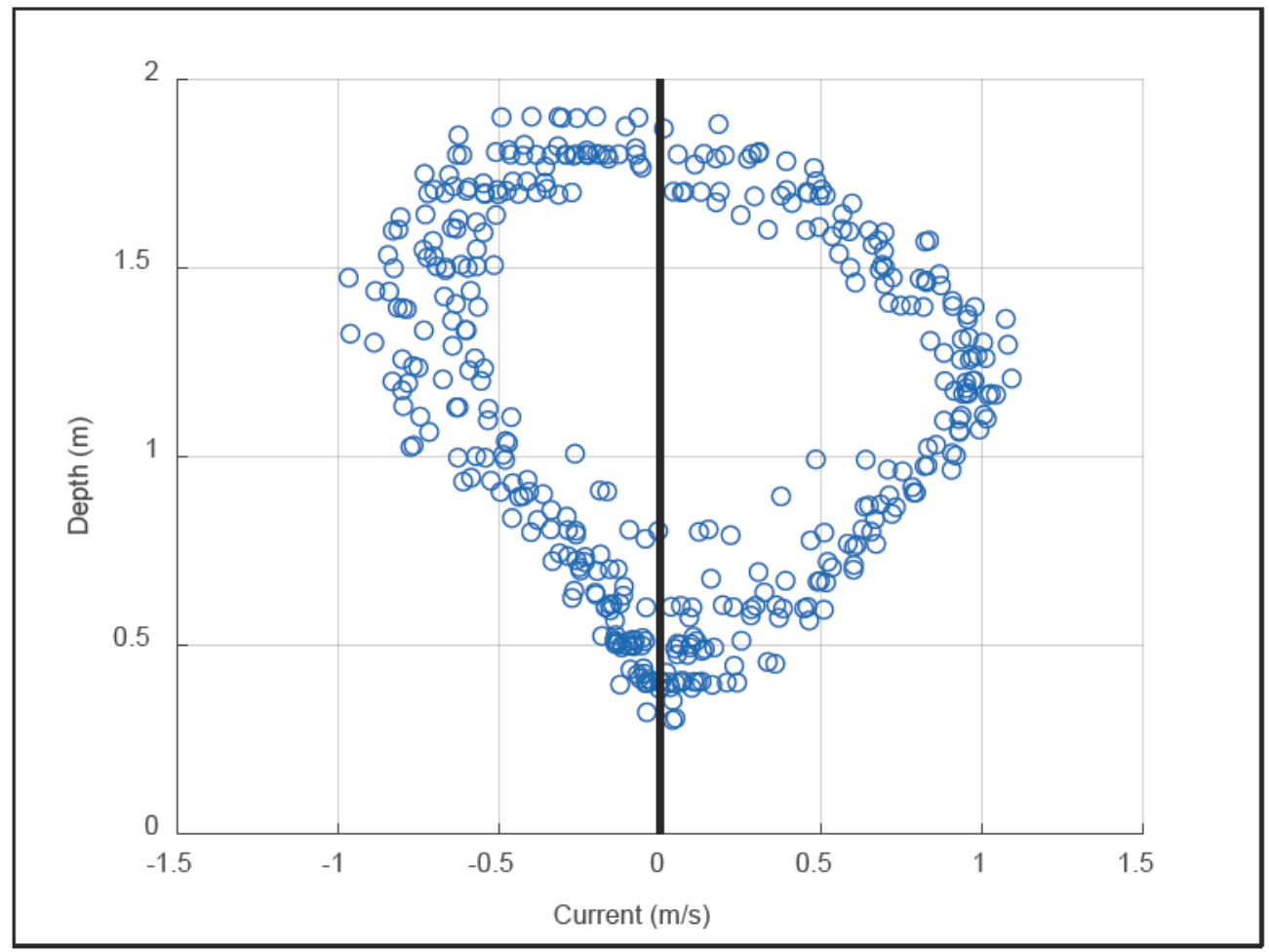

\subsection{Acoustic backscatter}

The acoustic backscatter from the ADCP provided a qualitative measure of the particulate concentration in the water column. Plotting backscatter as a function of the along-channel current helped elucidate any asymmetries between flood and ebb that could suggest net transport into or out of the basin. There was significant variability in the backscatter signal, but the overall trend indicated an increase in intensity with current speed during flood that was not as apparent during ebb (Figure 36). Both flood and ebb showed a trend in that the lowest intensity recorded increased as a function of current speed. During ebb, however, the highest intensity did not increase with flow speed but, in fact, decreased. During flood, maximum intensity increased with flow speed suggesting a trend between concentration and flow speed. The correlation coefficient was 0.39 during flood and $5.2 \times 10^{-4}$ during ebb, indicating a relatively weak positive trend during flood and practically no trend during ebb. If the backscatter signal was indicative of concentration, then a portion of the dynamic response was to resuspend sediment and transport it into the basin. During ebb some bed material was likely resuspended, but the large variability combined with the fact that maximum intensity was overall lower suggested a net import of sediment into Hamilton Wetlands during this timeframe. 
Figure 36. Acoustic backscatter as a function of flow. Positive current denotes flood.

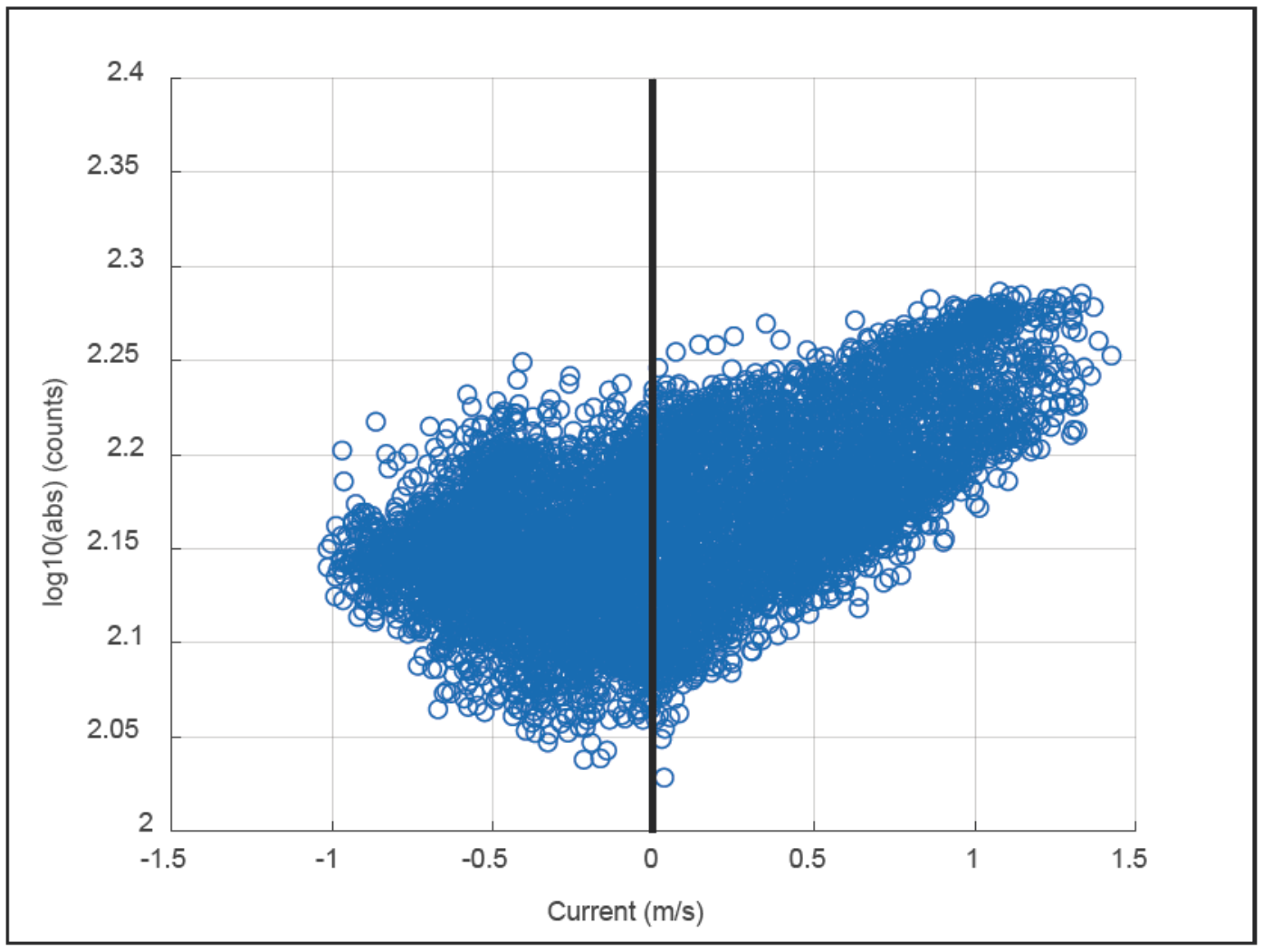

\subsection{Cohesive sediment erosion}

Analysis of cohesive sediment erosion data obtained from undisturbed field cores was inherently complex. Cohesive sediment erosion is sensitive to slight changes in bed density, deposit mineralogy, gas content, organic content, biological activity, and a host of other factors. In many cases, these factors change significantly at relatively small vertical scales (such as depositional bed sequences). Consequently, measured cohesive sediment erosion rates from field cores are notoriously noisy. To counter the large variance in measured erosion rates, field erosion experiments are conducted in a manner to produce a large sample from which to derive statistically representative fits to various numerical erosion algorithms. To ensure high quality in the data analysis, data and associated experimental notes are evaluated to identify outliers in the dataset. Outliers are rejected based on comparisons between adjacent data points and experimental log notes.

While performing erosion testing of the Station 1 core on July 28,2015 , it was observed that the o-ring on the plunger inserted into the bottom of the core had become pinched between the plunger and core barrel. Failure of the o-ring seal occurred, allowing air to enter into the system through the 
bottom of the core. This resulted in large air bubbles rising through the sediment column and into the flume, thus destroying the integrity of the core. Erosion testing of the core was suspended following o-ring failure; however, usable erosion data were collected down to a depth of $\sim 7 \mathrm{~cm}$ prior to the core failure. A replicate core (Station 1-2) was collected for erosion analysis at Station 1.

Erosion experiments revealed all cores to be notably layered. Consequently, erosion datasets from the core stations were segmented by bed layers, as seen in Figure 37. Layer segmentation during analysis was based on visual core descriptions logged in the field, physical sampling, erosion experiment notes, and erosion rate data. Core descriptions including photographs, visual descriptions, and results of physical sample analysis are provided in Appendix A. Figures that identify bed layers for cores are provided in Appendix B.

Figure 37. Plot depicting the change in erosion rate with depth for core Station 1-2. Colors indicate bed layers; symbols indicate applied shear stress.

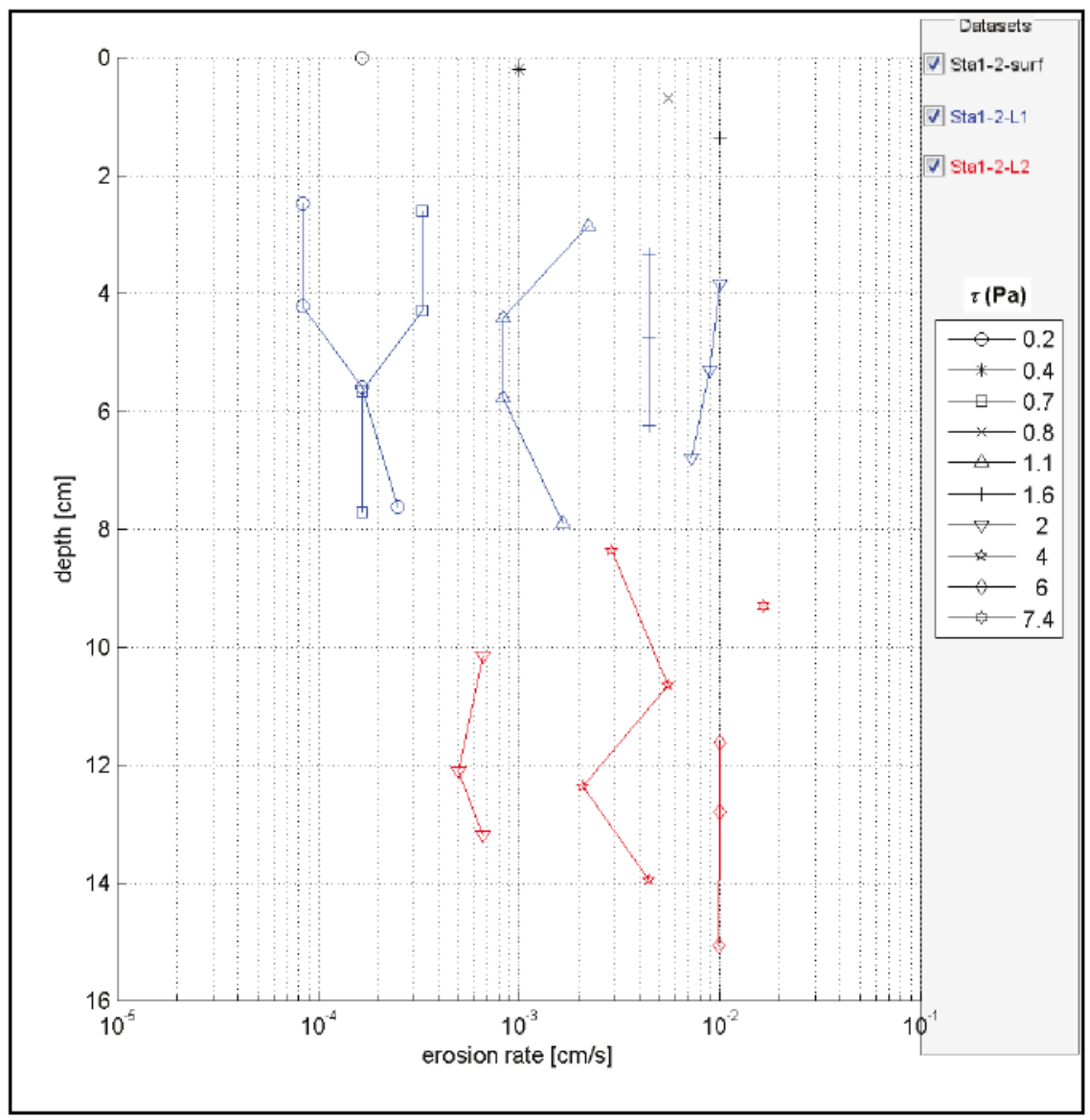


In general, it was observed that erosion rates decreased with depth down core. Erosion data from core Station 1-2 is presented to illustrate this pattern. Erosion data from all cores collected can be found in Appendix B. As seen in Figure 37, erosion rates at individual applied shear stresses tended to decrease with depth and between layers. This is perhaps best seen at a shear stress of 2.0 $\mathrm{Pa}$, which starts with an erosion rate of $0.01 \mathrm{~cm} / \mathrm{s}$ in layer 1 at a depth of $4 \mathrm{~cm}$ but decreased by a factor of 16 to approximately $6.7 \times 10^{-4} \mathrm{~cm} / \mathrm{s}$ in layer 2 at a depth of $13 \mathrm{~cm}$. While the magnitude of change was found to be smaller for other shear stresses tested in Station 1-2, the trend of decreasing erosion rates with depth was still observed in most cases.

\subsection{Erosion parameterization}

Erosion rate data were evaluated for relationships between erosion rate and applied shear stress. As mentioned previously, each of the analyzed cores indicated bed layering. In some instances, boundaries between layers were very distinct; in other cases, transitions between bed layers were more gradual. Each of the identified sediment layers within a core were first analyzed separately. Figure 38A shows the multivariate least squares fit of erosion rate to shear stress for the three layers identified in the Station 1-2 core. When appropriate, bed layers were combined to form groupings that contain a larger number of erosion data points. For example, after initial analysis, layers identified in the Station 1 core were grouped with similar layers identified in its replicate core, Station 1-2. Figure 38B shows the multivariate least squares fit of each layer after the data from Station 1 and Station 1-2 had been combined. Additionally, it was observed that the surface layers (upper $2 \mathrm{~cm}$ ) of the four cores collected within the basin of Hamilton Wetlands displayed similar erosion characteristics. Data from these layers were combined, and a least squares fit was applied to characterize the surficial erosion of sediments within the wetland basin (Figure 39). Table 2 shows the layers and resulting erosion parameters for each core and grouping of cores. Figures showing the least squares fit through the erosion data for each core can be found in Appendix B. 
Figure 38. Erosion rate data and best fit lines to Equation 14 for $(A)$ layers within Station 1-2, and (B) layers after compiling data from Station 1 and Station 1-2.

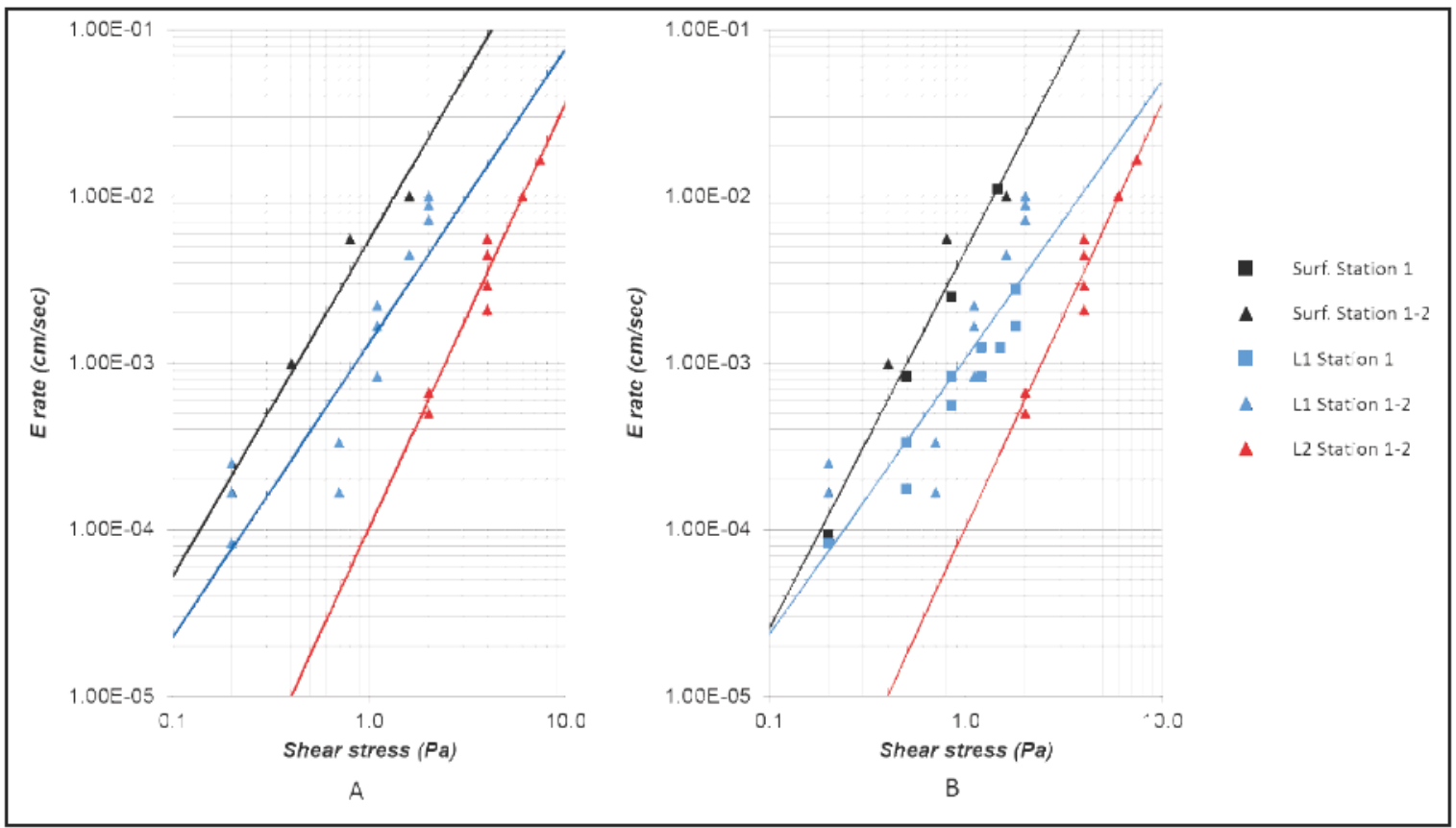

Figure 39. Erosion rate data and best fit lines to Equation 14 for the surface layers of cores located within the Hamilton Wetlands basin (Stations 1, 1-2, 2, and 4).

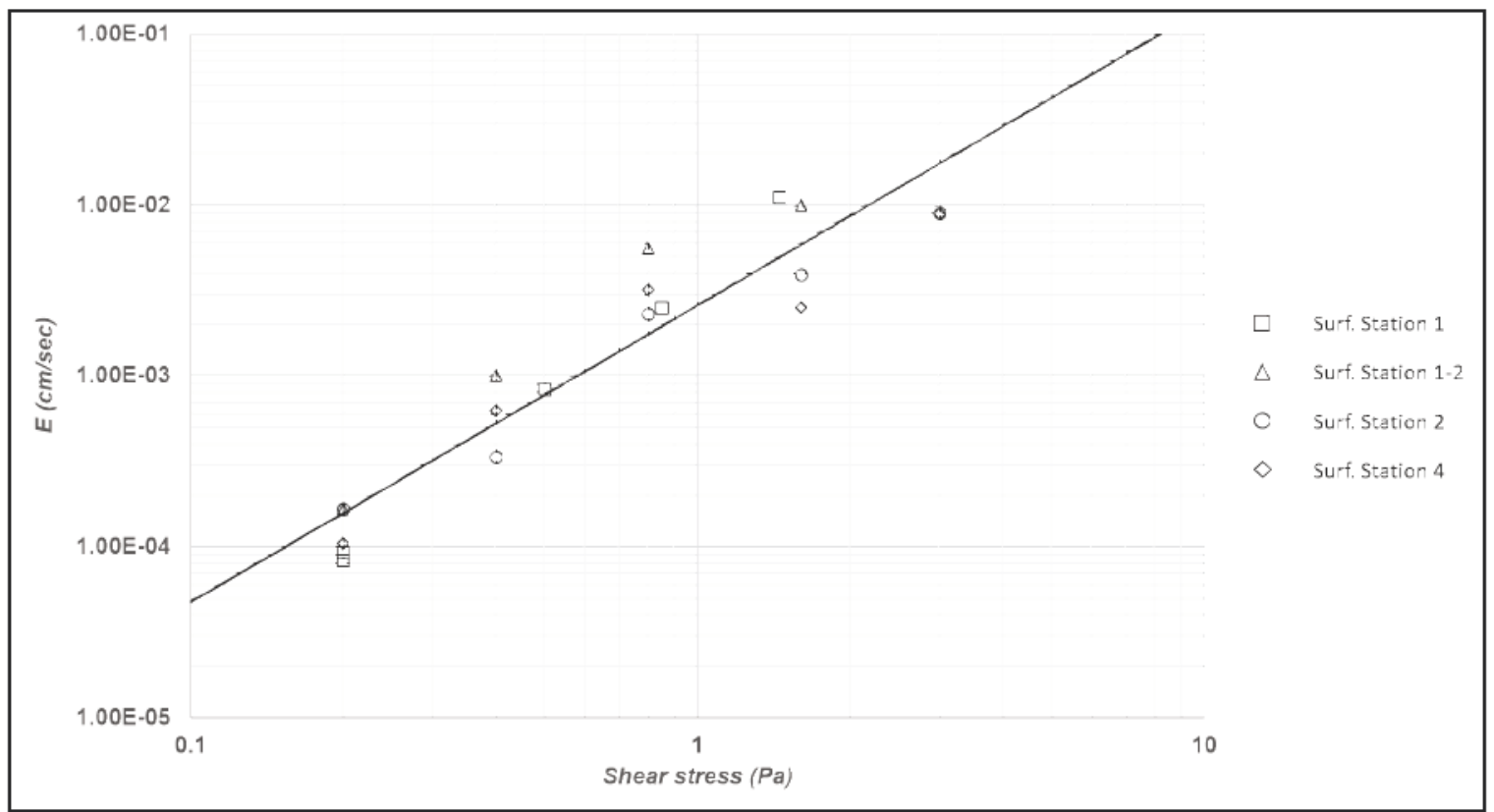


Table 2 Cohesive erosion parameterization. (L indicates layer)

\begin{tabular}{|l|c|c|c|c|c|}
\hline \multirow{2}{*}{ Core } & Depth & $\tau_{\mathrm{c}}$ & $\tau_{\mathrm{m}}$ & $\boldsymbol{A}$ & $n$ \\
\cline { 2 - 6 } & $\mathbf{( c m )}$ & $\mathbf{( P a})$ & $\mathbf{( P a})$ & & \\
\hline Station 1- Surface & $<3$ & 0.21 & 1.79 & $4.20 \mathrm{E}-03$ & 2.41 \\
\hline Station 1- L1 & $4-7$ & 0.25 & 7.87 & $8.00 \mathrm{E}-04$ & 1.48 \\
\hline Station 1-2- Surface & $<2$ & 0.14 & 1.75 & $5.50 \mathrm{E}-03$ & 2.01 \\
\hline Station 1-2- L1 & $2-8$ & 0.23 & 4.29 & $1.30 \mathrm{E}-03$ & 1.76 \\
\hline Station 1-2- L2 & $>8$ & 1.00 & 7.52 & $1.00 \mathrm{E}-04$ & 2.54 \\
\hline Grouped Station 1- Surface & $<3$ & 0.18 & 1.74 & $4.80 \mathrm{E}-03$ & 2.27 \\
\hline Grouped Station 1- L1 & $2-8$ & 0.24 & 5.20 & $1.10 \mathrm{E}-03$ & 1.66 \\
\hline Station 2- Surface & $<2$ & 0.14 & 4.16 & $1.92 \mathrm{E}-03$ & 1.54 \\
\hline Station 2- L1 & $2-6$ & 0.18 & 4.58 & $1.50 \mathrm{E}-03$ & 1.59 \\
\hline Station 2- L2 & $>6$ & 0.26 & 7.33 & $8.00 \mathrm{E}-04$ & 1.53 \\
\hline Station 4- Surface & $<2$ & 0.14 & 4.26 & $1.90 \mathrm{E}-03$ & 1.51 \\
\hline Station 4- L1 & $>2$ & 0.29 & 7.66 & $7.00 \mathrm{E}-04$ & 1.57 \\
\hline $\begin{array}{l}\text { Grouped Hamilton } \\
\text { Wetlands Basin- Surface }\end{array}$ & $<2$ & 0.15 & 2.95 & $2.60 \mathrm{E}-03$ & 1.74 \\
\hline Station 5N- Surface & $<2$ & 0.14 & 10.89 & $1.00 \mathrm{E}-03$ & 1.19 \\
\hline Station 5N- L1 & $2-4.5$ & 0.46 & 16.83 & $3.00 \mathrm{E}-04$ & 1.43 \\
\hline Station 5N- L2 & $>4.5$ & 0.62 & 22.42 & $2.00 \mathrm{E}-04$ & 1.43 \\
\hline
\end{tabular}

After grouping layers and performing the least squares fit to Equation 14, uncertainty confidence intervals were determined. The $95 \%$ confidence intervals of the $A$ parameter of Equation 14 were determined and utilized to calculate the upper and lower critical shear stress at $95 \%$ confidence. Figure 40 shows these uncertainties plotted as dashed lines for layer 1 of the Station 1-2 core. The number of data points in the layer (N), the coefficient of determination $\left(\mathrm{r}^{2}\right)$, and $\mathrm{p}$-value (p) for the best fit line are shown at the top of the figure. The $\mathrm{r}^{2}$ value was used to determine how close the data points fit the regression. In this case $79 \%$ of the data points can be explained by the regression. The $\mathrm{p}$-value indicates the probability of obtaining the $\mathrm{r}^{2}$ value by pure chance. In this case, the p-value of $1.97 \times 10^{-16}$ indicated that there was very little chance that the $\mathrm{r}^{2}$ value of 0.79 was due to chance. Typically, when $\mathrm{p}<0.05$, the test statistic is considered significant. This was the case for every layer and grouping in the cores analyzed in this study. The range of the $A$ parameter and $\tau_{c}$, along with the $\mathrm{N}, \mathrm{r}^{2}$, and $\mathrm{p}$ for all the groupings in each core are listed in Table 3 . Figures showing the uncertainties in the best fit line for layers and groupings of each core can be 
found in Appendix B. Due to small degrees of freedom, no values were reported for groupings that had $\mathrm{N}$ values $\leq 4$.

Figure 40. Erosion parameterization uncertainty for layer L1 Station 1-2. Shear stress in Pascals and erosion rate $(E)$ in centimeters per second are plotted on the $x$ and $y$ axis, respectively. The solid line presents the best fit to Equation 14, with sample size

$(\mathrm{N}), \mathrm{r}^{2}$, and $\mathrm{p}$-value displayed at the top of the figure. The $95 \%$ confidence intervals on the fit are indicated with the dashed lines.

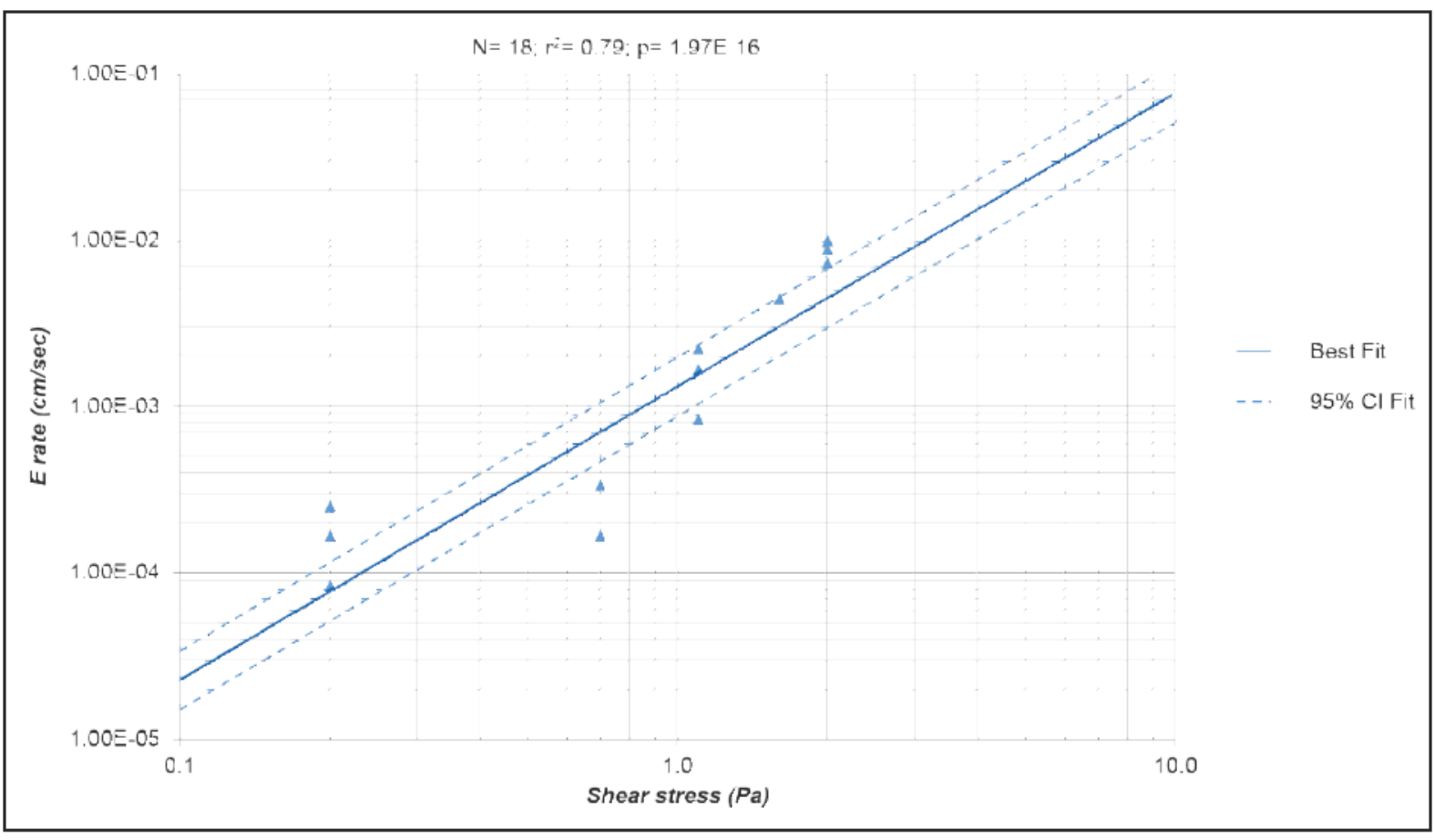

Table 3. Cohesive erosion parameterization uncertainties ( $L$ indicates layer).

\begin{tabular}{|l|c|c|c|c|c|c|c|}
\hline \multirow{2}{*}{ Core } & \multirow{2}{*}{$\mathrm{N}$} & \multirow{2}{*}{$\mathrm{r}^{2}$} & \multirow{2}{*}{ p-value } & \multicolumn{2}{|c|}{$A 95 \%$} & \multicolumn{2}{c|}{$\tau_{\mathrm{c}} 95 \%(\mathrm{~Pa})$} \\
\cline { 6 - 8 } & & & & low & high & low & high \\
\hline Station 1- Surface & 5 & 0.99 & $3.23 \mathrm{E}-06$ & $3.46 \mathrm{E}-03$ & $5.14 \mathrm{E}-03$ & 0.19 & 0.22 \\
\hline Station 1- L1 & 11 & 0.93 & $1.82 \mathrm{E}-14$ & $6.53 \mathrm{E}-04$ & $9.48 \mathrm{E}-04$ & 0.22 & 0.28 \\
\hline Station 1-2- Surface & 4 & - & - & - & - & - & - \\
\hline Station 1-2- L1 & 18 & 0.79 & $1.97 \mathrm{E}-16$ & $8.78 \mathrm{E}-04$ & $1.99 \mathrm{E}-03$ & 0.18 & 0.29 \\
\hline Station 1-2- L2 & 11 & 0.95 & $4.15 \mathrm{E}-11$ & $5.88 \mathrm{E}-05$ & $1.82 \mathrm{E}-04$ & 0.79 & 1.23 \\
\hline Grouped Station 1- Surface & 9 & 0.96 & $1.48 \mathrm{E}-08$ & $3.10 \mathrm{E}-03$ & $7.40 \mathrm{E}-03$ & 0.15 & 0.22 \\
\hline Grouped Station 1- L1 & 29 & 0.79 & $8.51 \mathrm{E}-29$ & $8.25 \mathrm{E}-04$ & $1.40 \mathrm{E}-03$ & 0.20 & 0.28 \\
\hline Station 2- Surface & 5 & 0.96 & $4.75 \mathrm{E}-05$ & $1.12 \mathrm{E}-03$ & $3.38 \mathrm{E}-03$ & 0.10 & 0.21 \\
\hline Station 2- L1 & 5 & 0.92 & $1.54 \mathrm{E}-04$ & $6.40 \mathrm{E}-04$ & $3.53 \mathrm{E}-03$ & 0.11 & 0.31 \\
\hline Station 2- L2 & 19 & 0.86 & $1.23 \mathrm{E}-19$ & $6.06 \mathrm{E}-04$ & $1.13 \mathrm{E}-03$ & 0.21 & 0.31 \\
\hline
\end{tabular}




\begin{tabular}{|l|c|c|c|c|c|c|c|}
\hline \multirow{2}{*}{ Core } & \multirow{2}{*}{$\mathrm{N}$} & \multirow{2}{*}{$\mathrm{r}^{2}$} & \multirow{2}{*}{ p-value } & \multicolumn{2}{|c|}{$A 95 \%$} & \multicolumn{2}{c|}{$\tau_{\mathrm{c}} 95 \%(\mathrm{~Pa})$} \\
\cline { 6 - 8 } & & & & low & high & low & high \\
\hline Station 4- Surface & 5 & 0.90 & $2.27 \mathrm{E}-04$ & $7.62 \mathrm{E}-04$ & $4.93 \mathrm{E}-03$ & 0.08 & 0.26 \\
\hline Station 4- L1 & 34 & 0.78 & $3.32 \mathrm{E}-32$ & $4.96 \mathrm{E}-04$ & $8.91 \mathrm{E}-04$ & 0.25 & 0.36 \\
\hline $\begin{array}{l}\text { Grouped Hamilton Wetlands } \\
\text { Basin- Surface }\end{array}$ & 19 & 0.89 & $4.37 \mathrm{E}-18$ & $1.87 \mathrm{E}-03$ & $3.57 \mathrm{E}-03$ & 0.13 & 0.18 \\
\hline Station 5N- Surface & 6 & 0.86 & $1.44 \mathrm{E}-05$ & $4.59 \mathrm{E}-04$ & $2.09 \mathrm{E}-03$ & 0.08 & 0.28 \\
\hline Station 5N- L1 & 5 & 0.91 & $1.58 \mathrm{E}-04$ & $1.16 \mathrm{E}-04$ & $9.66 \mathrm{E}-04$ & 0.20 & 0.90 \\
\hline Station 5N- L2 & 19 & 0.88 & $1.25 \mathrm{E}-20$ & $1.18 \mathrm{E}-04$ & $2.29 \mathrm{E}-04$ & 0.56 & 0.89 \\
\hline
\end{tabular}

It was observed that critical shear stress increased with depth below the sediment water interface for each core. This trend, along with the decrease in erosion rate with depth, was expected for cohesive sediments. Cohesive sediments typically have a trend of increasing density with depth due to self-weight consolidation. Consolidation produces stronger, more frequent bonds between particles. Note, though, that density did not increase consistently with depth for each core. Density profiles from Station 2 and Station $5 \mathrm{~N}$ showed decreases in density with depth. The decreasing density with depth in the Station 2 core was likely linked to the fining downward textural trend that was observed in the grain size data. Sand content was found to be approximately $20 \%$ in the surface layer $(2 \mathrm{~cm})$ and decreased to approximately $9 \%$ at a depth of $16 \mathrm{~cm}$. Likewise, the $\mathrm{D}_{50}$ also decreased down core from $19 \mu \mathrm{m}$ at the surface to $9 \mu \mathrm{m}$ at $16 \mathrm{~cm}$ depth. By comparison, no substantial grain size changes were noted with depth within the core from Station $5 \mathrm{~N}$. Other natural variation in sediment properties such as water or gas content, mineralogical composition, organic content, and aggregation state may have been responsible for the observed decrease in density with depth at Station ${ }_{5} \mathrm{~N}$. Density profiles and grain size distribution plots for individual cores are presented in Appendix A.

Surficial critical shear stresses ranged between 0.14 and $0.21 \mathrm{~Pa}$. As previously mentioned, surface erosion data from the four cores collected within the Hamilton Wetlands basin displayed similar trends and were therefore compiled into one data set. While the reported $\tau_{\mathrm{c}}$ for surface sediment at Station ${ }_{5} \mathrm{~N}(0.14 \mathrm{~Pa})$ was equivalent to surficial $\tau_{\mathrm{c}}$ values within the wetland basin, the rate of surface erosion was diminished at Station $5 \mathrm{~N}$ when compared to locations within the basin (Figure 41). This trend continued with depth at Station ${ }_{5} \mathrm{~N}$. Erosion rates across the range 
of shear stresses evaluated in this study were typically lower at Station ${ }_{5} \mathrm{~N}$ than they were for the cores collected within the Hamilton Wetlands basin. Station ${ }_{5} \mathrm{~N}$ was located outside of the area where placement of dredged material occurred. The open waters of San Pablo Bay also exposed the sediments at $5 \mathrm{~N}$ to larger wave conditions and higher energy. Therefore, the more erosion resistant nature of the sediments at this location was not unexpected.

Figure 41. Erosion rate data and best fit lines to Equation 14 for the surface layers of cores located within the Hamilton Wetlands basin (black symbols) (Stations 1, 1-2, 2, and 4). Surface layer data from Station $5 \mathrm{~N}$, located outside the basin, are indicated in red.

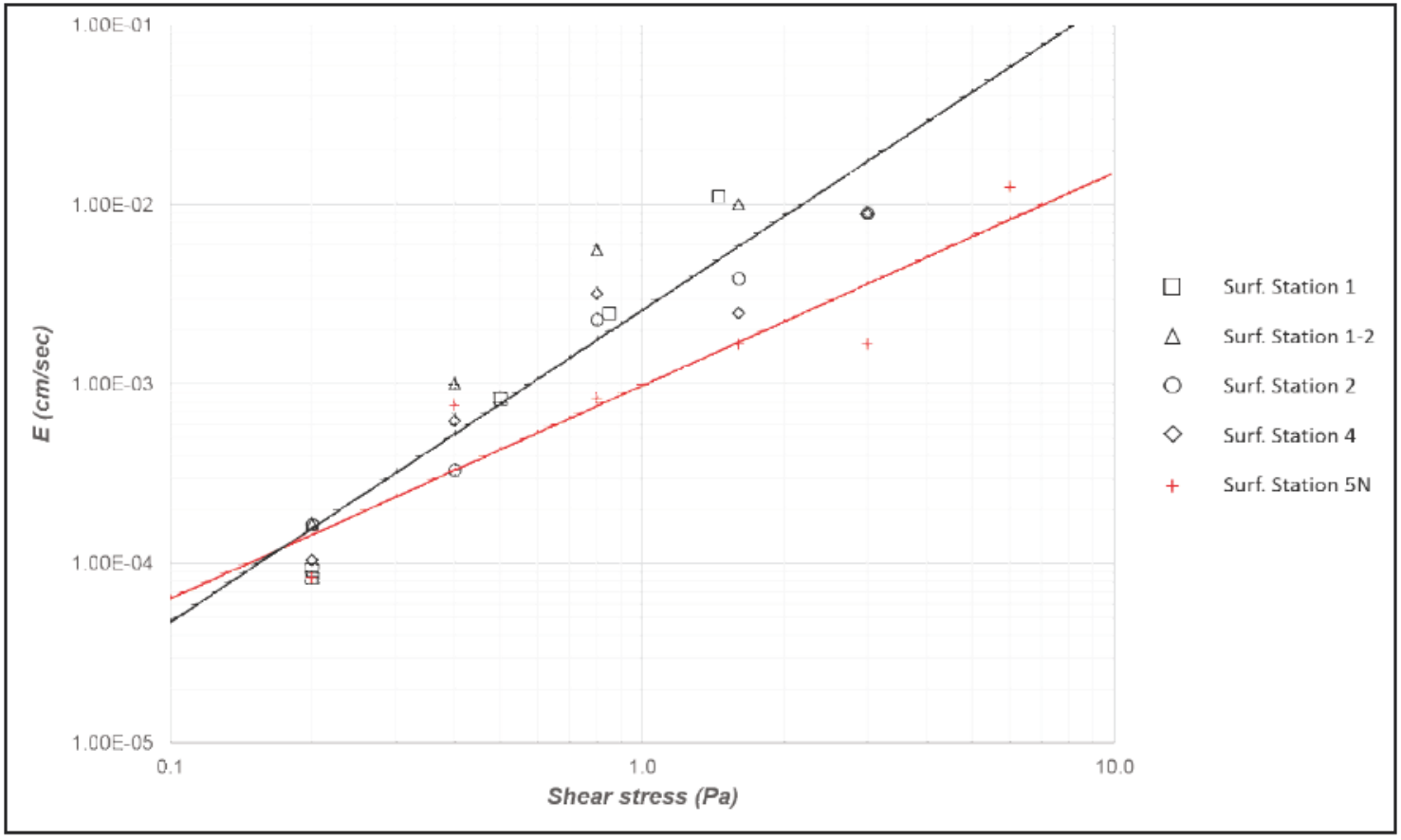

\subsection{Bottom shear stress estimates}

Time-averaged shear velocity at each station showed variation between the different methodologies and through time (Figure 42, Figure 43, and Figure 44). Temporal variability resulted from the changing wave and current environment. Diurnal variations correspond to the tides in which tidal currents cause corresponding oscillations in boundary layer shear stress and associated $u^{*}$. The three methods produced similar ranges but varied between the different methodologies. Overall, shear velocities were relatively weak with a mean less than $0.01 \mathrm{~m} / \mathrm{s}$ at all stations and all methods. The inertial dissipation method had the highest overall mean of $0.008 \mathrm{~m} / \mathrm{s}$, and the covariance method had the lowest of $0.004 \mathrm{~cm} / \mathrm{s}$. 
Figure 42. Time-averaged shear velocity derived from the velocity time series at Hamilton 1.

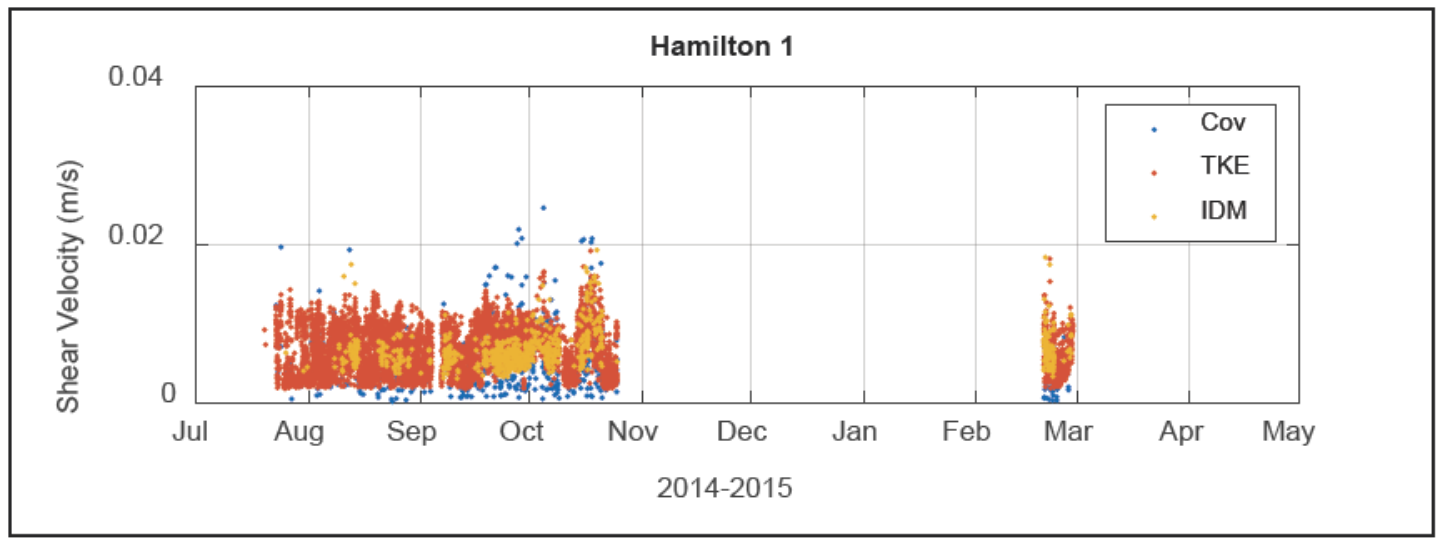

Figure 43. Shear velocity derived from the velocity time series at Hamilton 2.

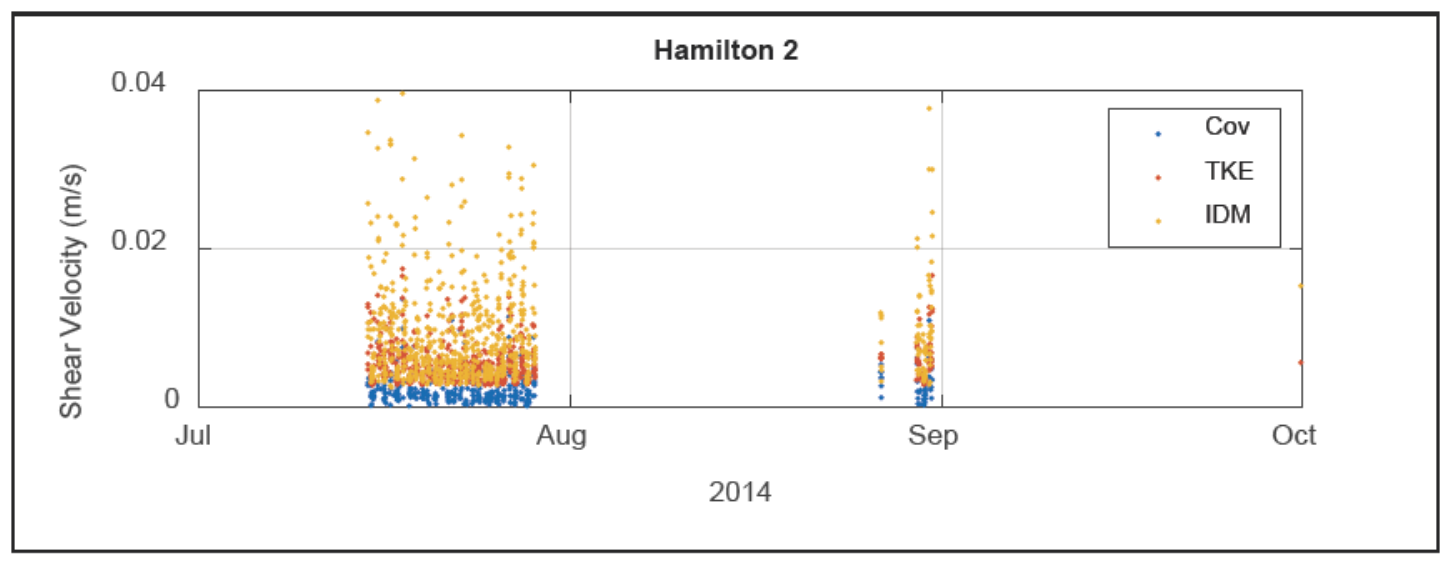

Figure 44. Shear velocity derived from velocity time series at Hamilton 4.

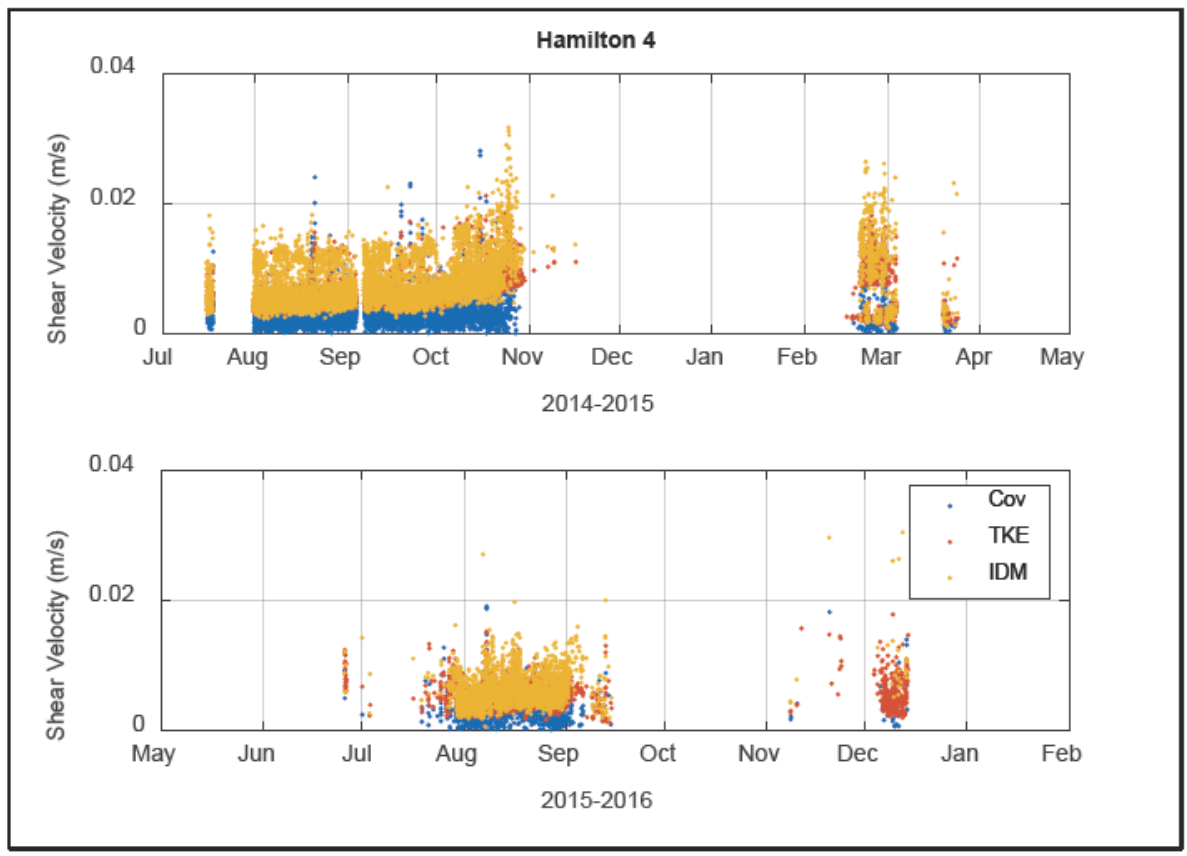


The maximum combined shear velocity $\left(u^{*} c w\right)$, which includes contributions from the waves and the time-averaged shear velocity for the current $\left(u{ }^{*}\right)$ derived from the BBLM, showed variability among stations and through time (Figure 45). Because of the sparse current data at Hamilton 2, there were no incidences of overlapping wave and current measurements to provide input to the BBLM. As such, products derived from the BBLM are only shown for Hamilton 1 and 4. Furthermore, Station 4 did not have wave measurements during the first part of the deployment so the model simulations began in February 2015. In general $u^{*} c w$ exceeded $u_{c}$ by at least a factor of two indicating that the wave stress dominates. The predicted $u^{*}{ }_{c}$ was lower than obtained from the data.

Figure 45. Time-averaged shear velocity and the maximum combined shear velocity for the wave and current predicted from the BBLM for Hamilton 1 and 4.

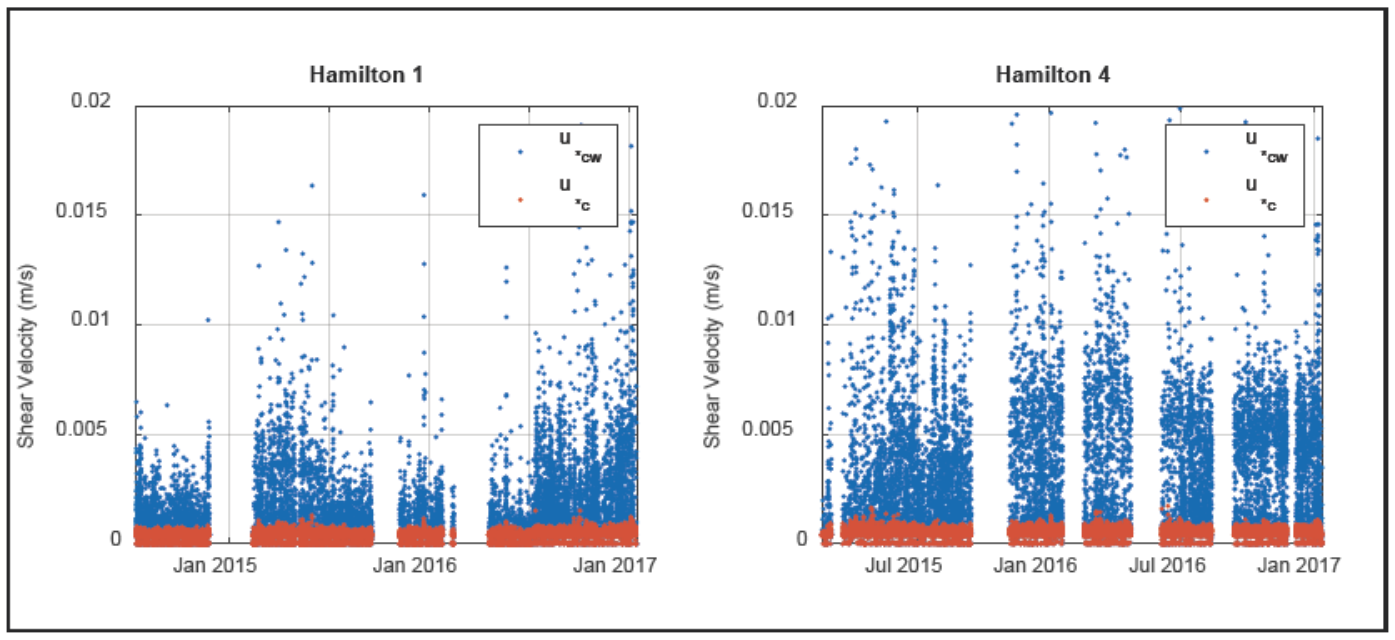

\subsubsection{Initiation of sediment motion}

The critical stress for the initiation of sediment motion ( $0.14 \mathrm{~Pa})$ as represented by the Shields parameter (0.1) indicates that local sediment resuspension is rare (Figure 46 ). Less than $4 \%$ of the bursts per station exceeded the critical threshold. The relatively weak wave and current environment over the shallow fetch-limited wetland reduced the potential to resuspend bed sediments. However, fine-grained particles carried in suspension can penetrate the island interior and redeposit during slack tide. The results suggested that local resuspension can intermittently resuspend sediment, but it was not a primary mechanism controlling sediment dynamics. 
Figure 46. Shields parameter and critical Shields parameter for the initiation of sediment motion at Hamilton 1 and 4.

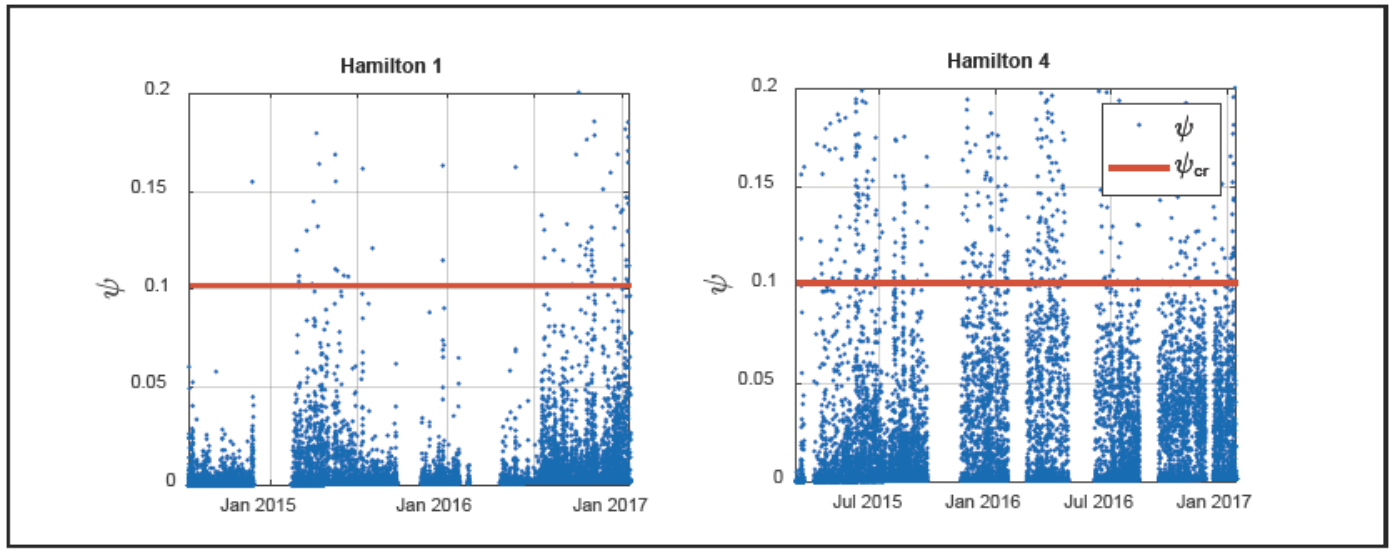

\subsubsection{Micro-scale turbulence and floc size}

The shear parameter $(G)$ was variable at each station (Figure 47). Values between 1.0 and 10 are indicative of a shearing level sufficient to create flocs through random collisions but insufficient for significant floc breakup. Floc breakup typically begins when $G>10$ (Manning and Dyer 1999). The conditions in the interior basin supported floc formation or maintenance but were too weak to induce significant floc breakup.

Figure 47. Shear parameter estimates at Hamilton 1 and 4.

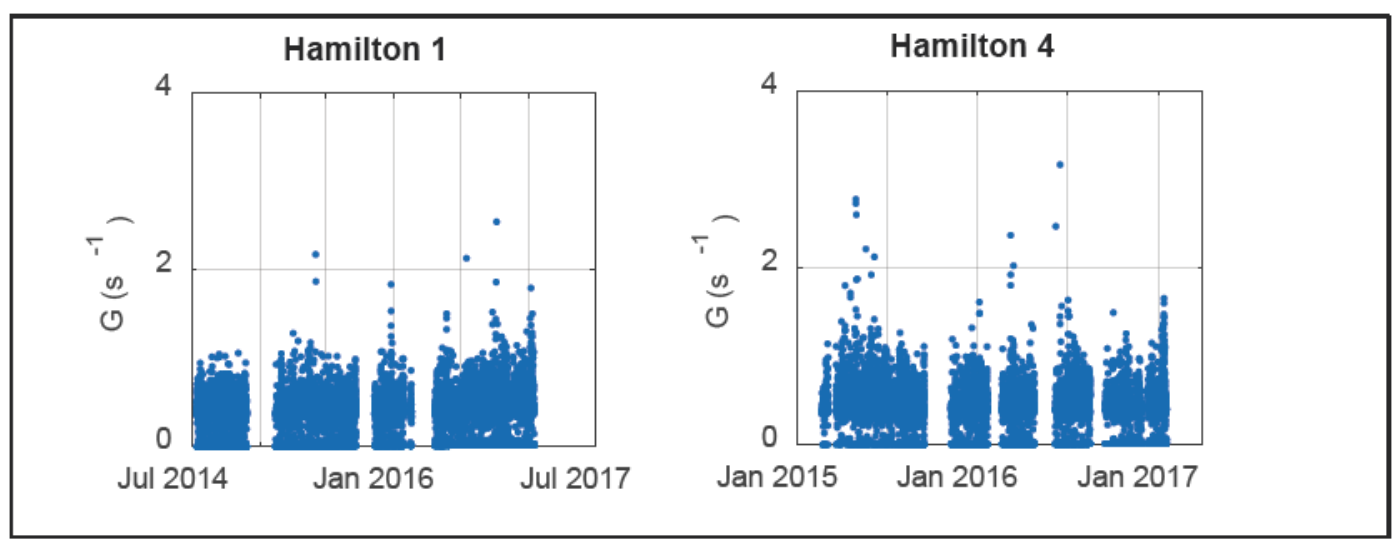

The Kolmogorov micro-scale is shown in Figure 48. Assuming $\lambda_{0}$ is a representative measure of the maximum floc size, the water column can support flocs on the order of a few centimeters. Given that the BBLM predicts a low $u^{*} c$ and associated $G$, the ambient currents were generally not very energetic such that large consolidated material was less likely to be disaggregated by tidal flow. 
Figure 48. Kolmogorov micro-scale at Hamilton 1 and 4. Vertical axis is plotted on a log scale.

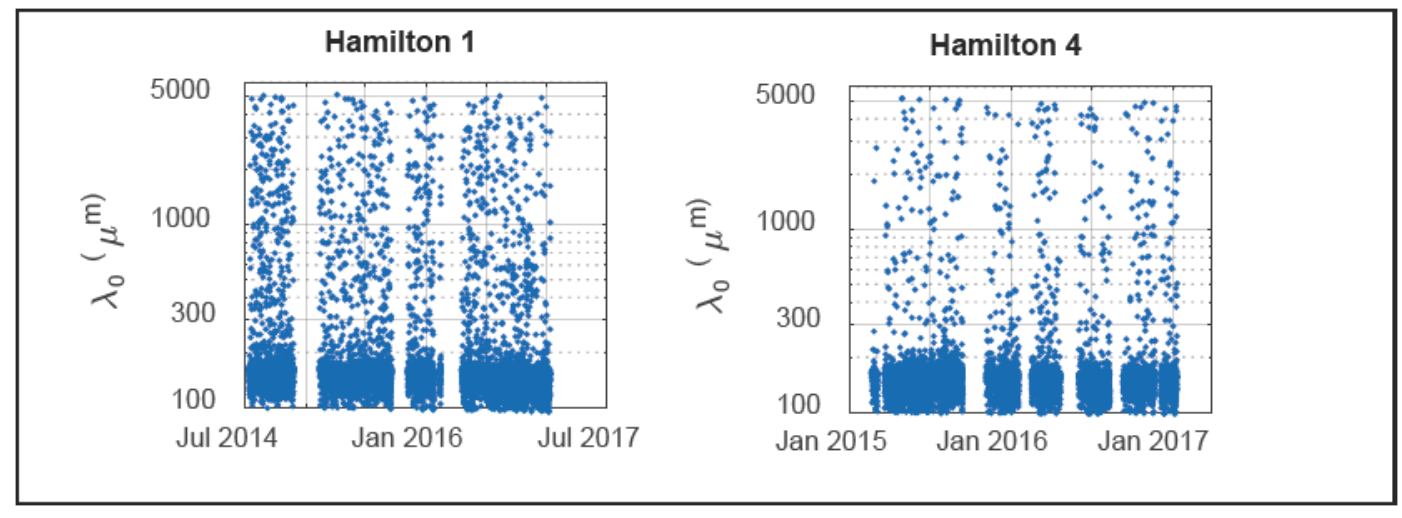




\section{Conceptual Site Model}

\subsection{Hydrodynamic forcing}

The climatology of Hamilton Wetlands can be described by an increase in westerlies in the spring and summer and variable winds associated with frontal systems in the fall and winter. During the warmer months, the Pacific high shifts northward bringing dryer air and reduced rainfall over California's Central Valley. In turn, temperatures increase, and the higher pressure along the coast drives westward flowing air and an increase in average wind speeds during the summer. The dry season also brings less rainfall, leading to higher salinities at Hamilton Wetlands. Extreme winds are higher in the winter but are generally shorter in duration, consistent with synoptic cold fronts in the 3- to 7-day band. The winter coincides with the rainy season, and Hamilton Wetlands receives greater freshwater runoff, leading to lower salinities.

The summer westerlies lead to higher-than-average wind stress on the water surface. The higher wind stress produces higher local waves, and given the shallow depths, the wind and wave energy penetrates the water column to resuspend sediment. The data indicated a positive correlation between turbidity and wind speed, and the highest average winds and turbidity occurred in the summer. The shallow embayment and inlet filter longer waves from the adjacent San Pablo Bay, which is consistent with the 1 to $3 \mathrm{~s}$ waves measured at the platforms. All waves are generated locally so that fetch within the small wetland limits wave growth. Average wave height as a function of distance to the closest shore point shows a trend in which the largest waves are associated with an approach angle that corresponds to the greatest fetch.

Currents within the inlet throat were the strongest measured in the system with spring tidal currents exceeding $100 \mathrm{~cm} / \mathrm{s}$. The flows were persistent across the inlet throat with a noticeable decrease in the middle of the channel during the latter phase of ebb. The cause for the reduction is not clear and requires more information such as bathymetric surveys and flow visualization of surface currents to detect any eddies or other anomalies that would cause the observed flow patterns.

Current variability followed a pattern that is consistent with the largerscale environmental forcing. The major flow in the system was driven by 
the tides. The inlet controls the tidal exchange and reduces the amplitude of the tidal current. Interior basin currents were generally weak $(<10$ $\mathrm{cm} / \mathrm{s}$ ) but persistent throughout the wetland with a clearly defined spring/neap modulation. Tidal currents vary within the basin such that amplitudes at Hamilton 1 are much smaller than at the other sites. Note that the available current data were very sparse and did not capture transient events such as storms or periods of increased freshwater runoff. These events may drive stronger flows in the system but will be short lived. Given the weak tidal forcing; however, the cumulative effect of these transient events may be responsible for any major modifications to the system that are driven by flow strength, especially erosion.

Shear velocity estimates derived from the data were much greater than computed with the BBLM. The difference was not generally within model or measurement error as it would be expected that the two methods should be of similar magnitude. Obtaining shear velocity from the covariance method was problematic in the presence of waves as even slight misalignment of the sensor could cause correlations between the waves that can appear as turbulent fluctuations when, in fact, they are coherent nearly irrotational orbital motions (Shaw and Trowbridge 2001; Trowbridge 1998). As such, covariance methods tend to overestimate shear velocity in the presence of waves, as was the case here. Also, the current magnitudes were small compared to typical applications of the covariance method, as the signal-to-noise ratio decreased as flow strength diminished. Thus, instrument noise became more problematic, and covariance shear velocity estimates became less accurate. Weaker currents also have lower Reynolds numbers, so the flow may not be fully turbulent, which is a necessary condition to compute turbulent shear velocities.

\subsection{Sediment dynamics}

The BBLM model results indicated that resuspension events were infrequent, mainly due to the weak hydrodynamic forcing of the system. Maximum tidal currents did not exceed $10 \mathrm{~cm} / \mathrm{s}$ and were much less at Hamilton 1. Likewise, the average $u^{*} c$ was less than $1 \mathrm{~cm} / \mathrm{s}$. This translated to a bottom stress $<0.1 \mathrm{~Pa}$, which is lower than the surface critical shear stress (o.14 Pa) measured at the site. While tidal currents in the interior of the wetland are not very energetic, waves can intermittently stir sediment, leading to resuspension events. The limited model results indicated that waves superimposed on the current can cause the bottom stress to exceed the critical value for the initiation of sediment motion. However, the 
sparsity of data to drive the model suggests that resuspension events were fairly rare. As such, waves played the leading role in generating bottom stresses large enough to mobilize bed sediment.

Kolmogorov micro-scale estimates indicated the weak turbulent environment can sustain flocs on the order of a few millimeters to centimeter-size particles. The ability for the flocs to persist was due to the weak tidal flow, which was insufficient to maintain the shearing force necessary to disrupt the bonding strength as measured by $G$. The results indicated that larger flocs were more likely to persist when $G$ is smallest. Reduced shear permits larger flocs but lower overall concentrations as maximum turbulence levels are reduced and cannot sustain higher concentrations in the water column. Larger flocs have higher settling velocities (Manning and Dyer 1999) which promotes deposition and bed elevation growth. As such, when new sediment enters the system through the energetic tidal inlet, it is likely to remain sequestered, as the ambient forcing is not strong enough to vigorously erode and transport bed material once it has been dispersed within the wetland interior.

\subsection{Morphological discussion}

The data indicate that local forcing within Hamilton Wetlands relatively weak. This weak forcing has implications for the rate and degree of morphological change in the system. The primary dynamical process of Hamilton Wetlands is the exchange with the adjacent San Pablo Bay. The inlet allows for tidal exchange and the delivery of sediment to the system. The basin area is approximately 2.38 million $\mathrm{m}^{2}$, with a tidal range of 1 to 2 $\mathrm{m}$. This translates to an average tidal prism of 36 million $\mathrm{m}^{3}$. The relatively small and shallow basin lends further support to the idea that tidal exchange accounts for the majority of the dynamical forcing at Hamilton Wetlands. Tidal currents can deliver or remove sediment from the system. However, the analysis indicates that tidal currents alone are not energetic enough to resuspend sediment or to maintain concentrations of suspended material in the water column. It is surmised that tidal currents alone are an inefficient mechanism for localized sediment redistribution within Hamilton Wetlands. However, strong currents at the inlet throat appear to be able to deliver new sediment into the basin. The asymmetry between backscatter intensity indicates a net influx of suspended material. Thus, tidal currents are an efficient way to deliver sediment, but tidal currents in conjunction with other forcing are necessary for redistribution of sediment within the basin. Morphological change is a combination of sediment 
delivery through the inlet combined with wave and wind forcing to rework the interior of the system.

Wind stress, which generates local waves and promotes vertical mixing, is also a major factor in controlling the dynamics of this shallow water system. With the exception of the inlet, the basin is isolated from windgenerated waves so that all wave forcing is generated locally. The relatively small size of the basin limits fetch and the associated maximum wave height. However, during periods of high winds, waves of nearly $0.4 \mathrm{~m}$ are seen at Hamilton 2 and 4. The bay contains a number of small berms and islands that are remnants of the former impoundment before Hamilton Wetlands was hydraulically reconnected to San Pablo Bay. These subaerial features are exposed even at high tide and further restrict fetch and associated wave growth.

This analysis revealed a relationship between average wave height and distance of closest approach to land such that waves originating from points closest to the sensors were smaller than waves originating at points further from the sensors. The trend is not absolute because other factors such as wind magnitude also affect wave height. Given that the system consists of a relatively small bay that is dissected by subaerial features in the form of discrete berms, Hamilton Wetlands can be classified as extremely fetch limited. As such, wind direction and speed are critical factors in understanding the dominant mechanisms for sediment transport.

The building material for morphological change at Hamilton Wetlands is fine-grained consolidated sediment that likely transports as low-density flocs. The weak forcing suggests that bedload transport is minimal except near the inlet throat where currents are strong. The relationship between turbidity and wind, as well as the BBLM results, suggests that transport dominated by low-density flocs is likely a major mechanism for sediment redistribution which drives morphological change. The model results indicated that, even with waves, the instances of sediment resuspension are very sparse. Additionally, the shearing force required to break up flocs as measured by $G$ indicates that large flocs can persist. The low-energy environment makes it difficult to maintain sediment in suspension, so only flocs with densities slightly greater than water can be sustained in the water column. The acoustic backscatter results indicated that particulate concentrations during slack tide vary widely, and for Hamilton 1 and 4, the greatest intensity is when the current magnitude is zero. 
The motivation for breaching the bay front levee was to trigger a natural process of sediment and flow delivery to allow Hamilton Wetlands to evolve into a mature coastal marsh system. Presently, aerial photography indicates that the intertidal areas have started to form creek networks in a manner similar to salt marshes and other tidally driven coastal wetlands. Also, the inlet throat has widened, and the edges of the adjacent shoreline have become more rounded, indicative of erosion around barrier island inlets to streamline the flow. 


\section{Conclusions}

This technical report provides a summary of a field data collection effort carried out between July 2014 and March 2017 at Hamilton Wetlands located in San Pablo Bay, California. Four platforms were equipped with sensors to measure the hydrodynamic and sediment transport processes in this recently restored wetland in the San Francisco Bay area. The results documented the role of climatology and morphology in modulating the hydrodynamics and associated sediment transport in this small reestablished wetland.

The main conclusions are summarized as follows:

- Extreme fetch-limited environment: Hamilton Wetlands is a relatively small system consisting of a series of disjointed berms that are remnants of the previously impounded airstrip, and initial dredged material placement. This analysis revealed a trend between average wave height and distance to closest land point such that higher waves correlate with greater distance (fetch). The complex distribution of subaerial berms within the basin interior subdivide the flooded portions into disjointed pools that block wave propagation. The berms, however, are not interconnected, so exchange flow is not disrupted by their presence.

- Weak tidal flow: Tidal flow within the basin is weak with maximum flows $<10 \mathrm{~cm} / \mathrm{s}$. The weak currents lead to reduced transport and weaker shear-generated turbulence. This reduces particle excursion distance and makes it more difficult to sustain negatively buoyant particles in the water column. However, inlet currents are strong, and the results suggest a net inflow of sediment into the system.

- Low capacity for resuspension: The data and BBLM results indicate that Hamilton Wetlands is a relatively low-energy environment with weak tidal flows and intermittent waves that infrequently generate bed stresses sufficient to resuspend material. The lack of energetic flow reduces turbulence and the carrying capacity for suspended sediment while the lower shear stresses limit resuspension and erosion. As such, once particles are in the system, they are likely to settle out and remain sequestered, forming newly deposited bed building material. Note that bed level change was not measured, so this conclusion is speculative, but 
it can also be considered as a reasonable deduction based on what is known about the wave and current dynamics.

- Seasonal control on the system: The results indicate that the summer months possess the highest average wind speeds and associated turbidity. The correlation between wind and turbidity suggests that the sediment dynamics in this shallow water system are modulated by wind-driven processes and that the effects of wind is more pronounced in the summer.

The sparsity of data precludes a more in-depth analysis of the hydrodynamics and sediment dynamics of Hamilton Wetlands. In particular, the combination of available wave and current data does not adequately cover storms which can generate large waves and currents, and can alter local water levels beyond those measured in this study. As such, the full range of environmental conditions that contribute to building Hamilton Wetlands is unavailable, and acquiring additional data during storms would provide greater insight into wetland restoration dynamics. Furthermore, direct measurement of sediment delivery through the inlet throat and periodic bathymetric surveys would help correlate hydrodynamics to land building as this system continues to evolve. 


\section{References}

Best, E., H. Fredrickson, V. McFarland, H. Hintelmann, R. Jones, C. Lutz, G. Kiker, A. Bednar, R. Millward, and R. Price. 2005. Pre-Construction Biogeochemical Analysis of Mercury in Wetlands Bordering the Hamilton Army Airfield Wetlands Restoration Site. Vicksburg, MS: US Army Engineer Research and Development Center.

Blanton, J. O., G. Lin, and S. A. Elston. 2002. "Tidal Current Asymmetry in Shallow Estuaries and Tidal Creeks." Continental Shelf Research 22: 1731-1743.

Cahoon, D. R., P. F. Hensel, T. Spencer, D. J. Reed, K. L. McKee, and N. Saintilan. 2006. "Coastal Wetland Vulnerability to Relative Sea-Level Rise: Wetland Elevation Trends and Process Controls." Wetlands and Natural Resource Management. Berlin: Springer.

CERC (Coastal Engineering Research Center). 1984. Shore Protection Manual - Volume I (Fourth Edition). Army, D.o.t. (Ed.). Vicksburg, MS: Corps of Engineers, Coastal Engineering Research Center, Waterways Experiment Station.

Dean, R. G., and R. A. Dalrymple. 1991. Water Wave Mechanics for Engineers and Scientists. New Jersey: World Scientific.

Friedrichs, C. T., and D. G. Aubrey. 1988. "Non-Linear Tidal Distortion in Shallow Wellmixed Estuaries: A Synthesis." Estuarine, Coastal and Shelf Science 27: 521-545.

Gedan, K. B., M. L. Kirwan, E. Wolanski, E. B. Barbier, and B. R. Silliman. 2011. "The Present and Future Role of Coastal Wetland Vegetation in Protecting Shorelines: Answering Recent Challenges to the Paradigm." Climatic Change 106: 7-29.

Glenn, S. M., and W. D. Grant. 1987. "A Suspended Sediment Stratification Correction for Combined Wave and Current Flows." Journal of Geophysical Research-Oceans 92: 8244-8264.

Goring, D. G., and V. I. Nikora. 2002. "Despiking Acoustic Doppler Velocimeter Data." Journal of Hydraulic Engineering 128: 117-126.

Hinze, J. O. 1975. Turbulence, 2nd ed. New York: McGraw-Hill Inc.

Kim, S. C., C. T. Friedrichs, J. P. Y. Maa, and L. D. Wright. 200o. "Estimating Bottom Stress in Tidal Boundary Layer from Acoustic Doppler Velocimeter Data." Journal of Hydraulic Engineering-ASCE 126: 399-406.

Kolmogorov, A. N. 1941. The Local Structure of Turbulence in Incompressible Viscous Fluid for Very Large Reynolds Numbers. Dokl. Akad. Nauk SSSR. JSTOR.

Kumar, P. 2012. The Economics of Ecosystems and Biodiversity: Ecological and Economic Foundations. Routledge. https://doi.org/10.4324/9781849775489 
Lake, P., M. A. Palmer, P. Biro, J. Cole, A. P. Covich, C. Dahm, J. Gibert, W. Goedkoop, K. Martens, and J. Verhoeven. 200o. "Global Change and the Biodiversity of Freshwater Ecosystems: Impacts on Linkages between Above-Sediment and Sediment Biota: All Forms of Anthropogenic Disturbance-Changes in Land Use, Biogeochemical Processes, or Biotic Addition or Loss-Not Only Damage the Biota of Freshwater Sediments but Also Disrupt the Linkages between AboveSediment and Sediment-Dwelling Biota." BioScience 50: 1099-1107.

Manning, A. J., and K. R. Dyer. 1999. "A Laboratory Examination of Floc Characteristics with Regard to Turbulent Shearing." Marine Geology 160: 147-170.

McNeil, J., C. Taylor, and W. Lick. 1996. "Measurements of Erosion of Undisturbed Bottom Sediments with Depth." Journal of Hydraulic Engineering 122(6): 316324 .

Middleton, B. A. 2002. Flood Pulsing in Wetlands: Restoring the Natural Hydrological Balance. Hoboken, NJ: John Wiley \& Sons.

Mitsch, W. J., and S. E. Jørgensen. 2004. Ecological Engineering and Ecosystem Restoration. Hoboken, NJ: John Wiley \& Sons.

Novakowski, K. I., R. Torres, L. R. Gardner, and G. Voulgaris. 2004. "Geomorphic Analysis of Tidal Creek Networks." Water Resources Research 40: 1-13.

Pope, N., J. Widdows, and M. Brinsley. 2006. "Estimation of Bed Shear Stress Using the Turbulent Kinetic Energy Approach-A Comparison of Annular Flume and Field Data." Continental Shelf Research 26: 959-970.

Prince, H. 2008. Wetlands of the American Midwest: A Historical Geography of Changing Attitudes. Chicago, IL: University of Chicago Press.

Salehi, M., and K. Strom. 2012. "Measurement of Critical Shear Stress for Mud Mixtures in the San Jacinto Estuary under Different Wave and Current Combinations." Continental Shelf Research 47: 78-92.

Shaw, W. J., and J. H. Trowbridge. 2001. "The Direct Estimation of Near-Bottom Turbulent Fluxes in the Presence of Energetic Wave Motions." Journal of Atmospheric and Oceanic Technology 18: 1540-1557.

Sheaves, M., R. Baker, I. Nagelkerken, and R. M. Connolly. 2015. "True Value of Estuarine and Coastal Nurseries for Fish: Incorporating Complexity and Dynamics." Estuaries and Coasts 38: 401-414.

Stapleton, K., and D. Huntley. 1995. "Seabed Stress Determinations Using the Inertial Dissipation Method and the Turbulent Kinetic Energy Method." Earth Surface Processes and Landforms 20: 807-815.

Styles, R., and S. M. Glenn. 200o. "Modeling Stratified Wave and Current Bottom Boundary Layers on the Continental Shelf." Journal of Geophysical ResearchOceans 105: 24119-24139.

Trowbridge, J. H. 1998. "On a Technique for Measurement of Turbulent Shear Stress in the Presence of Surface Waves." Journal of Atmospheric and Oceanic Technology 15: 290-298. 
Verhoeven, J. T. 2014. "Wetlands in Europe: Perspectives for Restoration of a Lost Paradise." Ecological Engineering 66: 6-9.

Wahl, T. L. 2003. "Discussion of 'Despiking Acoustic Doppler Velocimeter Data' by Derek G. Goring and Vladimir I. Nikora." Journal of Hydraulic Engineering 129: 484487.

Welch, P. D. 1967. "The Use of Fast Fourier Transform for the Estimation of Power Spectra: A Method Based on Time Averaging over Short, Modified Periodograms." IEEE Transactions on Audio and Electroacoustics 15: 70-73.

Winterwerp, J. C. 1998. "A Simple Model for Turbulence Induced Flocculation of Cohesive Sediment.” Journal of Hydraulic Research 36: 309-326.

Winterwerp, J. C., and W. G. Van Kesteren. 2004. "Introduction to the Physics of Cohesive Sediment Dynamics in the Marine Environment." Amsterdam, Netherlands: Elsevier.

Zedler, J. B., and S. Kercher. 2005. "Wetland Resources: Status, Trends, Ecosystem Services, and Restorability." Annu. Rev. Environ. Resour. 30: 39-74.

Zhang, L., M.-H. Wang, J. Hu, and Y.-S. Ho. 2010. "A Review of Published Wetland Research, 1991-2008: Ecological Engineering and Ecosystem Restoration." Ecological Engineering 36: 973-980. 


\section{Appendix A: Core Descriptions}

Appendix A includes core photographs, core descriptions, locations, and analysis of physical samples. 
Table A-1a. Core Description, Station 1.

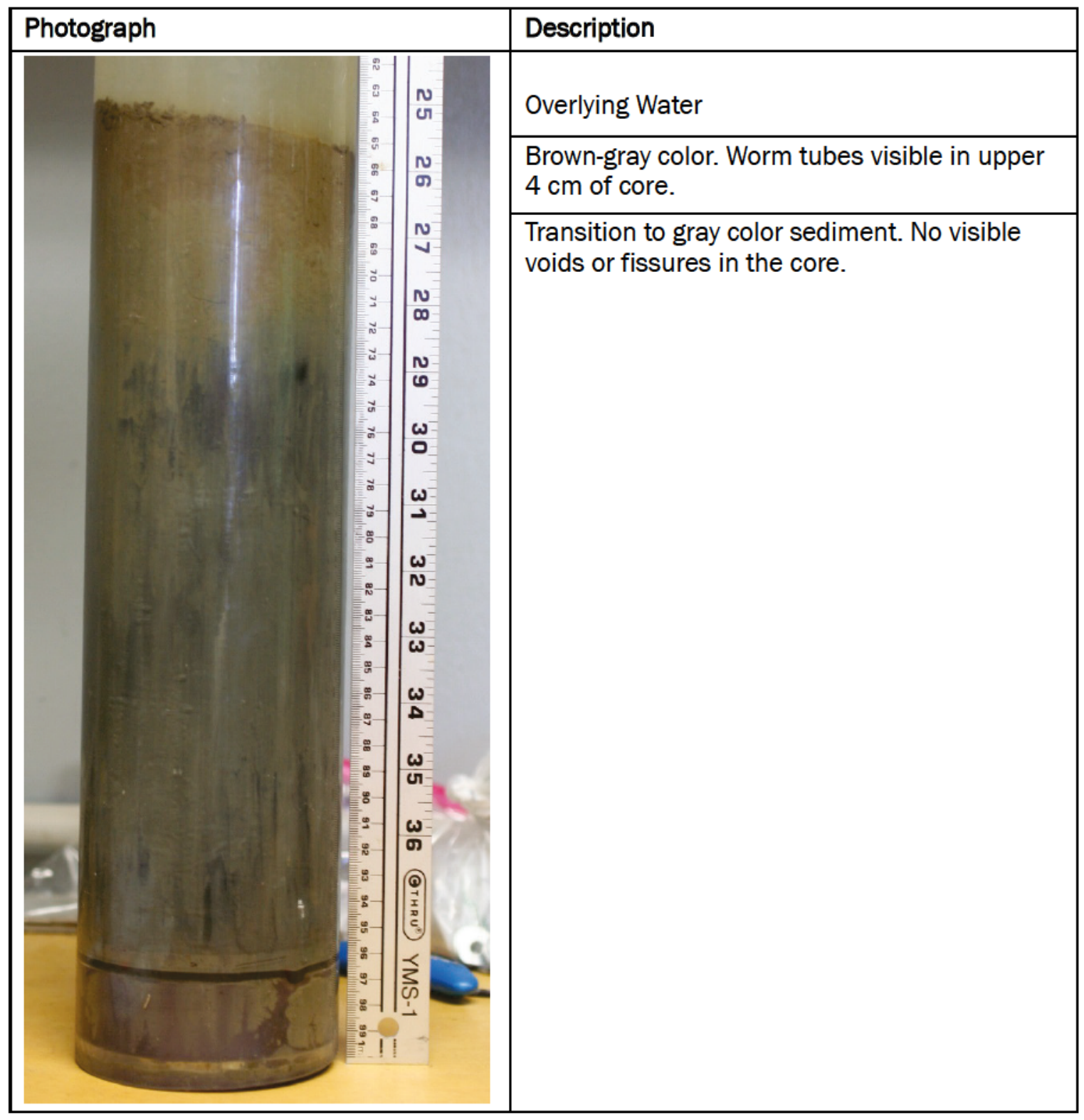


Table A-1b. Core Surface Photographs, SF-1.

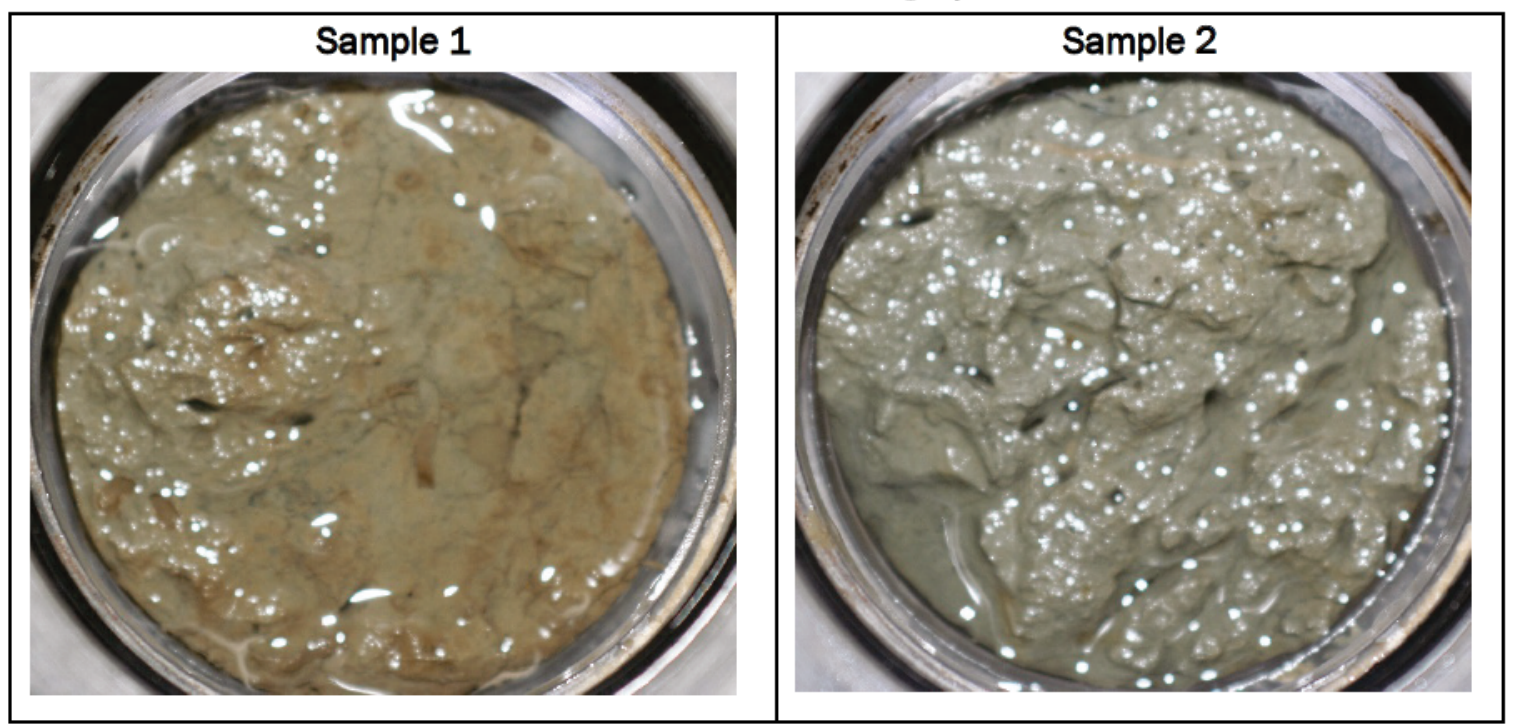

Table A-1c. Physical Sample Properties, Station 1.

\begin{tabular}{|c|c|c|c|c|c|c|c|c|}
\hline $\begin{array}{c}\text { Sample } \\
\#\end{array}$ & $\begin{array}{c}\text { Depth } \\
(\mathbf{c m})\end{array}$ & $\begin{array}{c}\text { Bulk } \\
\text { Density } \\
\left(\mathbf{g} / \mathbf{c m}^{\mathbf{3}}\right)\end{array}$ & $\begin{array}{c}\mathbf{d}_{10} \\
(\mu \mathrm{m})\end{array}$ & $\begin{array}{c}\mathbf{d}_{\mathbf{5 0}} \\
(\mu \mathrm{m})\end{array}$ & $\begin{array}{c}\mathbf{d}_{90} \\
(\mu \mathrm{m})\end{array}$ & $\begin{array}{c}\% \\
\text { Sand }\end{array}$ & $\begin{array}{c}\% \\
\mathbf{S i l t}\end{array}$ & $\begin{array}{c}\% \\
\text { Clay }\end{array}$ \\
\hline 1 & 1.32 & 1.25 & 2.91 & 9.67 & 35.09 & 3.4 & 78.3 & 18.3 \\
\hline 2 & 5.13 & 1.26 & 2.80 & 8.86 & 31.23 & 2.3 & 77.8 & 19.9 \\
\hline
\end{tabular}

Figure A-1a. Cumulative grain size distributions for Station 1 physical samples.

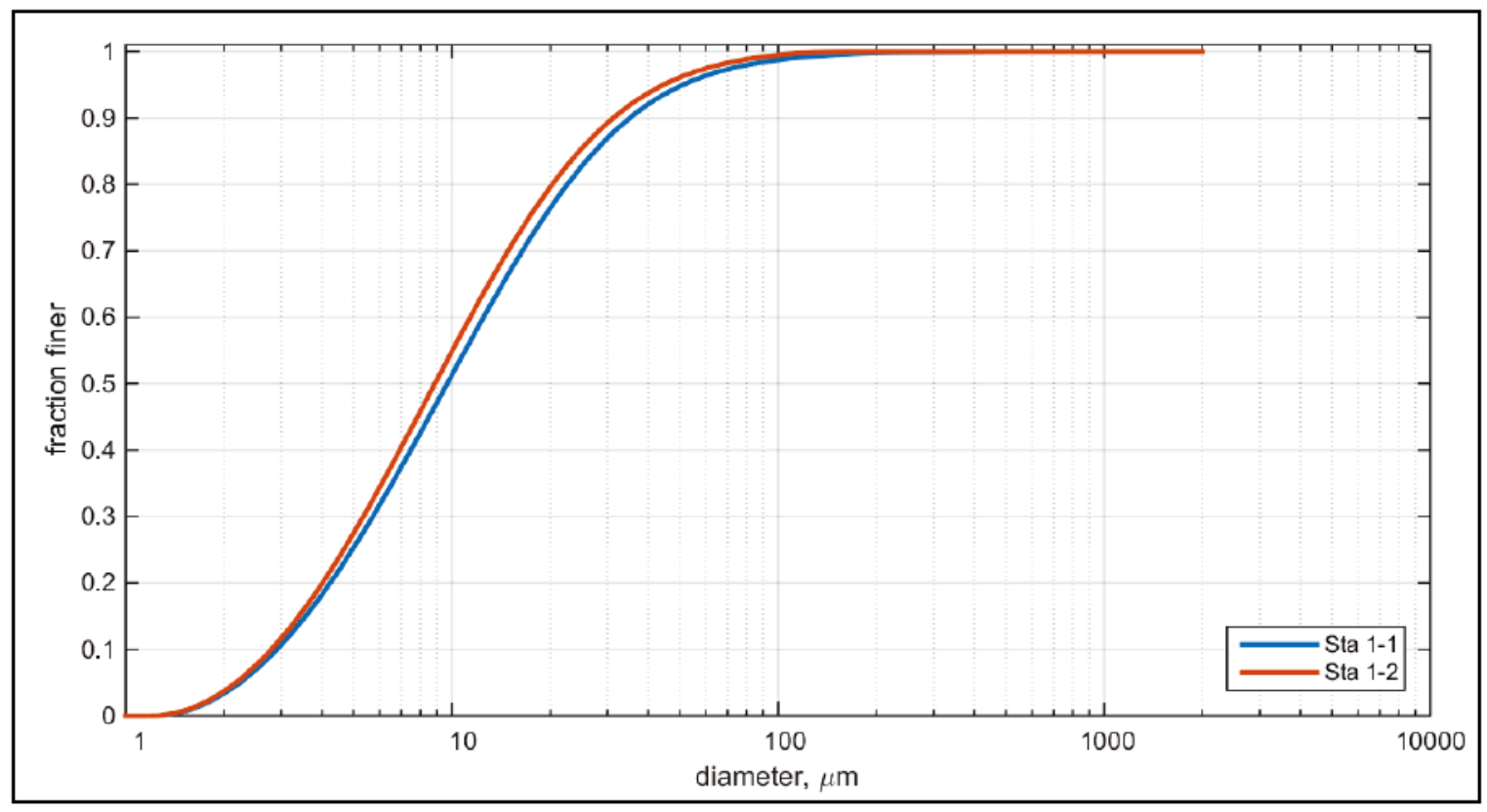


Figure A-1b. Grain size distributions for Station 1 physical samples.

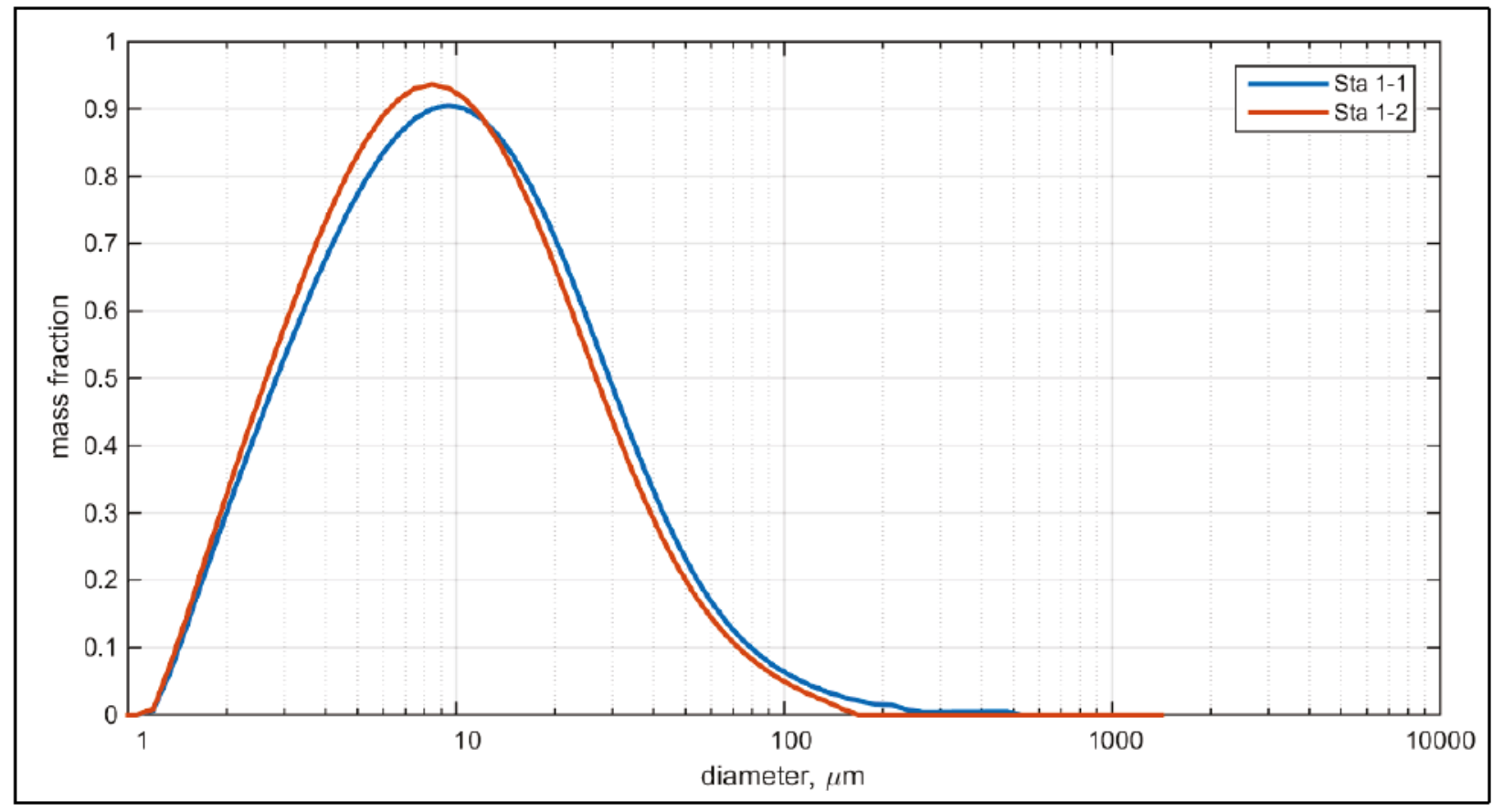


Figure A-1c. Bulk density profile for core Station 1.

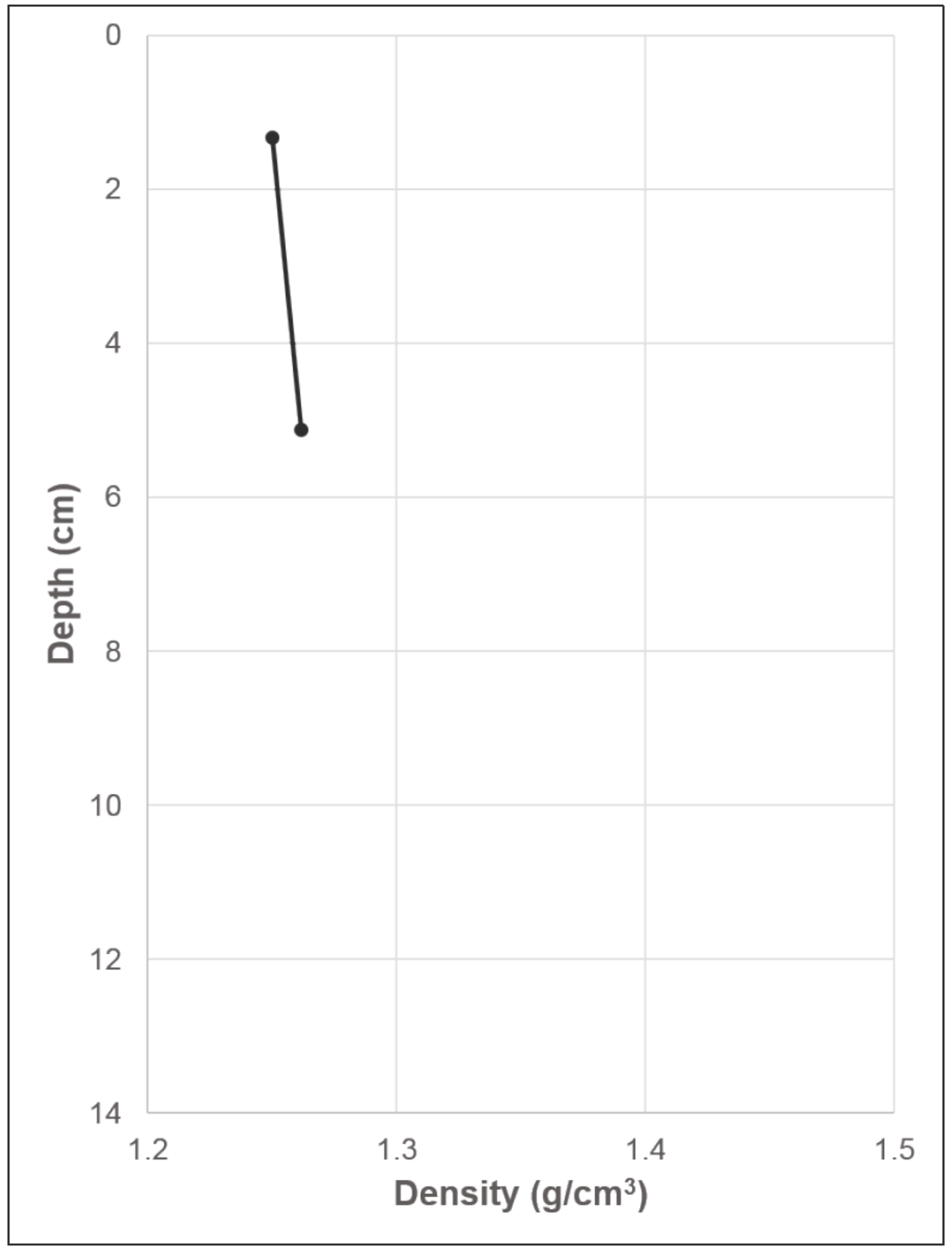


Table A-2a. Core Description, Station 1-2.

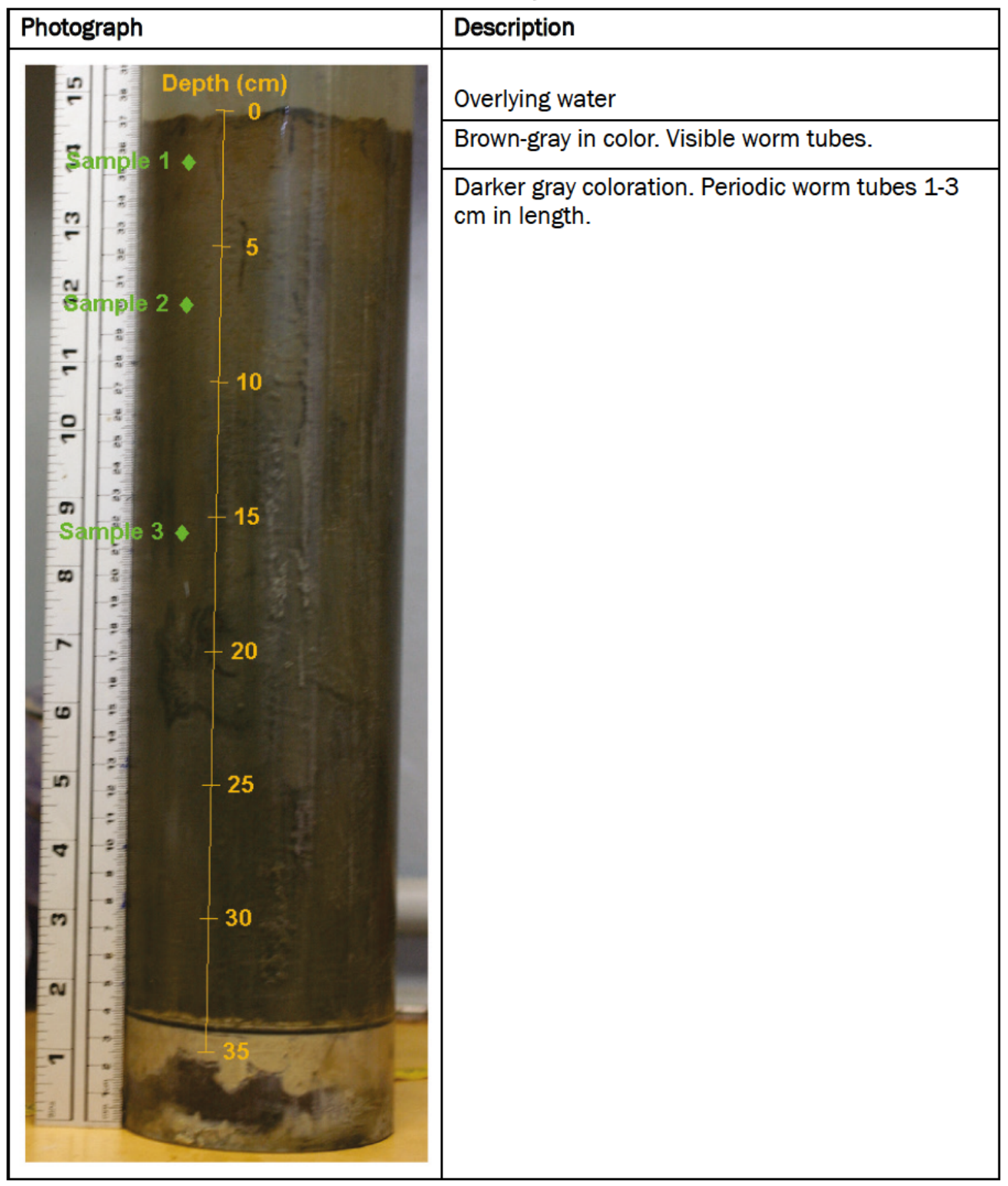


Table A-2b. Core Surface Photographs, Station 1-2.

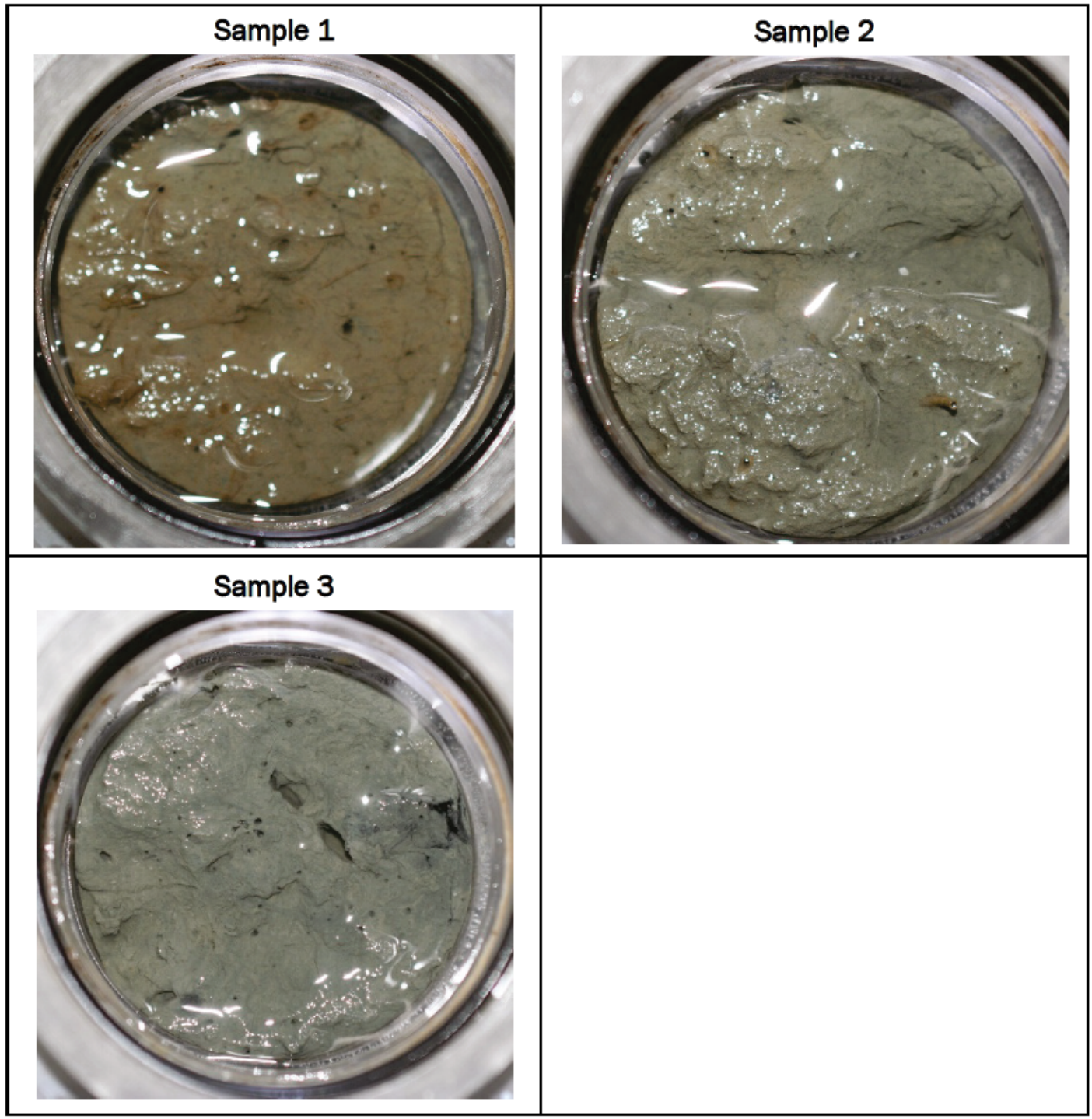

Table A-2c. Physical Sample Properties, Station 1-2.

\begin{tabular}{|c|c|c|c|c|c|c|c|c|}
\hline Sample \# & $\begin{array}{c}\text { Depth } \\
(\mathbf{c m})\end{array}$ & $\begin{array}{c}\text { Bulk } \\
\text { Density } \\
(\mathrm{g} / \mathrm{cm})\end{array}$ & $\begin{array}{c}\mathrm{d} 10 \\
(\mu \mathrm{m})\end{array}$ & $\begin{array}{c}\mathrm{d} 50 \\
(\mu \mathrm{m})\end{array}$ & $\begin{array}{c}\mathrm{d} 90 \\
(\mu \mathrm{m})\end{array}$ & \% Sand & \% Silt & \% Clay \\
\hline 1 & 2.02 & 1.24 & 2.83 & 9.14 & 32.03 & 2.6 & 78.0 & 19.4 \\
\hline 2 & 7.27 & 1.28 & 2.80 & 8.60 & 29.47 & 1.9 & 78.0 & 20.1 \\
\hline 3 & 15.67 & 1.32 & 2.83 & 9.14 & 32.45 & 2.6 & 78.0 & 19.4 \\
\hline
\end{tabular}


Figure A-2a. Cumulative grain size distributions for Station 1-2 physical samples.

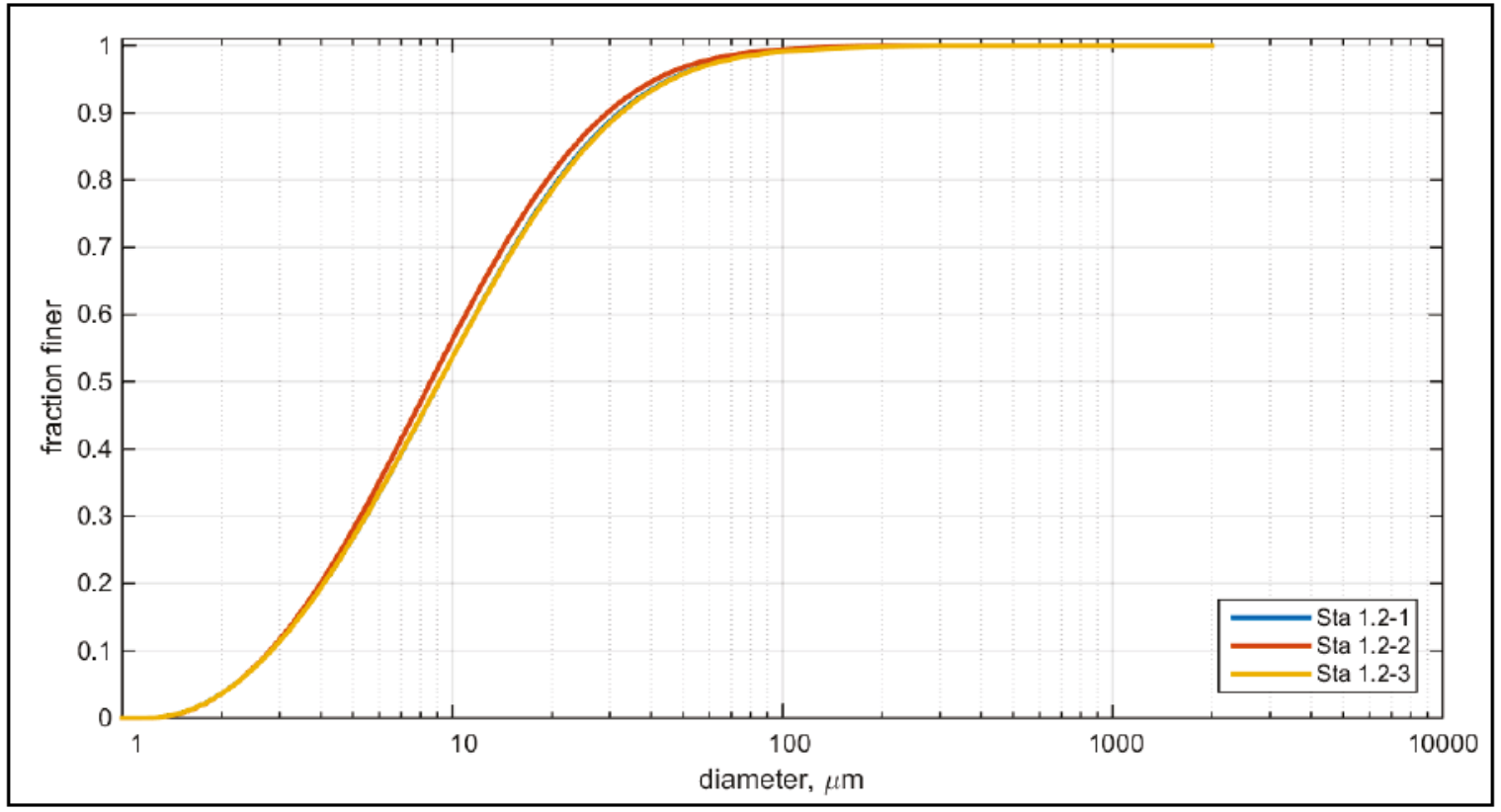

Figure A-2b.Grain size distributions for Station 1-2 physical sample.

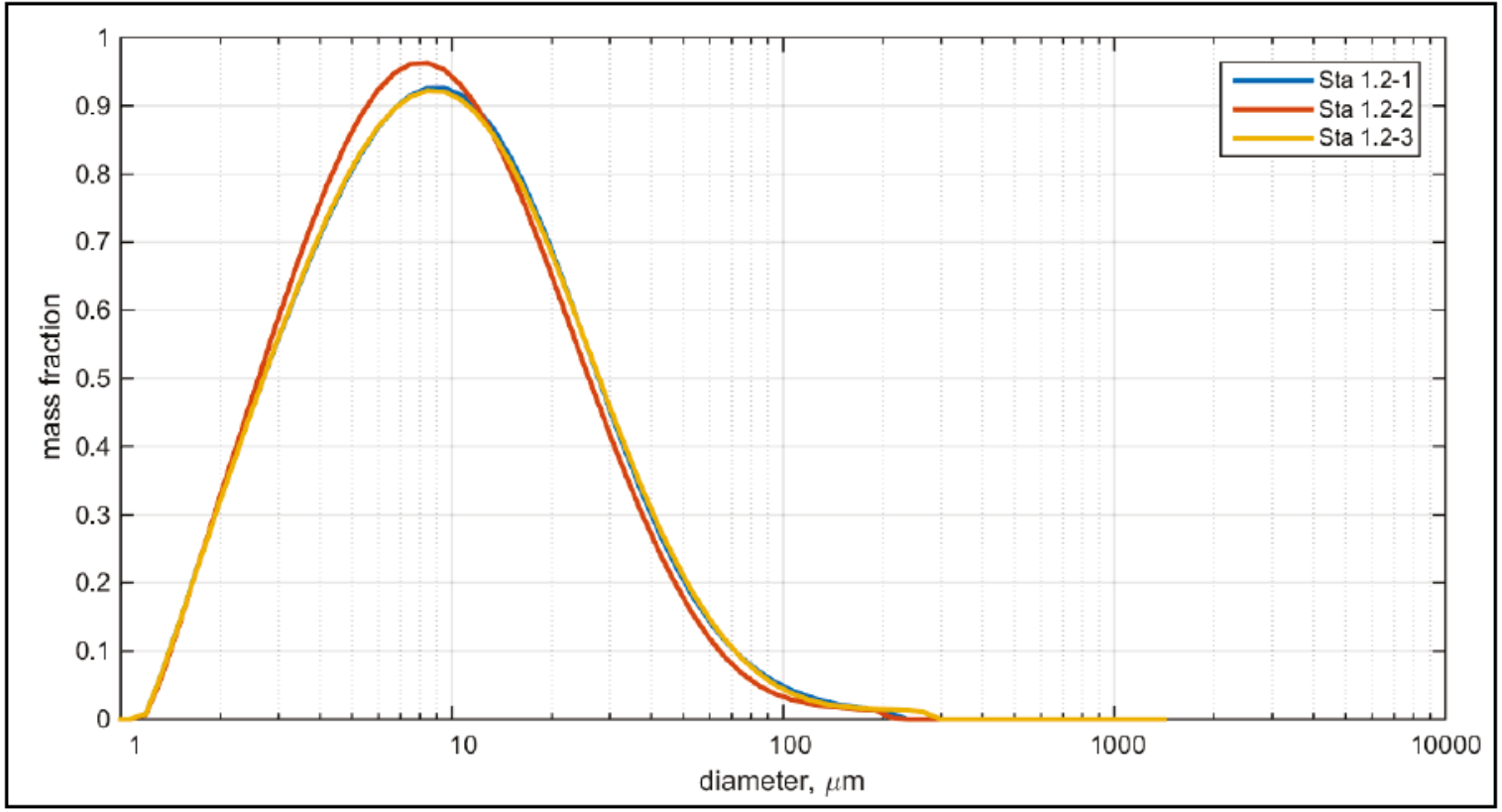


ERDC/CHL TR-20-11

77

Figure A-2c. Bulk density profile for core Station 1-2.

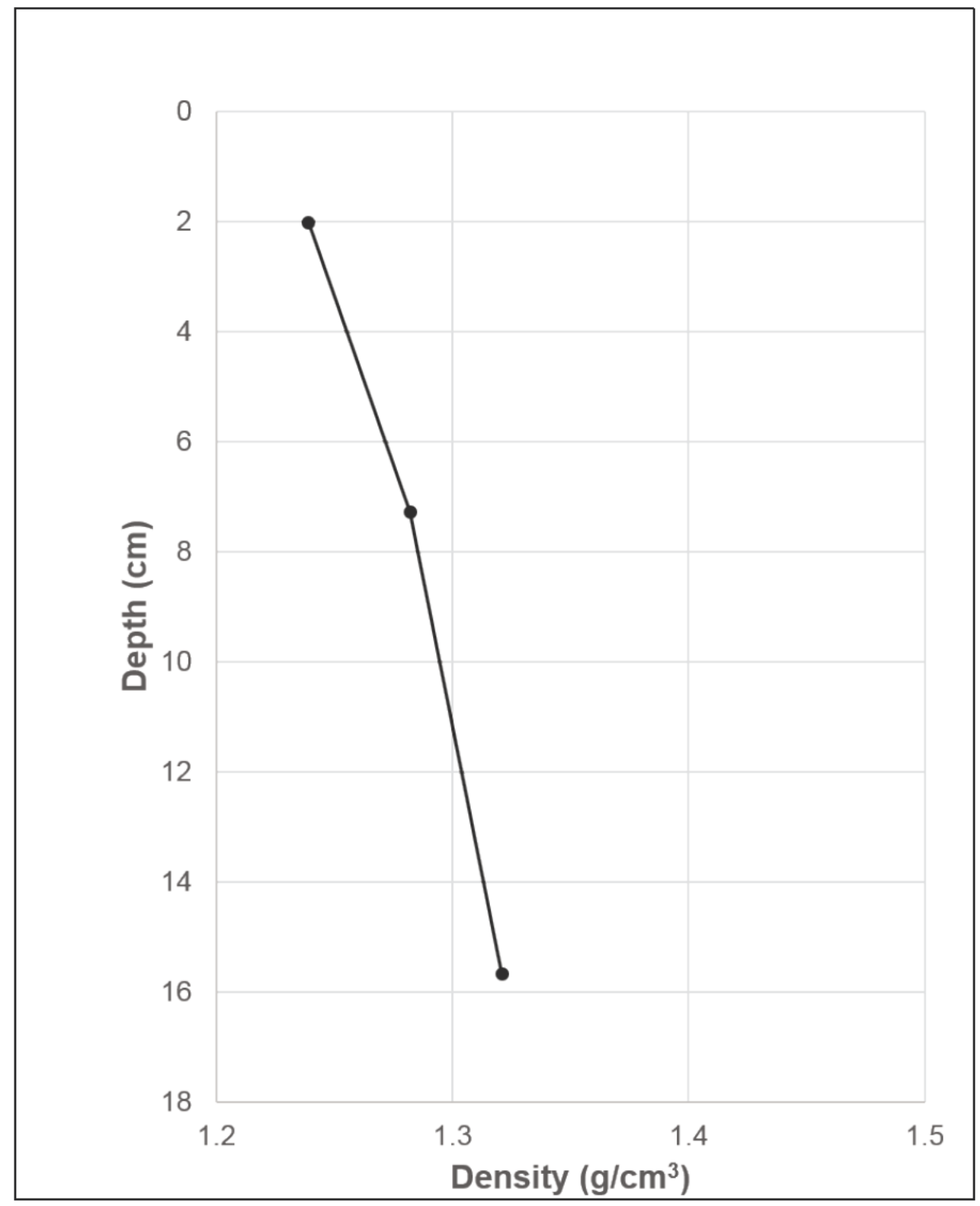


Table A-3a. Core Description, Station 2.

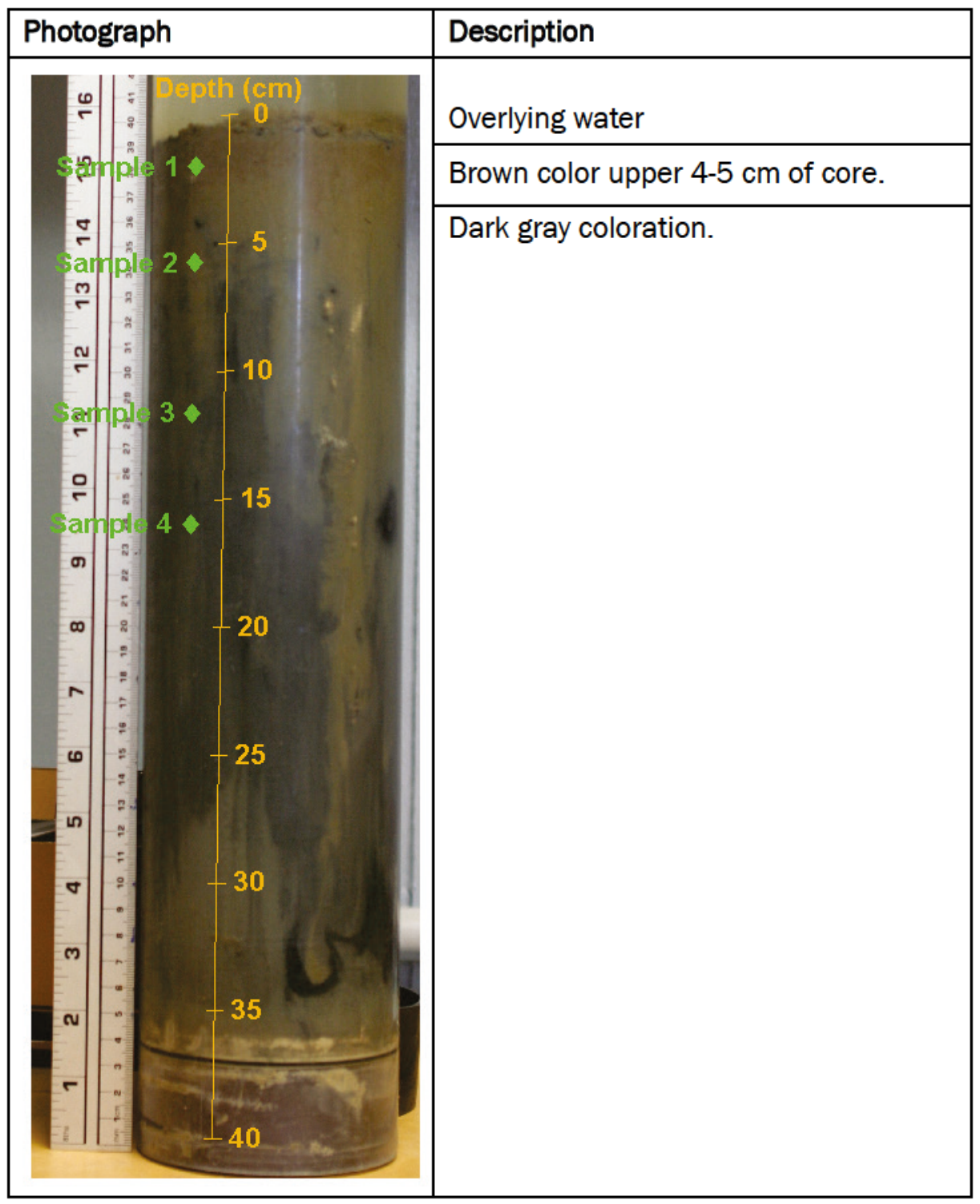


Table A-3b. Core Surface Photographs, Station 2.

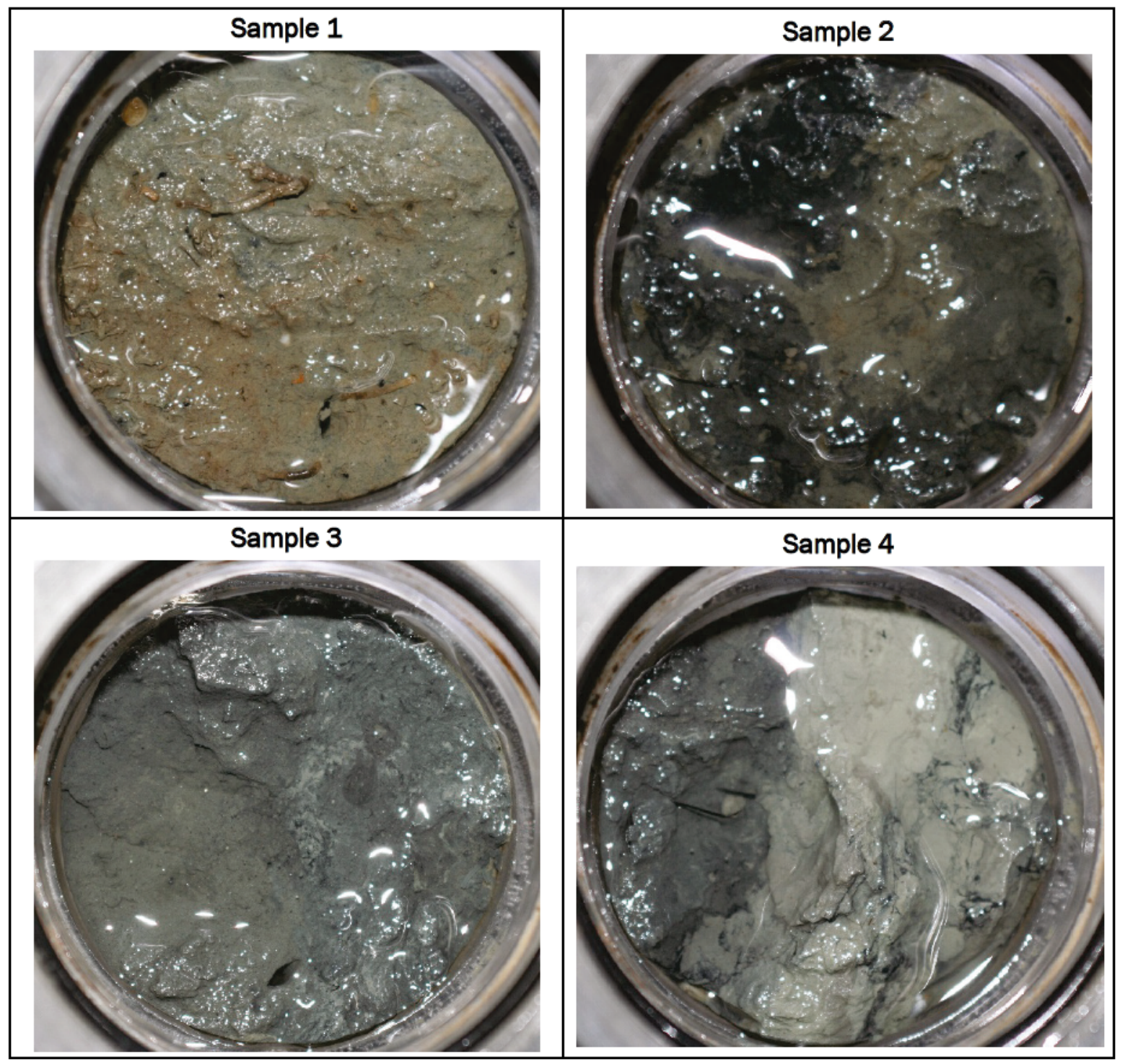

Table A-3c. Physical Sample Properties, Station 2.

\begin{tabular}{|c|c|c|c|c|c|c|c|c|}
\hline $\begin{array}{c}\text { Sample } \\
\#\end{array}$ & $\begin{array}{c}\text { Depth } \\
(\mathbf{c m})\end{array}$ & $\begin{array}{c}\text { Bulk } \\
\text { Density } \\
\left(\mathbf{g} / \mathbf{c m}^{3}\right)\end{array}$ & $\begin{array}{c}\mathbf{d}_{10} \\
(\mu \mathrm{m})\end{array}$ & $\begin{array}{c}\mathbf{d}_{50} \\
(\mu \mathrm{m})\end{array}$ & $\begin{array}{c}\mathbf{d}_{90} \\
(\mu \mathrm{m})\end{array}$ & \% Sand & \% Silt & \% Clay \\
\hline 1 & 2.02 & 1.41 & 3.47 & 19.07 & 106.48 & 20.4 & 66.7 & 12.8 \\
\hline 2 & 5.77 & 1.34 & 3.50 & 13.57 & 76.22 & 13.0 & 74.1 & 12.9 \\
\hline 3 & 11.65 & 1.35 & 3.10 & 11.77 & 77.40 & 12.6 & 71.3 & 16.1 \\
\hline 4 & 15.97 & 1.26 & 2.64 & 8.86 & 54.48 & 8.7 & 69.3 & 22.0 \\
\hline
\end{tabular}


Figure A-3a. Cumulative grain size distributions for Station 2 physical samples.

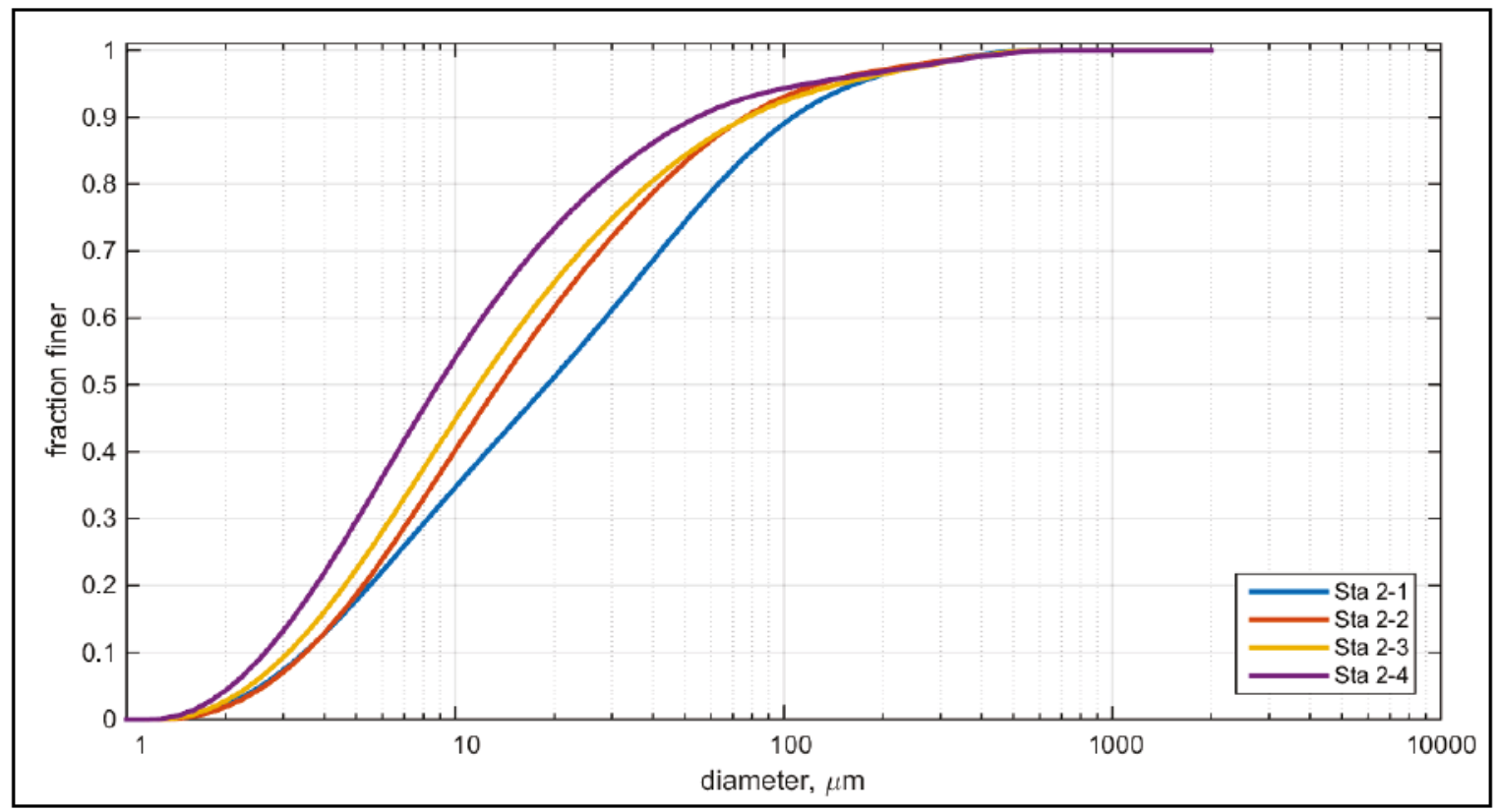

Figure A-3b. Grain size distributions for Station 2 physical samples.

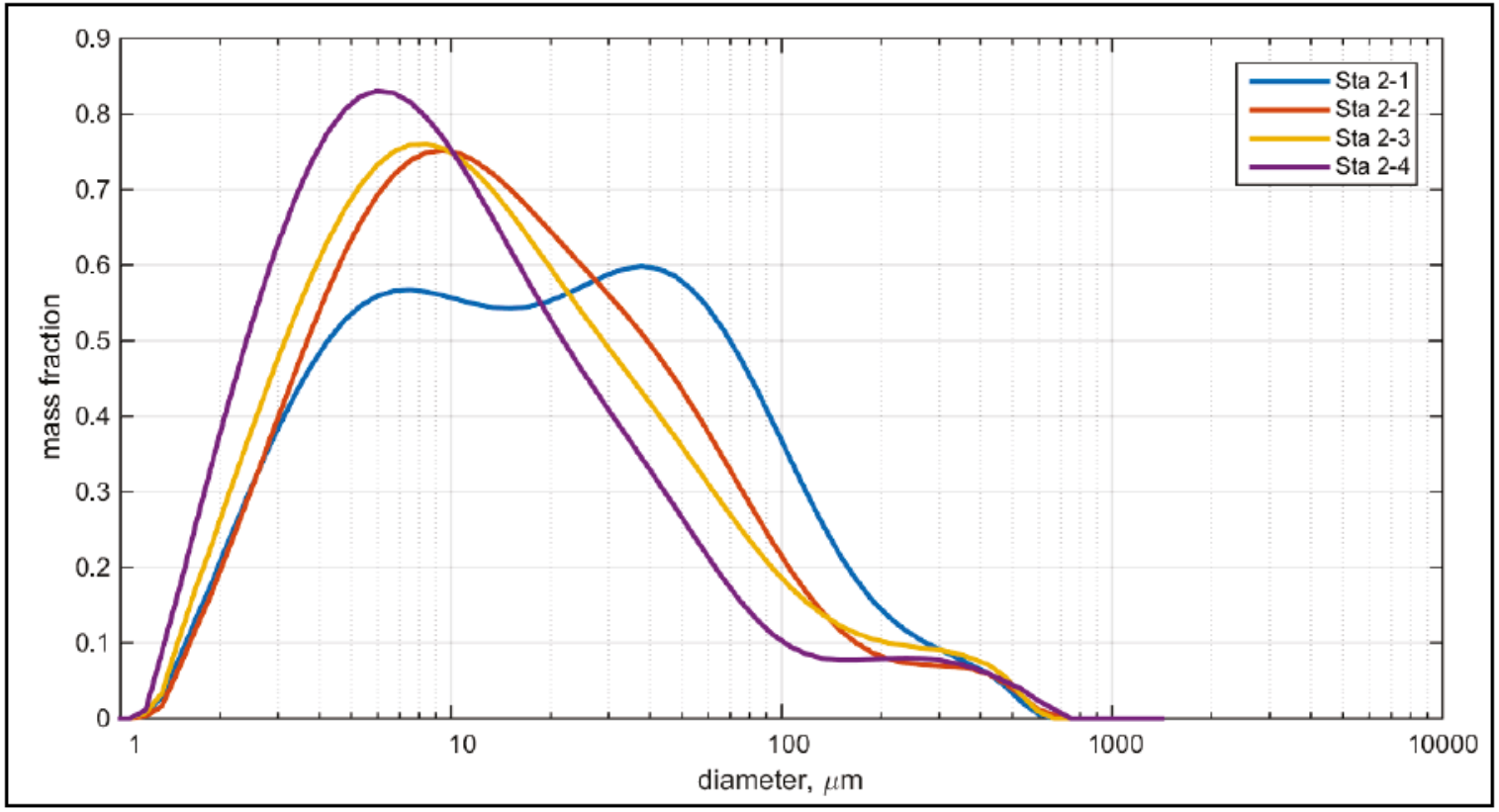


Figure A-3c. Bulk density profile for core Station 2.

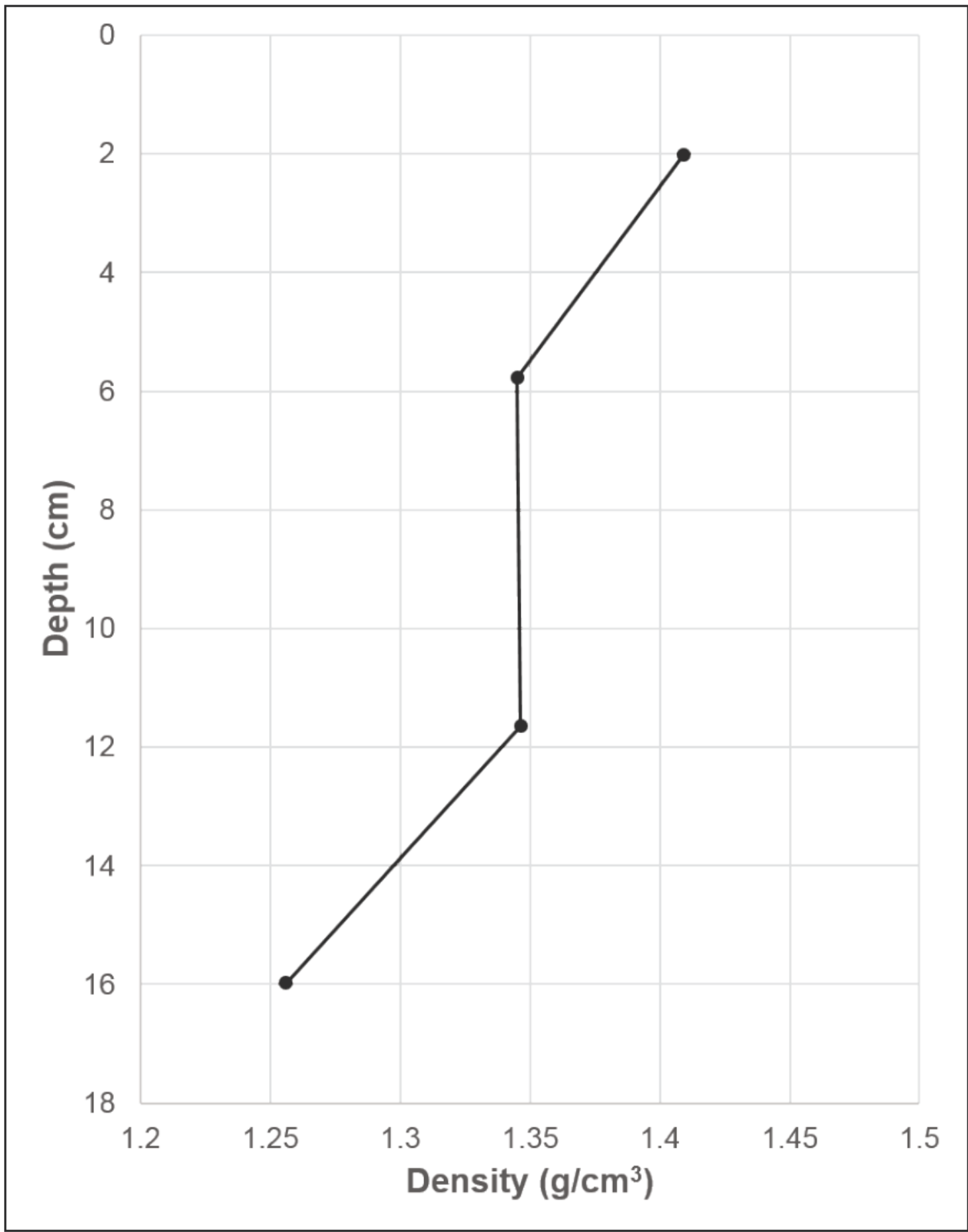


Table A-4a. Core Description, Station 4.

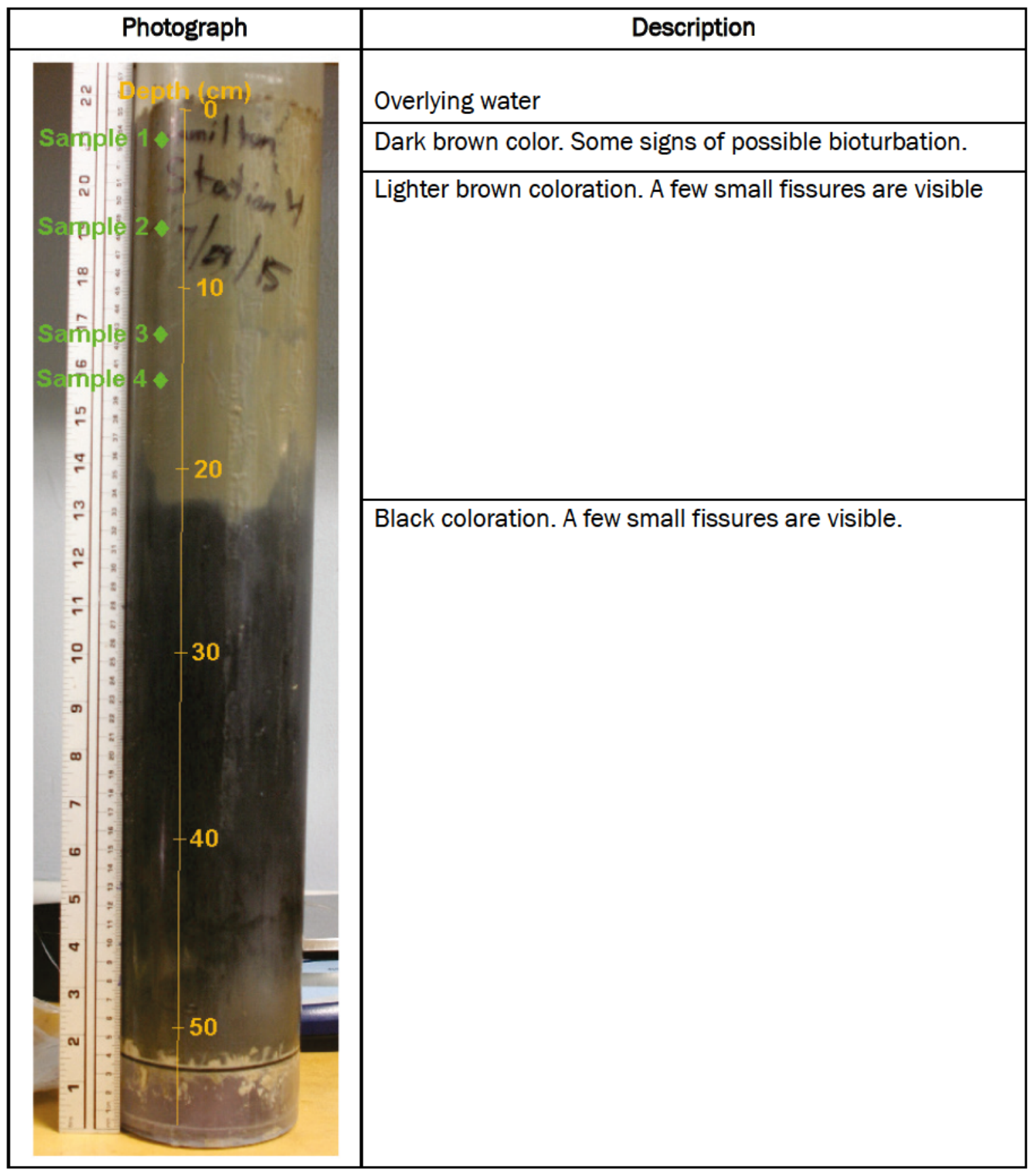


Table A-4b. Core Surface Photographs, Station 4.

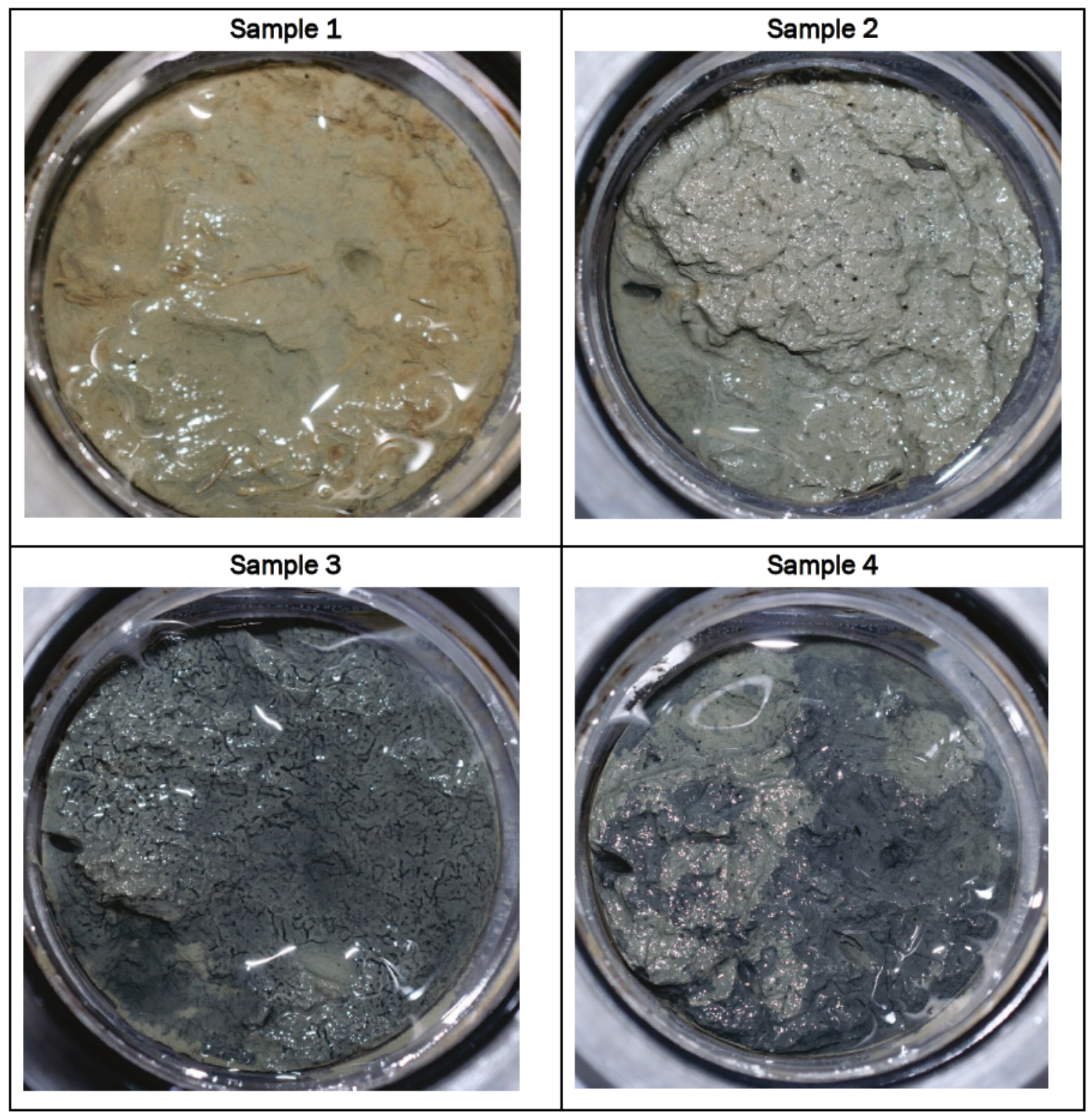


Table A-4c. Physical Sample Properties, Station 4.

\begin{tabular}{|c|c|c|c|c|c|c|c|c|}
\hline $\begin{array}{c}\text { Sample } \\
\#\end{array}$ & $\begin{array}{c}\text { Depth } \\
(\mathbf{c m})\end{array}$ & $\begin{array}{c}\text { Bulk } \\
\text { Density } \\
\left(\mathrm{g} / \mathrm{cm}^{3}\right)\end{array}$ & $\mathbf{d}_{10}(\mu \mathrm{m})$ & $\mathbf{d}_{50}(\mu \mathrm{m})$ & $\mathbf{d}_{90}(\mu \mathrm{m})$ & \% Sand & \% Silt & \% Clay \\
\hline 1 & 1.80 & 1.24 & 2.88 & 10.21 & 44.85 & 6.0 & 75.6 & 18.4 \\
\hline 2 & 6.77 & 1.24 & 2.79 & 9.18 & 36.79 & 4.1 & 76.1 & 19.7 \\
\hline 3 & 12.70 & 1.27 & 2.75 & 8.93 & 38.49 & 4.5 & 75.0 & 20.5 \\
\hline 4 & 15.20 & 1.26 & 2.47 & 7.51 & 28.58 & 2.4 & 72.4 & 25.2 \\
\hline
\end{tabular}

Figure A-4a. Cumulative grain size distributions for Station 4 physical samples.

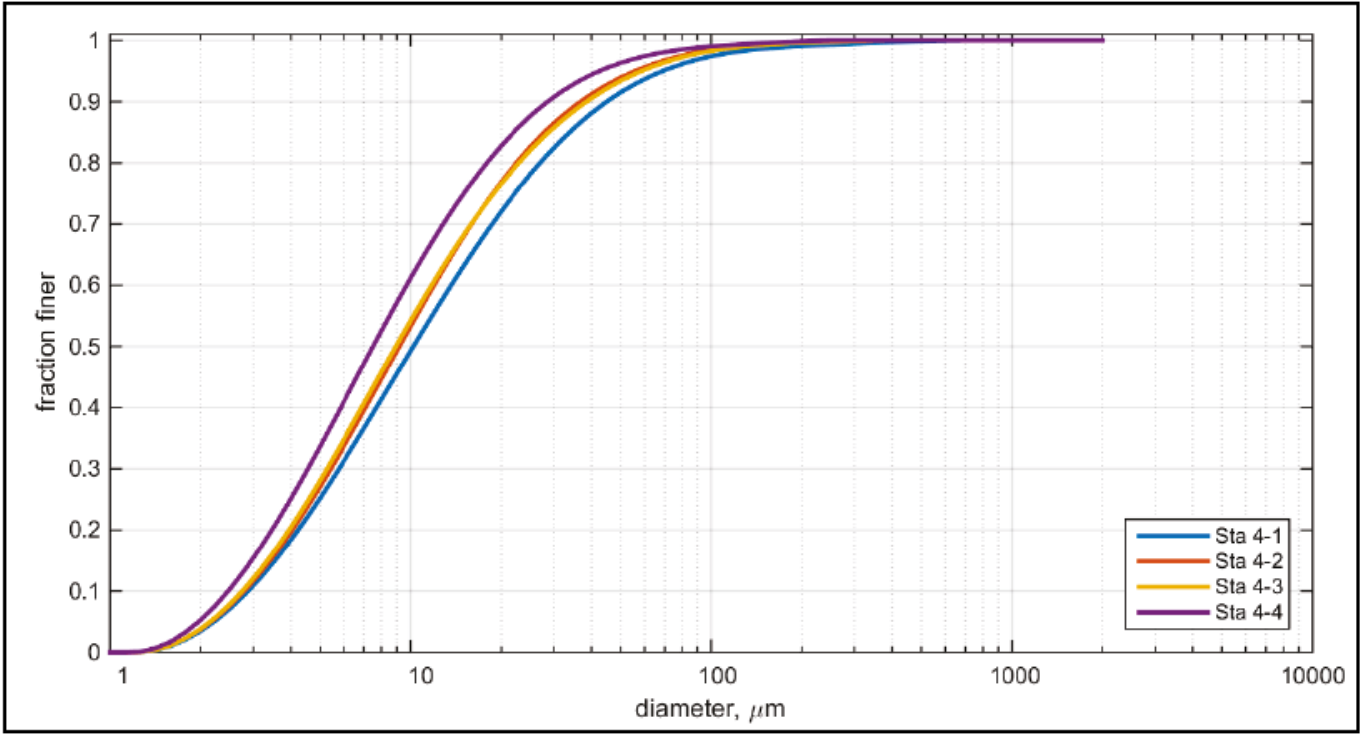

Figure A-4b. Grain size distributions for Station 4 physical samples.

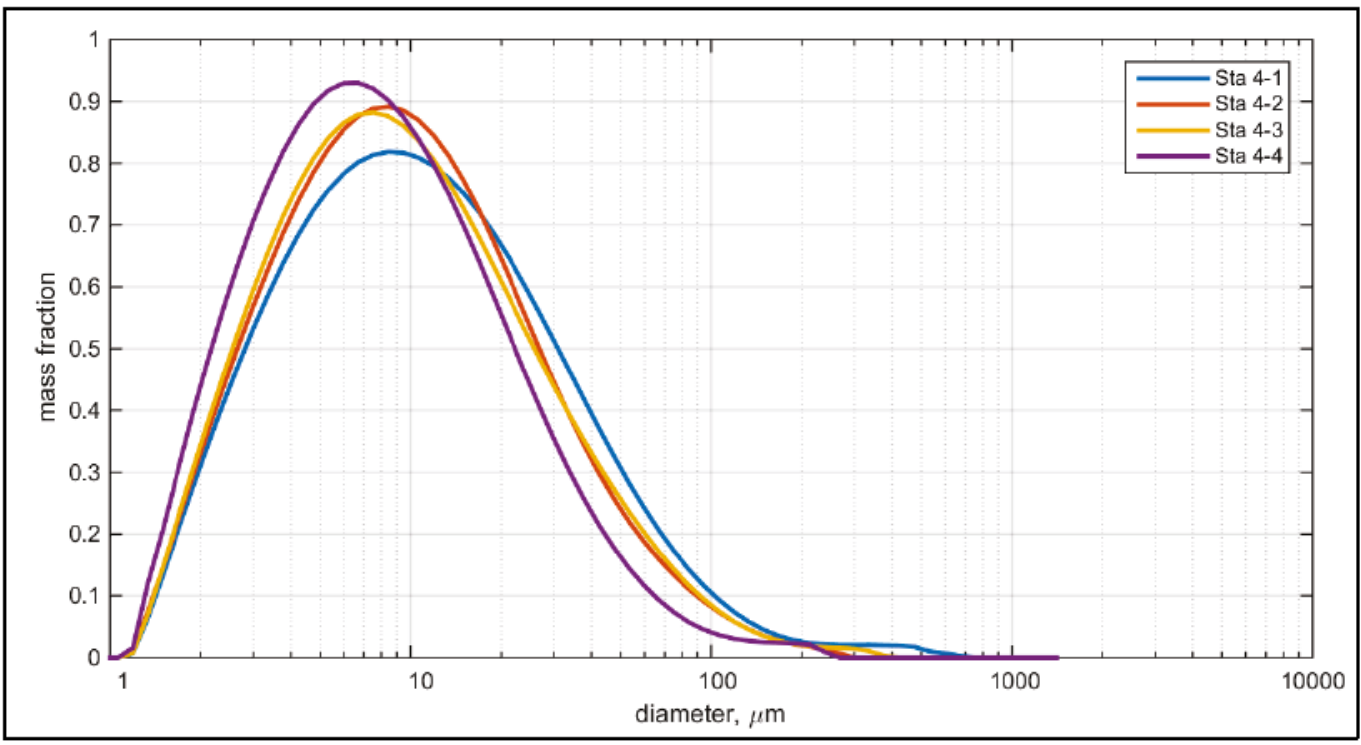


Figure A-4c. Bulk density profile for core SF-4.

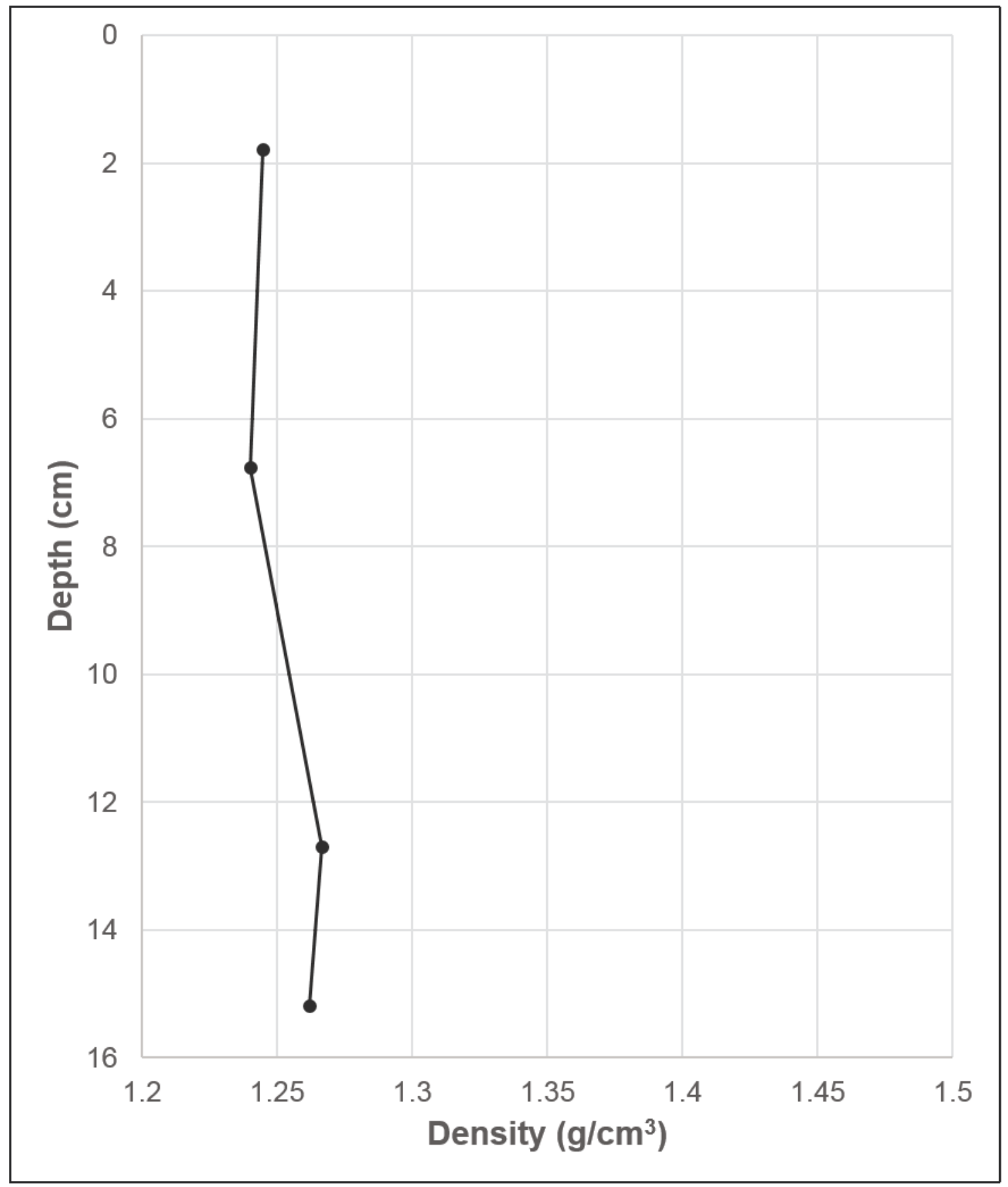


Table A-5a. Core Description, Station 5-N.

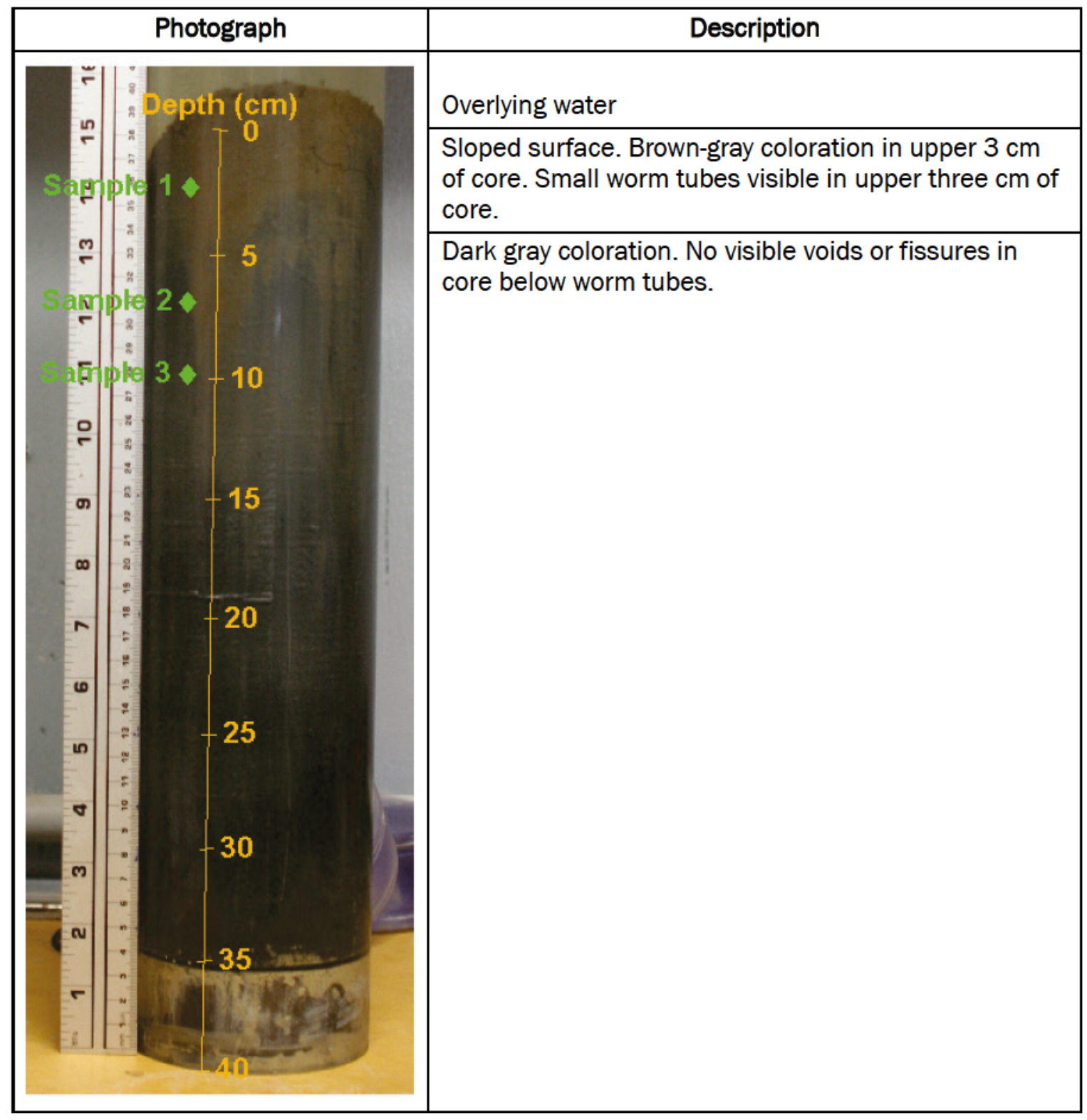


Table A-5b. Core Surface Photographs, Station 5-N.

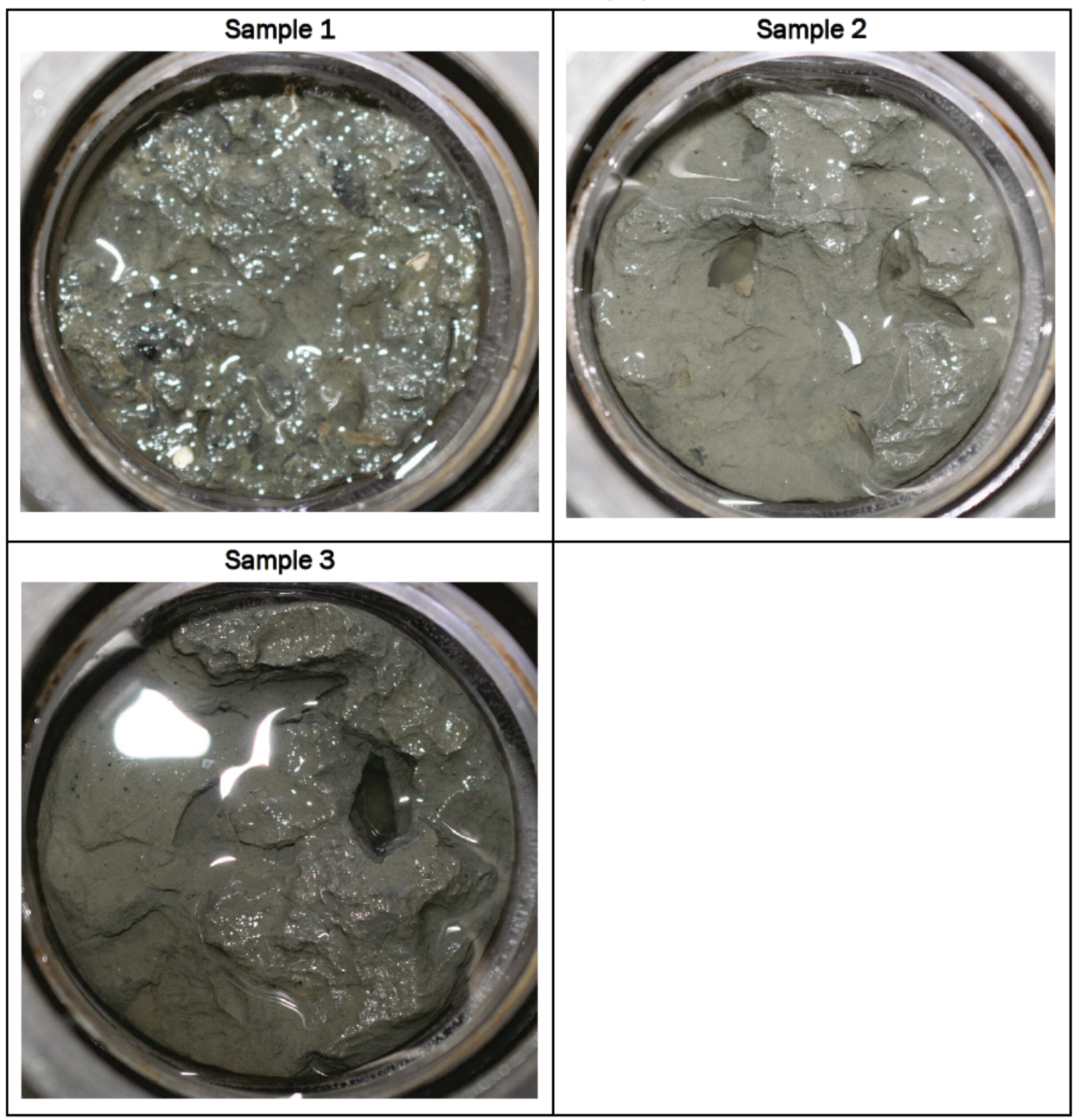

Table A-5c. Physical Sample Properties, Station 5-N.

\begin{tabular}{|c|c|c|c|c|c|c|c|c|}
\hline $\begin{array}{c}\text { Sample } \\
\#\end{array}$ & $\begin{array}{c}\text { Depth } \\
(\mathbf{c m})\end{array}$ & $\begin{array}{c}\text { Bulk } \\
\text { Density } \\
\left(\mathbf{g} / \mathbf{c m}^{3}\right)\end{array}$ & $\mathbf{d}_{10}(\mu \mathrm{m})$ & $\mathbf{d}_{50}(\mu \mathrm{m})$ & $\mathbf{d}_{90}(\mu \mathrm{m})$ & \% Sand & \% Silt & \% Clay \\
\hline 1 & 2.40 & 1.44 & 3.14 & 11.47 & 50.02 & 6.9 & 77.2 & 15.9 \\
\hline 2 & 7.00 & 1.40 & 3.25 & 12.41 & 48.49 & 6.4 & 78.7 & 14.8 \\
\hline 3 & 9.90 & 1.31 & 3.38 & 12.77 & 51.90 & 7.3 & 78.8 & 13.9 \\
\hline
\end{tabular}


Figure A-5a. Cumulative grain size distributions for Station 5-N physical samples.

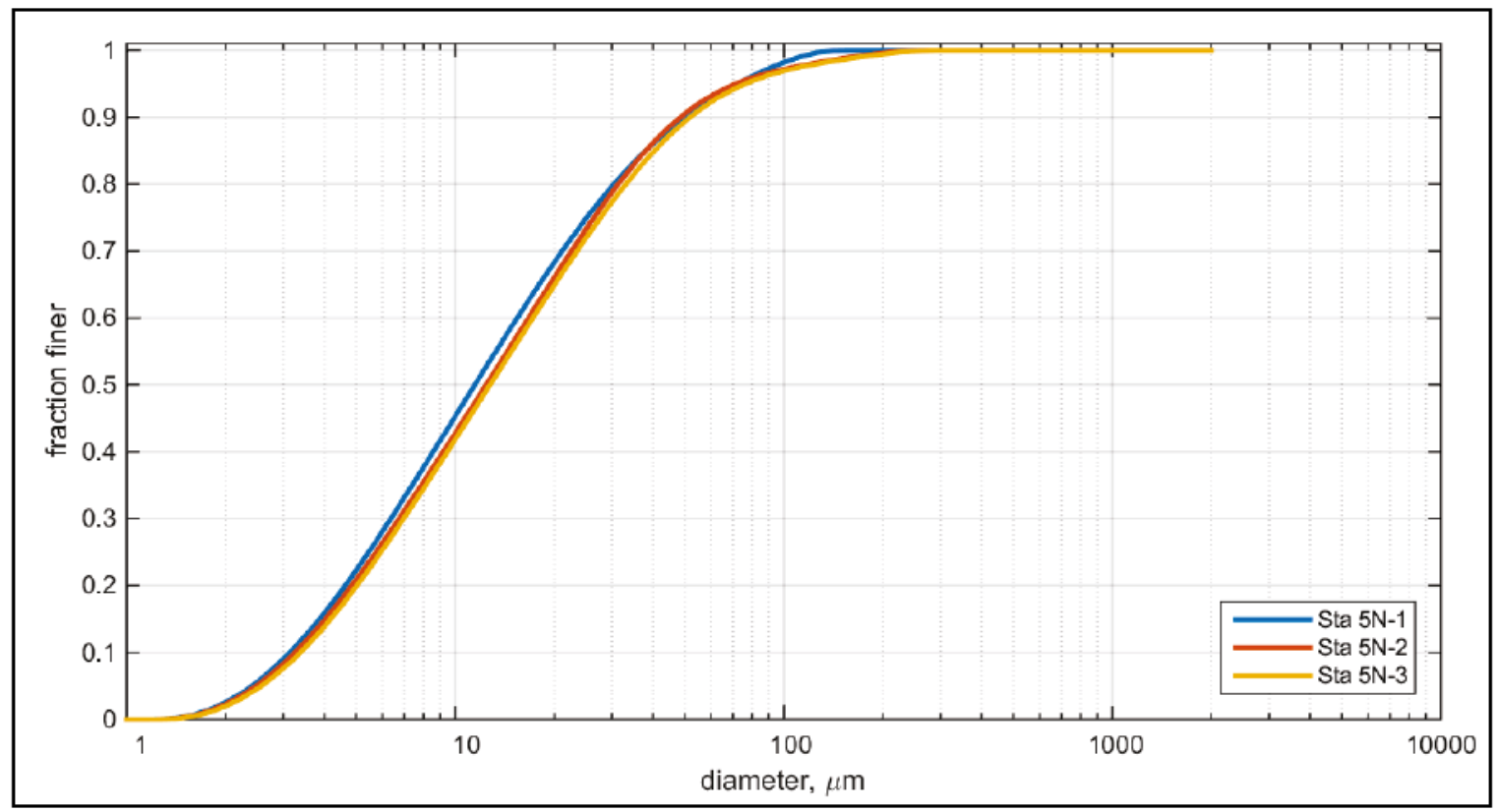

Figure A-5b. Grain size distributions for Station 5-N physical samples.

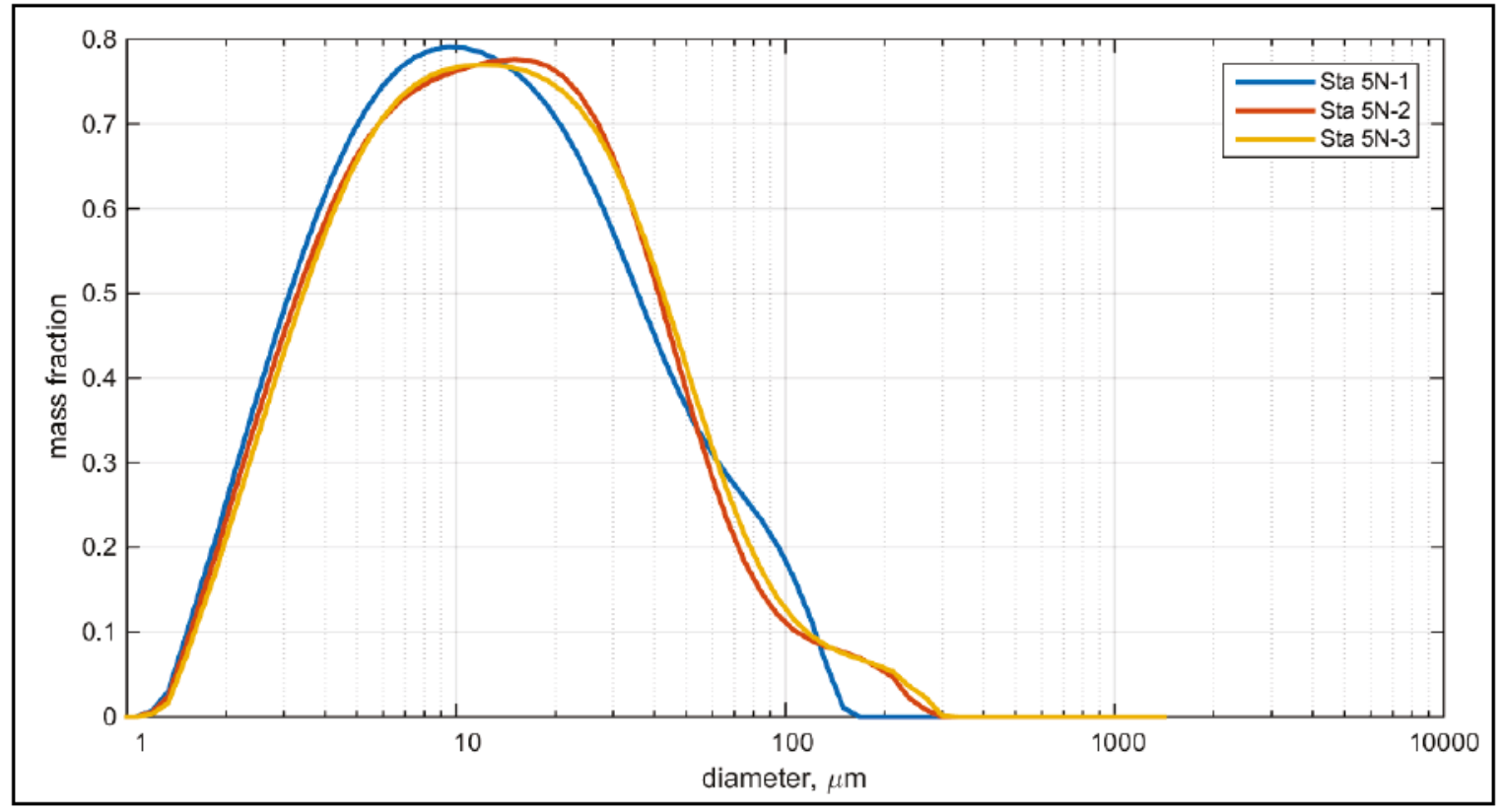


Figure A-5c. Bulk density profile for core Station 5-N.

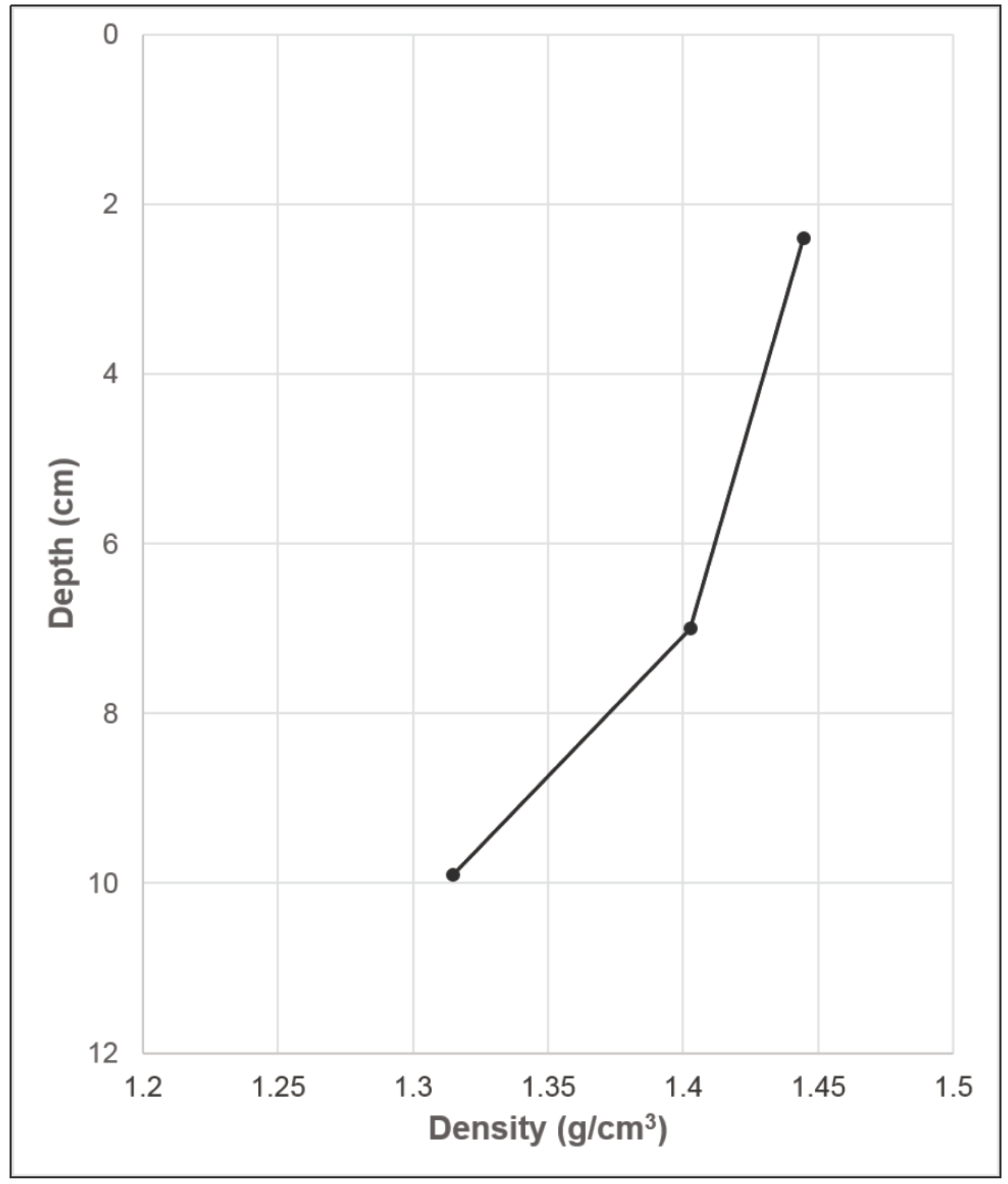




\section{Appendix B: Sedflume Erosion Data and Analysis}

Appendix B contains Sedflume erosion rate data and analysis results for Hamilton Wetlands Sedflume experiments. The appendix is presented in two parts: (1) erosion versus depth and (2) erosion data fits to cohesive sediment erosion function, $\mathrm{E}=\mathrm{A} \tau^{\mathrm{n}}$. 


\section{Erosion versus Depth}

Figure B-1. Erosion versus depth for core Station 1. Colors indicate bed layers; symbols indicate applied shear stress.

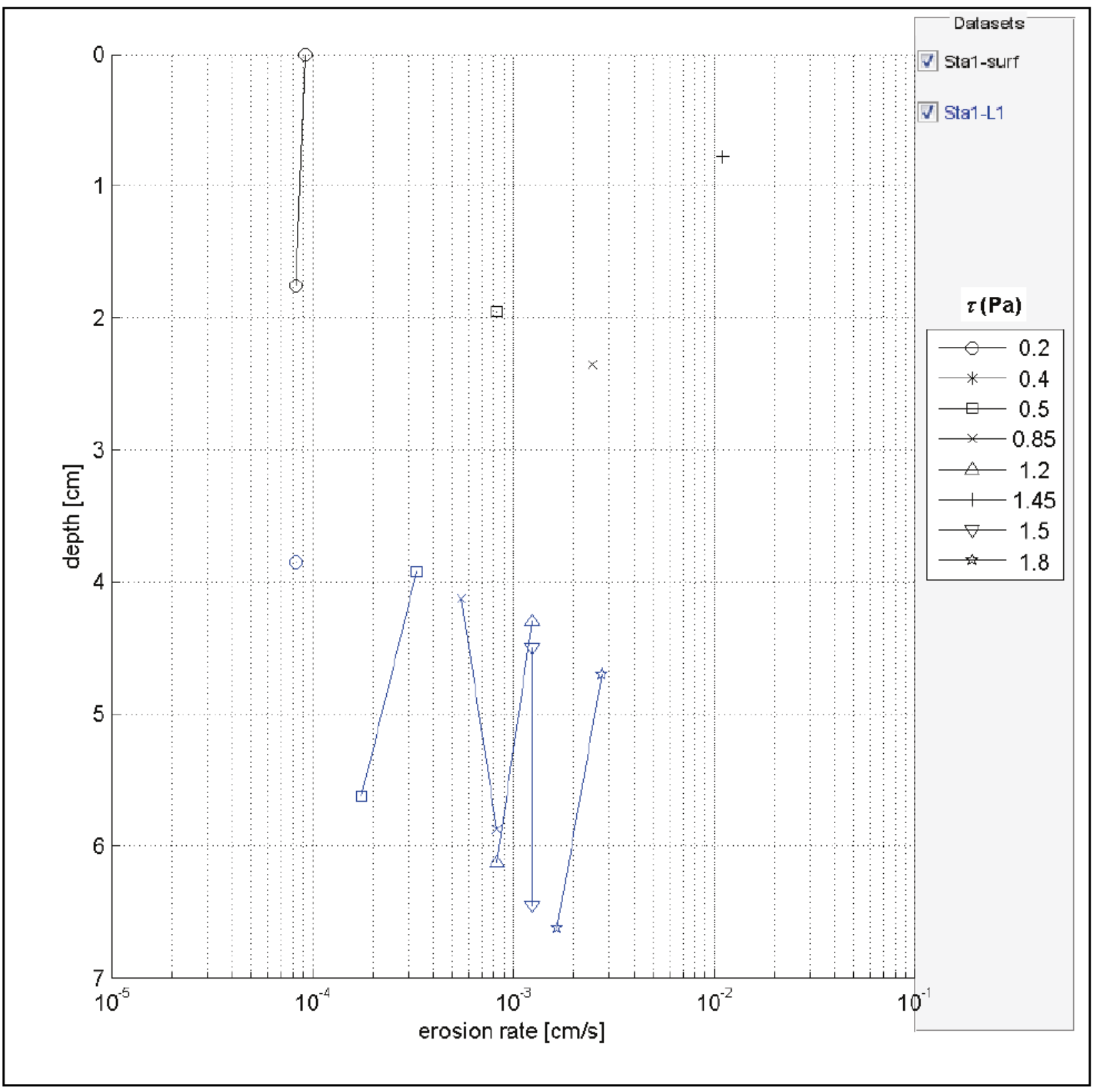


Figure B-2. Erosion versus depth for core Station 1-2. Colors indicate bed layers; symbols indicate applied shear stress.

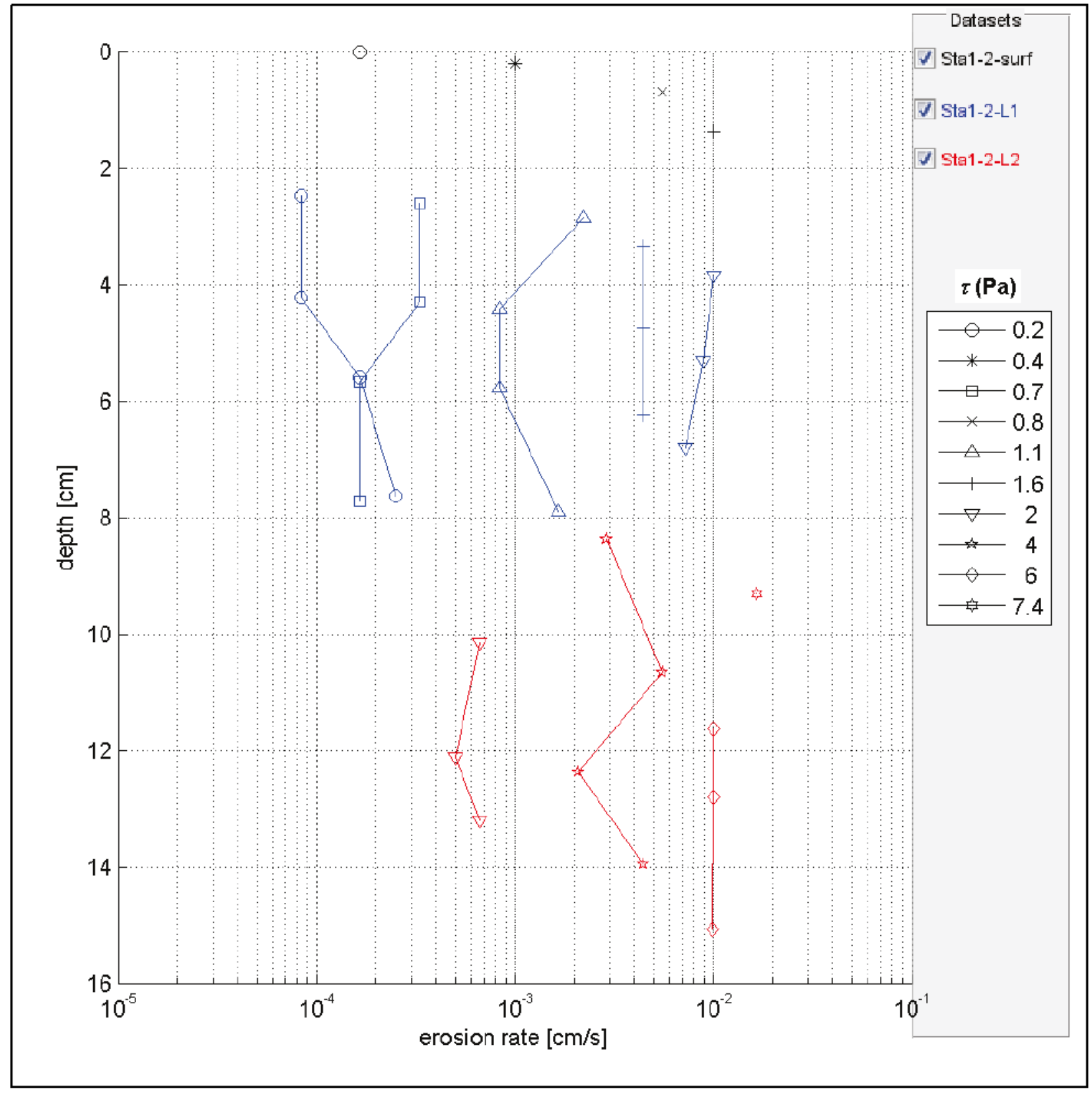


Figure B-3. Erosion versus depth for combined cores from Station 1. Colors indicate bed layers; symbols indicate applied shear stress.

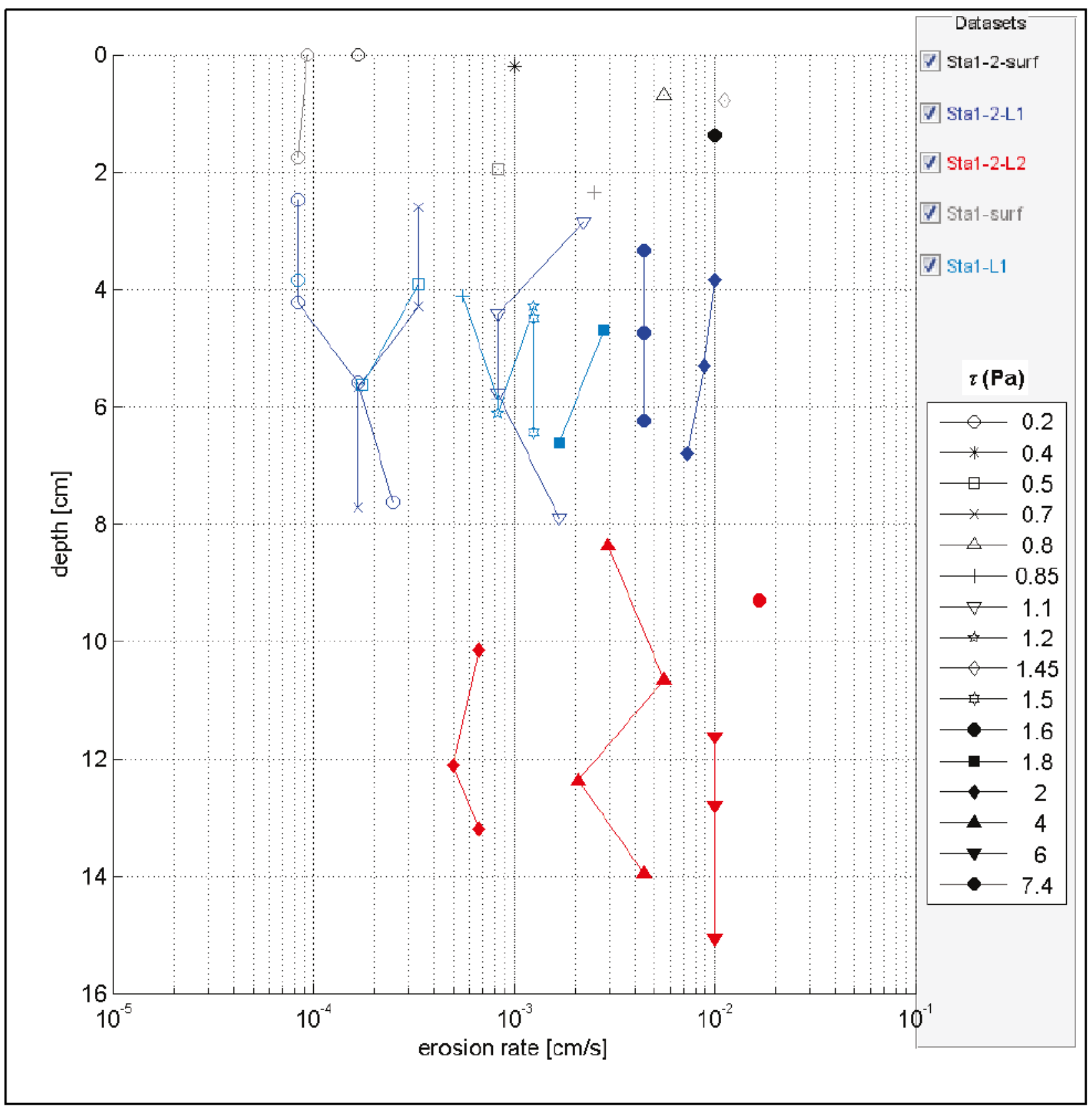


Figure B-4. Erosion versus depth for core Station 2. Colors indicate bed layers; symbols indicate applied shear stress.

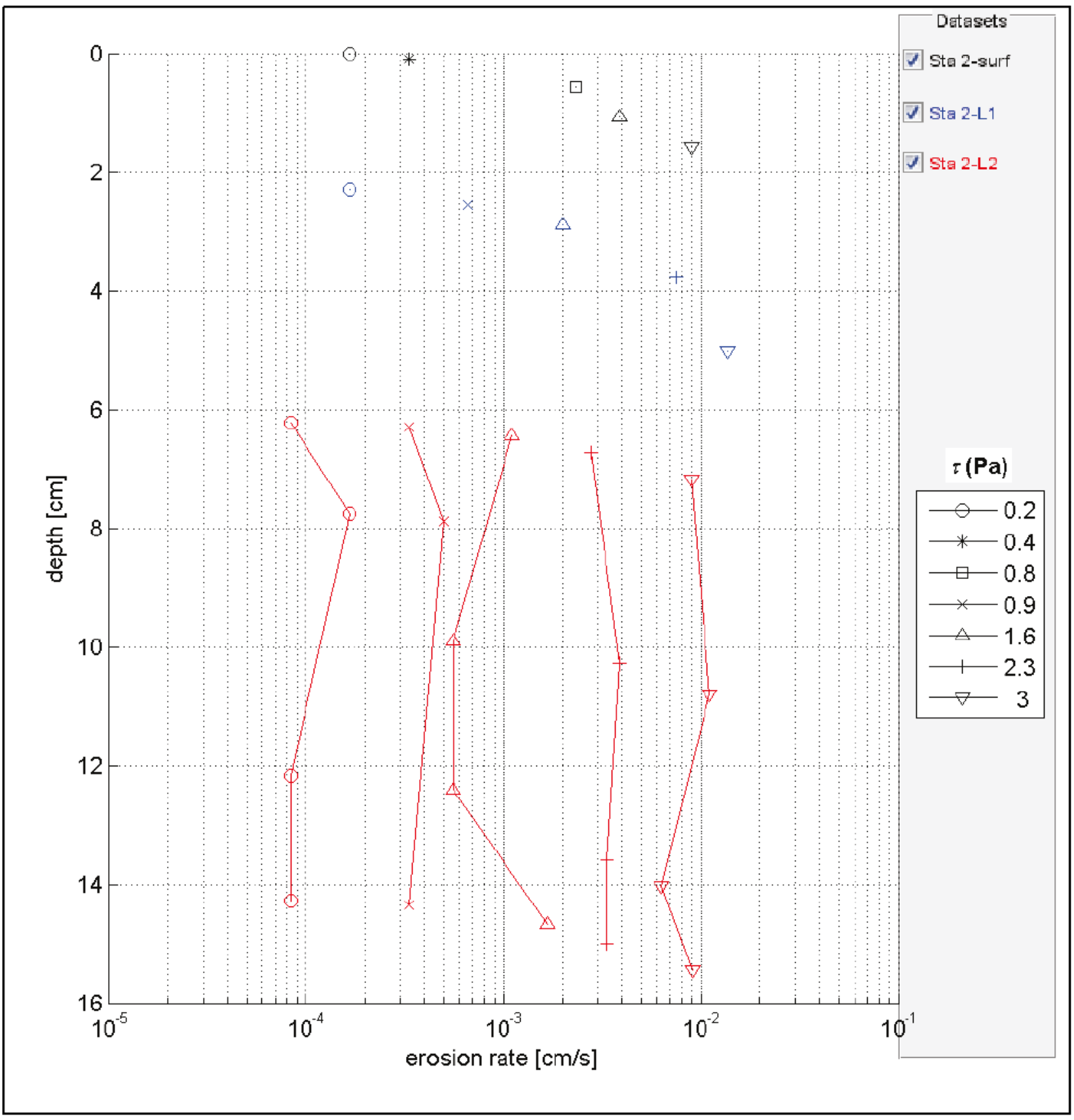


Figure B-5. Erosion versus depth for core Station 4. Colors indicate bed layers; symbols indicate applied shear stress.

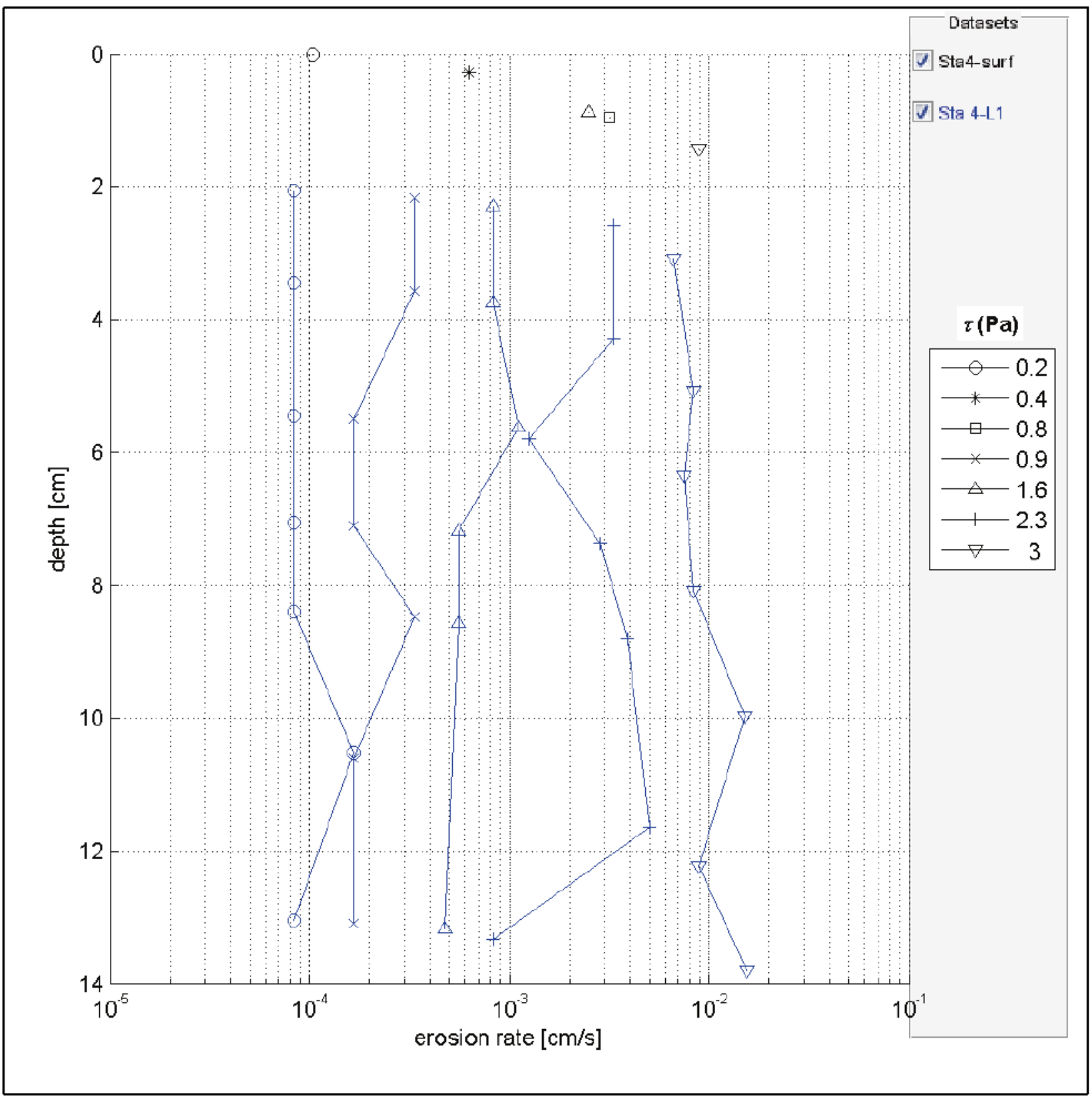


Figure B-6. Erosion versus depth for core Station 5-N. Colors indicate bed layers; symbols indicate applied shear stress.

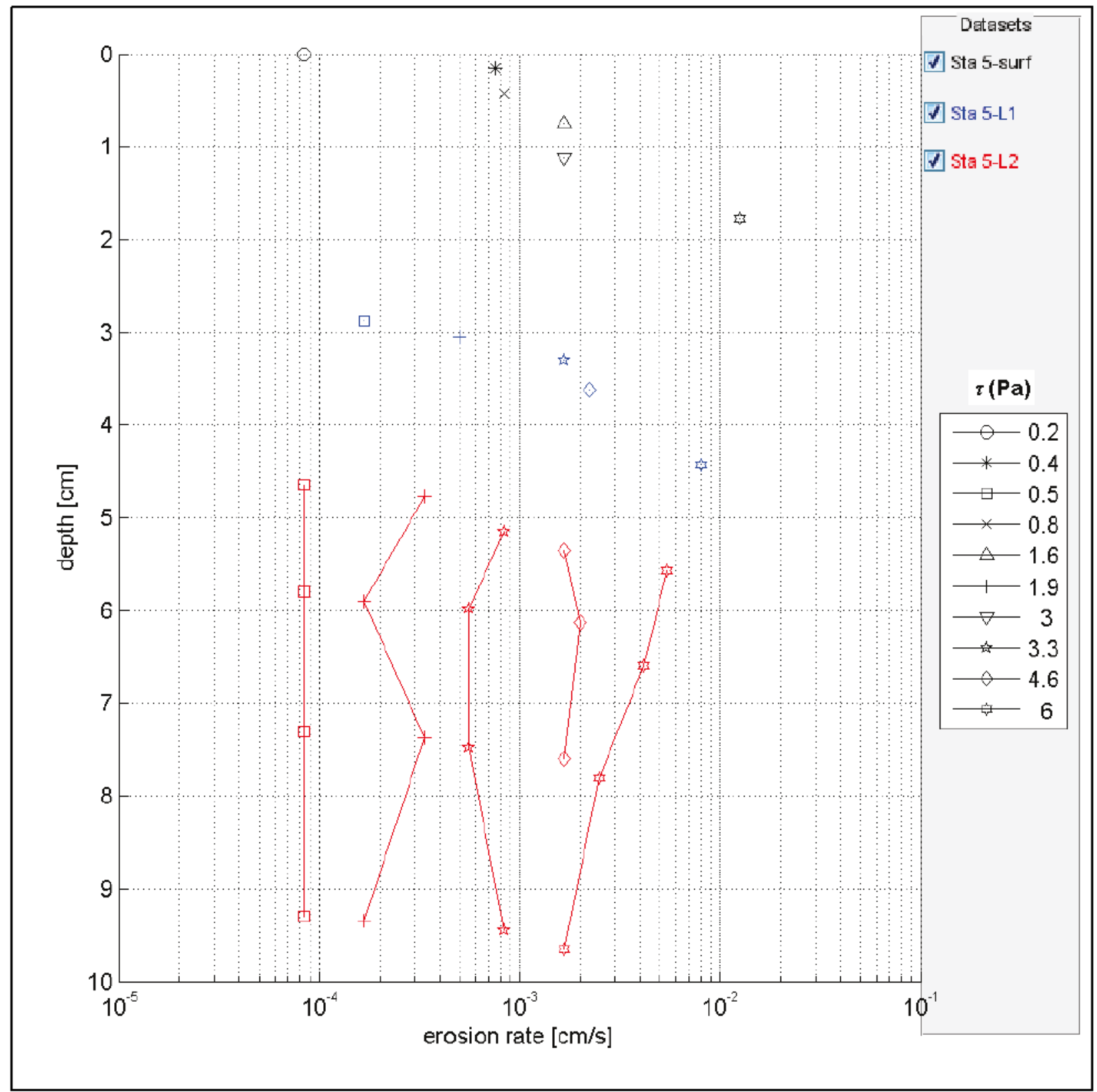


ERDC/CHL TR-20-11

97

Erosion versus shear stress

Core Station 1

Table B-1. Cohesive erosion parametrization.

\begin{tabular}{|c|c|c|c|c|c|c|c|}
\hline $\begin{array}{c}\text { Layer } \\
\text { ID }\end{array}$ & $\begin{array}{c}\text { Depth } \\
(\mathrm{cm})\end{array}$ & $\begin{array}{c}\tau_{\mathrm{c}} \\
(\mathrm{Pa})\end{array}$ & $\begin{array}{c}\tau_{\mathrm{m}} \\
(\mathrm{Pa})\end{array}$ & $\boldsymbol{A}$ & $\mathrm{n}$ & $\begin{array}{c}\tau_{\mathrm{c}}(\mathrm{Pa}) \\
\text { low }\end{array}$ & $\begin{array}{c}\tau_{\mathrm{c}}(\mathrm{Pa}) \\
\text { high }\end{array}$ \\
\hline Surface & $<3$ & 0.21 & 1.79 & $4.20 \mathrm{E}-03$ & 2.41 & 0.19 & 0.22 \\
\hline LI & $4-7$ & 0.25 & 7.87 & $8.00 \mathrm{E}-04$ & 1.48 & 0.22 & 0.28 \\
\hline
\end{tabular}

Figure B-7. Erosion versus applied shear stress for core Station 1. Colors indicate bed layers. Solid lines represent the linearized best-fit of $E=A$ t $\tau^{n}$ to the data. Dashed lines indicate the $95 \%$ confidence interval of the fit line.

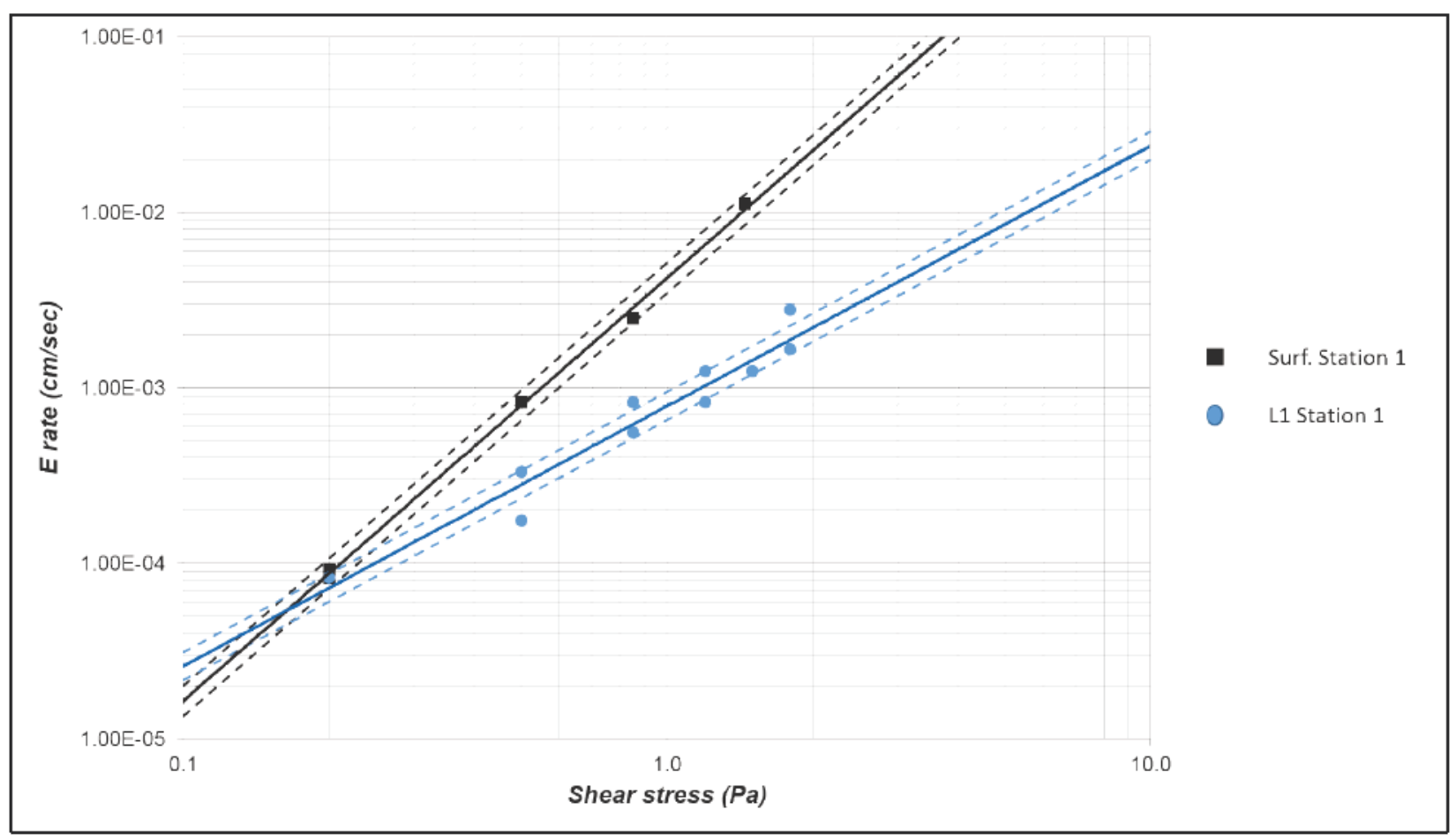




\section{Core Station 1-2}

Table B-2. Cohesive erosion parameterization,

\begin{tabular}{|c|c|c|c|c|c|c|c|}
\hline $\begin{array}{c}\text { Layer } \\
\text { ID }\end{array}$ & $\begin{array}{c}\text { Depth } \\
(\mathbf{c m})\end{array}$ & $\begin{array}{c}\tau_{\mathrm{c}} \\
(\mathrm{Pa})\end{array}$ & $\begin{array}{c}\tau_{\mathrm{m}} \\
(\mathrm{Pa})\end{array}$ & $\boldsymbol{A}$ & $\mathrm{n}$ & $\begin{array}{c}\tau_{\mathrm{c}}(\mathrm{Pa}) \\
\text { low }\end{array}$ & $\begin{array}{c}\tau_{\mathrm{c}}(\mathrm{Pa}) \\
\text { high }\end{array}$ \\
\hline Surface & $<2$ & 0.14 & 1.75 & $5.50 \mathrm{E}-03$ & 2.01 & - & - \\
\hline L1 & $2-8$ & 0.23 & 4.29 & $1.30 \mathrm{E}-03$ & 1.76 & 0.18 & 0.29 \\
\hline L2 & $>8$ & 1.00 & 7.52 & $1.00 \mathrm{E}-04$ & 2.54 & 0.79 & 1.23 \\
\hline
\end{tabular}

Figure B-8. Erosion versus applied shear stress for core Station 1-2. Colors indicate bed layers. Solid lines represent the linearized best-fit of $E=A \tau^{n}$ to the data. Dashed lines indicate the $95 \%$ confidence interval of the fit line. No dashed lines are present for the surface layer due to low number of observations $(\mathrm{N}<4)$.






\section{Combined Station 1 Cores}

Table B-3. Cohesive erosion parameterization.

\begin{tabular}{|c|c|c|c|c|c|c|c|}
\hline $\begin{array}{c}\text { Layer } \\
\text { ID }\end{array}$ & $\begin{array}{c}\text { Depth } \\
(\mathrm{cm})\end{array}$ & $\begin{array}{c}\tau_{\mathrm{c}} \\
(\mathrm{Pa})\end{array}$ & $\begin{array}{c}\tau_{\mathrm{m}} \\
(\mathrm{Pa})\end{array}$ & $A$ & $\mathrm{n}$ & $\begin{array}{c}\tau_{\mathrm{c}}(\mathrm{Pa}) \\
\text { low }\end{array}$ & $\begin{array}{c}\tau_{\mathrm{c}}(\mathrm{Pa}) \\
\text { high }\end{array}$ \\
\hline Surface & $<3$ & 0.18 & 1.74 & $4.80 \mathrm{E}-03$ & 2.27 & 0.15 & 0.22 \\
\hline L1 & $2-8$ & 0.24 & 5.20 & $1.10 \mathrm{E}-03$ & 1.66 & 0.20 & 0.28 \\
\hline L2 & $>8$ & 1.00 & 7.52 & $1.00 \mathrm{E}-04$ & 2.54 & 0.79 & 1.23 \\
\hline
\end{tabular}

Figure B-9. Erosion versus applied shear stress for combined Station 1 cores. Colors indicate bed layers. Solid lines represent the linearized best-fit of $E=A \tau^{n}$ to the data. Dashed lines indicate the $95 \%$ confidence interval of the fit line.

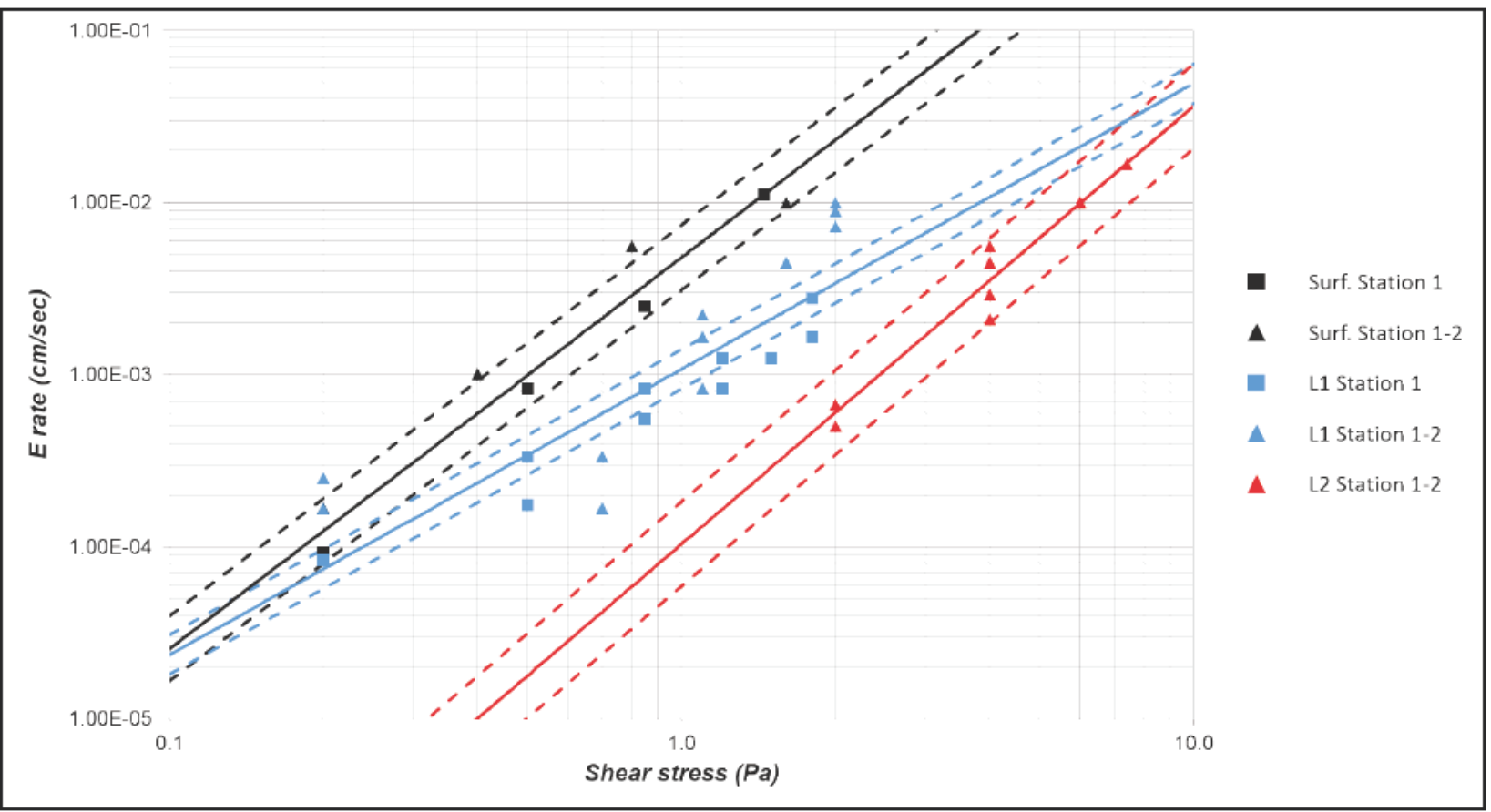




\section{Core Station 2}

Table B-4. Cohesive erosion parameterization.

\begin{tabular}{|c|c|c|c|c|c|c|c|}
\hline $\begin{array}{c}\text { Layer } \\
\text { ID }\end{array}$ & $\begin{array}{c}\text { Depth } \\
(\mathbf{c m})\end{array}$ & $\begin{array}{c}\tau_{\mathrm{c}} \\
(\mathrm{Pa})\end{array}$ & $\begin{array}{c}\tau_{\mathrm{m}} \\
(\mathrm{Pa})\end{array}$ & $\boldsymbol{A}$ & $\mathrm{n}$ & $\begin{array}{c}\tau_{\mathrm{c}}(\mathrm{Pa}) \\
\text { low }\end{array}$ & $\begin{array}{c}\tau_{\mathrm{c}}(\mathrm{Pa}) \\
\text { high }\end{array}$ \\
\hline Surface & $<2$ & 0.14 & 4.16 & $1.92 \mathrm{E}-03$ & 1.54 & 0.10 & 0.21 \\
\hline L1 & $2-6$ & 0.18 & 4.58 & $1.50 \mathrm{E}-03$ & 1.59 & 0.11 & 0.31 \\
\hline L2 & $>6$ & 0.26 & 7.33 & $8.00 \mathrm{E}-04$ & 1.53 & 0.21 & 0.31 \\
\hline
\end{tabular}

Figure B-10. Erosion versus applied shear stress for core Station 2. Colors indicate bed layers. Solid lines represent the linearized best-fit of $E=A \tau^{n}$ to the data. Dashed lines indicate the $95 \%$ confidence interval of the fit line.

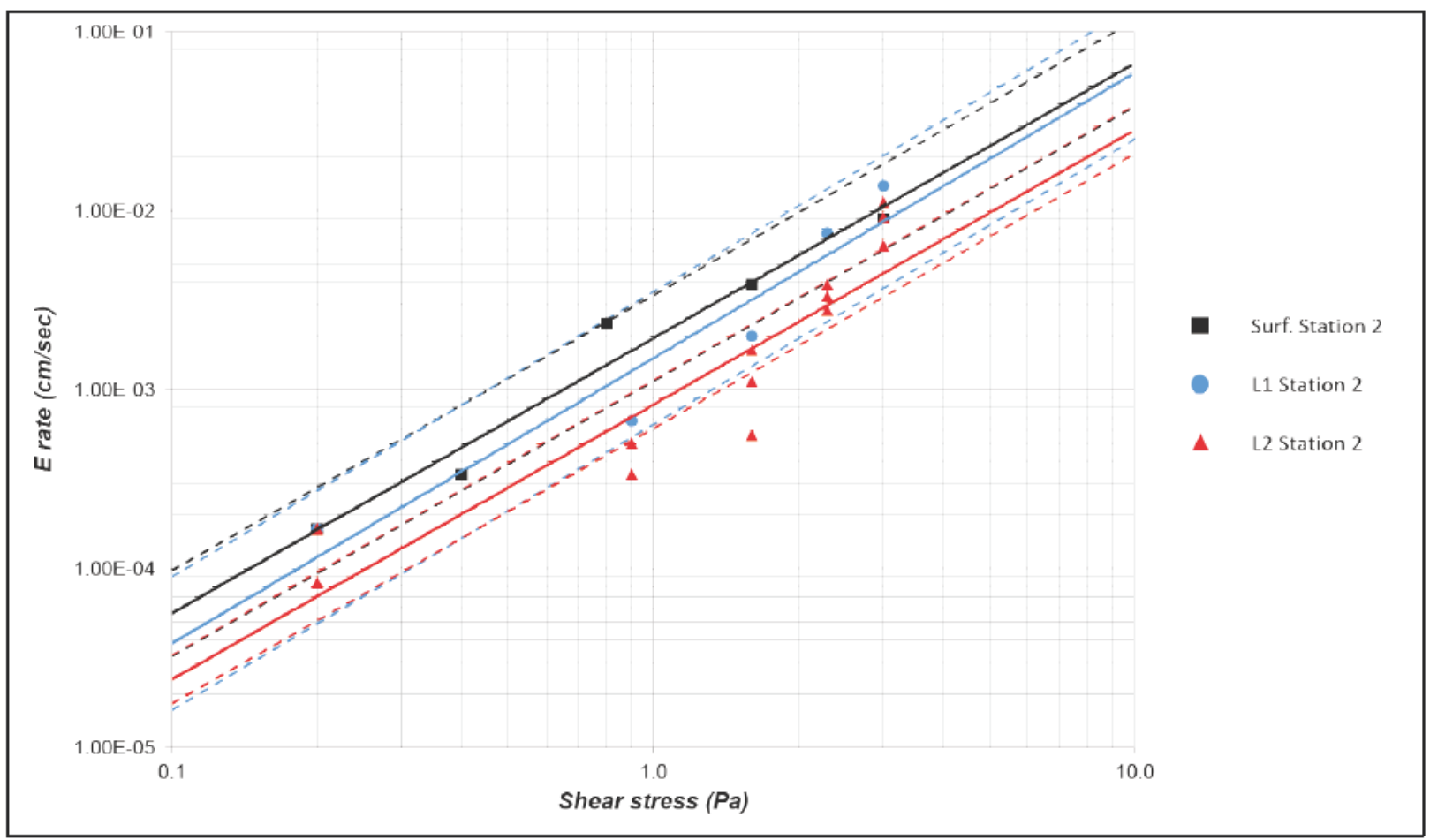




\section{Core Station 4}

Table B-5. Cohesive erosion parameterization.

\begin{tabular}{|c|c|c|c|c|c|c|c|}
\hline $\begin{array}{c}\text { Layer } \\
\text { ID }\end{array}$ & $\begin{array}{c}\text { Depth } \\
(\mathrm{cm})\end{array}$ & $\begin{array}{c}\tau_{\mathrm{c}} \\
(\mathrm{Pa})\end{array}$ & $\begin{array}{c}\tau_{\mathrm{m}} \\
(\mathrm{Pa})\end{array}$ & $\boldsymbol{A}$ & $\mathrm{n}$ & $\begin{array}{c}\tau_{c}(\mathrm{~Pa}) \\
\text { low }\end{array}$ & $\begin{array}{c}\tau_{\mathrm{c}}(\mathrm{Pa}) \\
\text { high }\end{array}$ \\
\hline Surface & $<2$ & 0.14 & 4.26 & $1.90 \mathrm{E}-03$ & 1.51 & 0.08 & 0.26 \\
\hline L1 & $>2$ & 0.29 & 7.66 & $7.00 \mathrm{E}-04$ & 1.57 & 0.25 & 0.36 \\
\hline
\end{tabular}

Figure B-11. Erosion versus applied shear stress for core Station 4. Colors indicate bed layers. Solid lines represent the linearized best-fit of $E=A \tau^{n}$ to the data. Dashed lines indicate the $95 \%$ confidence interval of the fit line.

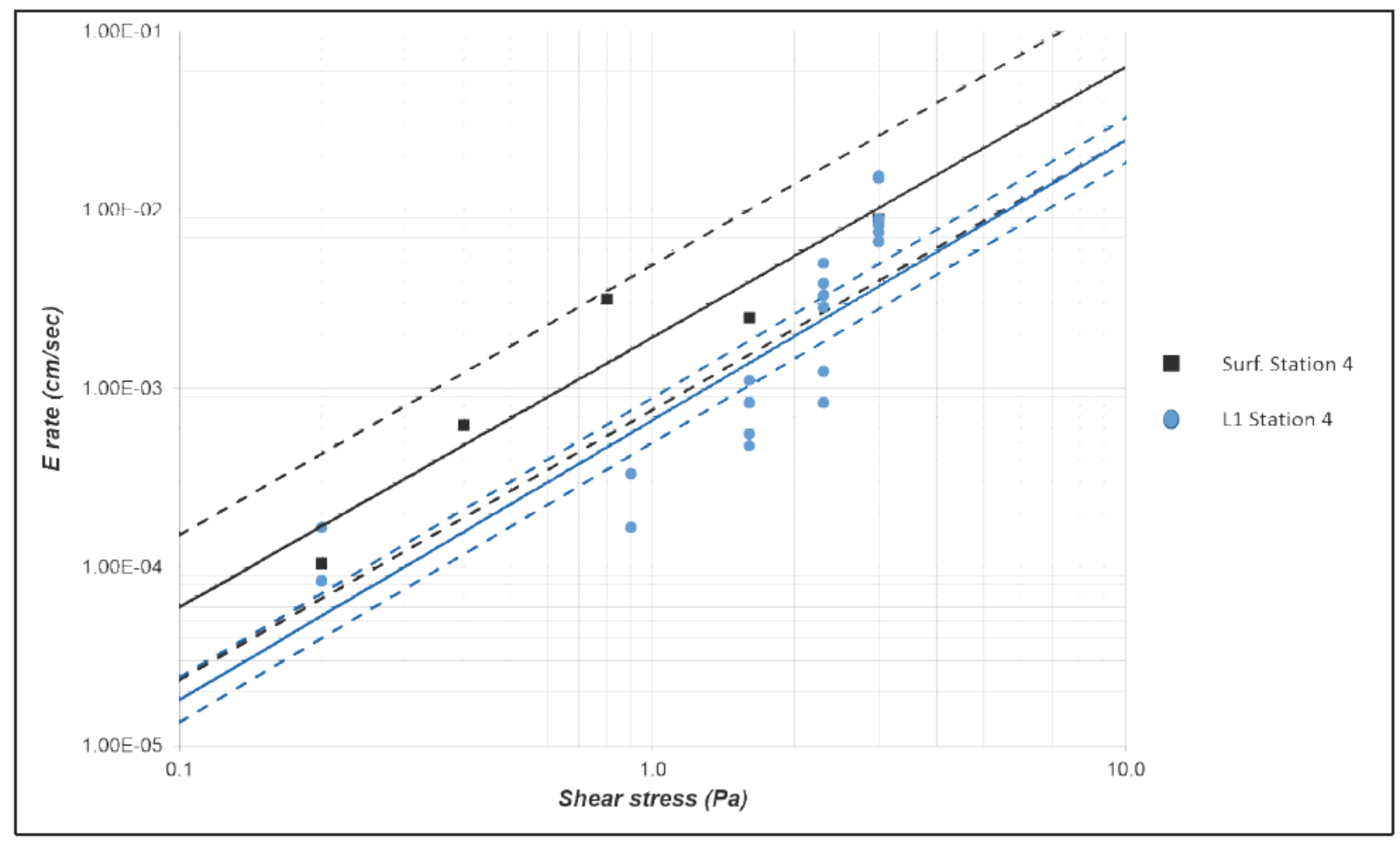




\section{Core Station 5N}

Table B-6. Cohesive erosion parameterization.

\begin{tabular}{|c|c|c|c|c|c|c|c|}
\hline $\begin{array}{c}\text { Layer } \\
\text { ID }\end{array}$ & $\begin{array}{c}\text { Depth } \\
(\mathrm{cm})\end{array}$ & $\begin{array}{c}\tau_{\mathrm{c}} \\
(\mathrm{Pa})\end{array}$ & $\begin{array}{c}\tau_{\mathrm{m}} \\
(\mathrm{Pa})\end{array}$ & $A$ & $\mathrm{n}$ & $\begin{array}{c}\tau_{\mathrm{c}} \\
\text { low }\end{array}$ & $\begin{array}{c}\tau_{\mathrm{c}} \\
(\mathrm{Pa}) \\
\text { high }\end{array}$ \\
\hline Surface & $<2$ & 0.14 & 10.89 & $1.00 \mathrm{E}-03$ & 1.19 & 0.08 & 0.28 \\
\hline L1 & $2-4.5$ & 0.46 & 16.83 & $3.00 \mathrm{E}-04$ & 1.43 & 0.20 & 0.90 \\
\hline L2 & $>4.5$ & 0.62 & 22.42 & $2.00 \mathrm{E}-04$ & 1.43 & 0.56 & 0.89 \\
\hline
\end{tabular}

Figure B-12. Erosion versus applied shear stress for core Station $5 \mathrm{~N}$. Colors indicate bed layers. Solid lines represent the linearized best-fit of $E=A \tau^{n}$ to the data. Dashed lines indicate the $95 \%$ confidence interval of the fit line.

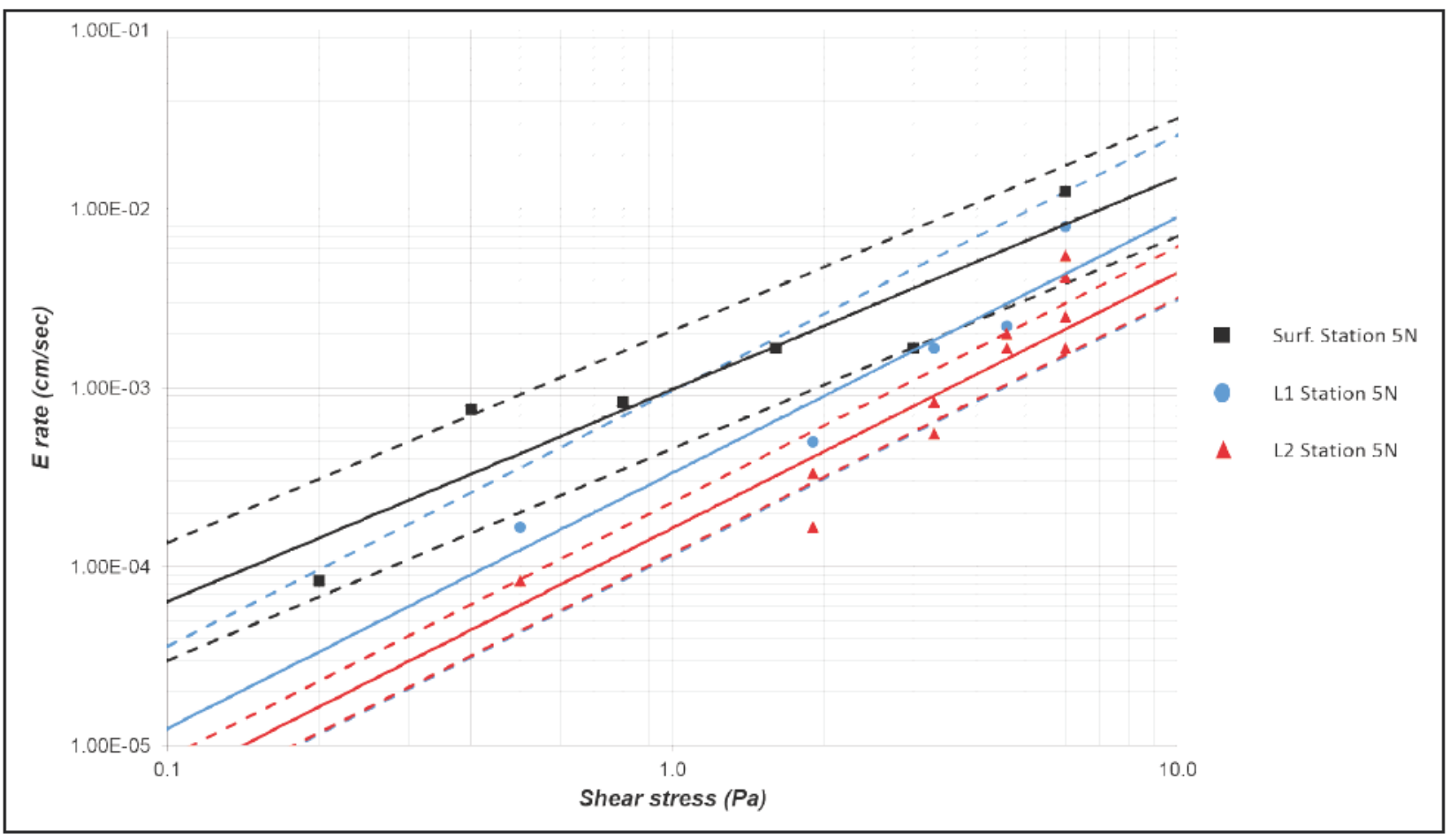




\section{Surface Layers within Hamilton Wetlands Basin}

Table B-7. Cohesive erosion parameterization.

\begin{tabular}{|c|c|c|c|c|c|c|c|}
\hline $\begin{array}{c}\text { Layer } \\
\text { ID }\end{array}$ & $\begin{array}{c}\text { Depth } \\
(\mathbf{c m})\end{array}$ & $\begin{array}{c}\tau_{\mathrm{c}} \\
(\mathrm{Pa})\end{array}$ & $\begin{array}{c}\tau_{\mathrm{m}} \\
(\mathrm{Pa})\end{array}$ & $A$ & $\mathbf{n}$ & $\begin{array}{c}\tau_{\mathrm{c}} \\
(\mathrm{Pa}) \\
\text { low }\end{array}$ & $\begin{array}{c}\tau_{\mathrm{c}} \\
(\mathrm{Pa}) \\
\text { high }\end{array}$ \\
\hline Surface & $<2$ & 0.15 & 2.95 & $2.60 \mathrm{E}-03$ & 1.74 & 0.13 & 0.18 \\
\hline
\end{tabular}

Figure B-13. Erosion versus applied shear stress for surface layers within the Hamilton Wetlands Basin. Symbols indicate data from varying cores. The solid line represents the linearized best-fit of $\mathrm{E}=\mathrm{A} \tau^{\mathrm{n}}$ to the data. Dashed lines indicate the $95 \%$ confidence interval of the fit line.

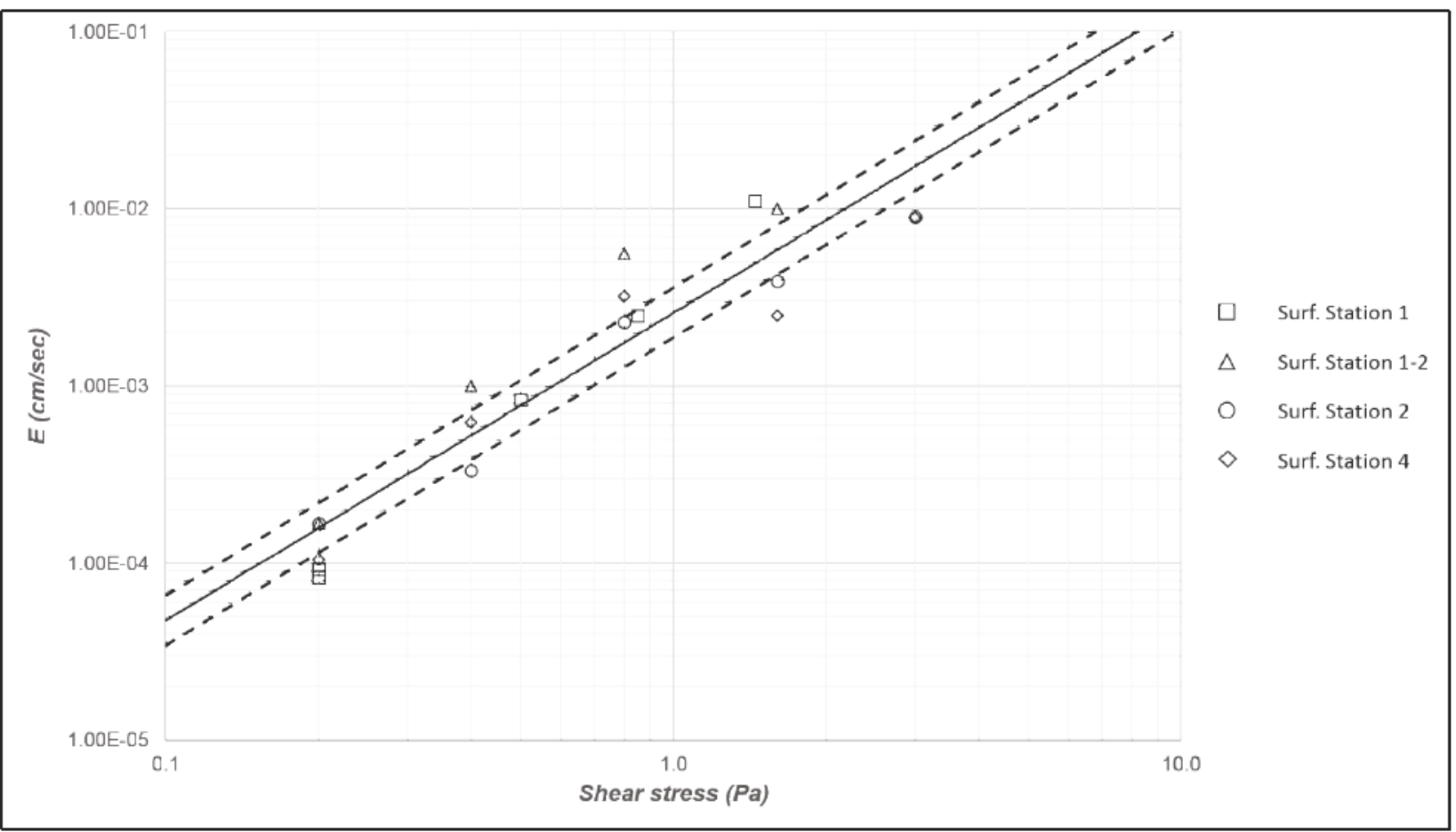




\title{
Acronyms and Abbreviations
}

\author{
ADCP acoustic Doppler current profiler \\ ADV acoustic Doppler velocimeter \\ BBLM bottom boundary layer model \\ ERDC US Army Research and Development Center \\ NOAA National Oceanographic and Atmospheric Administration \\ QC quality control \\ SNR signal to noise ratio \\ TKE turbulent kinetic energy \\ TR technical report \\ USACE US Army Corps of Engineers
}




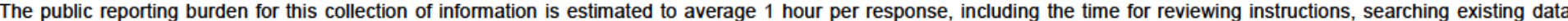

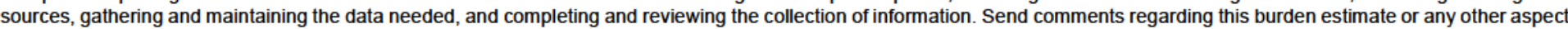

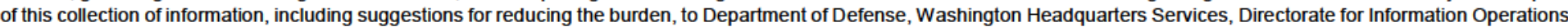

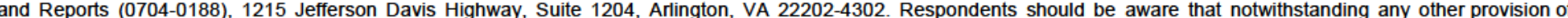
law, no person shall be subject to any penalty for failing to comply with a collection of information if it does not display a currently valid OMB control number. PLEASE DO NOT RETURN YOUR FORM TO THE ABOVE ADDRESS.

\begin{tabular}{l|l|l}
\hline $\begin{array}{l}\text { 1. REPORT DATE } \\
\text { July } 2020\end{array}$ & $\begin{array}{l}\text { 2. REPORT TYPE } \\
\text { Final Report }\end{array}$ & 3. DATES COVERED (FrOm - To)
\end{tabular}

\section{TITLE AND SUBTITLE}

Hydrodynamics of a Recently Restored Coastal Wetland: Hamilton Wetlands, California

5a. CONTRACT NUMBER

5b. GRANT NUMBER

5c. PROGRAM ELEMENT NUMBER

\section{AUTHOR(S)}

Richard Styles, David W. Perkey, S. Jarrell Smith, Duncan B. Bryant, Joe Gailani, and Brandon M. Boyd 5d. PROJECT NUMBER

5e. TASK NUMBER

5f. WORK UNIT NUMBER

ERDC-219CDR-14-TT-Sediment

Management

\section{PERFORMING ORGANIZATION NAME(S) AND ADDRESS(ES)}

Coastal and Hydraulics Laboratory

US Army Engineer Research and Development Center

3909 Halls Ferry Road

Vicksburg, MS 39180-6199

\section{SPONSORING/MONITORING AGENCY NAME(S) AND ADDRESS(ES)}

US Army Engineer Research and Development Center

3909 Halls Ferry Road

Vicksburg, MS 39180-6199
8. PERFORMING ORGANIZATION REPORT NUMBER

ERDC/CHL TR-20-11

10. SPONSOR/MONITOR'S ACRONYM(S) ERDC

11. SPONSOR/MONITOR'S REPORT NUMBER(S)

\section{DISTRIBUTION/AVAILABILITY STATEMENT}

Approved for public release; distribution is unlimited.

\section{SUPPLEMENTARY NOTES}

Section 219 Center for Directed Research

\section{ABSTRACT}

Hamilton Wetlands is a recently restored tidally influenced basin located along the northwest coast of San Pablo Bay, California.

Instruments to measure waves, currents, and wind were deployed for a period of up to 2 years shortly after tidal flow was re-introduced to the wetland to examine the sediment and hydrodynamic response. The results indicate that local re-suspension is relatively rare owing to the weak interior tidal currents and the limited fetch within the $3 \mathrm{~km}$ long basin. Asymmetries in the acoustic backscatter intensity combined with the much higher flow speeds measured at the entrance suggest a net import of fine sediment. The basin also experiences a distinct seasonal variation that likely contributes to sediment re-distribution. During the summer months, higher wind speeds correlate with turbidity suggesting local re-suspension of fines that are distributed by winds. Overall, the measurements suggest that the sediment dynamics in this shallow water system are controlled by two main factors: (1) net sediment import through the inlet entrance and (2) mixing of interior sediment through a combination of intermittent wind and wave stirring.

\section{SUBJECT TERMS}

Hydrodynamics, Restoration ecology, Restoration monitoring (Ecology), San Pablo Bay (Calif.). Sedimentation and deposition, Tidal basin, Wetland restoration, Wetlands

\section{SECURITY CLASSIFICATION OF:}

\begin{tabular}{|l|l|l|}
\hline a. REPORT & b. ABSTRACT & c. THIS PAGE \\
Unclassified & Unclassified & Unclassified \\
& & \\
\hline
\end{tabular}

17. LIMITATION OF
ABSTRACT
SAR

\section{NUMBER} OF PAGES

116 19a. NAME OF RESPONSIBLE PERSON Richard Styles

19b. TELEPHONE NUMBER (Include area code) 601-634-4065 
